UNIVERSIDADE DE SÃO PAULO

INSTITUTO DE ENERGIA E AMBIENTE

PROGRAMA DE PÓS-GRADUAÇÃO EM ENERGIA

LUIZ FERNANDO ALMEIDA FONTENELE

AVALIAÇÃO DE CONFIGURAÇÕES DE SISTEMAS

FOTOVOLTAICOS NA REGIÃO NORDESTE DO BRASIL 


\section{AVALIAÇÃO DE CONFIGURAÇÕES DE SISTEMAS FOTOVOLTAICOS NA REGIÃO NORDESTE DO BRASIL}

\section{Versão Corrigida}

(Versão original encontra-se na unidade que aloja

o Programa de Pós-Graduação)

Dissertação apresentada ao Programa de PósGraduação em Energia do Instituto de Energia e Ambiente da Universidade de São Paulo para obtenção do título de Mestre em Energia.

Orientador: Prof. Dr. Roberto Zilles 
AUTORIZO A REPRODUÇÃO E DIVULGAÇÃO TOTAL OU PARCIAL DESTE TRABALHO, POR QUALQUER MEIO CONVENCIONAL OU ELETRÔNICO, PARA FINS DE ESTUDO E PESQUISA, DESDE QUE CITADA A FONTE.

FICHA CATALOGRÁFICA

Fontenele, Luiz Fernando Almeida.

Avaliação de configurações de sistemas fotovoltaicos na região Nordeste do Brasil. / Luiz Fernando Almeida Fontenele; orientador: Roberto Zilles. - São Paulo, 2018. $129 \mathrm{f} .:$ il; $30 \mathrm{~cm}$.

Dissertação (Mestrado em Ciências) - Programa de PósGraduação em Energia - Instituto de Energia e Ambiente da Universidade de São Paulo.

Título.

1. Energia solar. 2. Sistemas fotovoltaicos - desempenho. I.

Elaborado por Maria Penha da Silva Oliveira CRB-8/6961 
Nome: Fontenele, Luiz Fernando Almeida

Título: Avaliação de configurações de sistemas fotovoltaicos na região Nordeste do Brasil

Dissertação apresentada ao Programa de Pós-Graduação em Energia do Instituto de Energia e Ambiente da Universidade de São Paulo para obtenção do título de Mestre em Energia.

Aprovado em: $\underline{23 / 10 / 2018}$

Banca Examinadora

Prof. Dr. $\quad$ Roberto Zilles (Presidente)

Instituição: $\quad$ Universidade de São Paulo (USP)

Prof. Dr. $\quad$ Ricardo Rüther

Instituição: $\quad$ Universidade Federal de Santa Catarina (UFSC)

Prof. Dr. João Tavares Pinho

Instituição: $\quad$ Universidade Federal do Pará (UFPA)

Dr. $\quad$ Rodrigo Lopes Sauaia

Instituição: $\quad$ Associação Brasileira de Energia Solar Fotovoltaica (ABSOLAR) 


\section{DEDICATÓRIA}

Aos meus avós, João Evangelista (in memoriam) e Elza.

Aos meus pais, Luiz Carlos e Fátima Evanilde.

Ao meu irmão, Luiz Carlos Junior.

Aos familiares e amigos. 


\section{AGRADECIMENTOS}

A Deus, por ter me concedido saúde, força e sabedoria durante esta caminhada.

À minha família, pelo amor infinito, pela educação e formação como pessoa, pelo apoio incondicional e pelo incentivo para chegar até esta etapa da minha vida. Não conseguiria expressar em palavras minha imensa gratidão a tudo o que ela representa para mim.

Ao Prof. Dr. Roberto Zilles, pela extraordinária orientação, pelos valiosos conhecimentos técnicos compartilhados, pelos sábios ensinamentos de vida e pelo exemplo de pessoa íntegra. O Prof. Ph.D. Eduardo Lorenzo, na apresentação do livro "Sistemas fotovoltaicos conectados à rede", retrata muito bem quando menciona que Zilles tem "o respeito unânime de quem teve a felicidade de se formar sob sua orientação".

À Petrobras, pela oportunidade, pelo incentivo e pelo apoio para conciliar atividades profissionais e acadêmicas. Aos amigos de trabalho, em especial à equipe de fotovoltaica, pela rica troca de conhecimentos, apoio, compreensão e ajuda nas ocasiões em que tive que me ausentar.

Às amizades feitas na Universidade de São Paulo, em especial aos amigos do Laboratório de Sistemas Fotovoltaicos, do Instituto de Energia e Ambiente (LSF/IEE/USP), pelo companheirismo, pelos estudos e pelos bons momentos passados juntos.

Aos amigos, pelo excelente convívio e pela compreensão nos momentos em que não pude estar presente.

À Empresa de Pesquisa Energética (EPE), por prover importantes informações técnicas.

Ao National Renewable Energy Laboratory (NREL), pelo suporte prestado e pela disponibilização de dados, materiais e ferramentas de qualidade.

À Universidade de São Paulo, pelo nível de excelência do ensino, do corpo docente e dos funcionários. 
"O conhecimento humanista produz ideias. As ideias produzem sonhos. Os sonhos transformam a sociedade..." (CURY, 2005, p. 101). 


\section{RESUMO}

FONTENELE, Luiz Fernando Almeida. Avaliação de configurações de sistemas fotovoltaicos na região Nordeste do Brasil. 2018. 129 f. Dissertação (Mestrado em Energia) - Instituto de Energia e Ambiente, Universidade de São Paulo, São Paulo, 2018.

Neste trabalho, são avaliadas diferentes configurações de sistemas fotovoltaicos, levando em consideração os principais tipos de módulos fotovoltaicos comercialmente disponíveis e estruturas de suporte. A comparação é delimitada na região Nordeste do Brasil e é baseada, fundamentalmente, em termos de fator de capacidade. Para uma melhor compreensão dos resultados, são mostradas, previamente, as influências que as variáveis meteorológicas exercem na saída do sistema, bem como os efeitos do fator de dimensionamento do inversor (FDI) e do índice de cobertura do terreno (ICT). Os resultados das simulações computacionais realizadas são apresentados em forma de mapas, nos quais é possível verificar as áreas em que os sistemas fotovoltaicos tendem a gerar mais energia elétrica. Entre as configurações estudadas, os maiores valores foram observados para sistemas que utilizam módulos genéricos de filmes finos montados em rastreadores solares de um eixo horizontal, chegando a $36 \%$ de fator de capacidade (em corrente alternada) em algumas regiões do Ceará, Rio Grande do Norte, Paraíba, Pernambuco e Bahia. Além disso, foram evidenciados os ganhos obtidos nos fatores de capacidade ao substituir as estruturas fixas por rastreadores solares. Para um ICT de 0,4, os sistemas que realizam o seguimento, ainda que em um eixo do movimento aparente do Sol, apresentaram ganhos de $18 \%$ a $28 \%$ na energia elétrica anual gerada.

Palavras-chave: Energia solar. Sistemas fotovoltaicos conectados à rede. Desempenho de sistemas fotovoltaicos. 


\begin{abstract}
FONTENELE, Luiz Fernando Almeida. Evaluation of photovoltaic system configurations in the Northeastern region of Brazil. 2018. $129 \mathrm{f}$. Dissertação (Mestrado em Energia) Instituto de Energia e Ambiente, Universidade de São Paulo, São Paulo, 2018.

In this work, different configurations of photovoltaic systems are evaluated, considering the main type of commercially available photovoltaic modules and mounting structures. The comparison is delimited to the Northeastern region of Brazil and is based, fundamentally, in terms of capacity factor. The influence on the output of the system of meteorological variables, the inverter loading ratio (ILR $-1 / F D I$ ) and ground coverage ratio (GCR - ICT) are shown in advance for a better understanding of the results. Computational simulations results are presented in maps, in which it is possible to verify the areas where photovoltaic systems tend to generate more electricity. Among the studied configurations, the largest values were observed for systems that use generic thin film modules mounted on one axis horizontal solar trackers, reaching $36 \%$ of capacity factor (in alternating current) in some regions of Ceará, Rio Grande do Norte, Paraíba, Pernambuco and Bahia. Additionally, the gains obtained in the capacity factors when replacing fixed structures by solar trackers were shown. For an GCR of 0.4 , systems that track, even on one axis, the apparent motion of the Sun showed gains of $18 \%$ to $28 \%$ on annual generated electricity.
\end{abstract}

Keywords: Solar energy. Grid-connected photovoltaic system. Photovoltaic system performance. 


\section{LISTA DE FIGURAS}

Figura 2.1 - Redução da radiação solar incidente na superfície terrestre através de reflexão, absorção e dispersão.

Figura 2.2 - Irradiação anual global no plano horizontal....................................................22

Figura 2.3 - Irradiação anual global no plano horizontal para o Brasil. ..................................2 23

Figura 2.4 - Comparação entre as projeções da capacidade fotovoltaica instalada no mundo e o

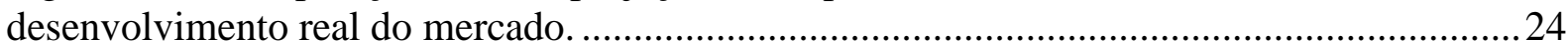

Figura 2.5 - Evolução da capacidade fotovoltaica instalada no mundo.................................25

Figura 2.6 - Evolução dos preços dos módulos fotovoltaicos. ……......................................26

Figura 2.7 - Evolução das eficiências das células fotovoltaicas de diferentes tecnologias. .... 26

Figura 2.8 - Empreendimentos fotovoltaicos cadastrados e habilitados no $1^{\circ}$ LER de 2014 por

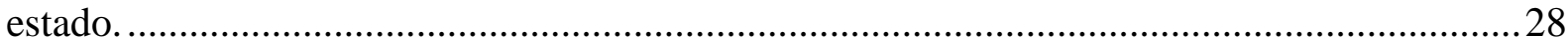

Figura 2.9 - Empreendimentos fotovoltaicos contratados no $1^{\circ}$ LER de 2014 por estado. ..... 29

Figura 2.10 - Situação atual dos empreendimentos fotovoltaicos contratados no $1^{\circ}$ LER de 2014

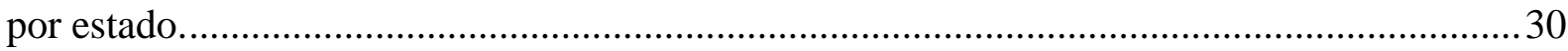

Figura 2.11 - Empreendimentos fotovoltaicos cadastrados e habilitados no $1^{\circ}$ LER de 2015 por

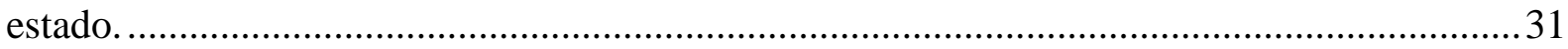

Figura 2.12 - Situação atual dos empreendimentos fotovoltaicos contratados no $1^{\circ}$ LER de 2015

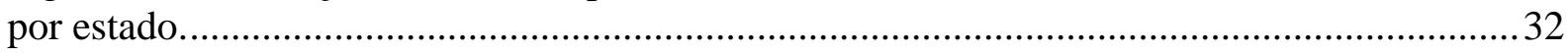

Figura 2.13 - Empreendimentos fotovoltaicos cadastrados e habilitados no $2^{\circ}$ LER de 2015 por estado.

Figura 2.14 - Situação dos empreendimentos fotovoltaicos contratados no $2^{\circ}$ LER de 2015 por estado.

Figura 2.15 - Empreendimentos fotovoltaicos cadastrados no $1^{\circ}$ LER de 2016 por estado.... 35 Figura 2.16 - Empreendimentos fotovoltaicos cadastrados no $2^{\circ}$ LER de 2016 por estado.... 36

Figura 2.17 - Empreendimentos fotovoltaicos cadastrados e habilitados no LEN A-4 de 2017 por estado.

Figura 2.18 - Empreendimentos fotovoltaicos contratados no LEN A-4 de 2017 por estado. 38 Figura 2.19 - Empreendimentos fotovoltaicos cadastrados e habilitados no LEN A-4 de 2018 por estado.

Figura 2.20 - Empreendimentos fotovoltaicos contratados no LEN A-4 de 2018 por estado. 39

Figura 2.21 - Resumo dos resultados dos leilões: potências c.c. e c.a.

Figura 2.22 - Resumo dos resultados dos leilões por quantidade de usinas: tipos de módulos e estruturas de suporte. 
Figura 2.23 - Resumo dos resultados dos leilões: fatores de capacidade e fatores de dimensionamento do inversor.

Figura 2.24 - Resumo dos resultados dos leilões: faixas de investimentos das usinas e preços da energia.

Figura 3.1 - Classificação de sistemas fotovoltaicos

Figura 3.2 - Diagrama simplificado de um sistema fotovoltaico. 45

Figura 3.3 - Classificação de células fotovoltaicas por tecnologia. 46

Figura 3.4 - (a) irradiância espectral e (b) resposta espectral de uma célula de silício cristalino.

Figura 3.5 - Célula fotovoltaica: (a) esquema simplificado e (b) curva I-V característica...... 48

Figura 3.6 - Classificação das estruturas de suporte.

Figura 3.7 - Exemplo de montagem em estruturas fixas em solo.

Figura 3.8 - Exemplo de montagem em rastreador solar de um eixo.

Figura 3.9 - Rastreador solar de um eixo horizontal: (a) sem backtracking e (b) com backtracking.

Figura 3.10 - Comparação das potências de saída de sistemas fotovoltaicos montados em estruturas fixas em solo e em rastreadores solares de um eixo horizontal.

Figura 3.11 - Classificação de inversores. 53

Figura 3.12 - Comparação das potências de sistemas fotovoltaicos para dois FDI, variando a potência do inversor.

Figura 3.13 - Comparação das potências de sistemas fotovoltaicos para dois FDI, variando a potência do arranjo fotovoltaico.

Figura 4.1 - Área de cobertura da base de dados. 59

Figura 4.2 - Diagrama de blocos do PSM.

Figura 4.3 - Média diária da irradiação global horizontal para a cidade de Fortaleza/CE para anos selecionados, ano meteorológico típico e média de longo prazo.

Figura 4.4 - Influência da temperatura na potência de cada tipo de módulo fotovoltaico........72

Figura 4.5 - Ângulos notáveis em energia solar. 72

Figura 4.6 - Curva de potência em relação ao carregamento.

Figura 4.7 - Curvas de eficiência em relação ao carregamento para diferentes eficiências nominais.

Figura 4.8 - Diagrama de blocos da conversão fotovoltaica.

Figura 4.9 - Comparação horária entre dados de simulação e medidos 78 
Figura 4.10 - Comparação anual entre dados de simulação e medidos. 80

Figura 4.11 - Influência da variação da irradiância direta no fator de capacidade. 82

Figura 4.12 - Influência da variação da irradiância difusa no fator de capacidade. 83

Figura 4.13 - Influência da variação da velocidade do vento no fator de capacidade. 83

Figura 4.14 - Influência da variação da temperatura ambiente no fator de capacidade. 84

Figura 4.15 - Influência da variação do albedo no fator de capacidade. .85

Figura 4.16 - Diagrama de blocos da metodologia. 86

Figura 4.17 - Mapa da região Nordeste do Brasil. 87

Figura 5.1 - Fatores de capacidade normalizados de sistemas fotovoltaicos fixos em função do ICT.

Figura 5.2 - Relação entre os fatores de capacidade de sistemas fotovoltaicos montados em rastreadores solares de um eixo horizontal com e sem backtracking em função do ICT.........90

Figura 5.3 - Fatores de capacidade normalizados de sistemas fotovoltaicos montados em rastreadores solares de um eixo horizontal com backtracking em função do ICT.....

Figura 5.4 - Relação entre os fatores de capacidade de sistemas fotovoltaicos montados em rastreadores solares de um eixo e em estruturas fixas, em função do ICT.

Figura 5.5 - Geração anual de energia elétrica normalizada de sistemas fotovoltaicos em função do FDI. .93

Figura 5.6 - Fator de capacidade para um sistema fotovoltaico fixo, com módulos do tipo padrão, ICT de 0,4 e FDI de 0,75.

Figura 5.7 - Fator de capacidade para um sistema fotovoltaico com módulos do tipo padrão, montados em rastreadores solares de um eixo, ICT de 0,4 e FDI de 0,75.

Figura 5.8 - Ganho no fator de capacidade para um sistema fotovoltaico com módulos do tipo padrão, montados em rastreadores solares de um eixo, ICT de 0,4 e FDI de 0,75, em relação ao montado em estrutura fixa.

Figura 5.9 - Fator de capacidade para um sistema fotovoltaico fixo, com módulos do tipo superior, ICT de 0,4 e FDI de 0,75 .

Figura 5.10 - Fator de capacidade para um sistema fotovoltaico com módulos do tipo superior, montados em rastreadores solares de um eixo, ICT de 0,4 e FDI de 0,75. 98

Figura 5.11 - Ganho no fator de capacidade para um sistema fotovoltaico com módulos do tipo superior, montados em rastreadores solares de um eixo, ICT de 0,4 e FDI de 0,75, em relação ao montado em estrutura fixa.

Figura 5.12 - Fator de capacidade para um sistema fotovoltaico fixo, com módulos de filme fino, ICT de 0,4 e FDI de 0,75.

Figura 5.13 - Fator de capacidade para um sistema fotovoltaico com módulos de filme fino, montados em rastreadores solares de um eixo, ICT de 0,4 e FDI de 0,75. 
Figura 5.14 - Ganho no fator de capacidade para um sistema fotovoltaico com módulos de filme fino, montados em rastreadores solares de um eixo, ICT de 0,4 e FDI de 0,75, em relação ao montado em estrutura fixa.

Figura 5.15 - Fatores de capacidade para sistemas fixos e com rastreadores solares de um eixo, com módulos dos tipos padrão, superior e filme fino e comparações entre as configurações de sistemas fotovoltaicos.

Figura 6.1 - Vista de satélite da UFV-AR e da UTE-JSP 105

Figura 6.2 - Identificação dos subsistemas da UFV-AR

Figura 6.3 - Imagens das instalações da UFV-AR: (a) subsistema 1, (b) subsistema 2, (c) subsistema 3, (d) subsistema 4 e (e) vista aérea da UFV-AR.

Figura 6.4 - Medição do recurso solar: (a) estação meteorológica, (b) piranômetro no plano do módulo com rastreador solar e (c) piranômetro no plano inclinado dos módulos fixos. ........ 108

Figura 6.5 - Diagrama unifilar simplificado da UFV-AR ................................................... 109

Figura 6.6 - Metodologia da comparação entre os resultados medidos e simulados 110

Figura 6.7 - Comparação entre os resultados medidos e simulados dos fatores de capacidade dos subsistemas da UFV-AR para o ano de 2016. 111

Figura 6.8 - Desvios entre os resultados medidos e simulados dos fatores de capacidade dos subsistemas da UFV-AR para o ano de 2016. 112

Figura 6.9 - Comparação entre as irradiâncias globais horizontais medidas pela estação solarimétrica da UFV-AR e proveniente do NSRDB para 09/2016.

Figura 6.10 - Comparação entre os resultados medidos e simulados das potências dos subsistemas da UFV-AR para o dia 07/09/2016. 114

Figura 6.11 - Comparação entre os resultados medidos e simulados dos fatores de capacidade dos subsistemas da UFV-AR para o dia 07/09/2016. 115

Figura 6.12 - Desvios entre os resultados medidos e simulados dos fatores de capacidade dos subsistemas da UFV-AR para o dia 07/09/2016. 


\section{LISTA DE TABELAS}

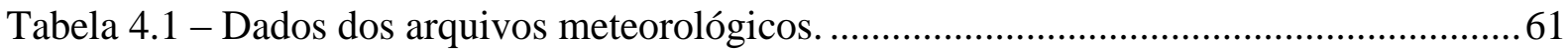

Tabela 4.2 - Pesos dos índices das variáveis na seleção dos meses típicos.............................64

Tabela 4.3 - Anos selecionados de cada mês para composição do AMT para a cidade de

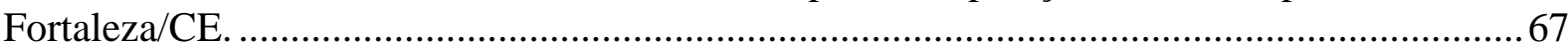

Tabela 4.4 - Dados horários de entrada para a simulação.....................................................69

Tabela 4.5 - Parâmetros de configuração do sistema fotovoltaico do módulo PVWatts......... 70

Tabela 4.6 - Parâmetros de entrada do módulo PVWatts. ........................................................ 71

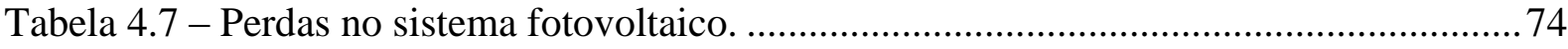

Tabela 4.8 - Comparação das métricas estatísticas das versões do módulo PVWatts............. 79

Tabela 4.9 - Resultado genérico da simulações para cada combinação de cidade e tipo de

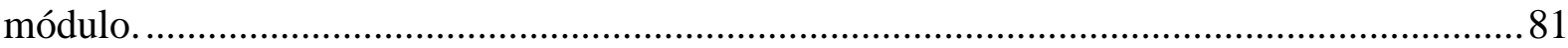

Tabela 6.1 - Características dos subsistemas da UFV-AR. ...............................................106 
LISTA DE SIGLAS

\begin{tabular}{|c|c|}
\hline Sigla & Descrição \\
\hline AVHRR & Advanced Very High Resolution Radiometer \\
\hline AERONET & Aerosol Robotic Network \\
\hline ANEEL & Agência Nacional de Energia Elétrica \\
\hline AL & Alagoas \\
\hline ACR & Ambiente de Contratação Regulada \\
\hline AMT & Ano Meteorológico Típico \\
\hline ABSOLAR & Associação Brasileira de Energia Solar Fotovoltaica \\
\hline ABNT & Associação Brasileira de Normas Técnicas \\
\hline BA & Bahia \\
\hline CEC & California Energy Commission \\
\hline CCEE & Câmara de Comercialização de Energia Elétrica \\
\hline $\mathrm{CE}$ & Ceará \\
\hline CER & Contrato de Energia de Reserva \\
\hline c.a. & Corrente alternada \\
\hline c.c. & Corrente continua \\
\hline DISC & Direct Insolation Simulation Code \\
\hline CIGS & Disseleneto de cobre, índio e gálio \\
\hline EPE & Empresa de Pesquisa Energética \\
\hline FARMS & Fast All-sky Radiation Model for Solar Applications \\
\hline GOES & Geostationary Operational Environmental Satellite \\
\hline IEA & International Energy Agency \\
\hline LER & Leilão de Energia de Reserva \\
\hline LEN & Leilão de Energia Nova \\
\hline MA & Maranhão \\
\hline MATLAB & Matrix Laboratory \\
\hline MMT & Mês Meteorológico Típico \\
\hline MME & Ministério de Minas e Energia \\
\hline MODIS & Moderate Resolution Imaging Spectroradiometer \\
\hline MERRA & Modern-Era Retrospective Analysis for Research and Applications \\
\hline MISR & Multi-angle Imaging Spectroradiometer \\
\hline NASA & National Aeronautics and Space Administration \\
\hline NOAA & National Oceanic and Atmospheric Administration \\
\hline
\end{tabular}




\begin{tabular}{|c|c|}
\hline Sigla & Descrição \\
\hline NREL & National Renewable Energy Laboratory \\
\hline NSIDC & National Snow and Ice Data Center \\
\hline NSRDB & National Solar Radiation Database \\
\hline OMI & Ozone Monitoring Instrument \\
\hline PB & Paraíba \\
\hline PATMOS-x & Pathfinder Atmospheres Extended \\
\hline $\mathrm{PE}$ & Pernambuco \\
\hline P\&D & Pesquisa e Desenvolvimento \\
\hline Petrobras & Petróleo Brasileiro S.A. \\
\hline PSM & Physical Solar Model \\
\hline PI & Piauí \\
\hline REST2 & Reference Evaluation of Solar Transmittance 2 \\
\hline RN & Rio Grande do Norte \\
\hline SSC & SAM Simulation Core \\
\hline SE & Sergipe \\
\hline $\mathrm{a}-\mathrm{Si}$ & Silício amorfo \\
\hline multi-Si & Silício multicristalino \\
\hline mono-Si & Silício monocristalino \\
\hline SIN & Sistema Interligado Nacional \\
\hline SDK & Software Development Kit \\
\hline SAM & System Advisor Model \\
\hline TIR & Taxa Interna de Retorno \\
\hline CdTe & Telureto de cádmio \\
\hline TOMS & Total Ozone Mapping Spectrometer \\
\hline UFV-AR & Usina Fotovoltaica Alto do Rodrigues \\
\hline UTE-JSP & Usina Termelétrica Jesus Soares Pereira \\
\hline VPL & Valor Presente Líquido \\
\hline
\end{tabular}




\begin{tabular}{|c|c|c|}
\hline Símbolo & Descrição & Unidade \\
\hline$\gamma$ & Ângulo azimutal da superfície & $\circ$ \\
\hline$\gamma_{s}$ & Ângulo azimutal do Sol & $\circ$ \\
\hline$\theta$ & Ângulo de incidência & $\circ$ \\
\hline$\theta_{z}$ & Ângulo zenital & $\circ$ \\
\hline$A_{M T}$ & Área total do módulo & $m^{2}$ \\
\hline$\gamma_{P}$ & Coeficiente térmico da potência do módulo fotovoltaico & $\% /{ }^{\circ} \mathrm{C}$ \\
\hline$I_{S C}$ & Corrente de curto-circuito & $A$ \\
\hline$I_{M P}$ & Corrente de máxima potência & $A$ \\
\hline$\eta$ & Eficiência da conversão fotovoltaica & $\%$ \\
\hline$\eta_{\text {nom }}$ & Eficiência nominal do inversor & $\%$ \\
\hline$\alpha$ & Elevação solar & $\circ$ \\
\hline$E_{c a}$ & Energia elétrica de saída do inversor injetada na rede & $W h$ \\
\hline$E A M$ & Erro absoluto médio & Igual à variável \\
\hline$E M$ & Erro médio & Igual à variável \\
\hline$E Q M$ & Erro quadrático médio & Igual à variável \\
\hline$E Q M N$ & Erro quadrático médio normalizado & $\%$ \\
\hline$F C$ & Fator de capacidade & $\%$ \\
\hline$F C_{i, j}$ & Fator de capacidade com fator multiplicativo $i$ da variável $j$ & $\%$ \\
\hline$\overline{F C_{l, J}}$ & $\begin{array}{l}\text { Fator de capacidade normalizado com fator multiplicativo } i \\
\text { da variável } j\end{array}$ & $\%$ \\
\hline FDI & Fator de dimensionamento do inversor & (adimensional) \\
\hline$\beta$ & Inclinação da superfície & $\circ$ \\
\hline$I C T$ & Índice de cobertura do terreno & (adimensional) \\
\hline$H_{H O R}$ & Irradiação global horizontal & $W h / m^{2}$ \\
\hline$H_{T O T}$ & Irradiação total & $W h / m^{2}$ \\
\hline$G_{\text {ref }}$ & Irradiância de referência & $W / m^{2}$ \\
\hline$G_{A L B}$ & Irradiância devida ao albedo & $W / m^{2}$ \\
\hline$G_{D I F}$ & Irradiância difusa horizontal & $W / m^{2}$ \\
\hline$G_{D I R}$ & Irradiância direta normal & $W / m^{2}$ \\
\hline$G_{H O R}$ & Irradiância global horizontal & $W / m^{2}$ \\
\hline$G_{T O T}$ & Irradiância total & $W / m^{2}$ \\
\hline$G_{T O T, T R}$ & Irradiância total transmitida para a célula fotovoltaica & $W / m^{2}$ \\
\hline$L$ & Perda individual & $\%$ \\
\hline
\end{tabular}




\begin{tabular}{clc}
\hline Símbolo & Descrição & Unidade \\
\hline$L_{T o t a l}$ & Perda total & $\%$ \\
$P_{c a}$ & Potência de saída do inversor, injetada na rede & $W$ \\
$P_{c c, i n v}$ & Potência do arranjo fotovoltaico após as perdas, na entrada & $W$ \\
$P_{c c}$ & Potência instantânea do arranjo fotovoltaico & $W$ \\
$P_{M P}$ & Potência máxima & $W$ \\
$P_{c c 0}$ & Potência nominal (de pico) do arranjo fotovoltaico & $W$ \\
$P_{c c 0, i n v}$ & Potência nominal de entrada do inversor & $W p$ \\
$P_{c a 0}$ & Potência nominal de saída do inversor & $W$ \\
$Y_{r}$ & Produtividade de referência & $W$ \\
$Y_{f}$ & Produtividade do sistema & $\mathrm{W} / \mathrm{dia}$ \\
$P R$ & Rendimento global do sistema & $\mathrm{Wh} / \mathrm{Wp}$ \\
$r$ & Resíduo da regressão linear & $\%$ \\
$T_{a m b}$ & Temperatura ambiente & Igual à variável \\
$T_{C}$ & Temperatura da célula fotovoltaica & ${ }^{\circ} \mathrm{C}$ \\
$T_{r e f}$ & Temperatura de referência & ${ }^{\circ} \mathrm{C}$ \\
$t$ & Tempo de operação da análise & ${ }^{\circ} \mathrm{C}$ \\
$V_{O C}$ & Tensão de circuito aberto & $\mathrm{h}$ \\
$V_{M P}$ & Tensão de máxima potência & $\mathrm{V}$ \\
\hline
\end{tabular}




\section{SUMÁRIO}

1 INTRODUÇÃ

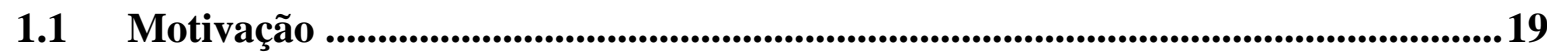

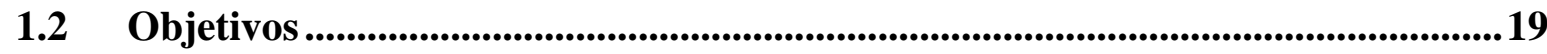

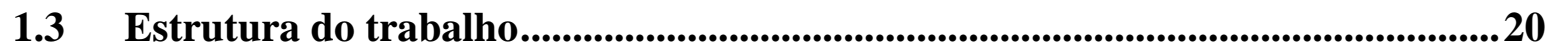

2 PANORAMA DA ENERGIA SOLAR FOTOVOLTAICA ...................................21

$2.1 \quad$ Recurso solar ................................................................................................................... 21

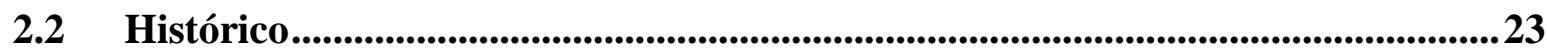

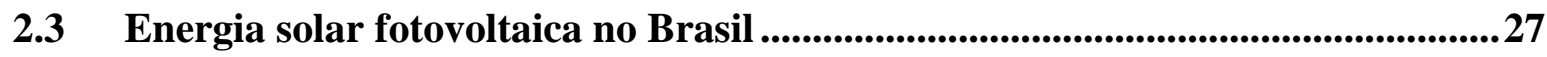

2.3.1 $\quad 1^{0}$ Leilão de Energia de Reserva de 2014 ...................................................27

2.3.2 $1^{\circ}$ Leilão de Energia de Reserva de 2015 .................................................. 30

2.3.3 $2^{\circ}$ Leilão de Energia de Reserva de 2015 ................................................... 32

2.3.4 $1^{0}$ Leilão de Energia de Reserva de 2016 ...........................................................34

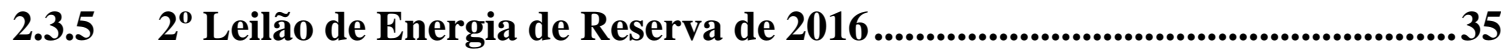

2.3.6 $25^{\circ}$ Leilão de Energia Nova A-4 de 2017 ................................................................36

2.3.7 $27^{\circ}$ Leilão de Energia Nova A-4 de 2018 ........................................................38

2.3.8 Comparação entre os leilões ...........................................................................40

$3 \quad$ SISTEMAS FOTOVOLTAICOS.................................................................................. 44

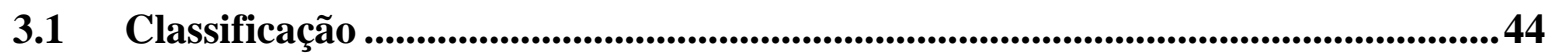

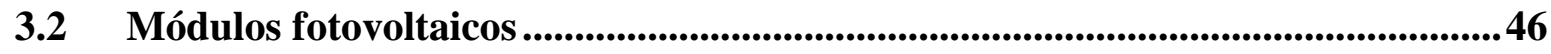

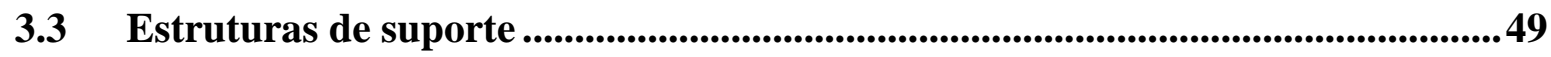

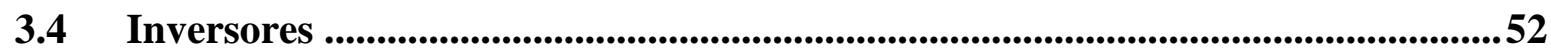

3.5 Parâmetros de desempenho ….................................................................................56

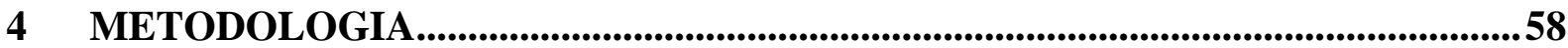

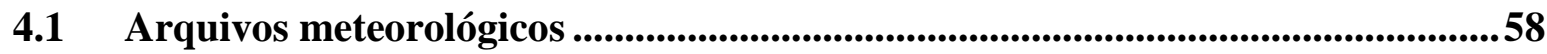

4.1.1 Modelo físico solar da base de dados ........................................................58

4.1.2 Ano Meteorológico Típico (AMT) ............................................................62 


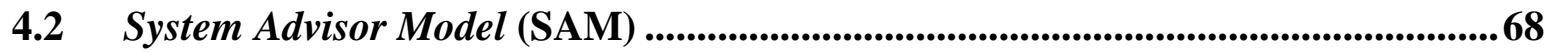

4.2.1 Módulo PVWatts ...............................................................................................................69

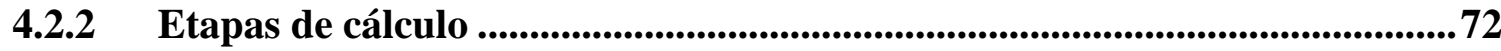

4.2.3 Influência das variáveis.......................................................................................................80

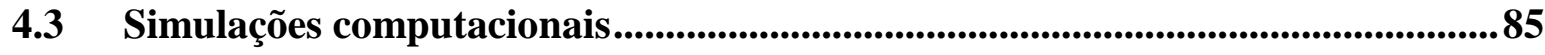

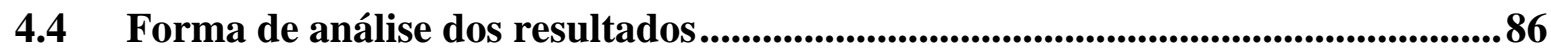

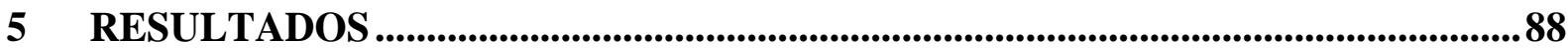

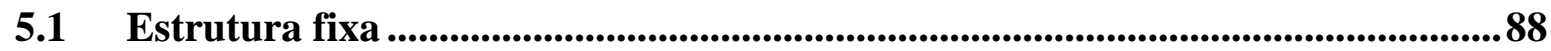

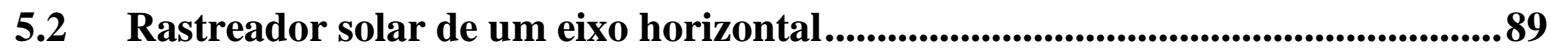

5.3 Comparação entre estruturas fixas e rastreadores solares de um eixo...............91

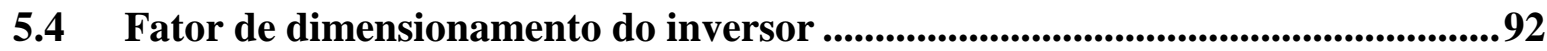

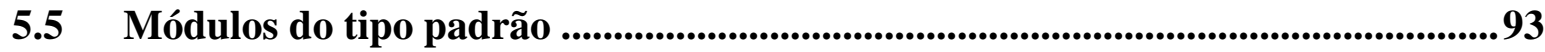

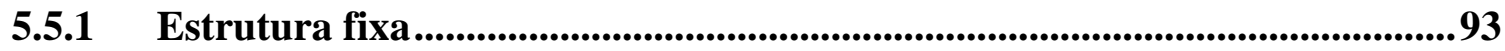

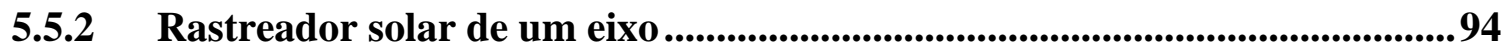

5.6 Módulos do tipo superior .......................................................................................96

5.6.1 Estrutura fixa ...............................................................................................96

5.6.2 Rastreador solar de um eixo .............................................................................99

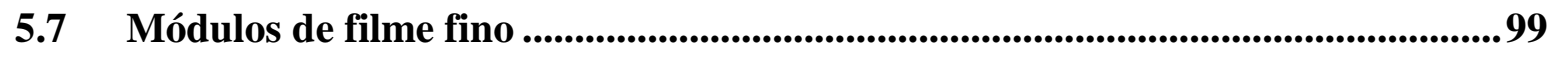

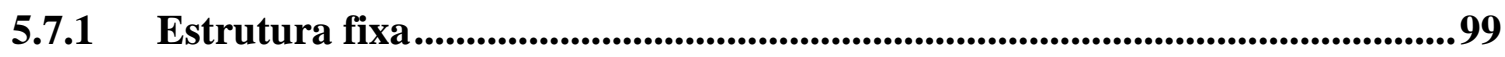

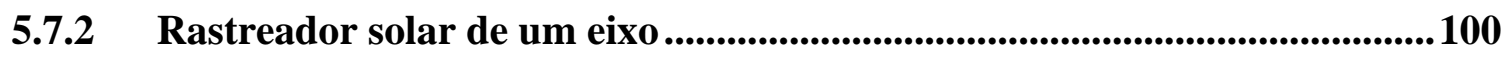

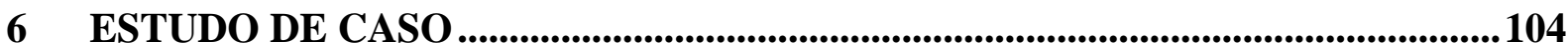

6.1 Usina Fotovoltaica Alto do Rodrigues (UFV-AR) ......................................104

6.2 Resultados medidos e simulados...............................................................................109

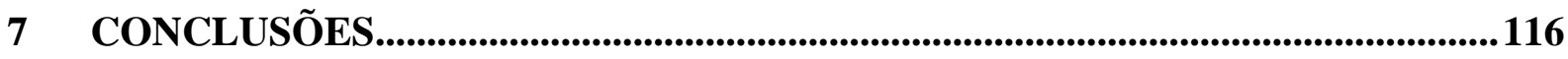

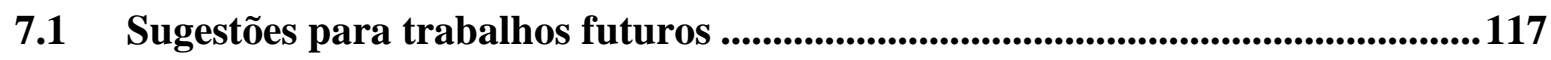

REFERÊNCIAS BIBLIOGRÁFICAS .....................................................................119 


\section{INTRODUÇÃo}

Esta seção possui como finalidade discorrer sobre os fatores pelos quais a presente dissertação foi elaborada, abordando as principais motivações que contribuíram para o seu desenvolvimento, os objetivos almejados e algumas contribuições. É descrita também a organização na qual este documento está estruturado.

\subsection{Motivação}

A partir da análise comparativa da consolidação dos resultados dos leilões de energia elétrica em que houve participação da fonte solar fotovoltaica, ocorridos de 2014 a 2018, verificam-se diferentes tipos de configurações de sistemas fotovoltaicos, levando em consideração principalmente as tecnologias de módulos utilizadas e as estruturas de suporte empregadas. Dessa forma, surgem, naturalmente, alguns questionamentos sobre esses arranjos:

- Quais configurações são melhores tecnicamente?

- Quais apresentam melhores resultados?

- Quais as vantagens de cada uma?

- Quais as desvantagens de cada uma?

- Para quais regiões cada uma delas é mais indicada?

A busca por respostas para essas perguntas motivou o desenvolvimento da pesquisa, que contempla a análise comparativa entre diferentes tipos de configurações de usinas fotovoltaicas, que foram simuladas no Nordeste brasileiro, utilizando ferramentas computacionais.

\subsection{Objetivos}

Esse trabalho consiste em avaliar configurações de sistemas fotovoltaicos, levando em consideração algumas combinações que podem ser obtidas com diferentes tipos de módulos fotovoltaicos e de estruturas de suporte.

O estudo aqui apresentado tem sua análise delimitada na região Nordeste do Brasil. Faz parte do escopo do trabalho a análise de diferentes tecnologias de módulos fotovoltaicos, como de silício cristalino e de filmes finos, excluindo-se novas tecnologias ainda não comercialmente disponíveis ou em estágio de pesquisa em laboratórios. Em relação às estruturas de suporte, a investigação abrange módulos fotovoltaicos montados em estruturas fixas em solo e em rastreadores solares de um eixo horizontal norte-sul. Não faz parte do trabalho, portanto, a 
análise de sistemas montados em telhados, fachadas ou que utilizam rastreamento solar em dois eixos.

\subsection{Estrutura do trabalho}

A dissertação está estruturada em sequência lógica, partindo da teoria e dos fundamentos necessários para a compreensão do trabalho e chegando aos objetivos pretendidos. Os capítulos constituintes estão dispostos da seguinte maneira:

- Capítulo 1 - Introdução: discorre sobre a motivação e os objetivos do trabalho e apresenta a estrutura da dissertação;

- Capítulo 2 - Panorama da energia solar fotovoltaica: aborda o conceito da energia solar fotovoltaica, mostrando o seu desenvolvimento no mundo e no Brasil, com destaque para os leilões de energia elétrica em que houve participação da fonte solar fotovoltaica;

- Capítulo 3 - Sistemas fotovoltaicos: apresenta as principais configurações de sistemas fotovoltaicos e seus componentes;

- Capítulo 4 - Metodologia: descreve a metodologia adotada no trabalho, com descrição das ferramentas empregadas para realização das simulações;

- Capítulo 5 - Resultados: apresenta, compara e discute os resultados das simulações computacionais realizadas;

- Capítulo 6 - Estudo de caso: utiliza os dados operacionais de uma usina fotovoltaica para realizar comparações com as simulações;

- Capítulo 7 - Conclusões: aborda as conclusões do trabalho e apresenta algumas sugestões para trabalhos futuros. 


\section{PANORAMA DA ENERGIA SOLAR FOTOVOLTAICA}

Neste capítulo, é abordado brevemente o conceito da energia solar e sua conversão em energia elétrica por meio do efeito fotovoltaico. É apresentado o desenvolvimento dessa fonte no mundo e no Brasil, ressaltando os leilões de energia elétrica ocorridos nos últimos anos em que houve participação da fonte solar fotovoltaica.

\subsection{Recurso solar}

Para melhor se compreender a energia solar, é necessário, antes, conhecer a sua fonte de energia. O Sol é uma estrela composta por matéria que se encontra no estado de gás ou plasma, aquecido a altas temperaturas. No núcleo, ocorrem processos de fusão nuclear, com liberação de grandes quantidades de energia, a uma taxa na ordem de $3,6 \cdot 10^{26} \mathrm{~J} / \mathrm{s}$, que são emitidas para o espaço em forma de luz e calor (BESSEMOULIN; OLIVIÉRI, 2000).

Devido à distância entre o Sol e a Terra, apenas uma pequena parcela dessa energia incide no planeta. Fora da atmosfera, a densidade superficial de potência é aproximadamente $1.367 \mathrm{~W} / \mathrm{m}^{2}$, e, à medida em que se aproxima da superfície da Terra, a irradiância é atenuada por fenômenos como reflexão, absorção e dispersão, conforme mostrado na figura 2.1 .

Figura 2.1 - Redução da radiação solar incidente na superfície terrestre através de reflexão, absorção e dispersão.

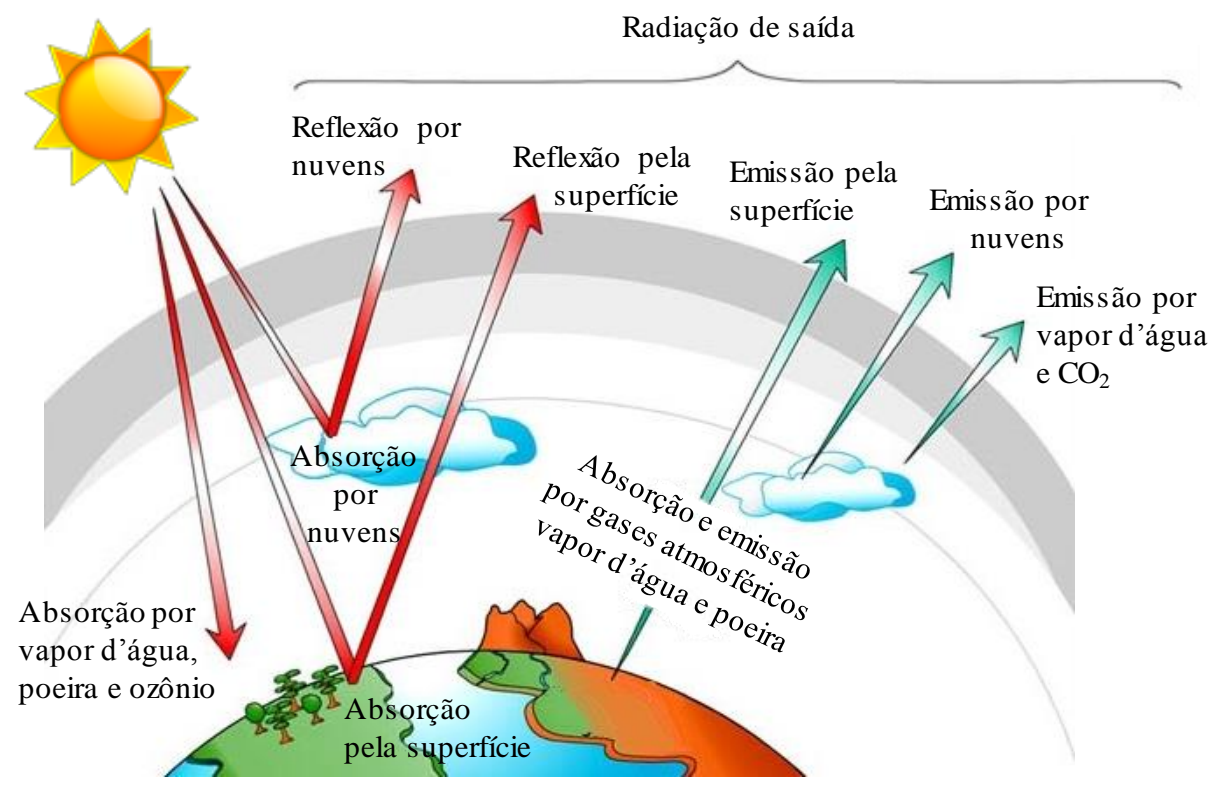

Fonte: elaborado a partir de (ATMOSPHERIC RADIATION MEASUREMENT (ARM), 2004).

Apesar de ser pequena quando comparada com a radiação solar total, a parcela que chega à superfície terrestre por ano é da ordem de 10.000 vezes maior que o consumo anual de 
energia global (NATIONAL OCEANIC AND ATMOSPHERIC ADMINISTRATION (NOOA), 2016).

$\mathrm{Na}$ figura 2.2, é mostrado o mapa de irradiação global incidente no plano horizontal acumulada no período de um ano na superfície dos continentes da Terra. É importante salientar que essas áreas possuem algum nível de energia solar incidente, e, portanto, diferentemente dos recursos fósseis, que são finitos, geograficamente concentrados e que só ocorrem em algumas regiões do planeta, o recurso solar é renovável, amplamente disperso e acessível, podendo ser considerado universal.

Figura 2.2 - Irradiação anual global no plano horizontal.

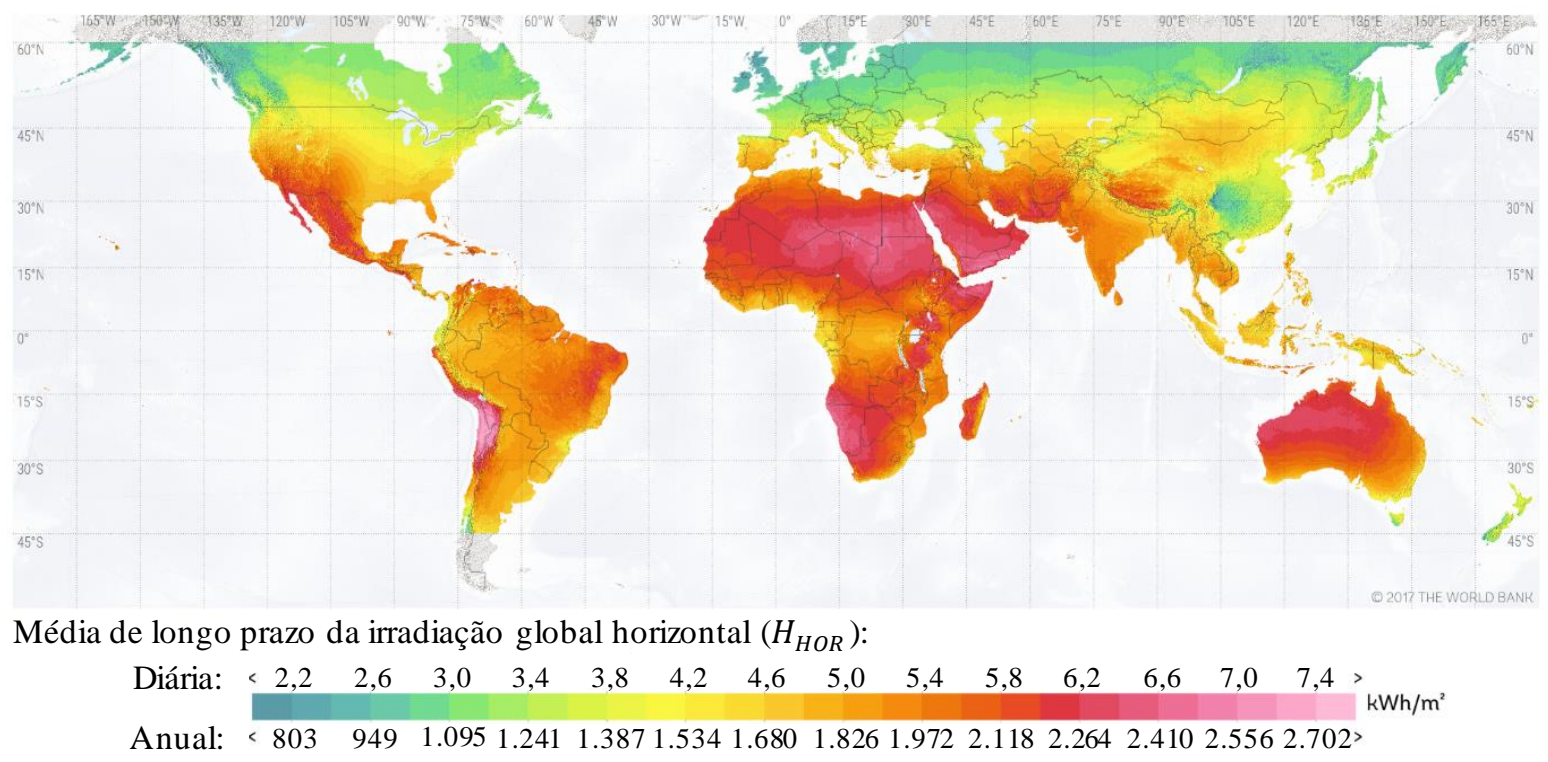

Fonte: elaborado a partir de (SOLARGIS, 2018).

De acordo com a figura 2.2, é possível verificar que o Brasil está entre os países que possuem um dos maiores potenciais em termos de recurso solar, com irradiação total anual média incidente no plano horizontal que varia em uma faixa aproximada de $1.500 \mathrm{kWh} / \mathrm{m}^{2}$ a $2.300 \mathrm{kWh} / \mathrm{m}^{2}$.

Na figura 2.3, é mostrada mais detalhadamente a irradiação global horizontal para o território brasileiro, sendo possível verificar as regiões com maiores incidências, como é o caso de boa parte da área central do Nordeste. 
Figura 2.3 - Irradiação anual global no plano horizontal para o Brasil.

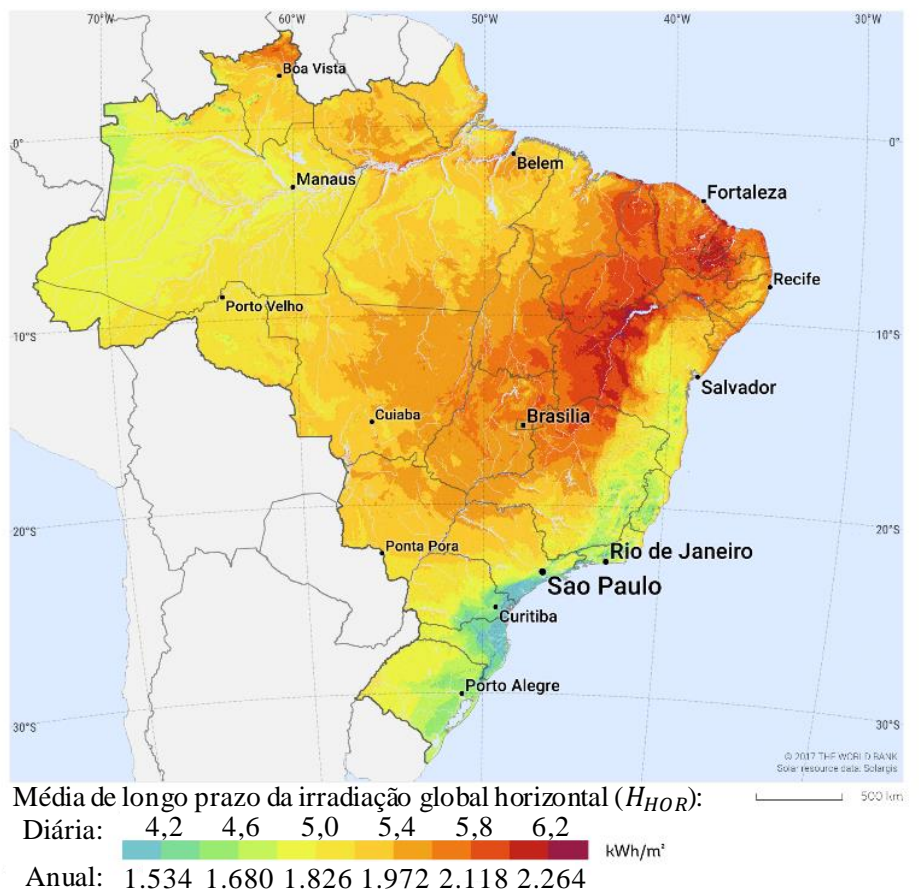

Fonte: elaborado a partir de (SOLARGIS, 2018).

Uma das formas de realizar a conversão da energia disponível na luz solar em energia elétrica é por meio do efeito fotovoltaico. Sua descoberta é atribuída ao físico francês Alexandre-Edmond Becquerel, quem, no ano de 1839, percebeu o aumento da condutividade de uma solução de um eletrólito com eletrodos de metal quando exposta à radiação luminosa (ZILLES et al., 2012).

A partir daí, deu-se início ao desenvolvimento de uma fonte de energia, que, mais de 170 anos mais tarde, se tornou a que teve a maior taxa de crescimento entre as potências adicionadas em 2017, superando em mais de $30 \%$ a marca do ano anterior (RENEWABLE ENERGY POLICY NETWORK FOR THE 21ST CENTURY (REN21), 2018).

\subsection{Histórico}

A comparação entre as projeções da capacidade solar fotovoltaica instalada no mundo realizada por algumas das principais agências e instituições de energia aponta que, em geral, as previsões subestimaram o desenvolvimento do mercado solar fotovoltaico (RENEWABLE ENERGY POLICY NETWORK FOR THE 21ST CENTURY (REN21), 2017). De acordo com a figura 2.4, é possível observar que a potência acumulada em 2015 foi superior a quase todas as projeções apresentadas, como é o caso da previsão realizada em 2011 pela Agência 
Internacional de Energia (IEA), que estimou uma potência de $144 \mathrm{GWp}$ para o cenário otimista (GREENPEACE INTERNATIONAL; GLOBAL WIND ENERGY COUNCIL; SOLARPOWER EUROPE, 2015).

A redução dos custos da tecnologia, o aumento da escala de produção, a melhoria na eficiência dos componentes, a implementação de políticas favoráveis e o avanço em processos produtivos foram alguns dos principais fatores que proporcionaram esse acelerado crescimento, superando as expectativas (RENEWABLE ENERGY POLICY NETWORK FOR THE 21ST CENTURY (REN21), 2018).

Figura 2.4 - Comparação entre as projeções da capacidade fotovoltaica instalada no mundo e o desenvolvimento real do mercado.

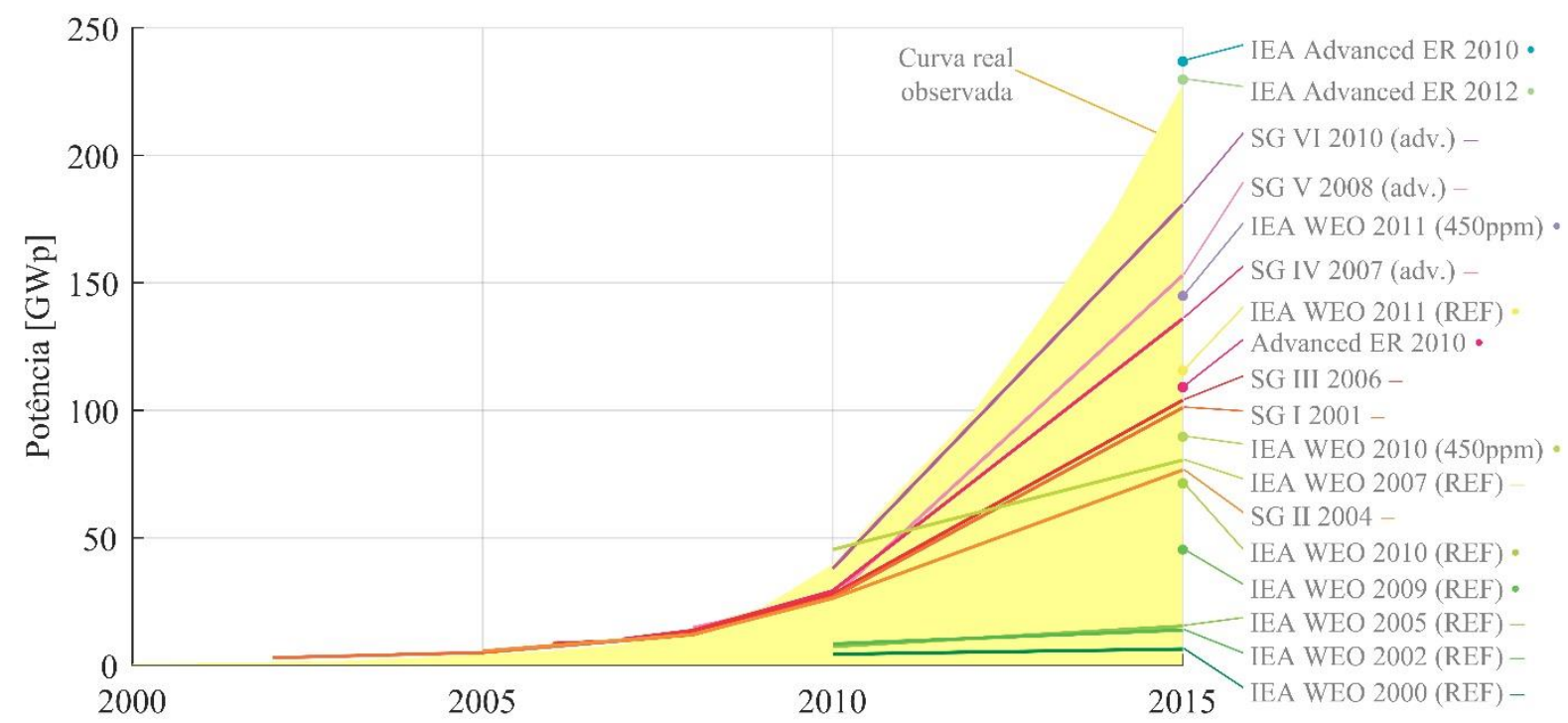

Fonte: elaborado a partir de (RENEWABLE ENERGY POLICY NETWORK FOR THE 21ST CENTURY (REN21), 2017).

No ano de 2017, o setor de energia solar fotovoltaica foi responsável por 3,4 milhões de empregos diretos e indiretos no mundo, tendo um crescimento de $9 \%$ em relação ao ano anterior (RENEWABLE ENERGY POLICY NETWORK FOR THE 21ST CENTURY (REN21), 2018). Já os investimentos nesse setor somaram um montante de US\$160,8 bilhões (BLOOMBERG NEW ENERGY FINANCE (BNEF), 2018).

$\mathrm{Na}$ figura 2.5, é mostrada a evolução da capacidade solar fotovoltaica instalada no mundo, tendo experimentado um notório crescimento desde 2008. No ano de 2017, a potência instalada atingiu a marca acumulada de $403 \mathrm{GWp}$. 
Figura 2.5 - Evolução da capacidade fotovoltaica instalada no mundo.

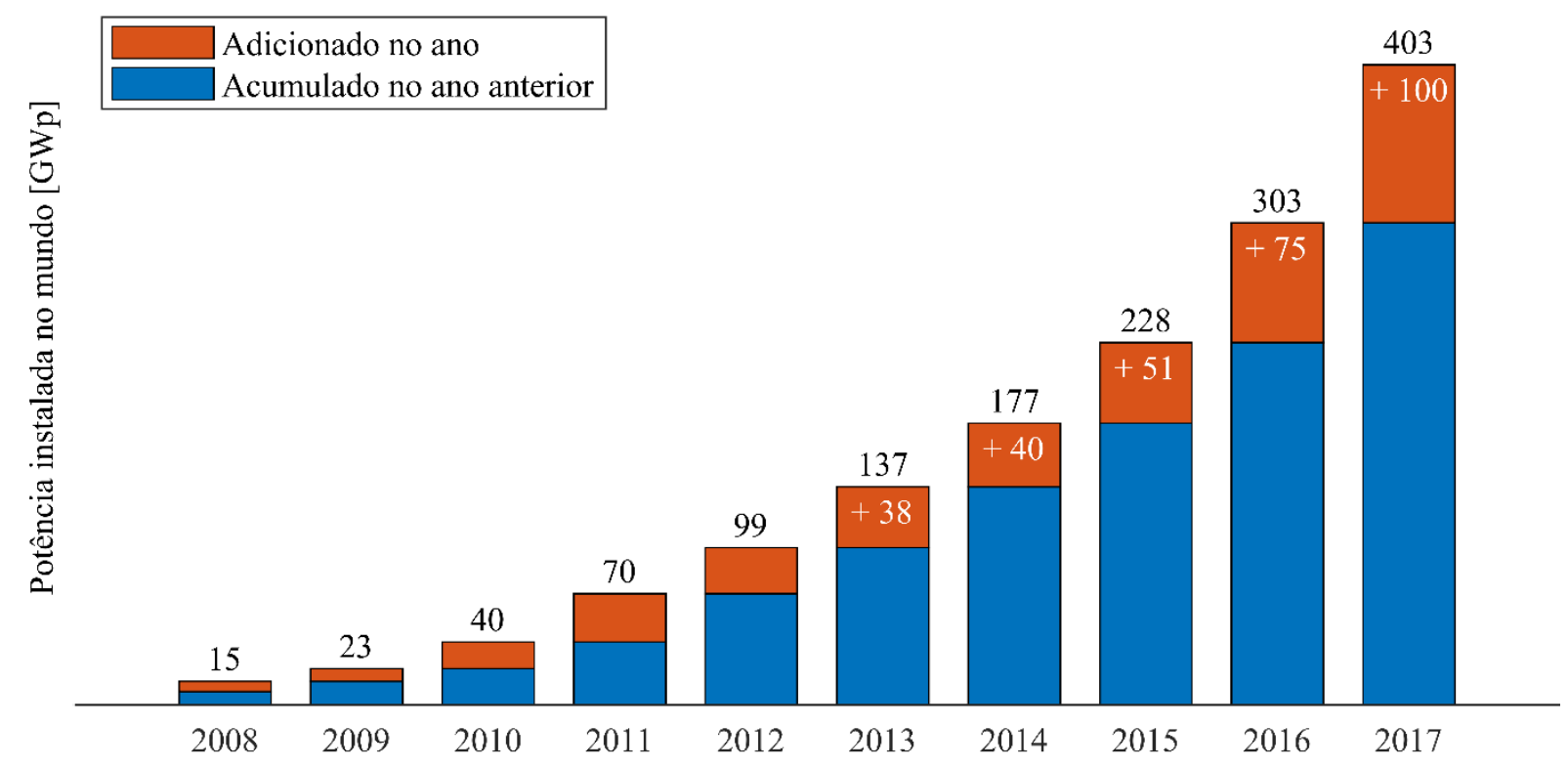

Fonte: elaborado a partir de (INTERNATIONAL ENERGY AGENCY (IEA), 2018a).

Diversos fatores contribuíram para que esse desenvolvimento ocorresse. Indubitavelmente, um deles é a redução dos custos dos módulos fotovoltaicos, que ocorre à medida em que a produção acumulada anual aumenta ao longo dos anos, conforme indicado na figura 2.6. A linha em vermelho retrata a taxa de aprendizagem e, nesse caso, denota que nos últimos 37 anos o preço reduziu em torno de $24 \%$ a cada vez que a produção acumulada foi duplicada (FRAUNHOFER INSTITUTE FOR SOLAR ENERGY SYSTEMS, 2018). É interessante observar a retroalimentação desse efeito, relacionando preços dos módulos e capacidade instalada acumulada. 
Figura 2.6 - Evolução dos preços dos módulos fotovoltaicos.

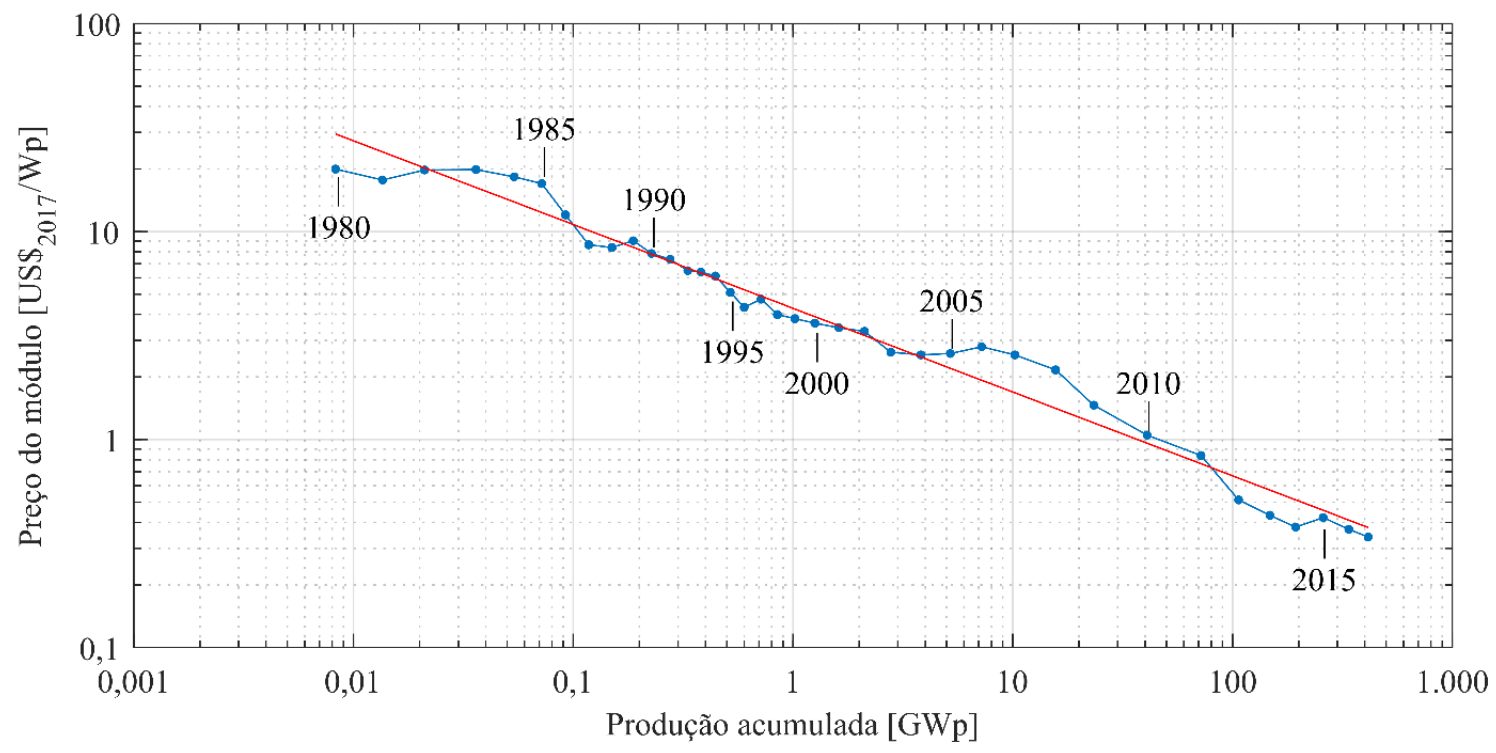

Fonte: elaborado a partir de (FRAUNHOFER INSTITUTE FOR SOLAR ENERGY SYSTEMS, 2018) e (INTERNATIONAL TECHNOLOGY ROADMAP FOR PHOTOVOLTAIC (ITRPV), 2018).

Ao mesmo tempo em que a capacidade instalada aumenta, e os preços dos módulos diminuem, verifica-se o aumento de eficiência das células fotovoltaicas, conforme indicado na figura 2.7, o que também contribui para o crescimento e a consolidação da energia solar fotovoltaica no mundo.

Figura 2.7 - Evolução das eficiências das células fotovoltaicas de diferentes tecnologias.

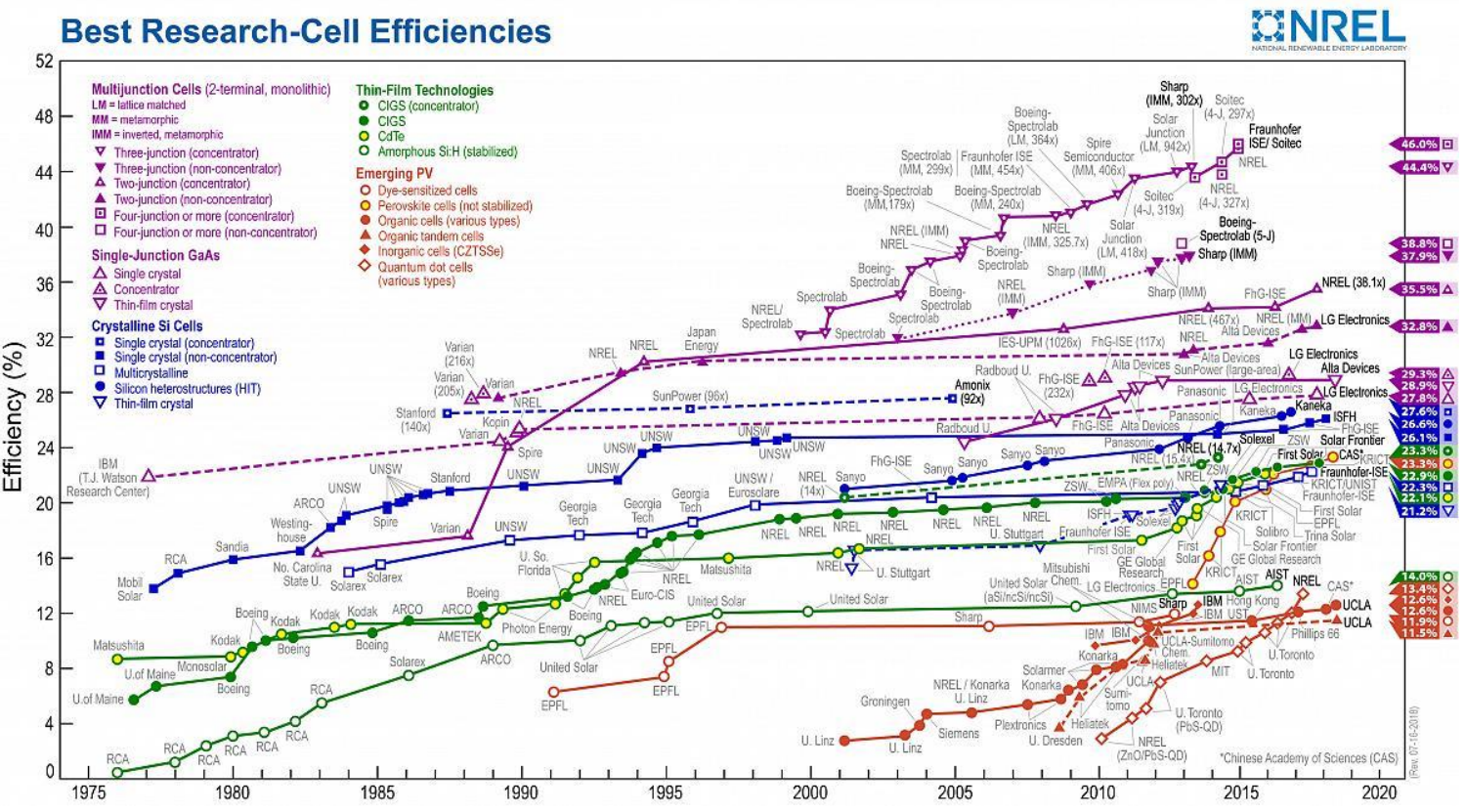

Fonte: (NATIONAL RENEWABLE ENERGY LABORATORY (NREL), 2018c). 


\subsection{Energia solar fotovoltaica no Brasil}

Os primeiros registros relacionados à energia fotovoltaica no Brasil datam da década de 1950 e estavam relacionados à pesquisa e desenvolvimento da tecnologia e a algumas aplicações isoladas (DHERE et al., 2005). Apenas a partir da década de 1990, é que se tem registros dos primeiros sistemas fotovoltaicos conectados à rede elétrica brasileira (PINHO; GALDINO, 2014).

No que diz respeito ao aumento da capacidade instalada, a energia solar fotovoltaica experimentou tímidos avanços até o ano de 2012, resumindo-se basicamente a alguns poucos sistemas fotovoltaicos instalados, sendo a maioria de sistemas de pesquisa e desenvolvimento junto a instituições acadêmicas do país. No entanto, com a publicação da resolução normativa da Agência Nacional de Energia Elétrica (ANEEL) no 482, de 17 de abril de 2012, que estabeleceu condições gerais para o acesso de microgeração e minigeração distribuída aos sistemas de distribuição de energia elétrica e o sistema de compensação de energia elétrica (AGÊNCIA NACIONAL DE ENERGIA ELÉTRICA (ANEEL), 2012), deu-se início a uma mudança significativa no panorama da energia solar fotovoltaica no Brasil. Juntamente com os leilões de energia elétrica ocorridos em anos posteriores, seu crescimento foi alavancado, marcando um ponto de destaque na curva da inserção da fonte solar fotovoltaica na matriz elétrica brasileira.

Nas seções de 2.3.1 a 2.3.7, são apresentadas as características gerais dos últimos leilões de energia elétrica em que houve participação da fonte solar fotovoltaica. As respectivas características técnicas são sumarizadas na seção 2.3.8.

\subsection{1 $\quad 1^{\circ}$ Leilão de Energia de Reserva de 2014}

Com a publicação da portaria do Ministério de Minas e Energia (MME) nº 236, de 30 de maio de 2014 (MINISTÉRIO DE MINAS E ENERGIA (MME), 2014a), foi anunciada a promoção do Leilão de Energia de Reserva (LER) de 2014, que seria realizado, inicialmente, no dia 10 de outubro de 2014. Por meio da portaria MME n 320, de 9 de julho de 2014 (MINISTÉRIO DE MINAS E ENERGIA (MME), 2014b), a data de ocorrência do leilão foi alterada para 31 de outubro de 2014. Nesse leilão, estava prevista a negociação de Contratos de Energia de Reserva (CER) para fornecimento de energia elétrica por 20 anos a partir de $1^{\circ}$ de outubro de 2017, na modalidade por quantidade de energia, havendo diferenciação por tipo de 
fonte geradora. Entre outros, puderam participar empreendimentos de geração a partir da fonte solar fotovoltaica com potência não inferior a $5 \mathrm{MW}$.

Da fonte solar, foram cadastrados 400 projetos de empreendimentos fotovoltaicos, o que representou $10.789 \mathrm{MW}$ de potência. Desse montante, 331 usinas foram habilitadas tecnicamente, correspondendo a uma potência de 8.870 MW. A distribuição de potência dos projetos cadastrados e habilitados por estado é mostrada na figura 2.8 , onde se verifica um destaque para a Bahia, que teve quase 4.200 MW em empreendimentos fotovoltaicos habilitados tecnicamente, o que corresponde a $47 \%$ do total dessa categoria.

Figura 2.8 - Empreendimentos fotovoltaicos cadastrados e habilitados no $1^{\circ}$ LER de 2014 por estado.

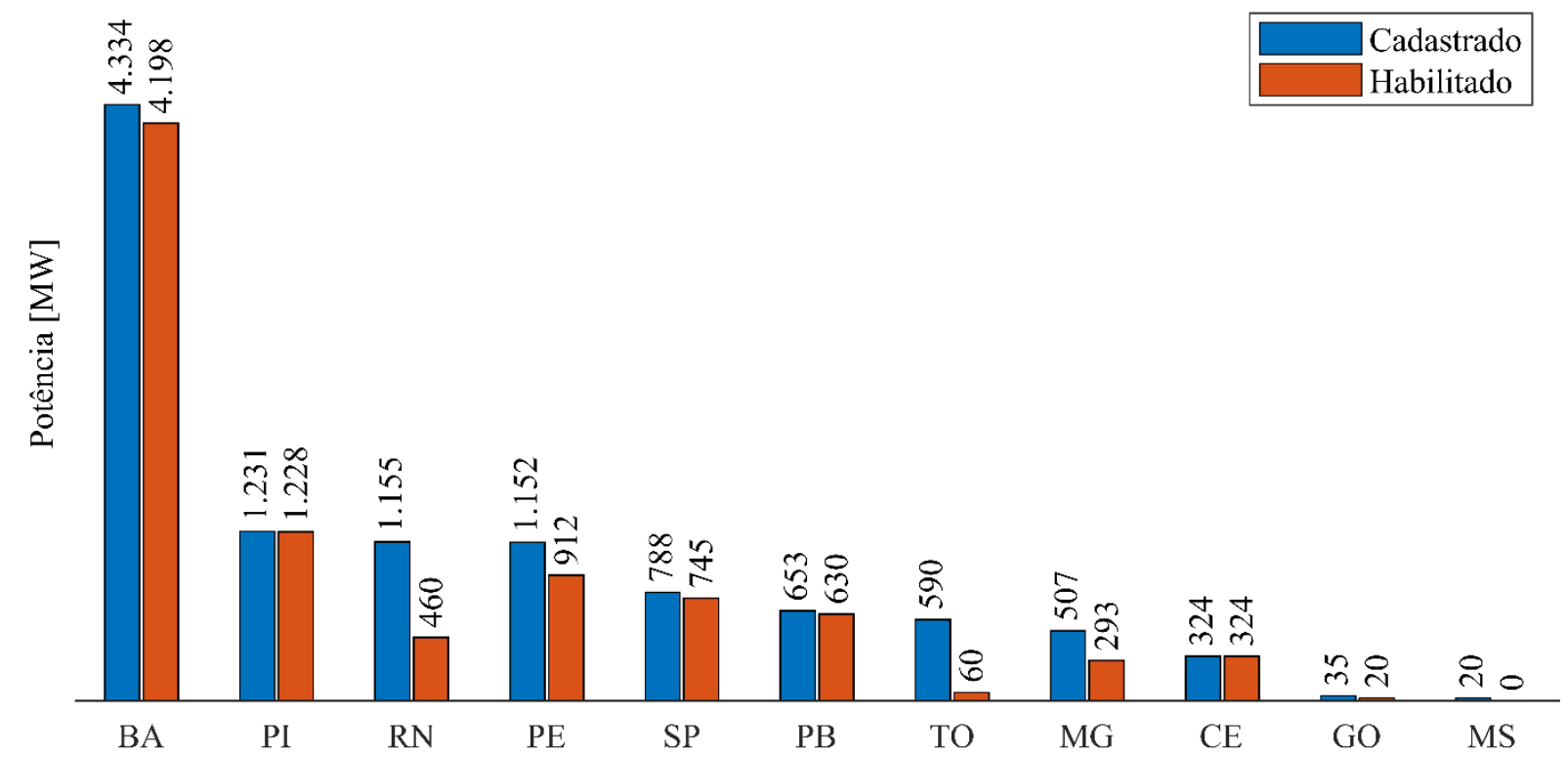

Fonte: elaborado a partir de (EMPRESA DE PESQUISA ENERGÉTICA (EPE), 2014b).

Entre os motivos pelos quais 69 projetos foram reprovados na etapa de habilitação técnica, estão inseridas questões relacionadas ao licenciamento ambiental, à certificação do projeto, ao registro junto à ANEEL, à regularização fundiária, além do parecer de acesso e conexão dos empreendimentos à rede elétrica (EMPRESA DE PESQUISA ENERGÉTICA (EPE), 2014b).

A etapa seguinte, de negociação durante a realização do leilão, durou cerca de oito horas e resultou na contratação de 202,1 $\mathrm{MW}_{\text {med }}$ de garantia física, oriundos de 31 empreendimentos fotovoltaicos. O preço médio da energia fotovoltaica negociada foi de R \$215,12/MWh, com um deságio de 17,9\% frente ao preço inicial de R \$262,00/MWh estabelecido para essa fonte (EMPRESA DE PESQUISA ENERGÉTICA (EPE), 2014a) (AGÊNCIA NACIONAL DE 
ENERGIA ELÉTRICA (ANEEL), 2014). Na figura 2.9, estão apresentadas as potências dos empreendimentos vendedores agrupadas por estados, o que totaliza uma potência de $890 \mathrm{MW}$.

Figura 2.9 - Empreendimentos fotovoltaicos contratados no $1^{\circ}$ LER de 2014 por estado.

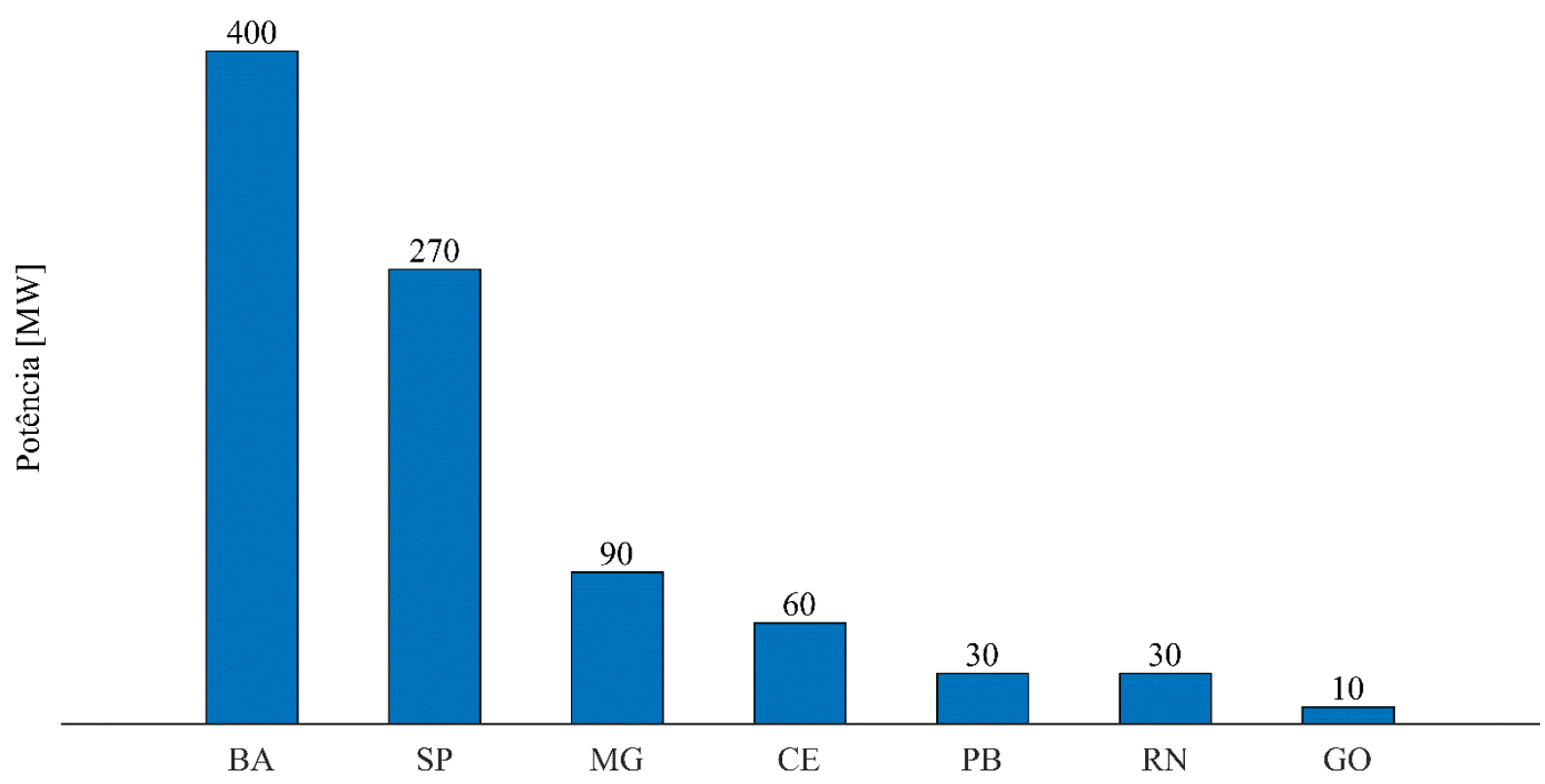

Fonte: elaborado a partir de (EMPRESA DE PESQUISA ENERGÉTICA (EPE), 2014b).

Particularmente, esse foi o primeiro leilão do governo federal em que se contratou energia proveniente de empreendimentos fotovoltaicos no Ambiente de Contratação Regulada (ACR) (EMPRESA DE PESQUISA ENERGÉTICA (EPE), 2014b) e foi caracterizado na época como sendo o mais disputado e competitivo da história dos leilões de energia elétrica no Brasil (EMPRESA DE PESQUISA ENERGÉTICA (EPE), 2014a). Foi considerado um marco histórico e um passo decisivo para o setor fotovoltaico brasileiro (ASSOCIAÇÃO BRASILEIRA DE ENERGIA SOLAR FOTOVOLTAICA (ABSOLAR), 2014). Para essas usinas, foram previstos investimentos no valor total de $\mathrm{R} \$ 4,1$ bilhões, que, quando divididos por empreendimentos, os valores variaram de $\mathrm{R} \$ 53$ milhões a $\mathrm{R} \$ 157$ milhões, dependendo das características de cada projeto.

No entanto, com base em estudos da EPE, que levaram em conta a situação econômica do Brasil e as então perspectivas futuras de demanda e oferta de energia, foi oficializado o mecanismo de descontratação de energia de reserva de 2017, por meio da portaria MME portaria $\mathrm{n}^{\mathrm{o}} 151$, de 18 de abril de 2017. Com isso, foi permitido o distrato ou aditamento de CER provenientes de empreendimentos fotovoltaicos que possuíssem CER vigentes, mas que não tivessem iniciado a fase de operação em testes. A descontratação de energia estava condicionada ao pagamento de um prêmio por parte dos empreendimentos que desejassem 
participar do certame. Aqueles que ofertassem o maior lance único, poderiam ter seus contratos rescindidos (MINISTÉRIO DE MINAS E ENERGIA (MME), 2017a).

No dia 28/08/2017, foram descontratados $250 \mathrm{MW}$ de usinas fotovoltaicas que venceram no $1^{\circ}$ LER de 2014, distribuídos em nove empreendimentos (CÂMARA DE COMERCIALIZAÇÃO DE ENERGIA ELÉTRICA (CCEE), 2017b). Na figura 2.10, é apresentada a situação atual dos empreendimentos fotovoltaicos do $1^{\circ}$ LER de 2014.

Figura 2.10 - Situação atual dos empreendimentos fotovoltaicos contratados no $1^{\circ}$ LER de 2014 por estado.

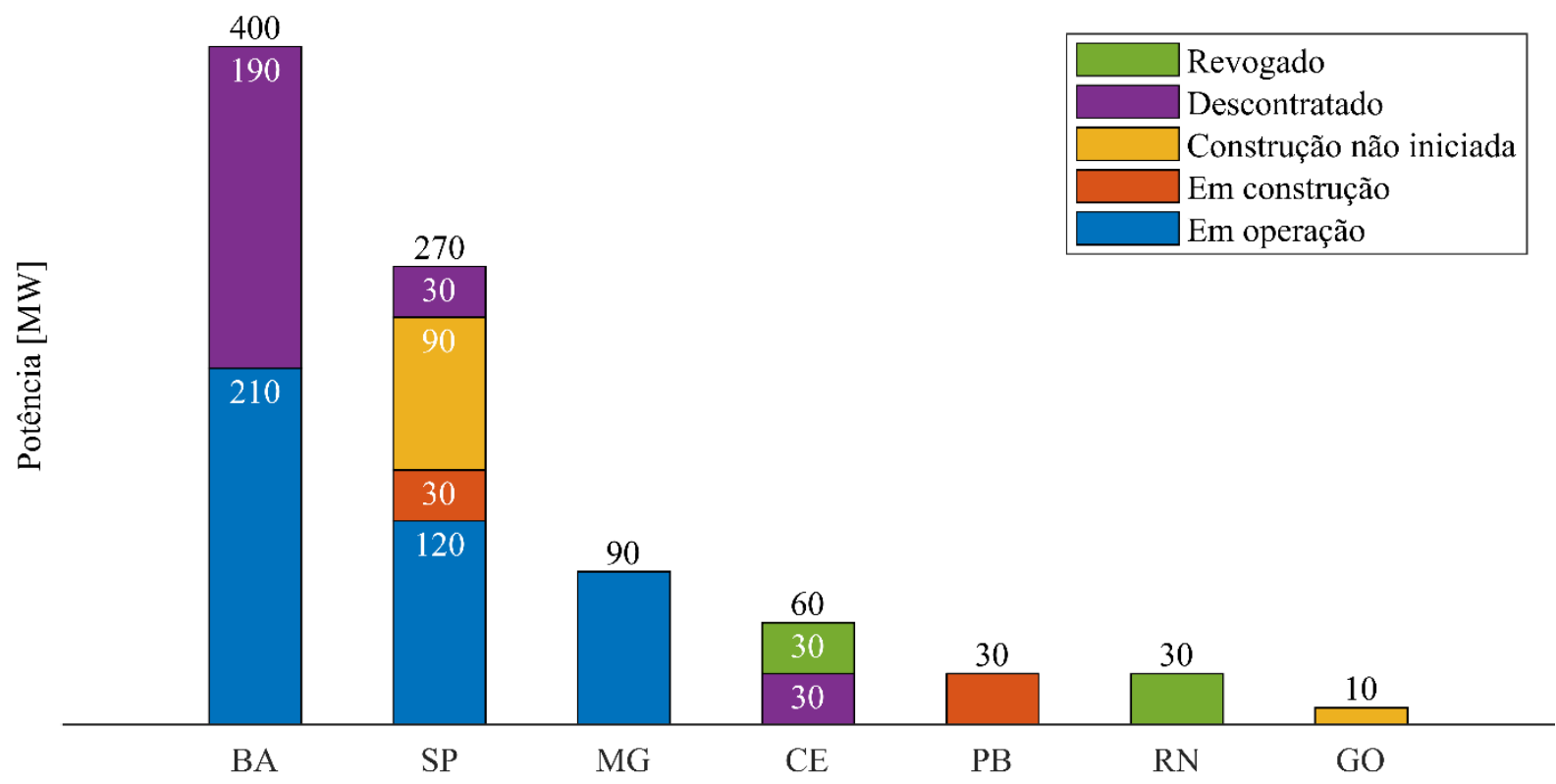

Fonte: elaborado a partir de (EMPRESA DE PESQUISA ENERGÉTICA (EPE), 2014b) e (AGÊNCIA NACIONAL DE ENERGIA ELÉTRICA (ANEEL), 2018a).

\subsection{2 $\quad 1^{\circ}$ Leilão de Energia de Reserva de 2015}

O leilão seguinte foi destinado exclusivamente para empreendimentos de geração a partir da fonte solar fotovoltaica. Denominado $1^{\circ}$ LER de 2015, foi oficializado por meio da portaria MME nº 69, de 13 de março de 2015, que estabeleceu as diretrizes para negociação de CER por 20 anos, a contar de $1^{\circ}$ de agosto de 2017, para empreendimentos fotovoltaicos com potência não inferior a 5 MW (MINISTÉRIO DE MINAS E ENERGIA (MME), 2015a).

Ao total, foram cadastrados 382 projetos, correspondendo a uma capacidade de 12.528 MW. Desses, 341 empreendimentos foram habilitados tecnicamente, o que representou 11.261 MW de potência. Na figura 2.11, pode-se verificar a distribuição de potência por estado dos projetos cadastrados e habilitados. 
Figura 2.11 - Empreendimentos fotovoltaicos cadastrados e habilitados no $1^{\circ}$ LER de 2015 por estado.

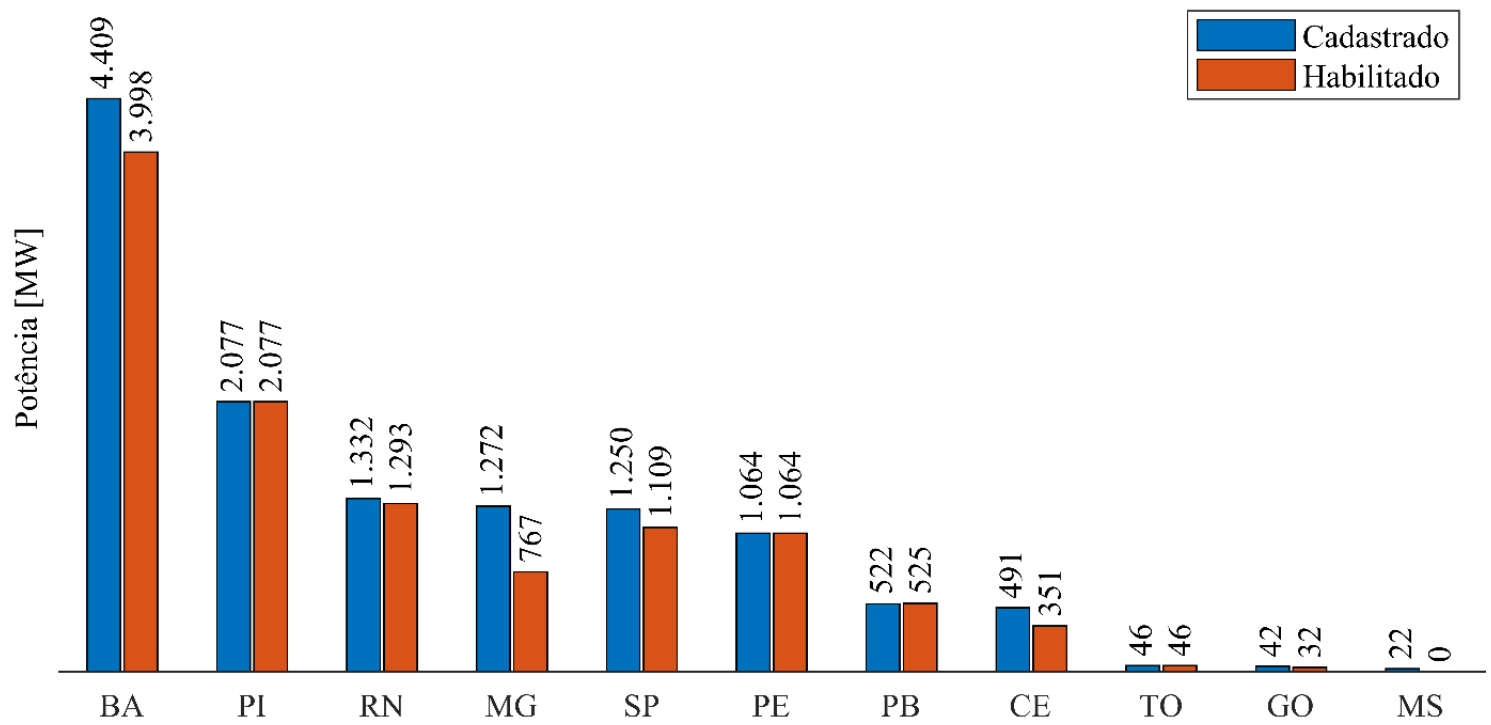

Fonte: elaborado a partir de (EMPRESA DE PESQUISA ENERGÉTICA (EPE), 2015).

Os principais motivos que estão por trás da inabilitação técnica dos 41 empreendimentos são relacionados ao parecer de acesso e conexão ao Sistema Interligado Nacional (SIN), à comprovação do direito de uso do terreno e ao licenciamento ambiental (EMPRESA DE PESQUISA ENERGÉTICA (EPE), 2015).

Após a realização do leilão, foram contratados 232,9 $\mathrm{MW}_{\text {med }}$ de garantia física, provenientes de 30 empreendimentos fotovoltaicos, o que totalizou uma potência de $834 \mathrm{MW}$ distribuída conforme indicado na figura 2.12. É mostrada também a situação atual dos empreendimentos. 
Figura 2.12 - Situação atual dos empreendimentos fotovoltaicos contratados no $1^{\circ}$ LER de 2015 por estado.

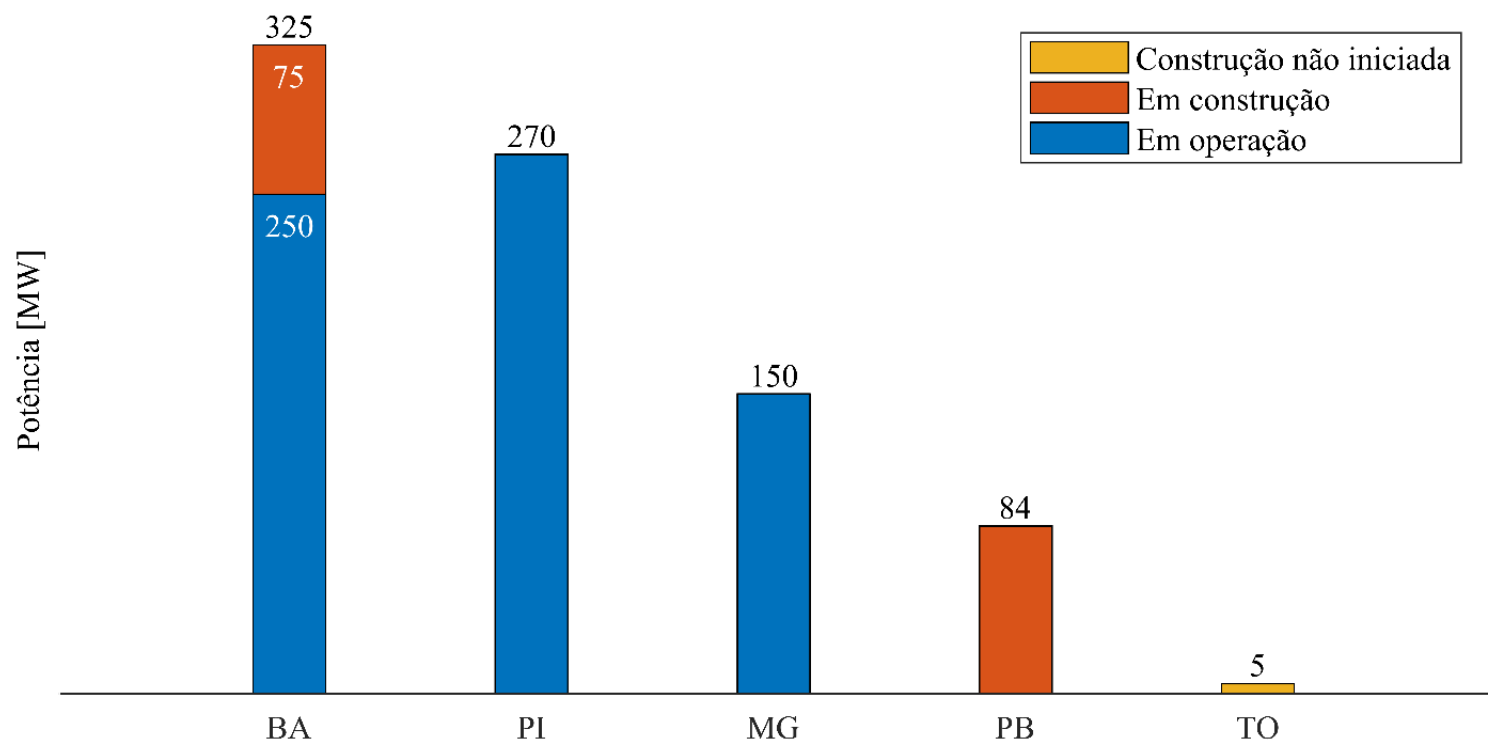

Fonte: elaborado a partir de (EMPRESA DE PESQUISA ENERGÉTICA (EPE), 2015) e (AGÊNCIA NACIONAL DE ENERGIA ELÉTRICA (ANEEL), 2018a).

O preço da energia negociada variou de $\mathrm{R} \$ 296,00 / \mathrm{MWh}$ a $\mathrm{R} \$ 305,51 / \mathrm{MWh}$, tendo um valor médio de $\mathrm{R} \$ 301,79 / \mathrm{MWh}$, com um deságio médio de 13,6 \% em relação ao preço teto de R \$349/MWh estabelecido inicialmente (EMPRESA DE PESQUISA ENERGÉTICA (EPE), 2015) (AGÊNCIA NACIONAL DE ENERGIA ELÉTRICA (ANEEL), 2015). É importante salientar que de 2014 para 2015, houve uma forte valorização cambial do dólar frente ao real, o que, junto com outros fatores econômicos, pode justificar o aumento de mais de $40 \%$ no preço médio da energia contratada no $1^{\circ}$ LER de 2015 em relação ao $1^{\circ}$ LER de 2014.

\subsection{3 $\quad 2^{\circ}$ Leilão de Energia de Reserva de 2015}

Na sequência, ainda no ano de 2015, foi divulgado o $2^{\circ}$ LER de 2015 por meio da portaria $\mathrm{n}^{\mathrm{o}} 70$, de 16 de março de 2015, que previa a negociação de CER diferenciados por fontes e com suprimento de energia por um período de 20 anos a contar do dia $1^{\circ}$ de novembro de 2018. Assim como nos outros dois leilões anteriores, apenas empreendimentos com potência não inferior a $5 \mathrm{MW}$ podiam ser candidatos ao processo de habilitação técnica. (MINISTÉRIO DE MINAS E ENERGIA (MME), 2015b).

Entre os empreendimentos cadastrados, 649 projetos foram de usinas fotovoltaicas, totalizando uma capacidade de $20.953 \mathrm{MW}$. Foram habilitados tecnicamente 493 
empreendimentos, com uma potência acumulada de $13.158 \mathrm{MW}$ e cuja distribuição entre os estados está disposta na figura 2.13.

Figura 2.13 - Empreendimentos fotovoltaicos cadastrados e habilitados no $2^{\circ}$ LER de 2015 por estado.

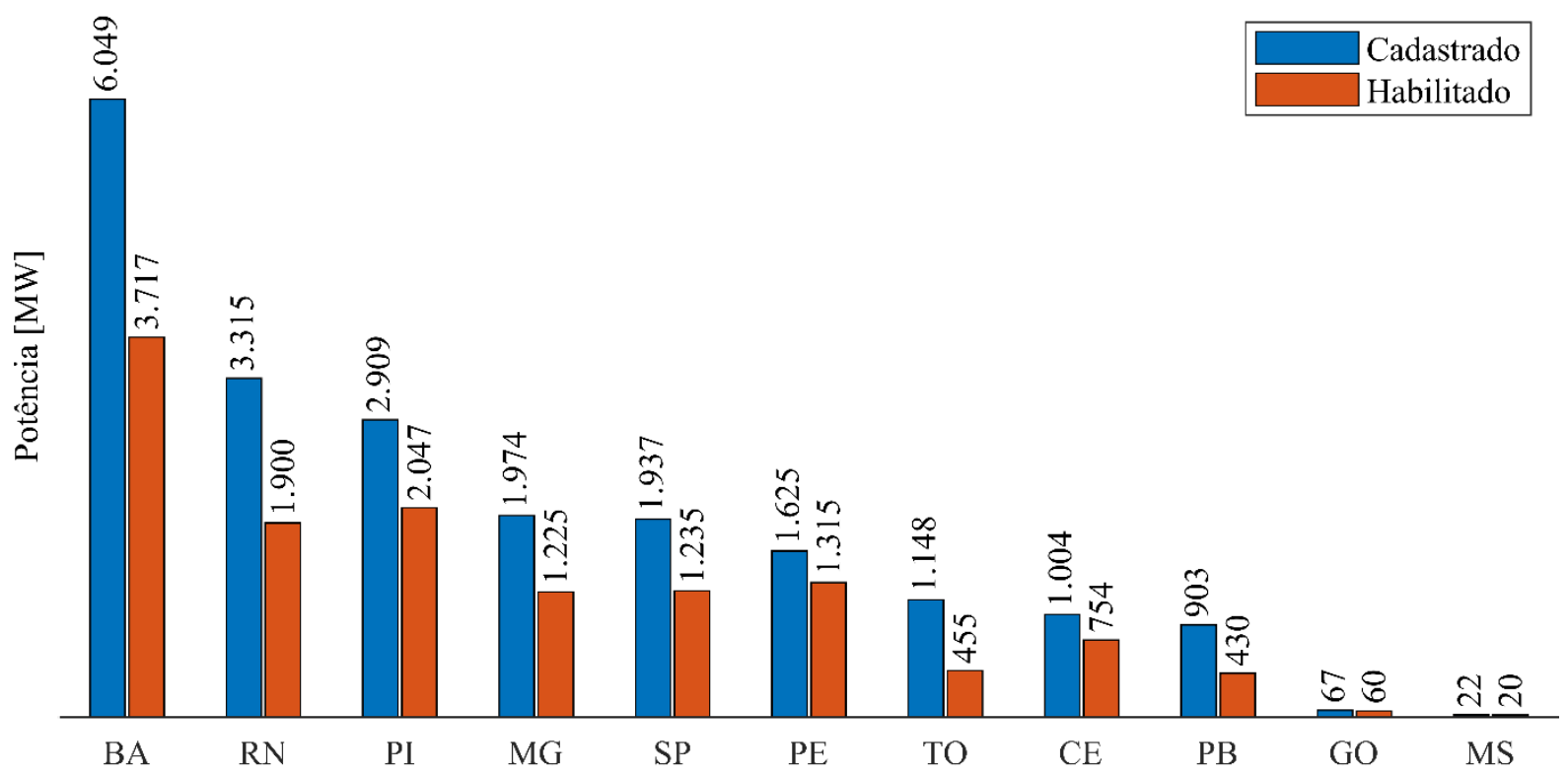

Fonte: elaborado a partir de (EMPRESA DE PESQUISA ENERGÉTICA (EPE), 2016d).

Dos 156 projetos não habilitados tecnicamente, 112 não cumpriram requisitos técnicos estabelecidos previamente pela EPE. Já os 44 restantes desistiram, seja por já terem sido negociados no $1^{\circ}$ LER de 2015, seja por dificuldades técnicas ou documentais (EMPRESA DE PESQUISA ENERGÉTICA (EPE), 2016d).

O leilão ocorreu no dia 13 de novembro de 2015 e finalizou com a contratação de 245,3 $\mathrm{MW}_{\text {med }}$ de garantia física vendidos por 33 empreendimentos fotovoltaicos, cuja potência total foi de 929 MW distribuída entre os estados conforme indicado na figura 2.14. Também é possível verificar a situação atual dos empreendimentos. 
Figura 2.14 - Situação dos empreendimentos fotovoltaicos contratados no $2^{\circ}$ LER de 2015 por estado.

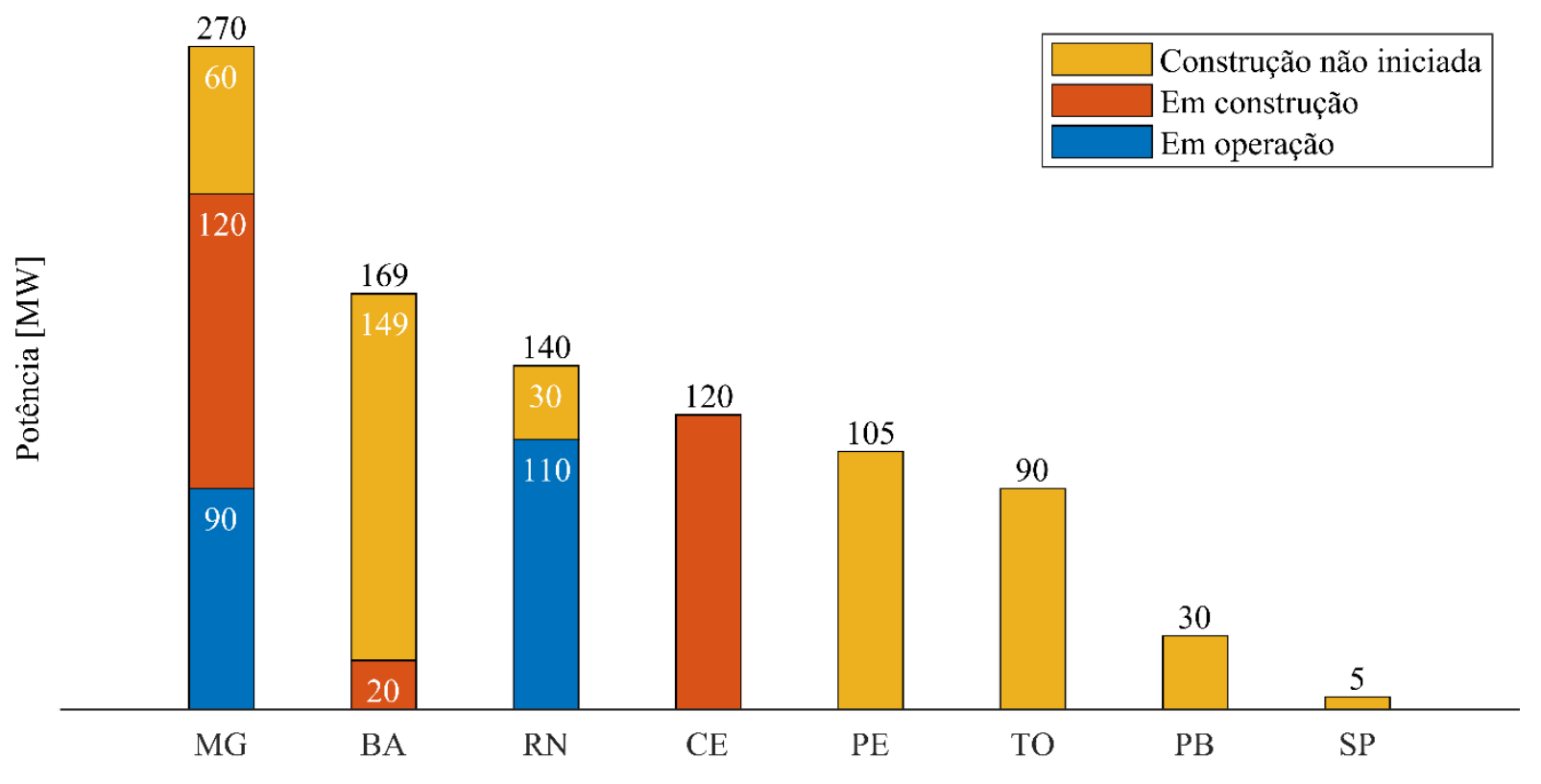

Fonte: elaborado a partir de (EMPRESA DE PESQUISA ENERGÉTICA (EPE), 2015) e (AGÊNCIA NACIONAL DE ENERGIA ELÉTRICA (ANEEL), 2018a).

O preço da energia contratada variou de $\mathrm{R} \$ 2$ 290,00/MWh a $\mathrm{R} \$ 302,99 / \mathrm{MWh}$, tendo um preço médio de $\mathrm{R} \$ 297,75 / \mathrm{MWh}$, o que corresponde a um deságio de 21,9\% frente ao preço teto de R\$381,00/MWh (CÂMARA DE COMERCIALIZAÇÃO DE ENERGIA ELÉTRICA (CCEE), 2015).

\subsection{4 $1^{\circ}$ Leilão de Energia de Reserva de 2016}

Em 23 de março de 2016, foi publicada a portaria do MME $\mathrm{n}^{\circ}$ 104, que previa a realização do $1^{\text {o }}$ LER de 2016 inicialmente para 29 de julho de 2016. Similar aos anteriores, esse leilão contemplaria a negociação de CER diferenciados por fonte, solar fotovoltaica e hidrelétrica (MINISTÉRIO DE MINAS E ENERGIA (MME), 2016a).

Dos 428 projetos cadastrados, 295 foram de empreendimentos fotovoltaicos, com uma potência total de 9.211 MW, distribuída entre os estados como mostrado na figura 2.15. 
Figura 2.15 - Empreendimentos fotovoltaicos cadastrados no $1^{\circ}$ LER de 2016 por estado.

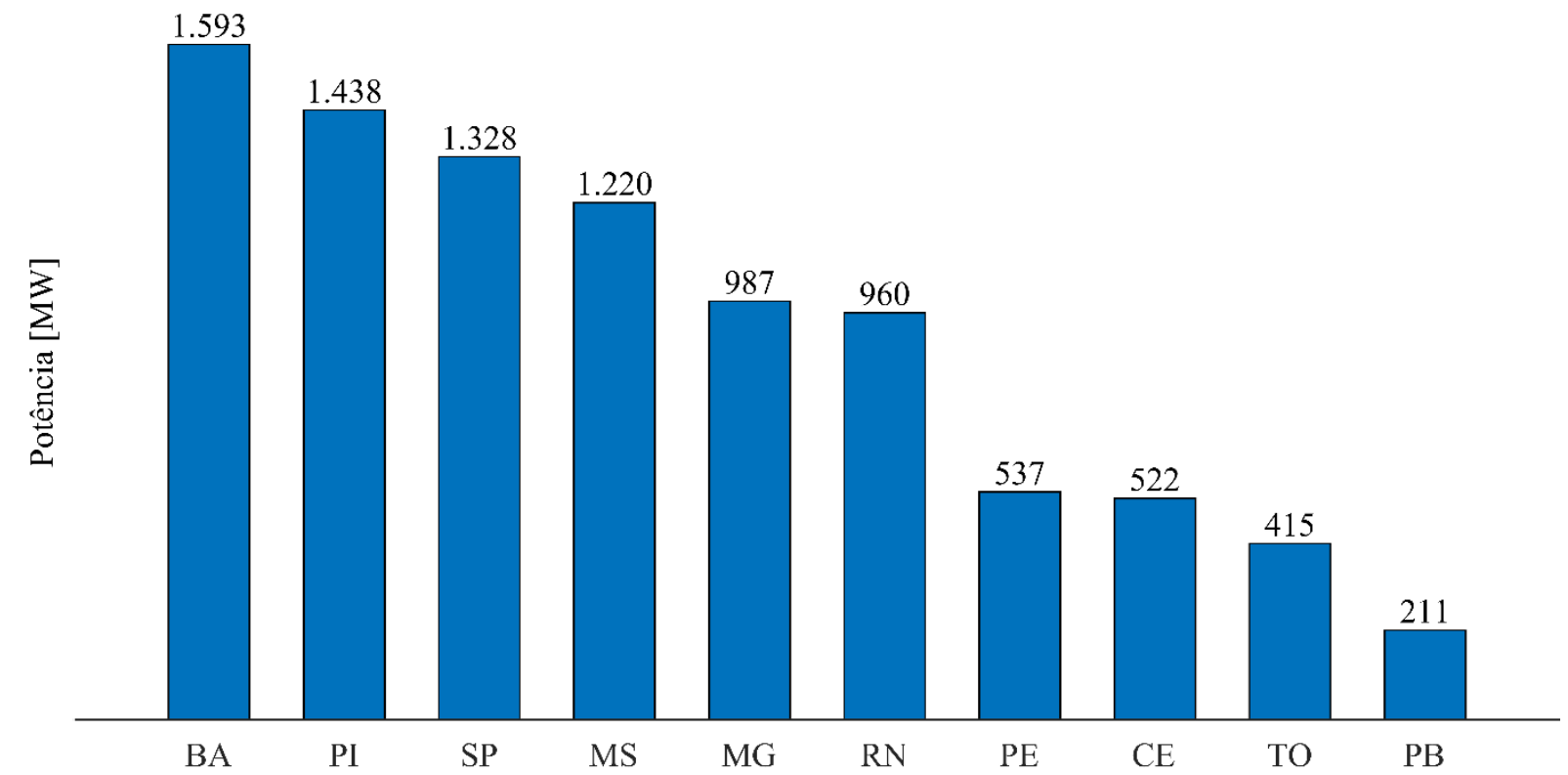

Fonte: elaborado a partir de (EMPRESA DE PESQUISA ENERGÉTICA (EPE), 2016c).

No entanto, com a publicação da portaria do MME no 390, de 26 de julho de 2016, apenas os empreendimentos de geração a partir da fonte hidrelétrica fariam parte do objeto de negociação dos CER, excluindo assim os de fonte solar fotovoltaica, que participariam de um futuro leilão a ser realizado ainda no mesmo ano. Com essa mesma portaria, a data de realização do $1^{\circ}$ LER de 2016 foi alterada para 23 de setembro de 2016 e resultou na contratação de 30 projetos de geração hidrelétrica, totalizando uma potência de 180,3 MW.

\subsection{5 $\quad 2^{\circ}$ Leilão de Energia de Reserva de 2016}

Com a mesma portaria que tornou pública a realização do $1^{\circ}$ LER 2016, já se previu a realização do $2^{\circ}$ LER de 2016, que ocorreria inicialmente em 28 de outubro de 2016. Seriam negociados CER diferenciados por fonte, solar fotovoltaica e eólica, na modalidade por quantidade de energia e com prazo de suprimento de 20 anos (MINISTÉRIO DE MINAS E ENERGIA (MME), 2016a).

A data de ocorrência do certame foi adiada pela primeira vez para 16 de dezembro de 2016, por meio da portaria MME n 390, de 26 de julho de 2016 (MINISTÉRIO DE MINAS E ENERGIA (MME), 2016b). Com a publicação da portaria MME n 621, de 17 de novembro de 2016 (MINISTÉRIO DE MINAS E ENERGIA (MME), 2016c), a data foi adiada pela segunda vez para 19 de dezembro de 2016. Com isso, foi permitido que mais empreendimentos 
pudessem ser cadastrados para participar do leilão. Dessa maneira, foram cadastrados 419 empreendimentos fotovoltaicos, totalizando uma potência de $13.389 \mathrm{MW}$, cuja distribuição entre os estados é disposta na figura 2.16 (EMPRESA DE PESQUISA ENERGÉTICA (EPE), 2016b).

Figura 2.16 - Empreendimentos fotovoltaicos cadastrados no $2^{\circ}$ LER de 2016 por estado.

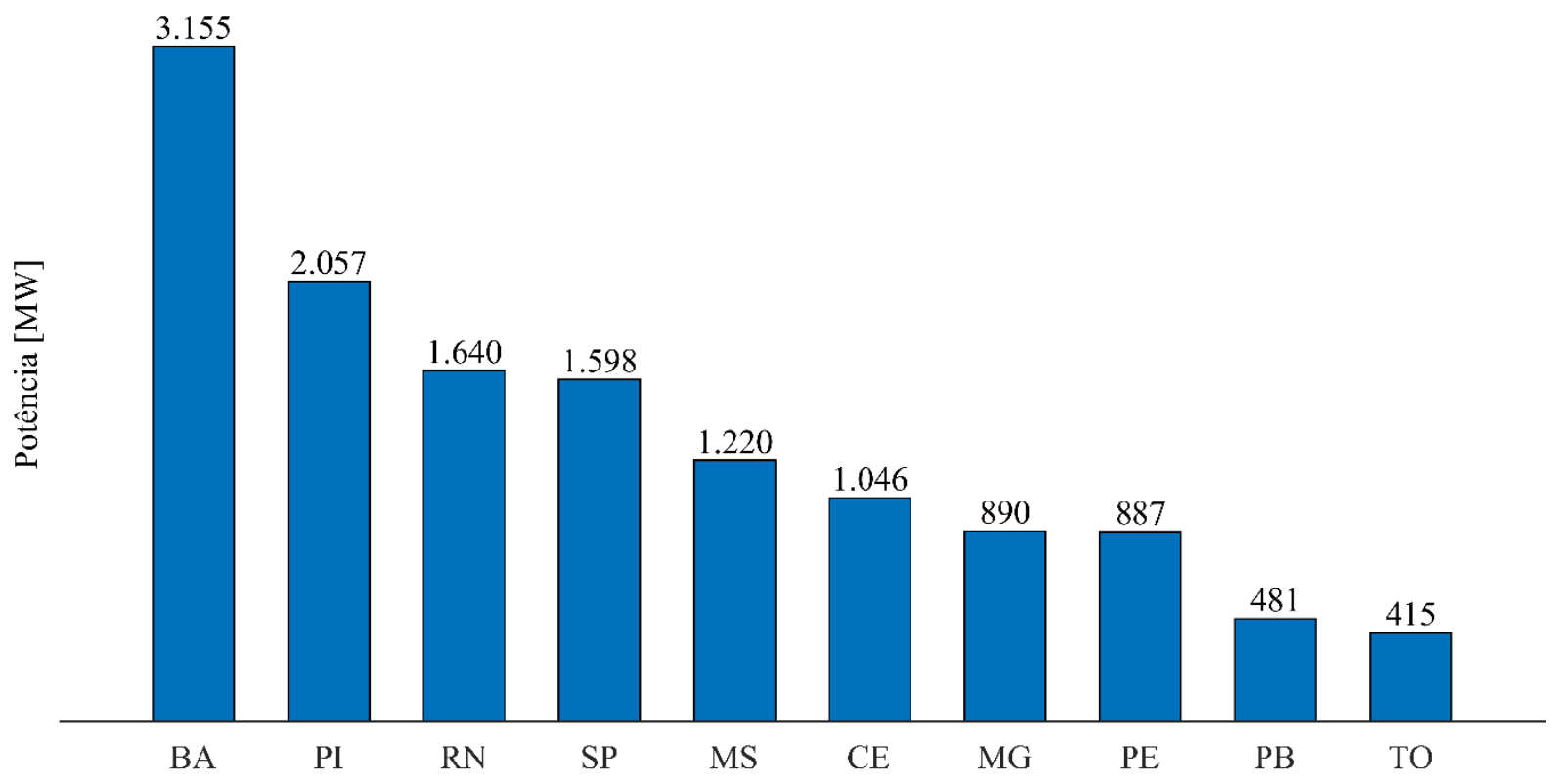

Fonte: elaborado a partir de (EMPRESA DE PESQUISA ENERGÉTICA (EPE), 2016b).

Por intermédio da portaria MME n ${ }^{\circ}$ 705, de 14 de dezembro de 2016, o $2^{\circ}$ LER de 2016 foi cancelado (MINISTÉRIO DE MINAS E ENERGIA (MME), 2016d). Entre os principais motivos que contribuíram para esse cancelamento, destacam-se a recessão econômica enfrentada pelo Brasil na época e a perspectiva do resultado de revisão ordinária de garantia física das hidrelétricas (EMPRESA DE PESQUISA ENERGÉTICA (EPE), 2016a).

\subsection{6 $25^{\circ}$ Leilão de Energia Nova A-4 de 2017}

Após não ter havido contratação de empreendimentos fotovoltaicos no ano de 2016, o MME publicou a portaria $\mathrm{n}^{\circ} 293$, de 4 de agosto de 2017, que estabeleceu as diretrizes para a realização do leilão de compra de energia, incluindo de empreendimentos fotovoltaicos (MINISTÉRIO DE MINAS E ENERGIA (MME), 2017b). Esse leilão, diferentemente dos anteriores, foi um Leilão de Energia Nova (LEN), com início do suprimento previsto para 01/01/2021. 
Na figura 2.17, é apresentada uma distribuição estadual com os somatórios das potências das usinas cadastradas e habilitadas nesse leilão. Foram cadastrados empreendimentos fotovoltaicos que totalizaram uma potência de 18.293 MW, tendo sido habilitados 10.344 MW (EMPRESA DE PESQUISA ENERGÉTICA (EPE), 2018b).

Figura 2.17 - Empreendimentos fotovoltaicos cadastrados e habilitados no LEN A-4 de 2017 por estado.

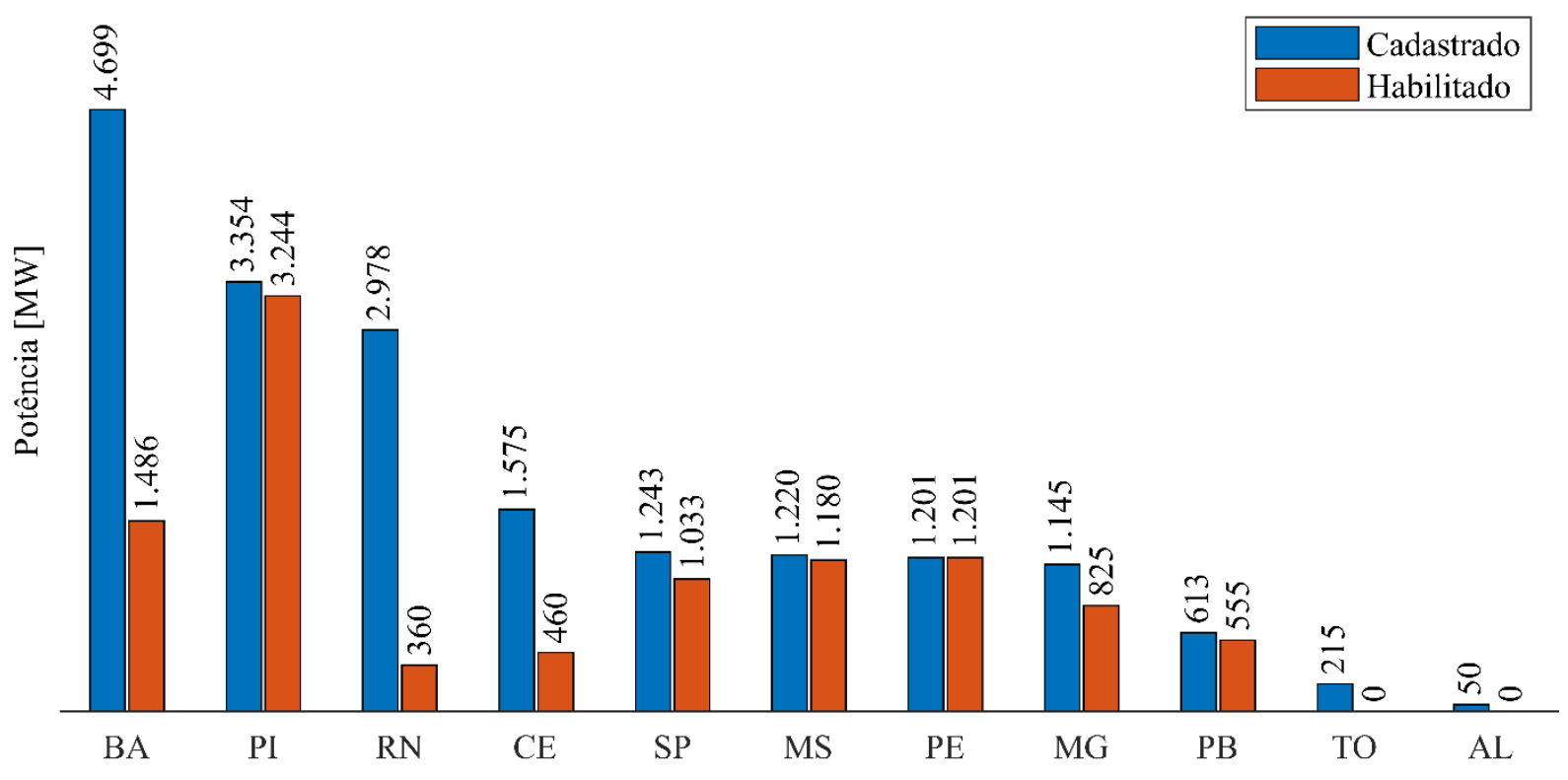

Fonte: elaborado a partir de (EMPRESA DE PESQUISA ENERGÉTICA (EPE), 2017).

Após a realização do certame, ocorrida em 18/12/2017, foi contratada uma potência total de $574 \mathrm{MW}$, cuja distribuição estadual é apresentada na figura 2.18. É possível verificar que mais de $85 \%$ da potência contratada encontra-se no Nordeste do Brasil. O preço médio da energia negociada foi de $\mathrm{R} \$$ 145,68/MWh (CÂMARA DE COMERCIALIZAÇÃO DE ENERGIA ELÉTRICA (CCEE), 2017a). 
Figura 2.18 - Empreendimentos fotovoltaicos contratados no LEN A-4 de 2017 por estado.

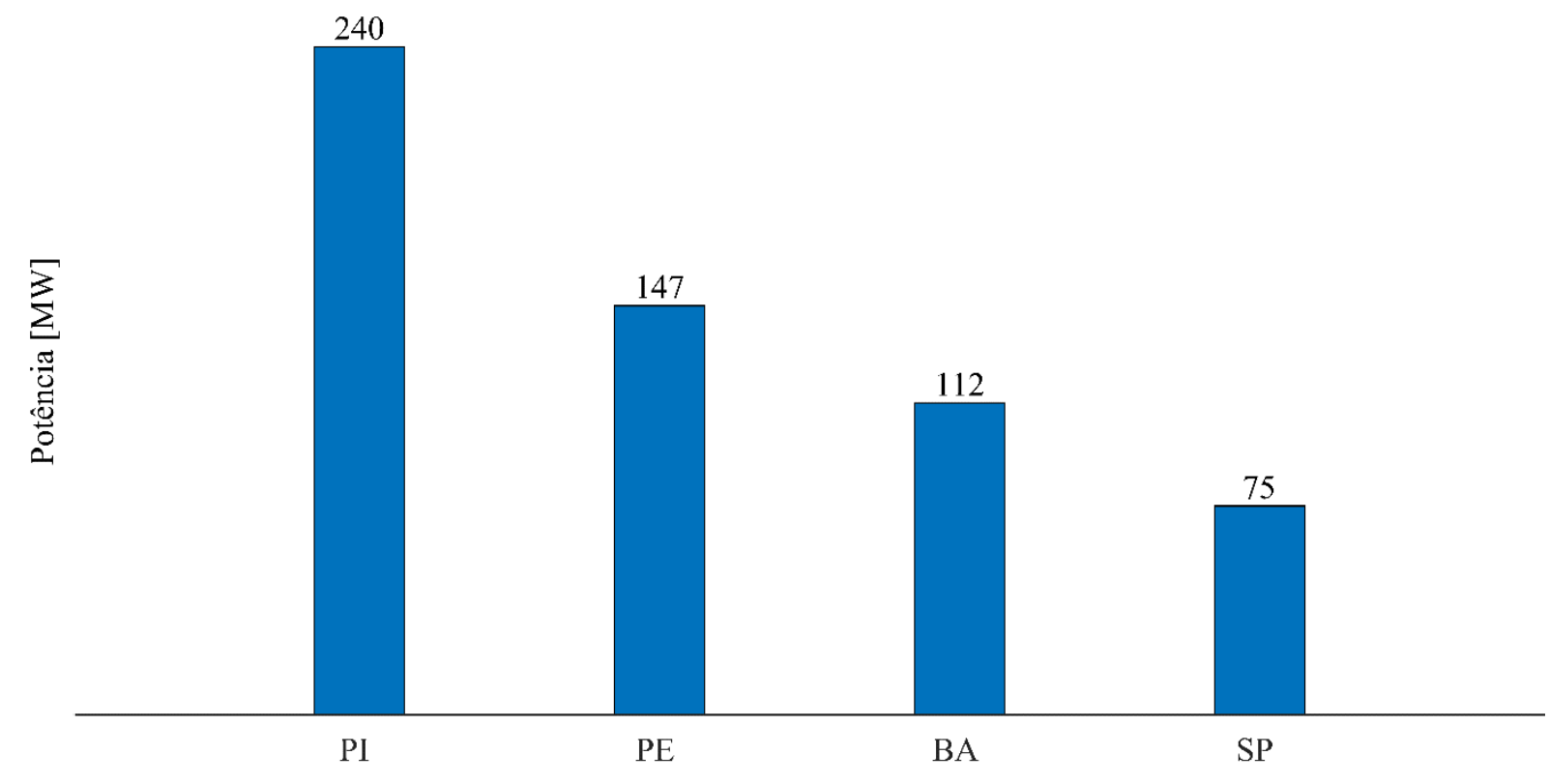

Fonte: elaborado a partir de (CÂMARA DE COMERCIALIZAÇÃO DE ENERGIA ELÉTRICA (CCEE), 2017a).

\subsection{7 $27^{\circ}$ Leilão de Energia Nova A-4 de 2018}

Retomando a continuidade da realização de leilões anuais, foi prevista a ocorrência do LEN A-4 de 2018, por meio da publicação da portaria MME no 465, de 30 de novembro de 2017. Nesse leilão, foi prevista também a compra de energia elétrica a partir da fonte solar fotovoltaica (MINISTÉRIO DE MINAS E ENERGIA (MME), 2017c).

Após as etapas de cadastramento e habilitação, o resumo das somas das potências dos empreendimentos agrupados por estado pode ser visto na figura 2.19. Foram cadastradas usinas que totalizaram uma potência de 20.026 MW, das quais, as habilitadas tecnicamente somaram 13.380 MW (EMPRESA DE PESQUISA ENERGÉTICA (EPE), 2018c). 
Figura 2.19 - Empreendimentos fotovoltaicos cadastrados e habilitados no LEN A-4 de 2018 por estado.

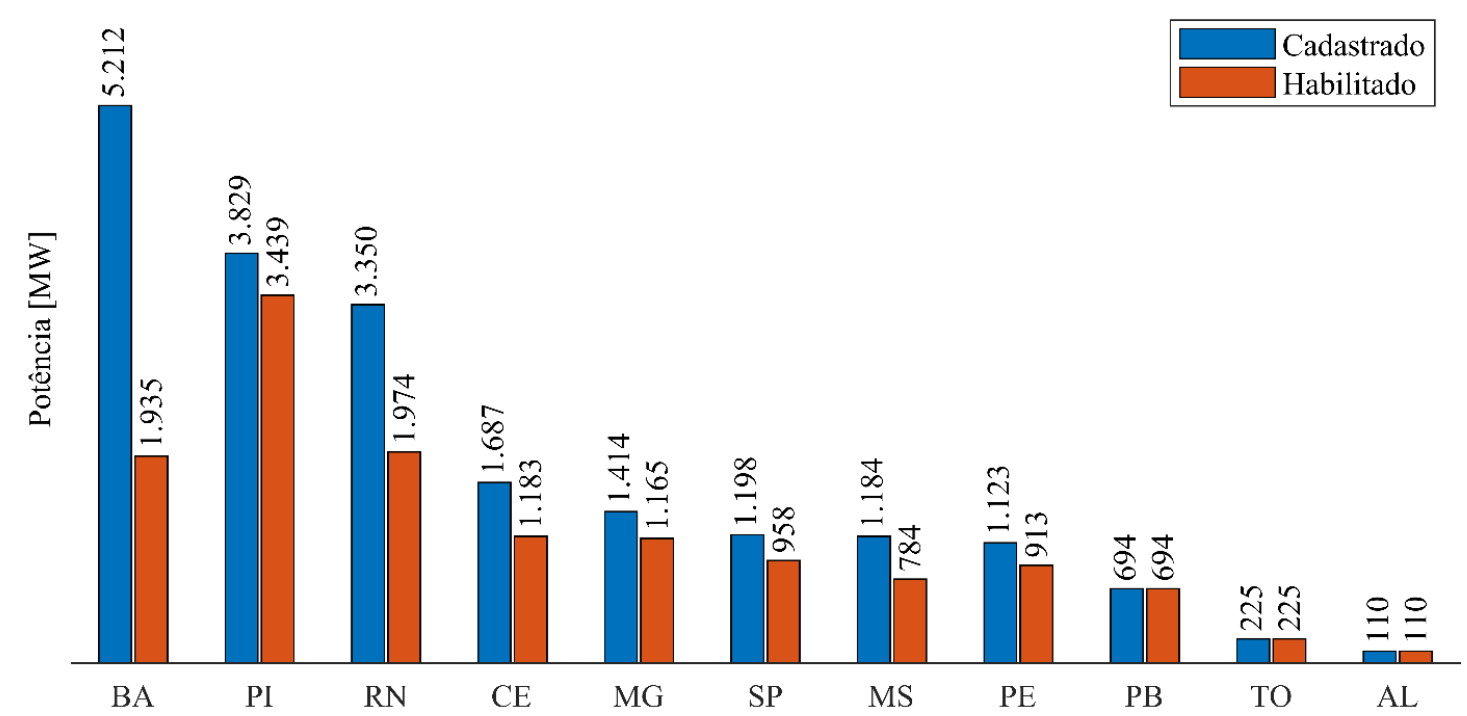

Fonte: elaborado a partir de (EMPRESA DE PESQUISA ENERGÉTICA (EPE), 2018a) e (EMPRESA DE PESQUISA ENERGÉTICA (EPE), 2018c).

Na figura 2.20, é mostrado o resultado do leilão, que ocorreu em 04/04/2018, com a contratação de $807 \mathrm{MW}$, distribuídos em quatro estados. Desse total, quase metade dos empreendimentos está localizada no Ceará, e o preço médio da energia elétrica negociada foi de R\$ 118,07/MWh (CÂMARA DE COMERCIALIZAÇÃO DE ENERGIA ELÉTRICA (CCEE), 2018).

Figura 2.20 - Empreendimentos fotovoltaicos contratados no LEN A-4 de 2018 por estado.

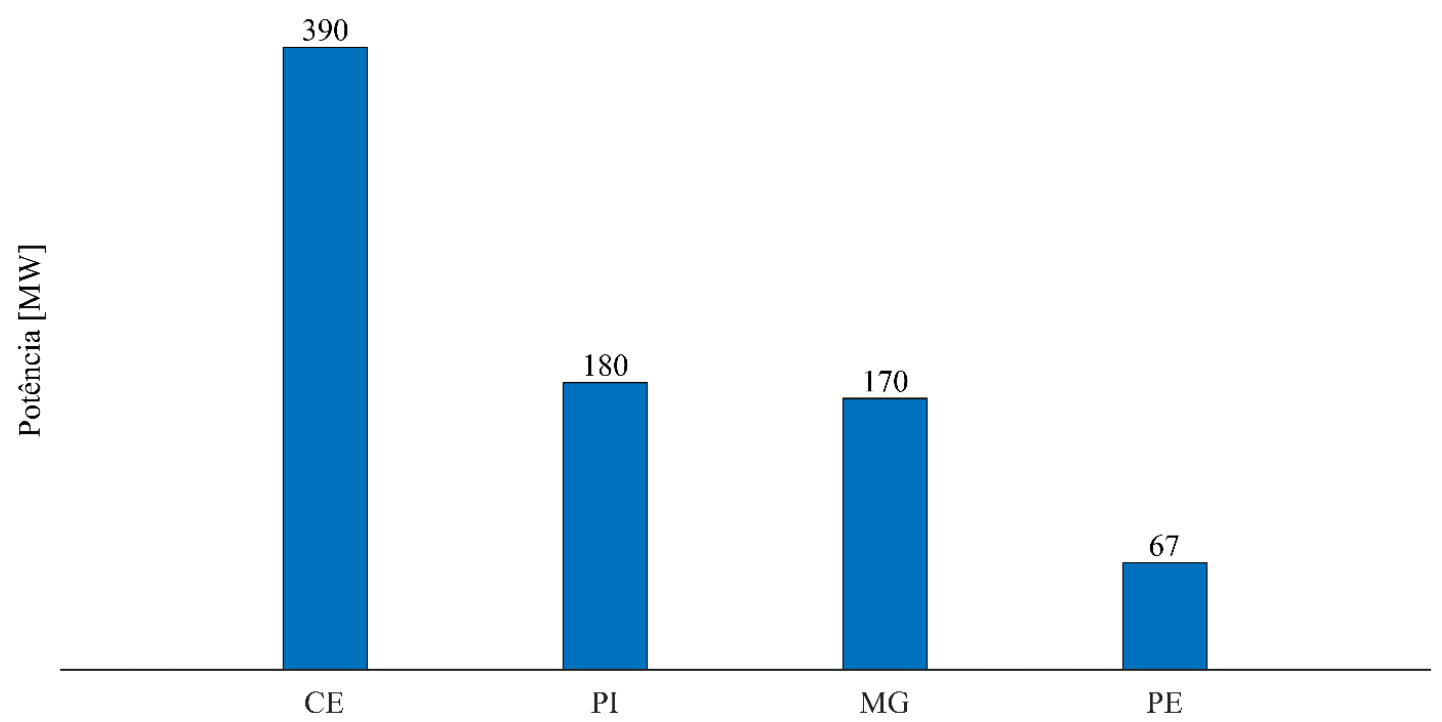

Fonte: elaborado a partir de (CÂMARA DE COMERCIALIZAÇÃO DE ENERGIA ELÉTRICA (CCEE), 2018). 


\subsubsection{Comparação entre os leilões}

Na figura 2.21, é mostrada uma consolidação dos resultados dos leilões de energia elétrica apresentados anteriormente, com dados das potências c.c. e c.a. É importante destacar que, como o objetivo é comparar as características técnicas dos empreendimentos, não foi levado em consideração, portanto, o leilão de descontração. Nesse sentido, verifica-se que, a cada leilão, foram contratados no mínimo 574 MW em usinas fotovoltaicas.

Figura 2.21 - Resumo dos resultados dos leilões: potências c.c. e c.a..

Potência $[M W p]$

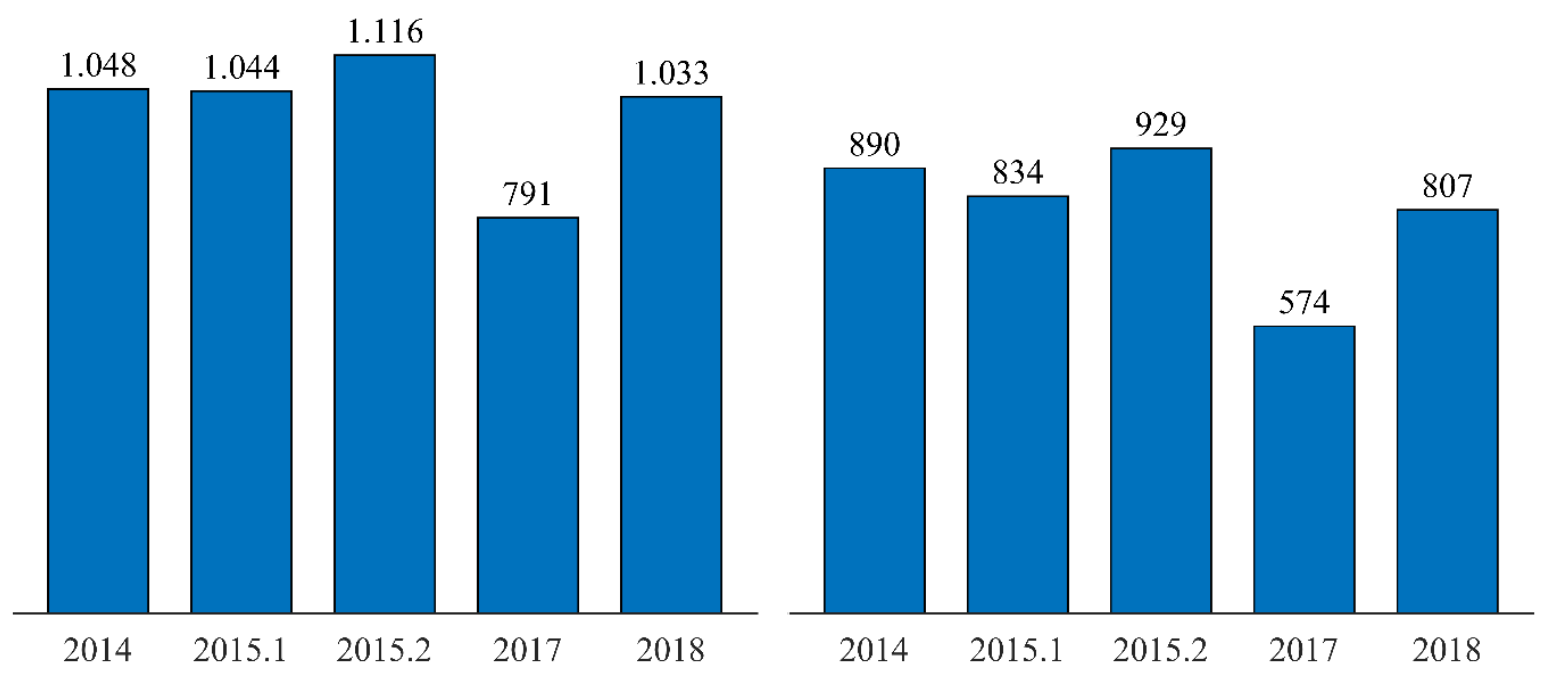

Fonte: elaborado a partir de (EMPRESA DE PESQUISA ENERGÉTICA (EPE), 2014b), (EMPRESA DE PESQUISA ENERGÉTICA (EPE), 2015), (EMPRESA DE PESQUISA ENERGÉTICA (EPE), 2016d), (CÂMARA DE COMERCIALIZAÇÃO DE ENERGIA ELÉTRICA (CCEE), 2017a) e (CÂMARA DE COMERCIALIZAÇÃO DE ENERGIA ELÉTRICA (CCEE), 2018).

Quando a comparação é realizada em relação às tecnologias de módulos fotovoltaicos e estruturas de suporte, é possível observar, na figura 2.22, que a maior parte das usinas utiliza módulos de silício cristalino e rastreadores solares de um eixo. Além disso, verifica-se que, nos dois últimos leilões, não houve empreendimentos vendedores que utilizassem estruturas fixas em solo para suporte dos módulos fotovoltaicos. 
Figura 2.22 - Resumo dos resultados dos leilões por quantidade de usinas: tipos de módulos e estruturas de suporte.

Tecnologia de módulo fotovoltaico

$\square$ multi-Si $\square$ mono-Si $\square$ Filme fino

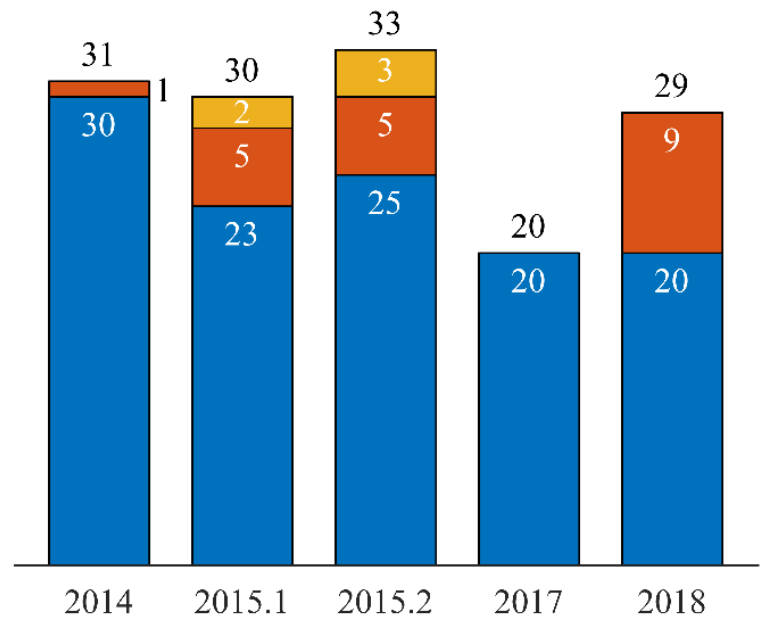

Estrutura de suporte
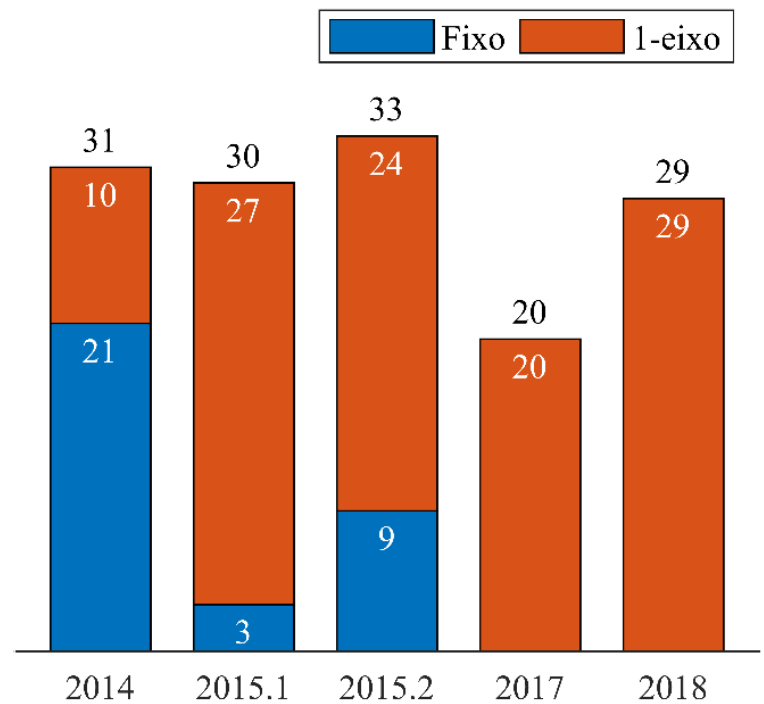

Fonte: elaborado a partir de (EMPRESA DE PESQUISA ENERGÉTICA (EPE), 2014b), (EMPRESA DE PESQUISA ENERGÉTICA (EPE), 2015), (EMPRESA DE PESQUISA ENERGÉTICA (EPE), 2016d), (CÂMARA DE COMERCIALIZAÇÃo DE ENERGIA ELÉTRICA (CCEE), 2017a) e (CÂMARA DE COMERCIALIZAÇÃO DE ENERGIA ELÉTRICA (CCEE), 2018).

No que diz respeito aos fatores de capacidade c.a. e de dimensionamento do inversor, verifica-se, na figura 2.23, um aumento dos fatores de capacidade máximos, que está relacionado à tendência de redução do fator de dimensionamento do inversor (FDI) e à utilização de rastreadores solares de um eixo, visto na figura 2.22. Ao se empregar rastreadores solares em vez de estruturas fixas em solo, a irradiação incidente no plano dos módulos fotovoltaicos tende a ser maior, contribuindo para uma maior geração de energia elétrica, o que aumenta o fator de capacidade. Além disso, ao se reduzir o fator de dimensionamento do inversor, o fator de capacidade em c.a. também aumenta. Do $1^{\circ}$ para o $2^{\circ}$ LER de 2015, observase um decréscimo dos valores mínimos dos fatores de capacidade, explicado pela utilização de estruturas fixas em solo numa região de menor irradiação. 
Figura 2.23 - Resumo dos resultados dos leilões: fatores de capacidade e fatores de dimensionamento do inversor.

Fator de capacidade $[\%]$

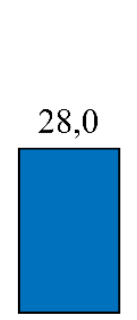

18,0

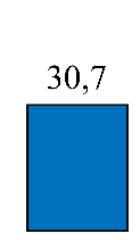

23,0
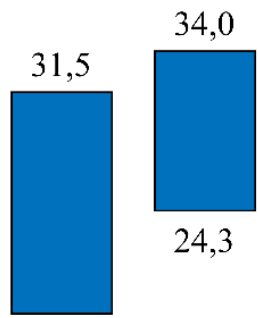

18,0
Fator de dimensionamento do inversor [p.u.]
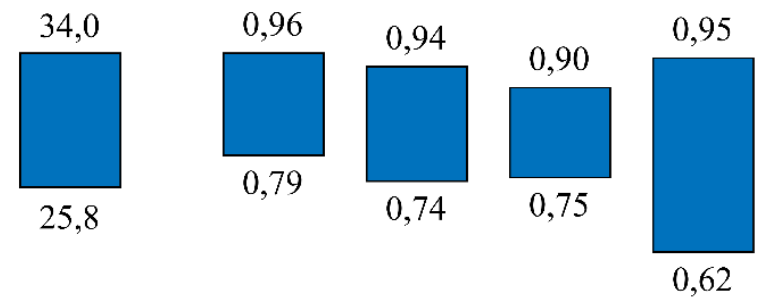

0,86

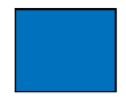

0,72

$2014 \quad 2015.1 \quad 2015.2 \quad 2017 \quad 2018$

$2014 \quad 2015.1 \quad 2015.2 \quad 2017 \quad 2018$

Fonte: elaborado a partir de (EMPRESA DE PESQUISA ENERGÉTICA (EPE), 2014b), (EMPRESA DE PESQUISA ENERGÉTICA (EPE), 2015), (EMPRESA DE PESQUISA ENERGÉTICA (EPE), 2016d), (CÂMARA DE COMERCIALIZAÇÃO DE ENERGIA ELÉTRICA (CCEE), 2017a) e (CÂMARA DE COMERCIALIZAÇÃO DE ENERGIA ELÉTRICA (CCEE), 2018).

$\mathrm{Na}$ figura 2.24, são apresentados os valores dos investimentos por potência c.a. e os preços de venda de energia elétrica. Cabe aqui destacar que os respectivos valores apresentados estão em dólares, tendo sido utilizada uma taxa de câmbio entre real e dólar média do mês de realização de cada um dos leilões, sendo os valores corrigidos pela inflação até o mês do último leilão. É importante lembrar ainda da grande variação ocorrida na taxa de câmbio nesse período analisado, devido à valorização da moeda norte-americana e instabilidade econômica brasileira. 
Figura 2.24 - Resumo dos resultados dos leilões: faixas de investimentos das usinas e preços da energia.

Investimento [US\$/W]

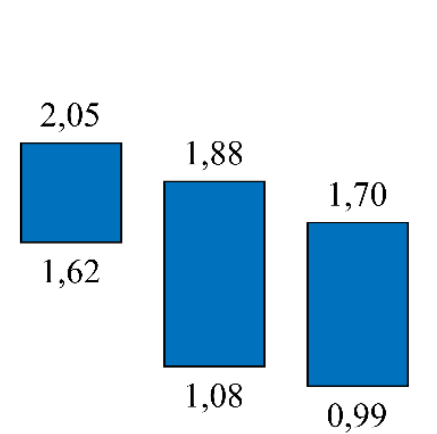

2,42

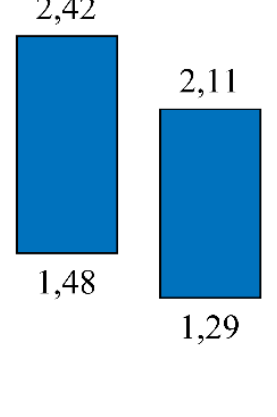

Energia [US\$/MWh]

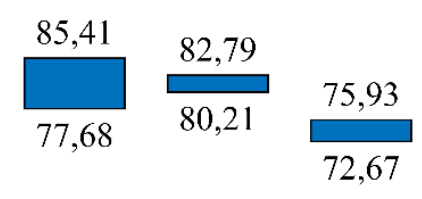

\section{$2014 \quad 2015.1 \quad 2015.2 \quad 2017 \quad 2018$}

$2014 \quad 2015.1 \quad 2015.2 \quad 2017$

2018

Fonte: elaborado a partir de (EMPRESA DE PESQUISA ENERGÉTICA (EPE), 2014b), (EMPRESA DE PESQUISA ENERGÉTICA (EPE), 2015), (EMPRESA DE PESQUISA ENERGÉTICA (EPE), 2016d), (CÂMARA DE COMERCIALIZAÇÃO DE ENERGIA ELÉTRICA (CCEE), 2017a), (CÂMARA DE COMERCIALIZAÇÃO DE ENERGIA ELÉTRICA (CCEE), 2018), (X-RATES, 2018) e (BUREAU OF LABOR STATISTICS, 2018).

Apesar de se observar uma variação no custo do investimento, essa torna-se pequena quando comparada à redução expressiva do preço da energia elétrica vendida no período analisado. Em relação ao $1^{\circ}$ LER de 2014, houve uma redução de mais de $50 \%$ no preço da energia comercializada em 2018, inferior a US\$35,00/MWh. Além disso, verifica-se uma redução da amplitude do preço de venda, denotando um aumento de competitividade entre os empreendedores, fruto da redução de preços dos equipamentos e da recuperação cambial da moeda brasileira frente ao dólar (ASSOCIAÇÃO BRASILEIRA DE ENERGIA SOLAR FOTOVOLTAICA (ABSOLAR), 2018). 


\section{SISTEMAS FOTOVOLTAICOS}

Esta seção tem por objetivo descrever suscintamente algumas das principais configurações de sistemas fotovoltaicos, sobretudo aquelas utilizadas em usinas de grande porte, abordando seus principais componentes, como módulos, estruturas de suporte e inversores. Outras informações relacionadas a esses itens, necessárias para a compreensão do trabalho, são apresentadas na seção 4.2.

É importante salientar que a expressão "configuração de sistema fotovoltaico" se refere a uma das possíveis combinações que podem ser realizadas, mesclando seus principais componentes, além das diferentes características físicas e elétricas que podem ser obtidas em cada caso.

\subsection{Classificação}

Na figura 3.1, é apresentada uma forma de classificação dos sistemas fotovoltaicos. Esses podem ser organizados quanto à interligação com o sistema de fornecimento de energia elétrica, dividindo-se em isolados e conectados à rede elétrica. Na sequência, cada um desses é classificado quanto à configuração, podendo ser puro ou híbrido (ASSOCIAÇÃO BRASILEIRA DE NORMAS TÉCNICAS (ABNT), 2008). Mesclando com a classificação de (LUQUE; HEGEDUS, 2003), os conectados à rede elétrica e puros podem se dividir em distribuído e centralizado, sendo esse último caracterizado pelo porte de usina. Quanto às estruturas de suporte, os módulos fotovoltaicos das usinas podem ser montados em estruturas fixas ou em rastreadores solares. 
Figura 3.1 - Classificação de sistemas fotovoltaicos.

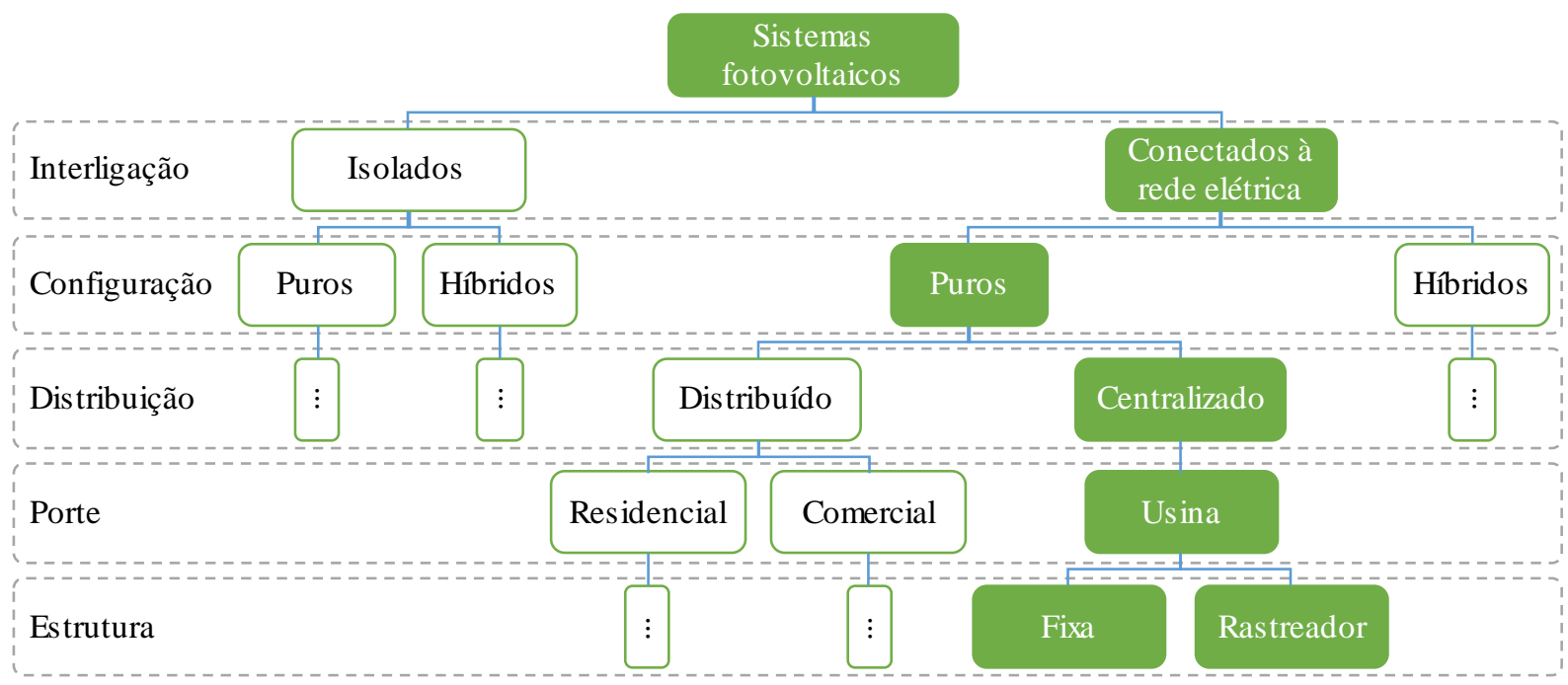

Fonte: elaborado a partir de (ASSOCIAÇÃO BRASILEIRA DE NORMAS TÉCNICAS (ABNT), 2008) e (LUQUE; HEGEDUS, 2003).

Cabe salientar que essa classificação não é definitiva nem exaustiva, e, portanto, outras formas de categorização podem ser realizadas. Entretanto, essa será adotada na dissertação, cujo escopo está pautado em usinas que utilizam estruturas fixas ou rastreadores solares, conforme destacado na figura 3.1. Os elementos que possuem reticências indicam que as classificações podem ser expandidas. A representação simplificada dos sistemas fotovoltaicos que são aqui abordados é mostrada na figura 3.2, com alguns de seus principais componentes.

Figura 3.2 - Diagrama simplificado de um sistema fotovoltaico.

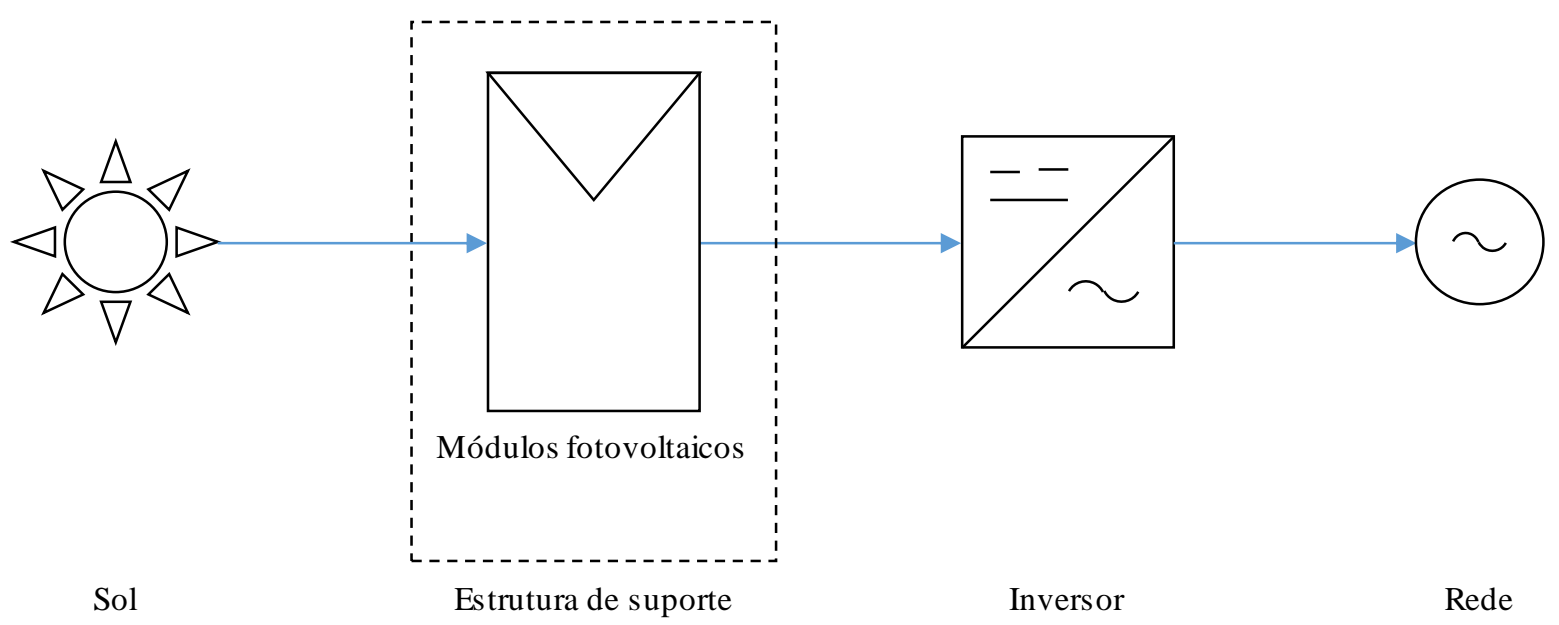




\subsection{Módulos fotovoltaicos}

O módulo fotovoltaico é considerado a unidade básica de um sistema fotovoltaico. Construtivamente, é formado por um conjunto de células fotovoltaicas, interligadas eletricamente e encapsuladas, que realizam a conversão direta da energia solar em energia elétrica (ASSOCIAÇÃO BRASILEIRA DE NORMAS TÉCNICAS (ABNT), 2013).

Conforme apresentado na figura 2.7 , as células fotovoltaicas podem ser classificadas em quatro grandes grupos, como sumarizado pela figura 3.3, com destaque para silício cristalino e filme fino, que fazem parte do escopo desse trabalho.

Figura 3.3 - Classificação de células fotovoltaicas por tecnologia.

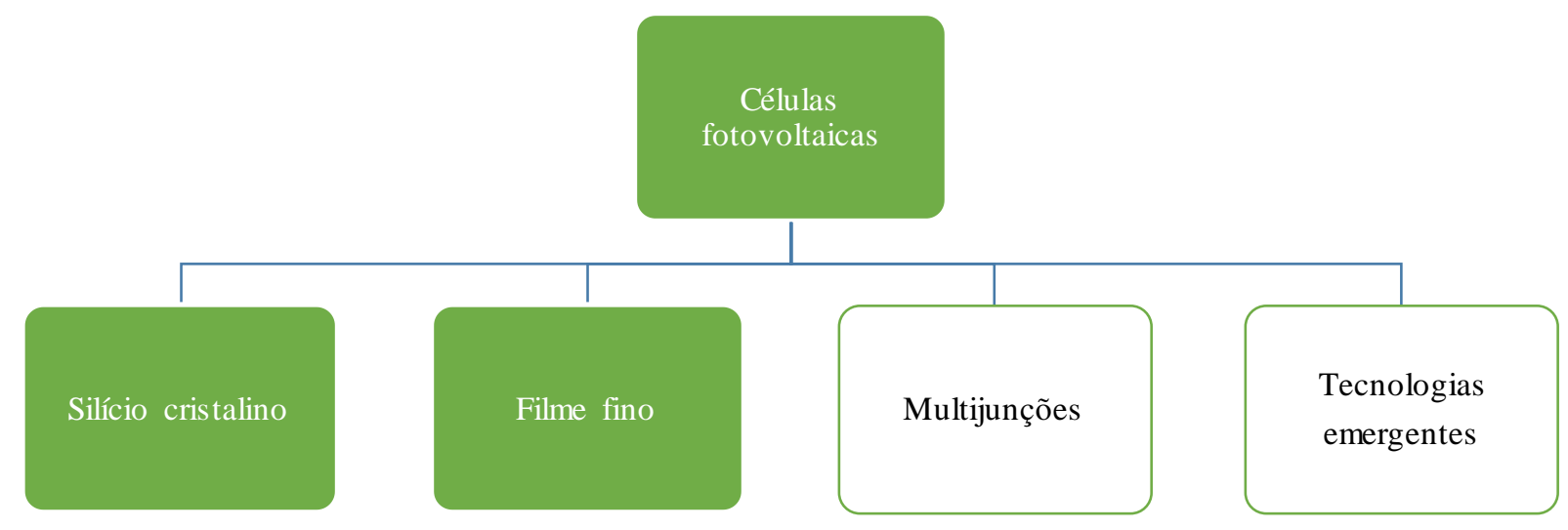

Fonte: elaborado a partir de (NATIONAL RENEWABLE ENERGY LABORATORY (NREL), 2018c).

Quando fótons presentes na radiação solar incidem sobre uma célula fotovoltaica, composta por um material semicondutor com determinadas características elétricas, parte dessa energia pode excitar elétrons, que poderão dar origem a uma corrente elétrica (RÜTHER, 2004). Na figura 3.4 (a), é mostrada a irradiância espectral incidente em uma superfície inclinada em $37^{\circ}$, para uma massa de ar de 1,5 , com destaque para os comprimentos de onda da faixa do visível. Já na figura 3.4 (b), pode ser observada a resposta espectral normalizada de uma célula fotovoltaica genérica de silício cristalino. 
Figura 3.4 - (a) irradiância espectral e (b) resposta espectral de uma célula de silício cristalino.

(a)

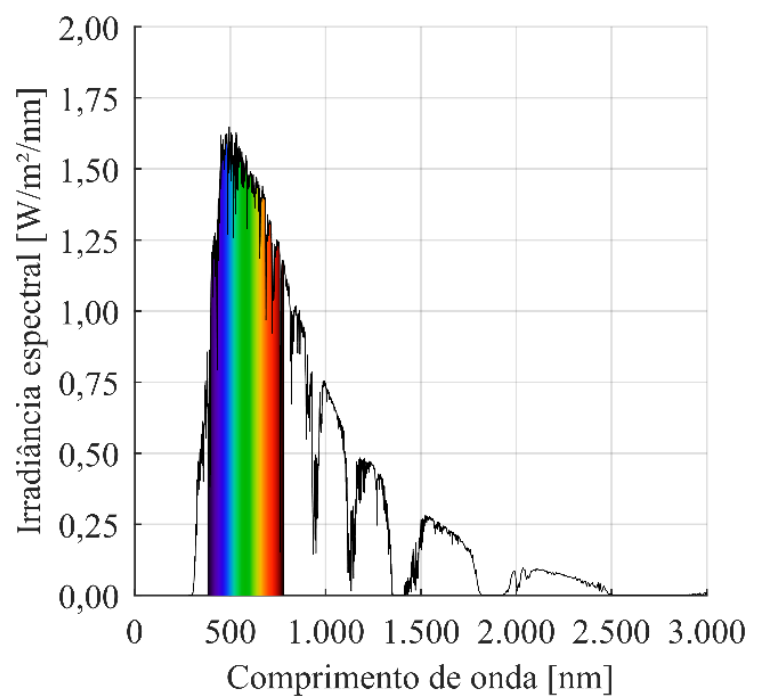

(b)

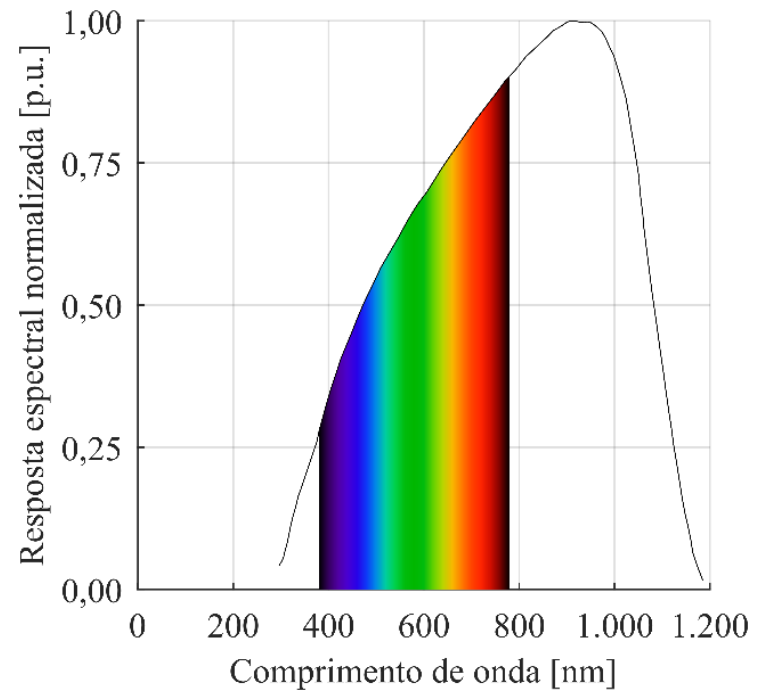

Fonte: elaborado a partir de (ASTM INTERNATIONAL, 2012) e (INTERNATIONAL ENERGY AGENCY (IEA), 2018b).

Na figura 3.5, são apresentados o esquema simplificado de uma célula fotovoltaica e sua curva I-V característica, com destaque para os pontos notáveis de corrente, tensão e potência. Quando as cargas elétricas são coletadas e conduzidas para um circuito externo, tem-se a circulação de corrente, o que caracteriza a geração de eletricidade. A escolha dos materiais utilizados na fabricação desses dispositivos considera, além das características de absorção em função do espectro solar, o custo de fabricação e os impactos ambientais causados no descarte do material (ZILLES et al., 2012). 
Figura 3.5 - Célula fotovoltaica: (a) esquema simplificado e (b) curva I-V característica.

(a)

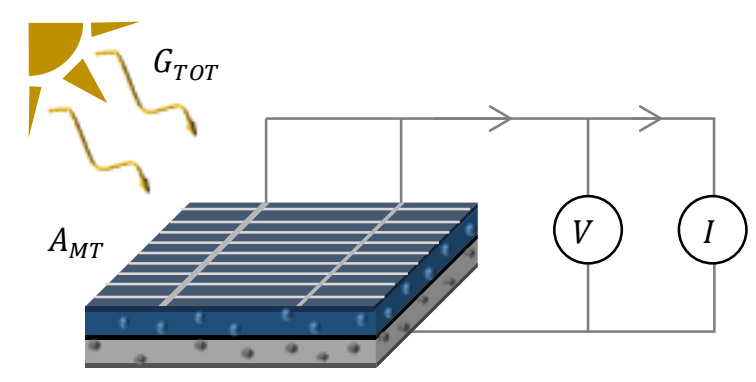

(b)

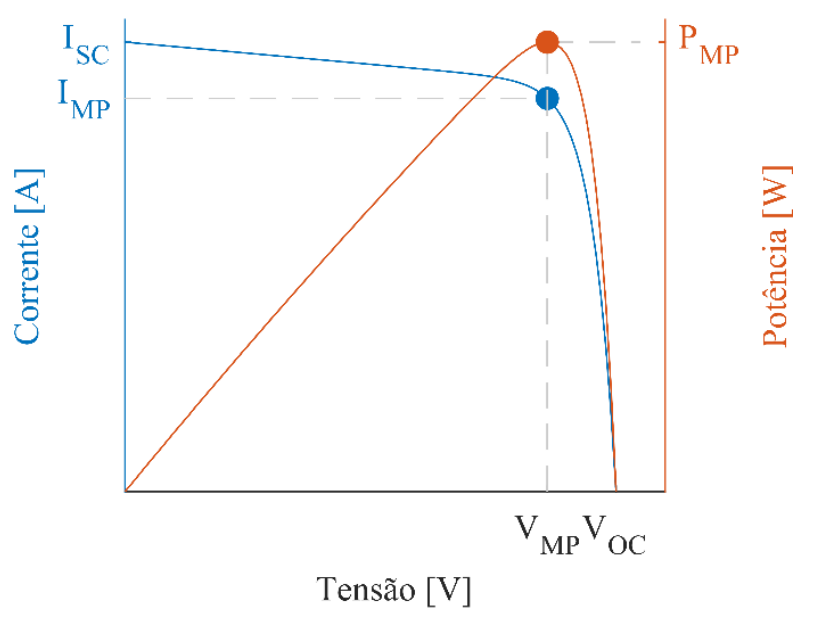

Fonte: elaborado a partir de (ZILLES et al., 2012).

Além das características elétricas apresentadas, a eficiência do módulo fotovoltaico, $\eta$, também é um parâmetro importante na concepção de projetos de sistemas fotovoltaicos. Matematicamente, é dada pela relação entre a potência máxima fornecida, $P_{M P}$, e o produto da área total do módulo, $A_{M T}$, pela irradiância total, para uma dada temperatura, conforme a expressão (3.1) (ASSOCIAÇÃO BRASILEIRA DE NORMAS TÉCNICAS (ABNT), 2013).

$$
\eta=\frac{P_{M P}}{A_{M T} G_{T O T}}
$$

Dessa maneira, para uma mesma potência de módulos fotovoltaicos, um sistema que utiliza os de maior eficiência possui menor área total de módulos e, consequentemente, necessita de uma menor área para instalação. É importante frisar que, se dois sistemas são idênticos, exceto pela eficiência dos módulos utilizados, o que emprega módulos mais eficientes não necessariamente gerará mais energia elétrica. Outras características devem ser observadas para análise mais detalhada, como os coeficientes de potência em relação à temperatura, e são abordadas na seção 4.2 .

Para um entendimento mais detalhado sobre o funcionamento das células fotovoltaicas e conhecimento sobre algumas caraterísticas dessas tecnologias, o leitor é convidado a conhecer também a obra de (PINHO; GALDINO, 2014). 


\subsection{Estruturas de suporte}

Assim como os sistemas fotovoltaicos podem ser classificados de várias maneiras, as estruturas de suporte também o podem. Mesclando as categorias trazidas por (HÄBERLIN, 2012) e (NATIONAL RENEWABLE ENERGY LABORATORY (NREL), 2018b), é possível dispô-las na figura 3.6, destacando as estruturas fixas em solo e os rastreadores solares de um eixo, que são objetos de estudo nesta dissertação.

Figura 3.6 - Classificação das estruturas de suporte.

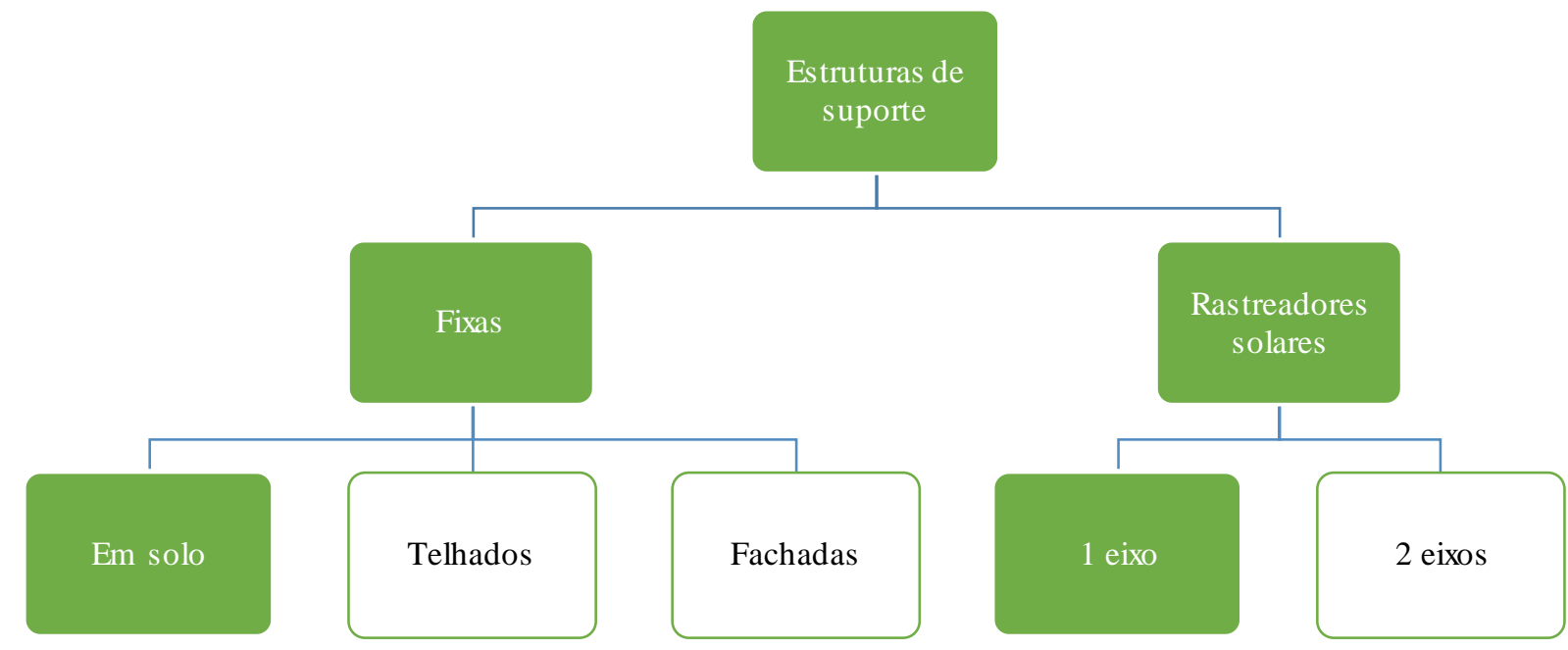

Fonte: elaborado a partir de (HÄBERLIN, 2012) e (NATIONAL RENEWABLE ENERGY LABORATORY (NREL), 2018c).

Além dos parâmetros de inclinação e azimute dos módulos fotovoltaicos, o índice de cobertura do terreno, ICT, é outro importante fator que está relacionado à montagem física de um sistema. Ele indica o grau de compactação de uma usina e é definido como sendo a relação entre a área de módulos fotovoltaicos e a área correspondente ocupada no terreno. Quando se trata de sistemas de grande porte, o ICT tende a ser calculado pela razão entre a largura de um arranjo fotovoltaico $^{1}$ e a distância até o arranjo adjacente, como indicado pela expressão (3.2).

$$
I C T=\frac{L}{D}
$$

\footnotetext{
${ }^{1}$ Um arranjo fotovoltaico é um conjunto de módulos fotovoltaicos mecânica e eletricamente integrados, incluindo a estrutura de suporte (ASSOCIAÇÃO BRASILEIRA DE NORMAS TÉCNICAS (ABNT), 2013).
} 
Exemplos de sistemas montados em estruturas fixas em solo e em rastreadores solares de um eixo horizontal são mostrados nas figuras 3.7 e 3.8, com indicação das variáveis utilizadas para calcular o ICT.

Figura 3.7 - Exemplo de montagem em estruturas fixas em solo.

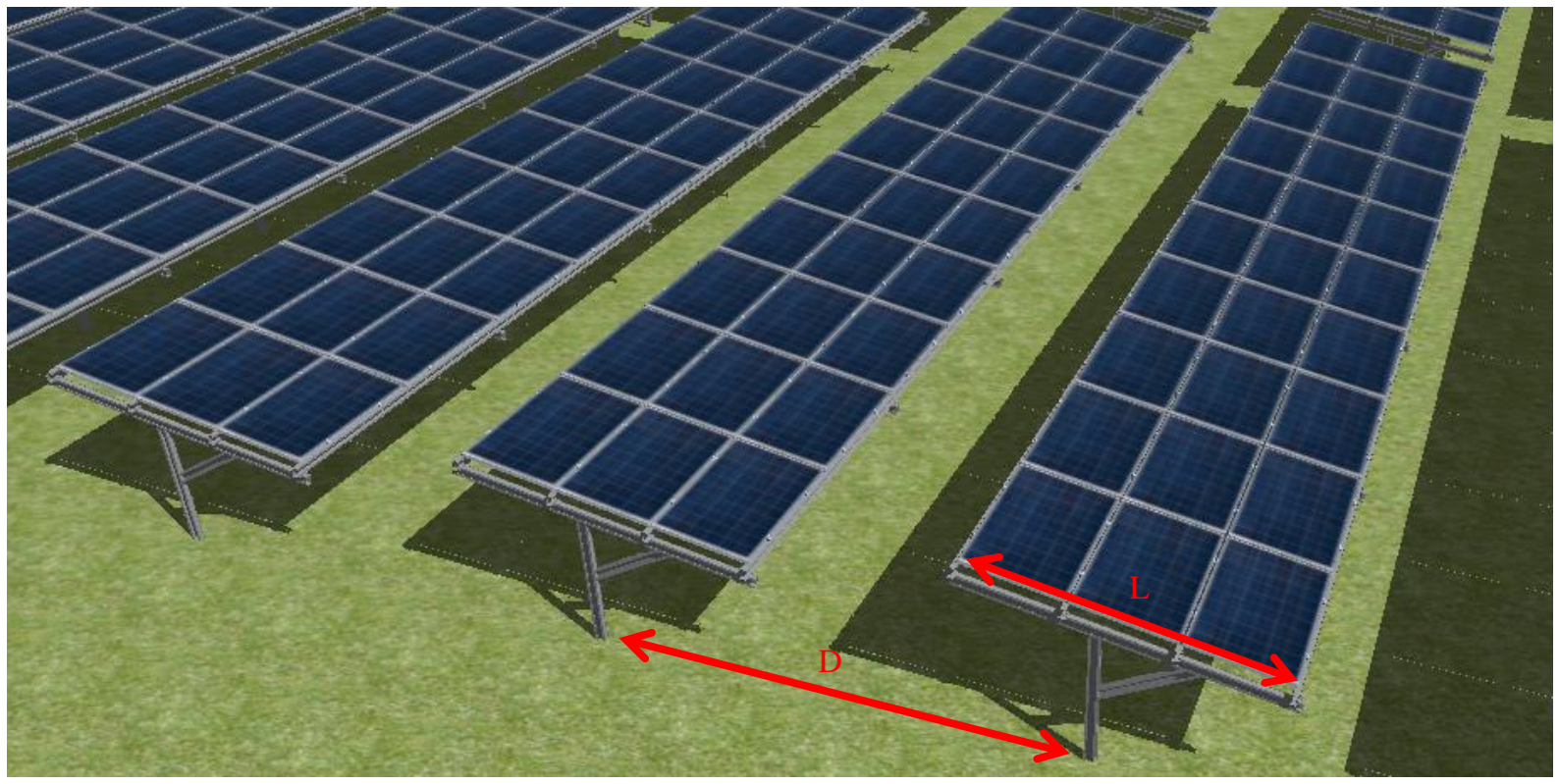

Figura 3.8 - Exemplo de montagem em rastreador solar de um eixo.

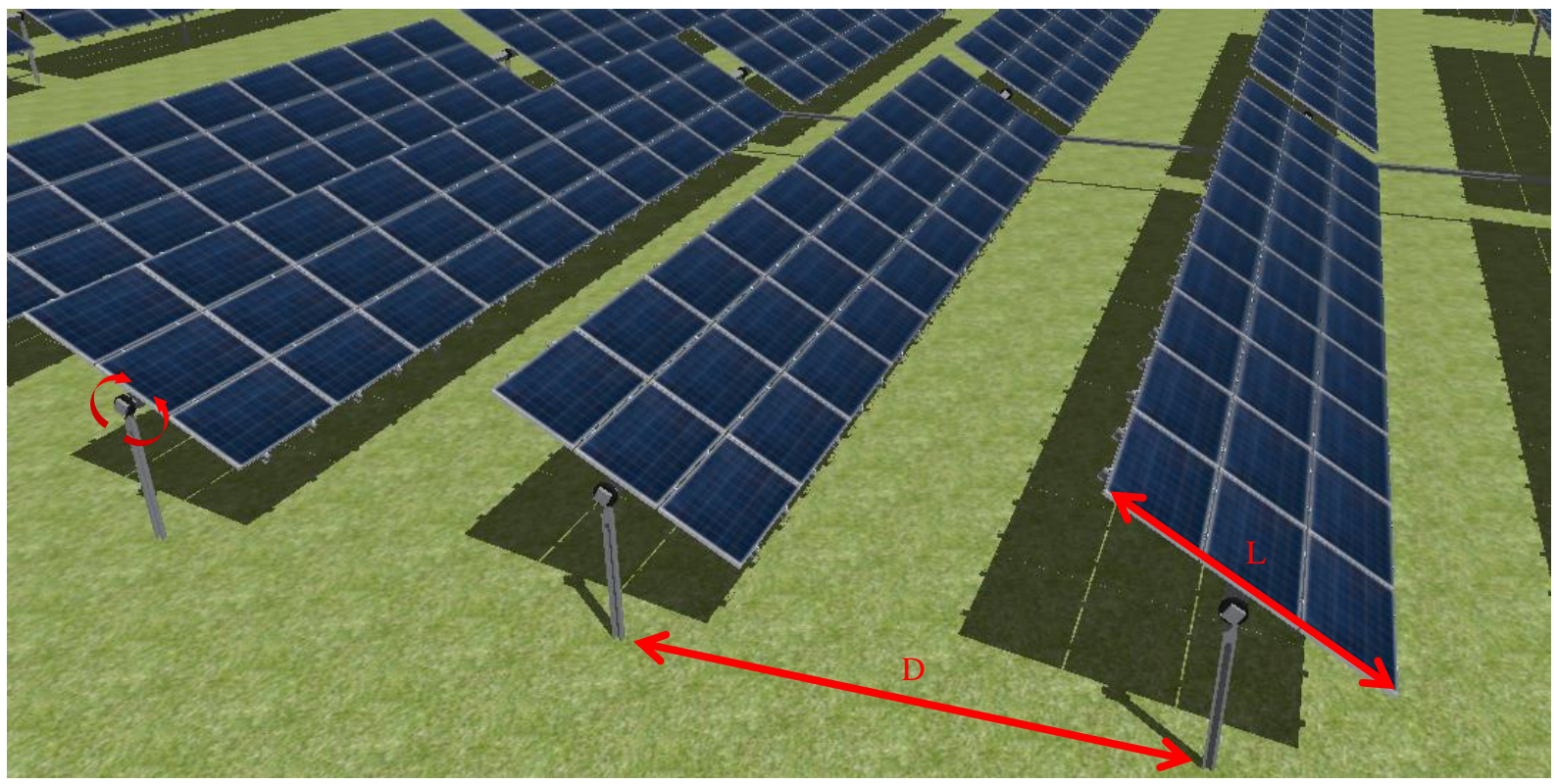


Uma vez que os rastreadores solares modificam as inclinações dos arranjos fotovoltaicos ao longo do dia, é possível que haja sombreamento mútuo quando o Sol está com baixas elevações, o que tende a reduzir a geração de energia elétrica do sistema fotovoltaico. Nesse sentido, estratégias de controle podem ser adotadas para que isso seja minimizado. O backtracking consiste em um algoritmo que realiza ajustes na orientação de módulos fotovoltaicos montados em rastreadores solares, de forma a reduzir as perdas causadas pelo sombreamento mútuo nos instantes mencionados, além de possibilitar uma maior compactação de uma usina fotovoltaica (NATIONAL RENEWABLE ENERGY LABORATORY (NREL), 2018b).

Duas representações de um rastreador solar de um eixo horizontal, com e sem backtracking, são mostradas na figura 3.9. É possível observar que a estratégia de controle com backtracking orientou os módulos em um ângulo diferente do ótimo, mas de forma a minimizar o sombreamento causado pelo rastreador solar adjacente e, com isso, permitir que parte dos módulos que estariam sombreados pudessem gerar energia elétrica.

Figura 3.9 - Rastreador solar de um eixo horizontal: (a) sem backtracking e (b) com backtracking.

(a)

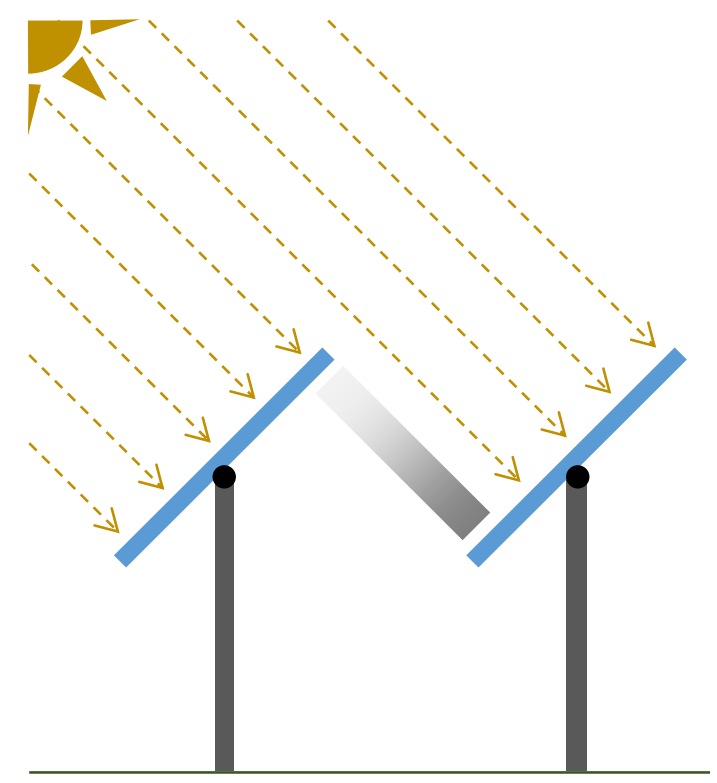

(b)

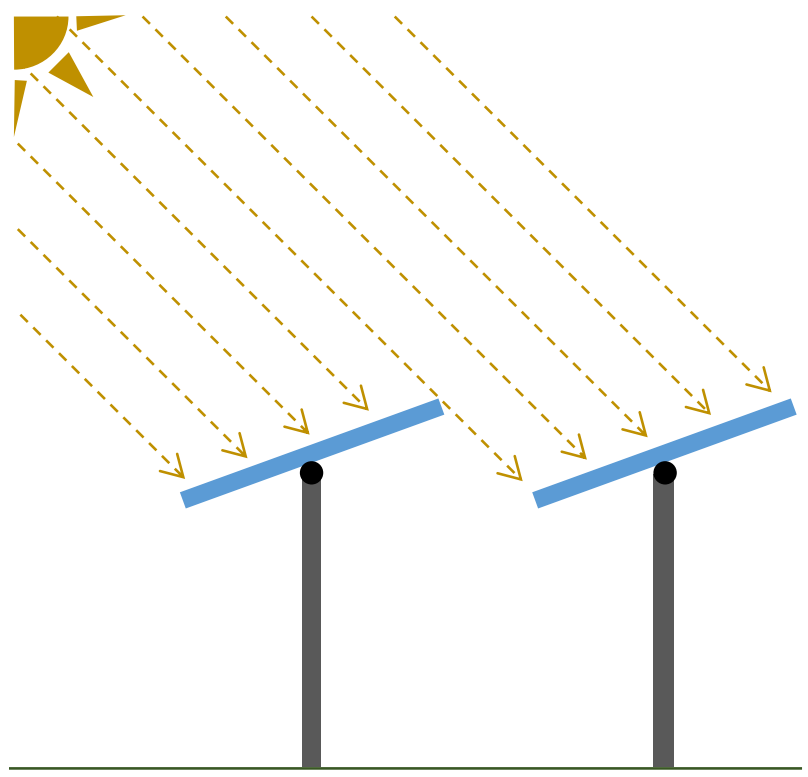

Fonte: elaborado a partir de (NATIONAL RENEWABLE ENERGY LABORATORY (NREL), 2018b).

Na figura 3.10, é apresentada uma comparação das potências normalizadas ao longo de um dia genérico numa dada localidade para dois sistemas fotovoltaicos genéricos, um montado em estruturas fixas em solo e outro em rastreadores solares de um eixo horizontal. As integrais das curvas representam as energias elétricas geradas por cada sistema, sendo a diferença energética representada pela área entre as duas curvas. Nesse caso específico, o emprego de 
rastreador solar proporcionou um ganho na geração de energia elétrica diária de 41,2 \%. Entretanto, esse valor pode variar em função da localidade onde o sistema está instalado, do dia do ano, das condições meteorológicas, além do recurso solar disponível. No ano, o valor médio observado foi de $25,3 \%$, dentro da faixa de $15 \%$ a $45 \%$ reportada por (RUSTEMLI et al., 2013).

Figura 3.10 - Comparação das potências de saída de sistemas fotovoltaicos montados em estruturas fixas em solo e em rastreadores solares de um eixo horizontal.

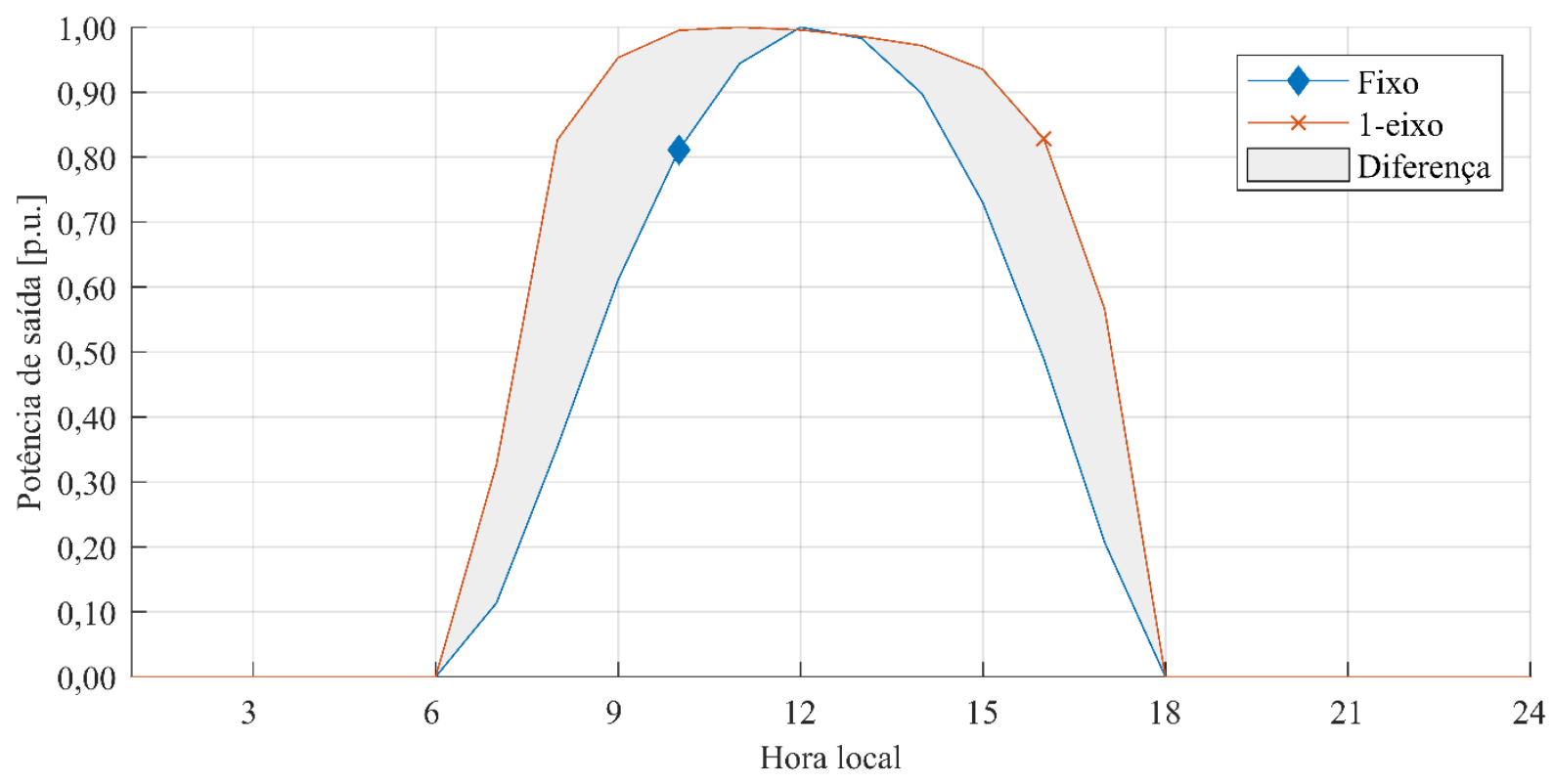

Fonte: elaborado a partir de (NATIONAL RENEWABLE ENERGY LABORATORY (NREL), 2018b).

Por utilizarem motores, acionadores e controladores, os rastreadores solares necessitam de estruturas metálicas mais robustas, assim como requerem obras civis, bases e fundações mais reforçadas para suportarem maiores pesos e cargas de vento, quando comparados às estruturas fixas em solo, o que implica custos adicionais.

A viabilidade econômica se dá quando, ao longo do horizonte do empreendimento, os ganhos financeiros auferidos pela diferença de receita oriunda da geração de energia elétrica superarem o acréscimo de investimento para montar os módulos fotovoltaicos em rastreadores solares em vez de utilizar estruturas fixas em solo.

\subsection{Inversores}

Os inversores fotovoltaicos são dispositivos eletrônicos que convertem a energia elétrica de corrente contínua (c.c.) para corrente alternada (c.a.), devendo suas características elétricas 
de saída, como amplitude, frequência e conteúdo harmônico, ser compatíveis com as da rede elétrica na qual injetam energia elétrica proveniente do sistema solar fotovoltaico (PINHO; GALDINO, 2014). Adicionalmente, esses equipamentos realizam o seguimento do ponto de potência máxima do gerador fotovoltaico, de modo a extrair a máxima potência que o arranjo fotovoltaico pode fornecer em dada condição (ZILLES et al., 2012).

$\mathrm{Na}$ figura 3.11, pode ser observada uma das maneiras de classificar os inversores fotovoltaicos, com evidência para os conectados à rede elétrica do tipo central, que estão contemplados nesse trabalho.

Figura 3.11 - Classificação de inversores.

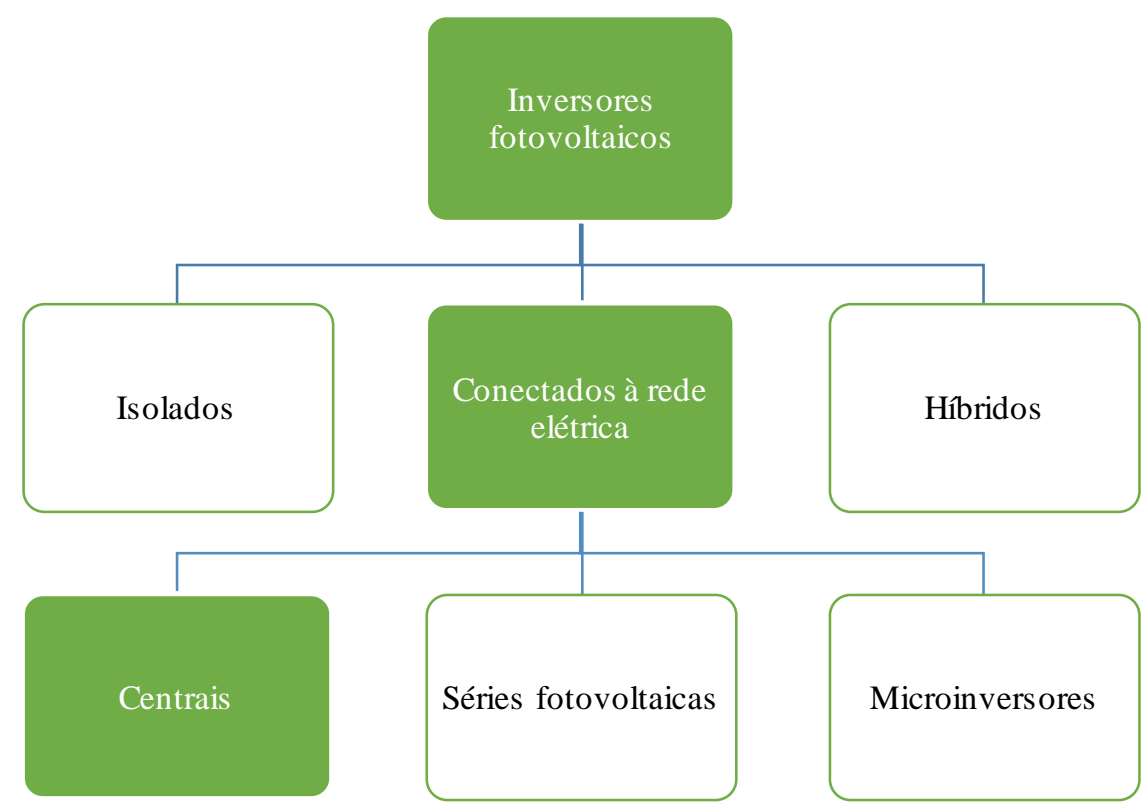

Fonte: elaborado a partir de (HÄBERLIN, 2012).

Uma das características que devem ser consideradas na seleção do inversor é a sua eficiência de operação (RÜTHER, 2004), cuja curva pode ser modelada em função da sua eficiência nominal, dada pela relação entre as potências nominais de saída e de entrada do inversor, conforme expressão (3.3) (NATIONAL RENEWABLE ENERGY LABORATORY (NREL), 2014a).

$$
\eta_{\text {nom }}=\frac{P_{c a 0}}{P_{c c 0, i n v}}
$$


Outro parâmetro importante é o fator de dimensionamento do inversor, FDI, que é definido pela relação entre a potência nominal do inversor e a do arranjo fotovoltaico, conforme mostrado na expressão (3.4).

$$
F D I=\frac{P_{c a 0}}{P_{c c 0}}
$$

De maneira análoga ao realizado na seção 3.3, o efeito do FDI é mostrado na figura 3.12, onde é possível observar a comparação das potências normalizadas ao longo de um dia para dois sistemas fotovoltaicos idênticos, a menos do FDI. Sem perda de generalidade, a análise foi realizada utilizando FDI de 0,60 e 1,00, esse último representando um inversor sem limitação de potência. Particularmente para essa situação, poder-se-ia gerar 13,6 \% a mais de energia elétrica caso se empregasse um inversor de potência maior. Como no cenário anterior, esse valor pode variar também em função das mesmas condições apresentadas. Quando a comparação é realizada na escala anual, o valor médio do aumento da energia elétrica gerada observado foi de $7,3 \%$.

Figura 3.12 - Comparação das potências de sistemas fotovoltaicos para dois FDI, variando a potência do inversor.

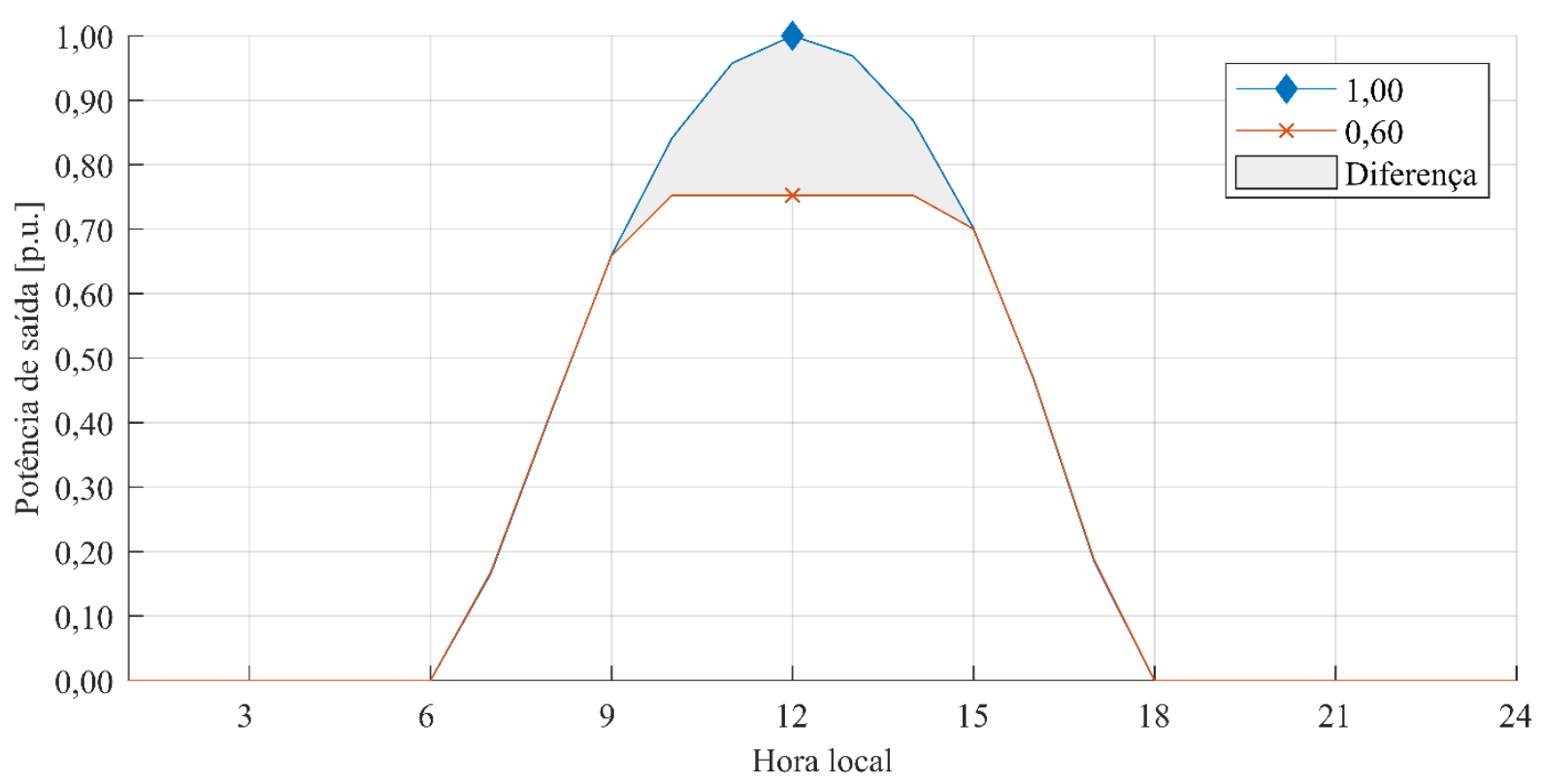

Fonte: elaborado a partir de (NATIONAL RENEWABLE ENERGY LABORATORY (NREL), 2018b).

Por processar mais energia, um inversor de maior potência tende a empregar componentes de maior capacidade, como semicondutores mais potentes e capacitores, indutores 
e dissipadores maiores, tornando-o mais caro quando comparado a um inversor de menor potência.

Do ponto de vista econômico, esses custos suplementares devem ser inferiores à receita proveniente da energia elétrica adicional gerada ao longo da vida do projeto quando trazidos a valor presente (KACO NEW ENERGY, 2013).

Outra forma de realizar essa análise é manter inalterada a potência do inversor e aumentar a potência do arranjo fotovoltaico, por meio da instalação de uma quantidade maior de módulos fotovoltaicos, respeitando os limites elétricos do sistema. Dessa maneira, conforme a expressão (3.4), reduz-se o FDI de modo que o inversor tende a operar por mais tempo na sua potência nominal, gerando mais energia elétrica. Na figura 3.13, é mostrada essa comparação para dois sistemas fotovoltaicos idênticos, exceto pelo FDI de 0,60 e 1,00, onde a área entre as curvas representa a energia elétrica adicional gerada pelo sistema com FDI de 0,60 nesse dia específico.

Figura 3.13 - Comparação das potências de sistemas fotovoltaicos para dois FDI, variando a potência do arranjo fotovoltaico.

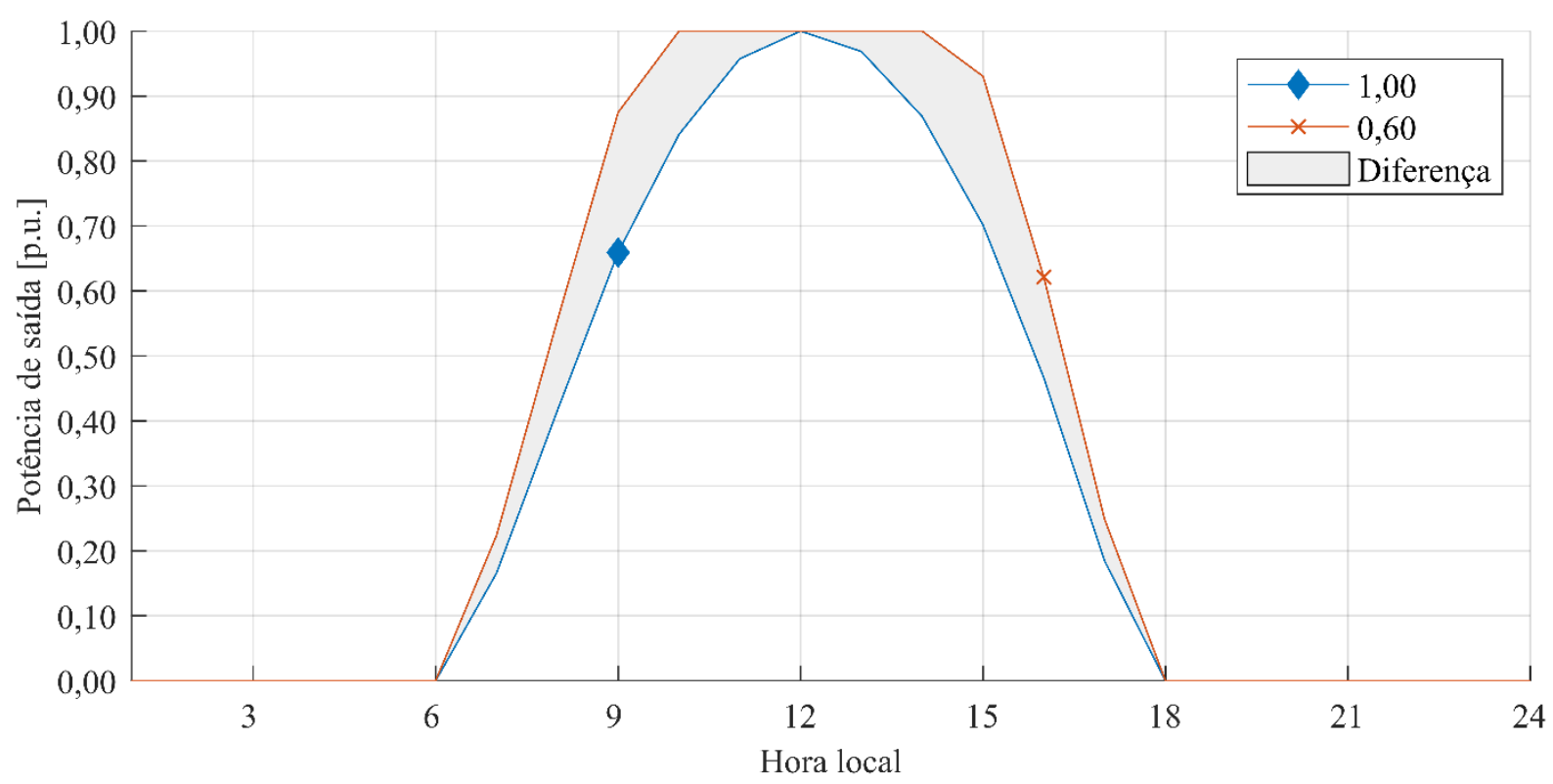

Fonte: elaborado a partir de (NATIONAL RENEWABLE ENERGY LABORATORY (NREL), 2018b).

Essa abordagem é fundamentada nos preços decrescentes dos módulos, como apresentados na figura 2.6, mas deve ser observado que haverá aumento de outros custos decorrentes do acréscimo da quantidade de módulos, como os relacionados à área do terreno, às estruturas de suporte e ao cabeamento. Como no caso anterior, sua economicidade é obtida 
quando o valor presente da receita oriunda da energia elétrica adicional gerada ao longo da vida do projeto superar o aumento dos investimentos.

\subsection{Parâmetros de desempenho}

O fator de capacidade, FC, é uma figura de mérito utilizada em sistemas de geração de energia elétrica e permite uma comparação entre diferentes sistemas. Conceitualmente, é definido como sendo a relação entre a energia elétrica gerada em um determinado período e a que seria gerada pela usina operando continuamente em sua capacidade nominal (INTERNATIONAL ELECTROTECHNICAL COMMISION (IEC), 2016). Pode ser representado matematicamente pela expressão (3.5).

$$
F C=\frac{E_{c a}}{P_{c a 0} t}
$$

Outro parâmetro de desempenho é a produtividade do sistema, $Y_{f}$, definida pela relação entre a energia elétrica injetada na rede e a potência nominal do arranjo fotovoltaico, conforme indicado pela expressão (3.6). Representa a quantidade de energia elétrica entregue à rede por unidade de potência do arranjo fotovoltaico, ou ainda o tempo equivalente necessário que o arranjo fotovoltaico tenha que operar, na sua potência nominal, para que seja gerada a mesma energia elétrica durante o período de análise (INTERNATIONAL ELECTROTECHNICAL COMMISION (IEC), 2017).

$$
Y_{f}=\frac{E_{c a}}{P_{c c 0}}
$$

Quando a análise é realizada em relação à entrada do sistema, pode ser definida a produtividade de referência, $Y_{r}$, que segundo a expressão (3.7), é calculada pela relação entre a irradiação incidente no plano dos módulos fotovoltaicos e a irradiância de referência na qual a potência nominal do arranjo fotovoltaico foi determinada (INTERNATIONAL ELECTROTECHNICAL COMMISION (IEC), 2017).

$$
Y_{r}=\frac{H_{T O T}}{G_{r e f}}
$$


Ao se relacionar as produtividades final e de referência, é possível definir o rendimento global do sistema, PR, que relaciona as grandezas de saída e entrada, indicando o efeito global das perdas na energia elétrica gerada (INTERNATIONAL ELECTROTECHNICAL COMMISION (IEC), 2017). Matematicamente, o PR pode ser calculado pela expressão (3.8)

$$
P R=\frac{Y_{f}}{Y_{r}}
$$

O PR considera as perdas envolvidas no sistema, como as devidas a temperatura, sombreamento, sujeira, poluição, erros no rastreamento (para sistemas com rastreadores solares), além de perdas na conversão c.c.-c.a. e no cabeamento, entre outras. Para mais detalhes, o leitor é convidado a conhecer a obra de (HÄBERLIN, 2012). 


\section{METODOLOGIA}

Este capítulo tem por objetivo descrever a metodologia empregada no trabalho, abordando as principais características das ferramentas adotadas, como o modelo solar físico e o procedimento de obtenção de um ano meteorológico representativo. Esses são as bases para simulações computacionais de longo prazo. Adicionalmente, é detalhado o procedimento adotado pelo simulador para o cálculo da energia elétrica gerada por um sistema fotovoltaico, bem como a influência que as variáveis exercem na saída.

\subsection{Arquivos meteorológicos}

\subsubsection{Modelo físico solar da base de dados}

A base de dados utilizada, proveniente do National Solar Radiation Database (NSRDB), utiliza informações de 1998 a 2016 e foi desenvolvida a partir do Physical Solar Model (PSM) pelo NREL em conjunto com outras instituições, como a Universidade de Wisconsin, National Oceanic and Atmospheric Administration (NOAA) e Solar Consulting Services. Ela compreende aproximadamente dois milhões de pontos, com uma resolução espacial de $0,038^{\circ}$ na latitude e na longitude, o que confere uma resolução nominal de $4 \mathrm{~km}$ por $4 \mathrm{~km}$. A área de cobertura está delimitada pelas longitudes $175^{\circ} \mathrm{O}$ e $25^{\circ} \mathrm{O}$, e latitudes $60^{\circ} \mathrm{N}$ e $20^{\circ} \mathrm{S}$, conforme destacado na figura 4.1, e, portanto, abrange integralmente a parte continental da região Nordeste brasileira, que é limitada pelas longitudes $48,75^{\circ} \mathrm{O}$ e $34,79^{\circ} \mathrm{O}$ e latitudes $1,04^{\circ} \mathrm{S}$ e $18,35^{\circ} \mathrm{S}$ (NATIONAL RENEWABLE ENERGY LABORATORY (NREL), 2018a) (INSTITUTO BRASILEIRO DE GEOGRAFIA E ESTATÍSTICA (IBGE), 2016). 
Figura 4.1 - Área de cobertura da base de dados.

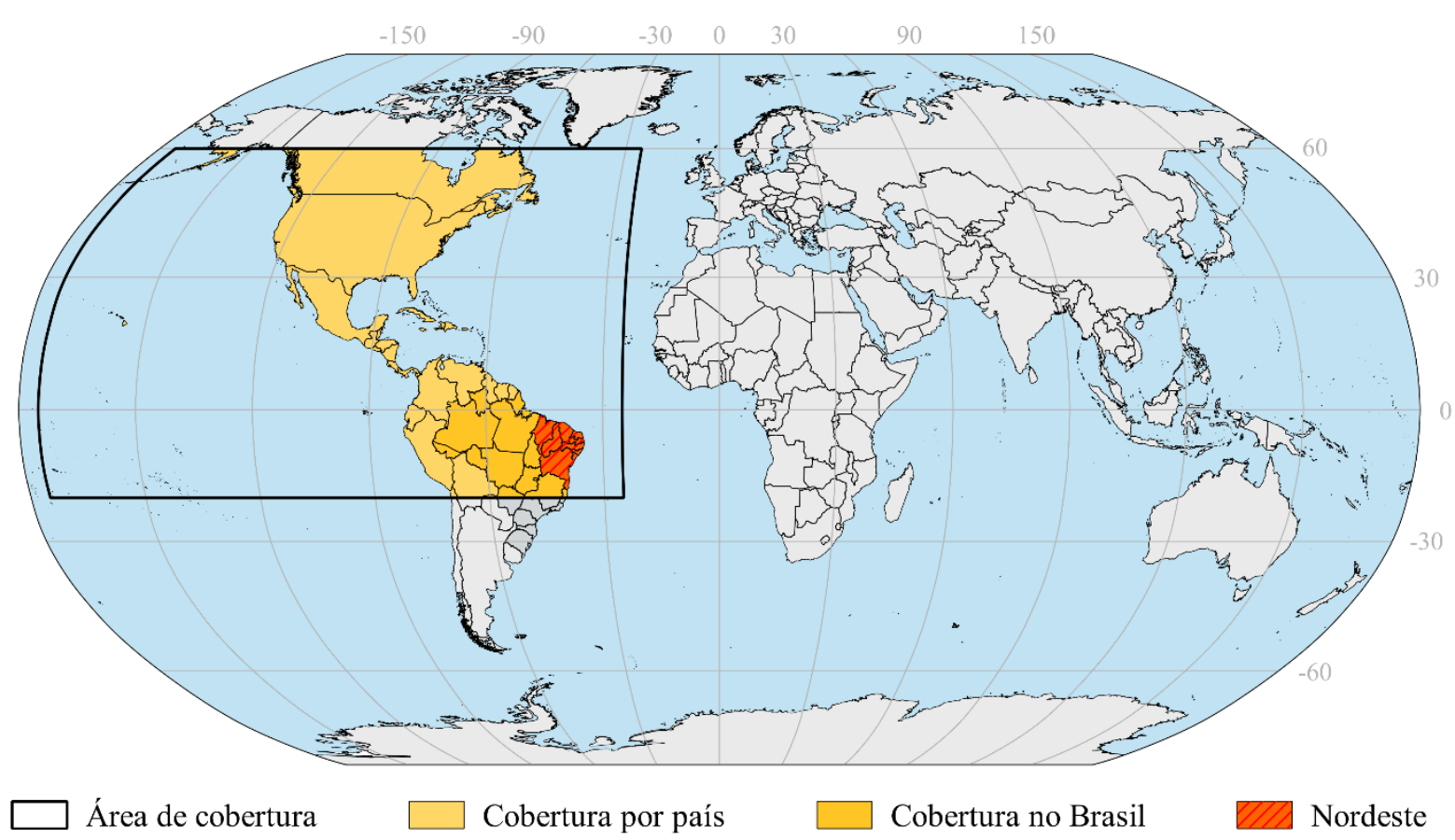

Fonte: elaborado a partir de (NATIONAL RENEWABLE ENERGY LABORATORY (NREL), 2018a).

De forma geral, o PSM utiliza a teoria da transferência radiativa, fazendo uso de informações de propriedades de nuvens, que são obtidas por meio de algoritmos que processam dados provenientes de satélites. Conjugando essas informações com as de estações terrestres de medição, é possível então calcular a radiação incidente na superfície terrestre. Na figura 4.2, é apresentado um diagrama de blocos que detalha a organização do modelo, abordando os principais processos envolvidos para a obtenção dos resultados a partir das várias fontes de dados. 
Figura 4.2 - Diagrama de blocos do PSM.

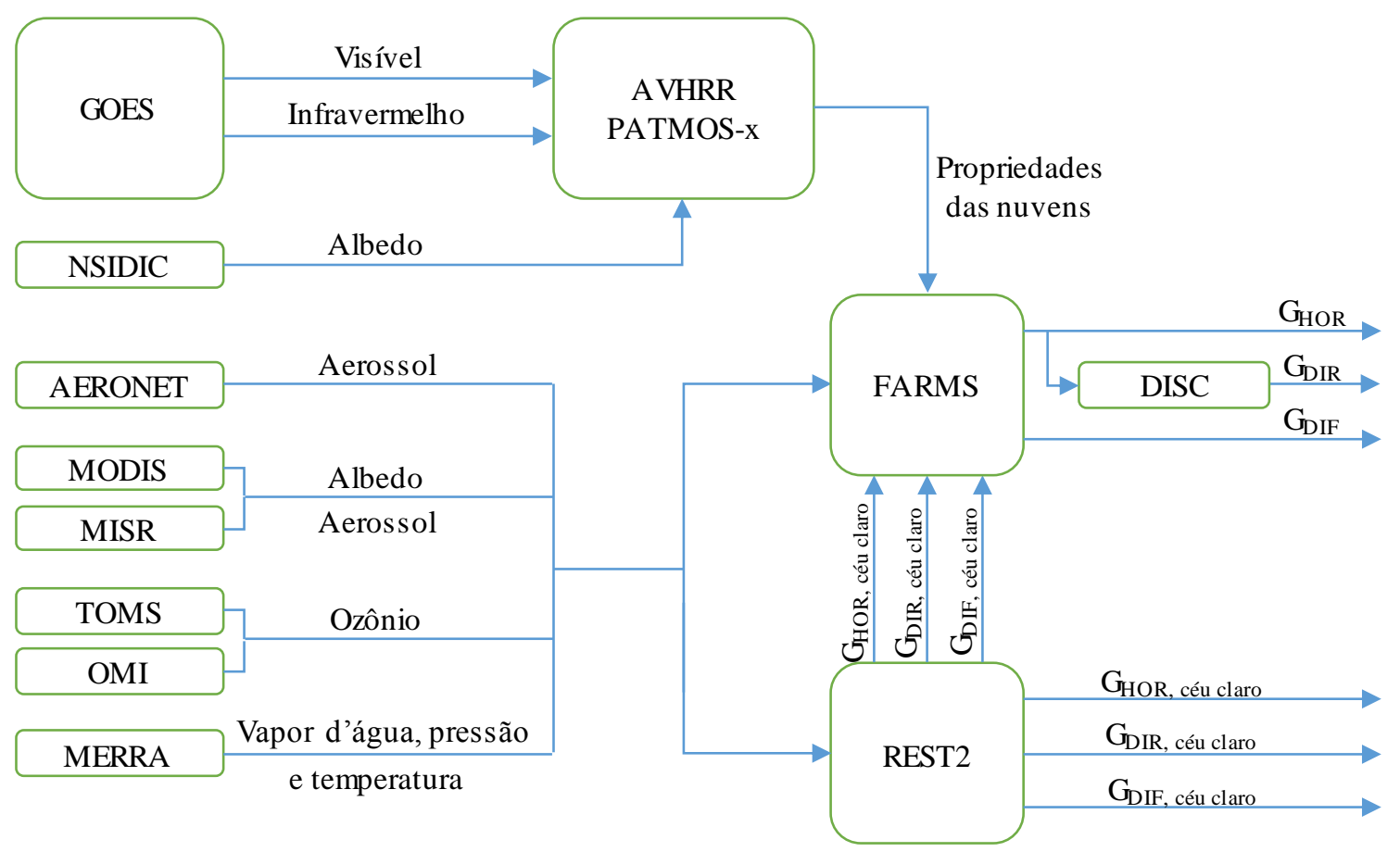

Fonte: elaborado a partir de (NATIONAL RENEWABLE ENERGY LABORATORY (NREL), 2018a), (SENGUPTA et al., 2014) (GUEYMARD, 2008) e (XIE, SENGUPTA e DUDHIA, 2016).

Um conjunto de imagens dos satélites Geostationary Operational Environmental Satellite (GOES), com resolução temporal de 30 minutos, distribuídas em cinco canais e sintonizadas nas faixas dos espectros visível e infravermelho, é utilizado, juntamente com dados de albedo provenientes do National Snow and Ice Data Center (NSIDC), pelos algoritmos Advanced Very High Resolution Radiometer (AVHRR) Pathfinder Atmospheres Extended (PATMOS-x) (HEIDINGER et al., 2014) para obter informações relacionadas às propriedades das nuvens. Os dados obtidos estão relacionados à espessura óptica e tamanho de partículas, além dos tipos de nuvens, obtidos pela máscara identificadora de nuvens (NATIONAL RENEWABLE ENERGY LABORATORY (NREL), 2018a).

Para calcular a radiação de céu claro, o modelo Reference Evaluation of Solar Transmittance 2 (REST2) (GUEYMARD, 2008) utiliza como dados de entrada uma combinação entre a profundidade óptica de aerossóis, albedo, ozônio, vapor de água precipitável, temperatura e pressão atmosférica. Os dois primeiros são obtidos a partir de uma combinação dos satélites Moderate Resolution Imaging Spectroradiometer (MODIS) e Multiangle Imaging Spectroradiometer (MISR) e de estações de medição terrestres da rede Aerosol Robotic Network (AERONET). Os dados de ozônio são provenientes dos satélites Total Ozone Mapping Spectrometer (TOMS) e Ozone Monitoring Instrument (OMI), enquanto os demais 
são oriundos de dados de reanálise meteorológica da National Aeronautics and Space Administration (NASA), Modern-Era Retrospective Analysis for Research and Applications (MERRA), mediante interpolação temporoespacial, para uma resolução de meia hora numa malha de $4 \mathrm{~km}$ por $4 \mathrm{~km}$ (NATIONAL RENEWABLE ENERGY LABORATORY (NREL), 2018a).

Os resultados de radiação de céu claro, obtidos pelo modelo REST2, são utilizados como insumos no modelo Fast All-sky Radiation Model for Solar Applications (FARMS) (XIE, SENGUPTA e DUDHIA, 2016), o qual também incorpora informações relacionadas às propriedades de nuvens, obtidas pelos algoritmos AVHRR PATMOS-x, e demais dados atmosféricos. Dessa maneira, o modelo FARMS obtém $G_{D I F}$ e $G_{H O R}$, utilizando essa última para estimar $G_{D I R}$ pelo modelo Direct Insolation Simulation Code (DISC) (MAXWELL, 1987).

O NSRDB consolida esses resultados e os disponibiliza em arquivos meteorológicos do período de 1998 a 2016, contendo as variáveis apresentadas na tabela 4.1.

Tabela 4.1 - Dados dos arquivos meteorológicos.

\begin{tabular}{cc}
\hline Campo & Unidade de medida / Faixa de valores \\
\hline Ano & $1998-2016$ \\
Mês & $1-12$ \\
Dia & $1-31$ \\
Hora & $0-23$ \\
Minuto & 0 ou 30 \\
Irradiância global horizontal & $\mathrm{W} / \mathrm{m}^{2}$ \\
Irradiância direta normal & $\mathrm{W} / \mathrm{m}^{2}$ \\
Irradiância difusa horizontal & $\mathrm{W} / \mathrm{m}^{2}$ \\
Irradiância global horizontal de céu claro & $\mathrm{W} / \mathrm{m}^{2}$ \\
Irradiância direta normal de céu claro & $\mathrm{W} / \mathrm{m}^{2}$ \\
Irradiância difusa horizontal de céu claro & $\mathrm{W} / \mathrm{m}^{2}$ \\
Temperatura ambiente de bulbo seco & ${ }^{\circ} \mathrm{C}$ \\
Temperatura do ponto de orvalho & ${ }^{\circ} \mathrm{C}$ \\
Velocidade do vento a 10 m do solo & $\mathrm{m} / \mathrm{s}$ \\
Direção do vento & $\circ$ \\
Albedo & $0-1$ \\
Umidade relativa & $\%$ \\
Pressão atmosférica & $\mathrm{obar}(\mathrm{hPa})$ \\
Coluna de água precipitável & $\mathrm{cm}$ \\
Ângulo zenital & $\circ$ \\
\hline
\end{tabular}

Fonte: elaborado a partir de (NATIONAL RENEWABLE ENERGY LABORATORY (NREL), 2014a). 


\subsubsection{Ano Meteorológico Típico (AMT)}

Geralmente, estudos e projetos relacionados a sistemas fotovoltaicos necessitam de dados climáticos para estimar a geração de energia elétrica ou avaliar o desempenho das diversas soluções tecnológicas que podem ser aplicadas. Algumas das principais ferramentas de simulação computacional, como SAM (NATIONAL RENEWABLE ENERGY LABORATORY (NREL), 2018b), PVsyst (PVSYST, 2018), e PV*SOL (VALENTIN SOFTWARE, 2018), consideram um período de análise de um ano com resolução temporal horária, sendo os resultados obtidos para a mesma resolução, o que possibilita a consolidação em resultados diários, mensais e anuais.

A escolha dos dados de entrada para um determinado local é fundamental para a simulação computacional desses sistemas, uma vez que os resultados obtidos são fortemente dependentes do recurso meteorológico disponível. Assim, caso se utilize, por exemplo, dados de medição de um determinado ano em que houve atividade vulcânica, pode-se subestimar o desempenho de um sistema fotovoltaico, uma vez que o recurso solar é atenuado pelas partículas e gases expelidos na atmosfera (MICHALSKY et al., 1994), (OLMO, BATLLES e ALADOS-ARBOLEDAS, 1996), (OLMO et al., 1999), (MOLINEAUX; INEICHEN, 1996) (GARRISON, 1995), (KHALIL; SHAFFIE, 2016), (RICHARDSON, 1984), (SAHAI, KIRCHHOFF e AVALÁ, 1997), (VERDECCHIA, VISCONTI e PITARI, 1992). Dessa maneira, os resultados obtidos podem não representar o comportamento esperado do sistema fotovoltaico para o horizonte da vida útil do sistema.

No entanto, isso não significa que dados de medição de variáveis meteorológicas de um determinado ano não possuem importância. Pelo contrário: juntamente com dados de saída, são úteis também em simulações computacionais, com o objetivo de se verificar o desempenho de um sistema no período em análise e até detectar a ocorrência de possíveis problemas, a fim de solucioná-los (WITTMER, MERMOUD e SCHOTT, 2015), (MALVONI, DE GIORGI e CONGEDO, 2017).

Nesse contexto, eis que surge a necessidade de se utilizar dados que sejam representativos e que possam estimar o comportamento esperado de longo prazo de um sistema fotovoltaico. Dessa forma, o desempenho simulado de um sistema para um ano típico pode fornecer uma boa estimativa do comportamento de longo prazo do sistema se os dados climáticos desse ano típico forem representativos. Cabe destacar que a expressão longo prazo refere-se ao período equivalente ou representativo da vida útil de um sistema, da ordem de 10 a 20 anos (KLEIN, BECKMAN e DUFFIE, 1976). 
Um Ano Meteorológico Típico (AMT) é composto por dados horários de irradiância solar e de outras variáveis meteorológicas no período de um ano, sendo formado pela seleção de 12 meses que melhor representam as condições típicas de longo prazo, podendo ser de anos diferentes. É indicado no uso de simulações computacionais para diversos sistemas de conversão de energia, onde inclui-se a energia solar fotovoltaica. É importante observar que os dados representam condições típicas, em vez de extremas, e que, por isso, não são apropriadas para determinar o pior caso em um dado lugar (NATIONAL RENEWABLE ENERGY LABORATORY (NREL), 2008).

Diversos trabalhos abordam a geração de AMT para várias cidades no planeta, propondo, utilizando, ou até mesmo mesclando algumas metodologias, como as obras de (HALL et al., 1978), (PETRIE; MCCLINTOCK, 1978), (PISSIMANIS et al., 1988), (FESTA; RATTO, 1993), (PETRAKIS et al., 1998), (KALOGIROU, 2003), (SAWAQED, ZURIGAT e AL-HINAI, 2005), (NATIONAL RENEWABLE ENERGY LABORATORY (NREL), 2008), (EBRAHIMPOUR; MAEREFAT, 2010), (CEBECAUER; SURI, 2015), (MURPHY, 2017) e (FARAH, SAMAN e BOLAND, 2018).

Um dos principais e mais utilizados métodos para gerar um AMT é o proposto por (HALL et al., 1978), que utiliza o método estatístico de (FINKELSTEIN; SCHAFER, 1971) e é fundamentado em três propriedades básicas:

1. Os dados meteorológicos selecionados devem possuir distribuições de frequência próximas às de longo prazo;

2. As relações entre as diferentes variáveis meteorológicas devem ser semelhantes às observadas na natureza;

3. As séries de dados selecionadas devem ser semelhantes às frequentemente observadas na natureza, na localidade em questão.

É importante destacar que, apesar de o método desenvolvido ter sido aplicado inicialmente para 26 estações localizadas nos Estados Unidos, ele tem sua abrangência a qualquer localidade geográfica, desde que se tenha uma base de dados meteorológicos de longo prazo (HALL et al., 1978).

A abordagem empírica adotada para formar um AMT de uma dada localidade consiste em selecionar os 12 meses distintos mais representativos do período da base de dados. Por exemplo, no caso de a base possuir 25 anos de dados, todos os meses de janeiro são analisados, e o que for mais típico é selecionado para ser incluído no AMT. Os demais meses são tratados de forma semelhante para então serem concatenados e formarem um ano completo. Uma vez que meses consecutivos de um AMT podem ser de diferentes anos, podem surgir 
descontinuidades entre as interfaces dos meses, que são suavizadas por meio de técnicas de ajuste de curvas.

A escolha de cada mês proposta por (HALL et al., 1978) é baseada inicialmente em 13 índices diários de quatro variáveis: irradiação global horizontal e mínimo, máximo, média e amplitude da velocidade do vento e das temperaturas de bulbo seco e do ponto de orvalho. Com o objetivo de melhorar o método, (NATIONAL RENEWABLE ENERGY LABORATORY (NREL), 2008) propôs a adição da irradiância direta normal, a desconsideração das amplitudes e a modificação dos pesos dos índices das variáveis, conforme a tabela 4.2, de modo a obter dez índices diários.

Tabela 4.2 - Pesos dos índices das variáveis na seleção dos meses típicos.

\begin{tabular}{ccccc}
\hline \multirow{2}{*}{ Variável } & \multicolumn{4}{c}{ Índice } \\
\cline { 3 - 5 } & Soma & Mínimo & Máximo & Média \\
& $5 / 20$ & - & - & - \\
Irradiância global horizontal & $5 / 20$ & - & - & - \\
Irradiância direta normal & $5 / 20$ & & $1 / 20$ & $2 / 20$ \\
Temperatura de bulbo seco & - & $1 / 20$ & $1 / 20$ & $2 / 20$ \\
Temperatura do ponto de orvalho & - & $1 / 20$ & & \\
Velocidade do vento & - & - & $1 / 20$ & $1 / 20$ \\
\hline
\end{tabular}

Fonte: elaborado a partir de (HALL et al., 1978) e (NATIONAL RENEWABLE ENERGY LABORATORY (NREL), 2008).

Assim, sem perda de generalidade, para cada ano e localidade, o mês de outubro possui 31 valores para cada um dos dez índices diários. Dessa forma, caso a base tenha 20 anos de dados para a localidade em questão, o conjunto de longo prazo de outubro possuirá 620 valores para cada índice. A seleção final do mês mais representativo, o Mês Meteorológico Típico (MMT), leva em consideração a média e a mediana mensal, além da persistência da média diária da temperatura de bulbo seco e da irradiação global horizontal diária. Esse processo pode ser dividido em etapas para uma melhor compreensão:

1. Construção das funções de distribuição acumulada de curto e longo prazos para cada um dos índices diários considerados. O curto prazo é referente a um mês específico, enquanto o longo prazo considera o conjunto de um mesmo mês de todos os anos disponíveis. 
2. Para um mesmo mês de todos os anos, são selecionados cinco candidatos que possuem os índices diários mais próximos aos de longo prazo, segundo a soma ponderada da estatística de Finkelstein-Schafer (FINKELSTEIN; SCHAFER, 1971). Inicialmente, a estatística de Finkelstein-Schafer do índice $j, F S_{j}$, é calculada conforme expressão (4.1), em que $n$ é a quantidade de dias no referido mês e $F D A_{C P}\left(x_{j, i}\right)$ e $\operatorname{FDA}_{L P}\left(x_{j, i}\right)$ são as funções de distribuição acumulada de curto e longo prazos do índice $j$ no dia $i$ do mês.

$$
F S_{j}=\frac{1}{n} \sum_{i=1}^{n}\left|\operatorname{FDA}\left(x_{j, i}\right)-F D A_{L P}\left(x_{j, i}\right)\right|
$$

A depender da aplicação, alguns índices podem ser considerados mais importantes que outros. Para a energia solar fotovoltaica, é usual que os relacionados à radiação solar possuam pesos maiores que os demais. Em seguida, é obtida a soma ponderada, $W S$, dos índices $F S_{j}$ para cada um dos meses, segundo a expressão (4.2), em que $k$ é a quantidade de índices considerados e $w_{j}$ é o peso do índice $j$, apresentados na tabela 4.2. O fim dessa etapa é obtido pela seleção dos cinco meses que apresentarem as menores somas ponderadas.

$$
W S=\sum_{j=1}^{k} w_{j} F S_{j}
$$

3. Os cinco meses selecionados são ordenados levando em consideração a proximidade do mês em relação à média e à mediana de longo prazo da temperatura de bulbo seco e da irradiância global horizontal.

4. As persistências da temperatura média de bulbo seco e da irradiação diária global horizontal são calculadas pela determinação da frequência e a quantidade de dias consecutivos com valores acima e abaixo de percentis fixos de longo prazo. Para a temperatura média de bulbo seco, são determinadas as quantidades de dias consecutivos acima do percentil 67 (dias quentes consecutivos) e abaixo do percentil 33 (dias frios consecutivos). Para a irradiação diária global horizontal, é determinada a quantidade de dias consecutivos abaixo do percentil 33 (dias 
consecutivos com baixa irradiação). O critério de persistência exclui o mês com a maior quantidade de dias consecutivos, o mês que possui a maior quantidade de intervalos com dias consecutivos e o mês que não possui dias consecutivos que atendam aos critérios dos percentis estabelecidos. O mês, entre os cinco meses candidatos, melhor classificado e que não foi excluído pelo critério de persistência, é utilizado para compor o AMT.

5. Os 12 meses selecionados são concatenados para formar um ano completo, sendo as descontinuidades entre as interfaces dos meses suavizadas, utilizando técnicas de ajustes de curvas.

Para um exemplo de aplicação com detalhamento de cada etapa, o leitor é convidado a conhecer o trabalho de (SAWAQED, ZURIGAT e AL-HINAI, 2005).

Uma vez determinado e conhecido o procedimento para a obtenção dos AMT e de posse dos arquivos meteorológicos de vários anos, o NSRBD também disponibiliza os arquivos dos AMT para cada uma das localidades citadas na seção 4.1.1.

Na figura 4.3, são apresentados os valores médios diários da irradiação global horizontal para cada mês de alguns anos selecionados no período de 1998 a 2016 para a cidade de Fortaleza/CE, nas coordenadas $3,75^{\circ} \mathrm{S}$ e $38,54^{\circ} \mathrm{O}$. Além disso, são mostrados os correspondentes valores mensais de longo prazo e do AMT, sendo possível verificar que essas duas curvas são quase coincidentes. Isso é explicado pelo fato de a irradiância global horizontal possuir um elevado peso em relação às demais variáveis, no procedimento da geração do AMT, conforme mostrado na tabela 4.2, o que indica que os valores dos MMT selecionados são próximos aos de longo prazo. Os anos selecionados para cada mês que compõem o AMT são sumarizados na tabela 4.3. 
Figura 4.3 - Média diária da irradiação global horizontal para a cidade de Fortaleza/CE para anos selecionados, ano meteorológico típico e média de longo prazo.

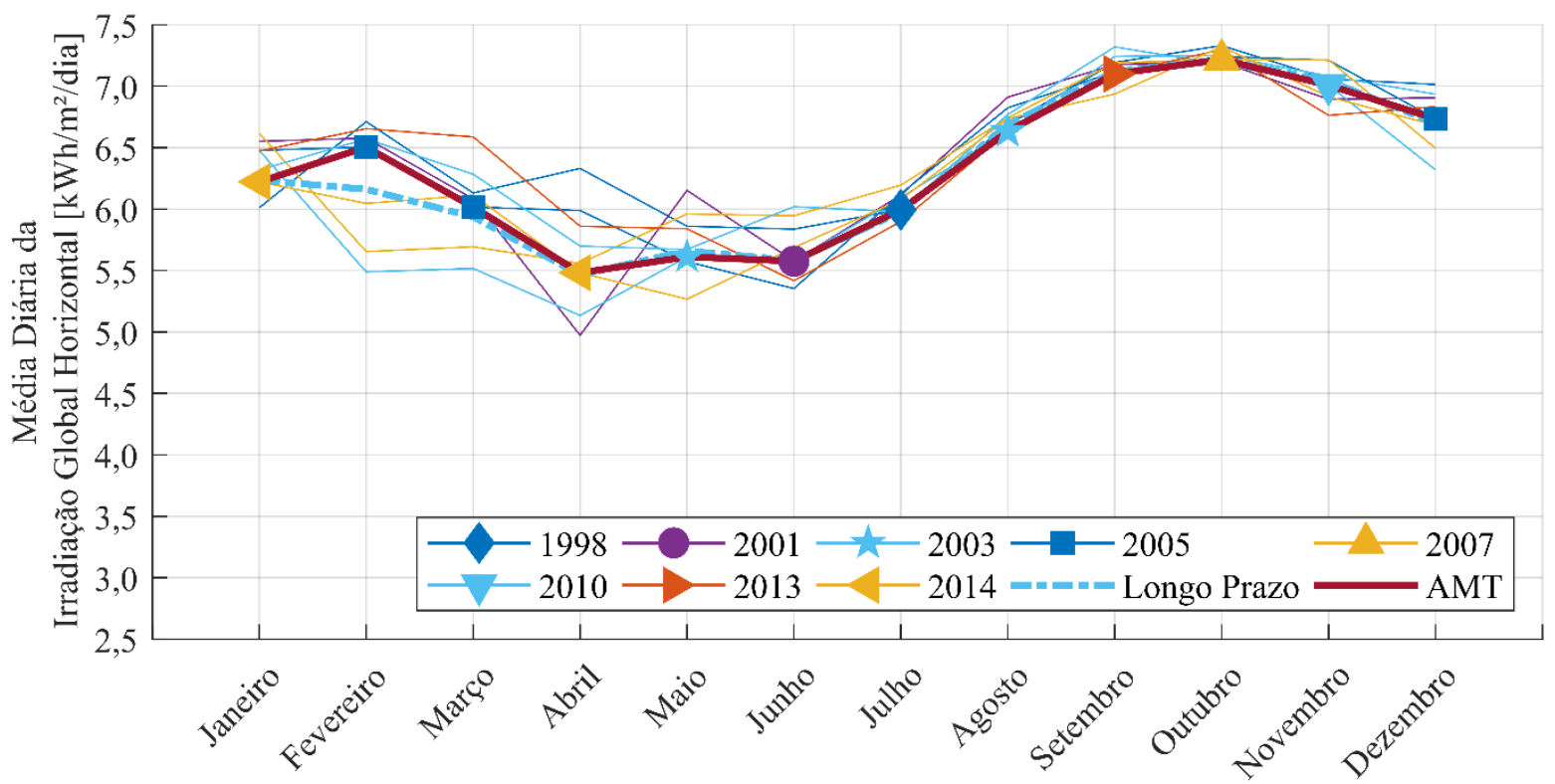

Fonte: elaborado a partir de (NATIONAL RENEWABLE ENERGY LABORATORY (NREL), 2018a).

Tabela 4.3 - Anos selecionados de cada mês para composição do AMT para a cidade de Fortaleza/CE.

\begin{tabular}{cc}
\hline Mês & Ano \\
\hline Janeiro & 2014 \\
Fevereiro & 2005 \\
Março & 2005 \\
Abril & 2014 \\
Maio & 2003 \\
Junho & 2001 \\
Julho & 1998 \\
Agosto & 2003 \\
Setembro & 2013 \\
Outubro & 2007 \\
Novembro & 2010 \\
Dezembro & 2005 \\
\hline
\end{tabular}

Fonte: elaborado a partir de (NATIONAL RENEWABLE ENERGY LABORATORY (NREL), 2018a). 


\subsection{System Advisor Model (SAM)}

Inicialmente, o System Advisor Model (SAM) foi desenvolvido pelo National Renewable Energy Laboratory (NREL) com a colaboração do Sandia National Laboratories em 2005 para uso interno pelo departamento de energia do governo norte-americano. Até o presente momento, novas versões do programa são disponibilizadas gratuitamente à comunidade científica, com atualizações periódicas e incorporações de melhorias, o que o tornou um programa internacionalmente conceituado para realização de simulações e análises de sistemas fotovoltaicos, sejam elas de cunho energético ou econômico. (NATIONAL RENEWABLE ENERGY LABORATORY (NREL), 2014b).

A ferramenta possui um modelo computacional que calcula desempenho e métricas financeiras de sistemas de energias renováveis, podendo ser utilizado para realizar simulações de sistemas de geração solar fotovoltaica, heliotérmica, biomassa, eólica e geotérmica. Entre as diversas funcionalidades que o programa possui, é possível realizar análise de sensibilidade, análises estatísticas com simulações de Monte Carlo, além de estudos de variabilidade do clima (P50/P90) (NATIONAL RENEWABLE ENERGY LABORATORY (NREL), 2014b).

O programa é composto por uma interface de usuário, uma ferramenta de cálculo e uma interface de programação. A primeira delas é a parte visível ao utilizador do programa, onde é possível ter acesso às variáveis de entrada, controles da simulação e gráficos e tabelas de resultados. Já a ferramenta de cálculo, chamada de SAM Simulation Core (SSC), é responsável por realizar as simulações para cada instante de tempo e calcular os resultados técnicos e econômicos do sistema estudado. A interface de programação permite que programas externos interajam com o SAM, acessando a ferramenta de cálculo por meio do Software Development Kit (SDK) (NATIONAL RENEWABLE ENERGY LABORATORY (NREL), 2014b).

Um grande diferencial desse programa em relação a alguns comercialmente disponíveis na área solar fotovoltaica é a disponibilização do SDK do SSC, o qual permite acessar a ferramenta de cálculo e simulação do SAM em segundo plano, sem que a interface gráfica seja aberta, e trocar informações com outras ferramentas ou linguagens de programação, como Matrix Laboratory (MATLAB), Java, PHP, Python e C\# (NATIONAL RENEWABLE ENERGY LABORATORY (NREL), 2018b). Especificamente nesse trabalho, utiliza-se o ambiente MATLAB para realizar esse intercâmbio de informações, as preparações dos dados de entrada e a compilação dos resultados. 


\subsubsection{Módulo PVWatts}

Em 1998, o NREL desenvolveu a primeira versão do módulo PVWatts, tendo sido concebido com o intuito de estimar a geração de energia elétrica de um sistema fotovoltaico conectado à rede elétrica a partir de alguns poucos parâmetros de entrada. São adotadas algumas simplificações e considerações nos cálculos, podendo os resultados ser considerados como uma estimativa representativa da operação de um sistema fotovoltaico em um ano típico. No ano seguinte, a ferramenta foi disponibilizada como aplicação online, e, desde então, algumas versões mais atualizadas foram lançadas. Atualmente, o PVWatts encontra-se na quinta versão, publicada em 2014, e incorporou mudanças que englobam uma modelagem mais precisa, não deixando o caráter simplificado de dados de entrada (NATIONAL RENEWABLE ENERGY LABORATORY (NREL), 2014a).

Inicialmente, para a realização da simulação utilizando o módulo PVWatts, é necessário que os dados de entrada sejam fornecidos em base horária, contendo irradiância direta normal e difusa horizontal, além de temperatura ambiente de bulbo seco e velocidade do vento a uma altura de 10 metros do solo. Opcionalmente, pode ser fornecido o albedo para cada uma das horas do ano. Caso não o seja, é considerado o valor padrão de 0,2 . Ao total, o arquivo possui 8.763 linhas, sendo 8.760 com os campos apresentados na tabela 4.4.

Tabela 4.4 - Dados horários de entrada para a simulação.

\begin{tabular}{cc}
\hline Campo & Unidade de medida / Faixa de valores \\
\hline Ano & $1950-2050$ \\
Mês & $1-12$ \\
Dia & $1-31$ \\
Hora & $0-23$ \\
Irradiância direta normal & $\mathrm{W} / \mathrm{m}^{2}$ \\
Irradiância difusa horizontal & $\mathrm{W} / \mathrm{m}^{2}$ \\
Temperatura ambiente de bulbo seco & ${ }^{\circ} \mathrm{C}$ \\
Velocidade do vento a 10 m do solo & $\mathrm{m} / \mathrm{s}$ \\
Albedo (opcional) & $0-1$ \\
\hline
\end{tabular}

Fonte: elaborado a partir de (NATIONAL RENEWABLE ENERGY LABORATORY (NREL), 2014a).

As outras três linhas do arquivo são de cabeçalho e contêm os nomes das variáveis, as unidades de medida e as informações da localidade, como latitude, longitude, altitude e fuso horário. Esses dados são utilizados para determinar a posição aparente do Sol no ponto médio 
do intervalo, calculando-se os ângulos azimutal e zenital do Sol, segundo o algoritmo ${ }^{2}$ proposto por (MICHALSKY, 1988a) e (MICHALSKY, 1988b). Nos intervalos em que há o nascer ou pôr do sol, o cálculo é realizado no ponto médio entre o horário em que o Sol cruza o horizonte e a hora adjacente em que o Sol está acima do horizonte (NATIONAL RENEWABLE ENERGY LABORATORY (NREL), 2014a).

Em seguida, deve ser determinada a configuração do sistema fotovoltaico a ser simulado, conforme os parâmetros listados na tabela 4.5, levando em consideração tanto as características elétricas quanto as físicas. O primeiro conjunto diz respeito à potência do arranjo fotovoltaico e sua relação com a potência de inversores, a eficiência da conversão da parte de corrente contínua para alternada, além das perdas envolvidas no sistema. Já o segundo grupo está relacionado à tecnologia dos módulos fotovoltaicos, à estrutura de suporte em que esses estão montados, bem como a orientação espacial. Para os sistemas que utilizam rastreadores solares de um eixo, com ou sem backtracking, é necessário informar também o índice de cobertura do terreno.

Tabela 4.5 - Parâmetros de configuração do sistema fotovoltaico do módulo PVWatts.

\begin{tabular}{|c|c|c|}
\hline Grupo & Parâmetro & Unidade \\
\hline \multirow{4}{*}{1} & Capacidade do sistema & $\mathrm{kWp}$ \\
\hline & $\begin{array}{c}\text { Relação entre potência de módulos e de } \\
\text { inversores (1/FDI) }\end{array}$ & (adimensional) \\
\hline & Eficiência do inversor & $\%$ \\
\hline & Perdas no sistema fotovoltaico & $\%$ \\
\hline \multirow{5}{*}{2} & Tipo de módulo fotovoltaico & $\begin{array}{c}\text { Padrão } \\
\text { Superior } \\
\text { Filme fino }\end{array}$ \\
\hline & Suporte & $\begin{array}{c}\text { Fixa em solo } \\
\text { Fixa em telhado } \\
\text { Rastreador solar de um eixo } \\
\text { Rastreador solar de um eixo com backtracking } \\
\text { Rastreador solar de dois eixos }\end{array}$ \\
\hline & Inclinação do arranjo fotovoltaico & $\circ$ \\
\hline & Ângulo azimutal do arranjo fotovoltaico & $\circ$ \\
\hline & Índice de cobertura do terreno (ICT) ${ }^{3}$ & (adimensional) \\
\hline
\end{tabular}

Fonte: elaborado a partir de (NATIONAL RENEWABLE ENERGY LABORATORY (NREL), 2014a).

\footnotetext{
${ }^{2} \mathrm{O}$ algoritmo proposto por (MICHALSKY, 1988a) para o cálculo da posição solar possui precisão de $0,01^{\circ}$ até o ano de 2050.

${ }^{3}$ Disponível somente para rastreadores solares de um eixo com ou sem backtracking.
} 
Os módulos fotovoltaicos do tipo padrão representam módulos típicos de silício multicristalino $^{4}$ ou monocristalino com eficiências na faixa de $14 \%$ a $17 \%$. Já os do tipo superior representam módulos de silício monocristalino com cobertura antirreflexiva e eficiência de $18 \%$ a $20 \%$. Os de filme fino possuem uma eficiência menor, aproximadamente $10 \%$, mas, por outro lado, possuem menores reduções de potência com o aumento da temperatura (NATIONAL RENEWABLE ENERGY LABORATORY (NREL), 2014a). Os valores dos coeficientes de temperatura de potência foram obtidos a partir de uma análise estatística de mais de 11.000 módulos fotovoltaicos da base de dados da California Energy Commission (CEC). Essas informações estão sumarizadas na tabela 4.6.

Tabela 4.6 - Parâmetros de entrada do módulo PVWatts.

\begin{tabular}{cccc}
\hline $\begin{array}{c}\text { Tipo de módulo } \\
\text { fotovoltaico }\end{array}$ & Eficiência & $\begin{array}{c}\text { Tipo de } \\
\text { cobertura }\end{array}$ & $\begin{array}{c}\text { Coeficiente de temperatura da } \\
\text { potência }\end{array}$ \\
\hline Padrão & $15 \%$ & Vidro & $-0,47 \% /{ }^{\circ} \mathrm{C}$ \\
Superior & $19 \%$ & Antirreflexiva & $-0,35 \% /{ }^{\circ} \mathrm{C}$ \\
Filme fino & $10 \%$ & Vidro & $-0,20 \% /{ }^{\circ} \mathrm{C}$ \\
\hline
\end{tabular}

Fonte: elaborado a partir de (NATIONAL RENEWABLE ENERGY LABORATORY (NREL), 2014a).

$\mathrm{Na}$ figura 4.4, é mostrada uma comparação do efeito da variação da temperatura na potência do módulo fotovoltaico, para cada uma das tecnologias listadas na tabela 4.6. Verificase que, a partir de $25^{\circ} \mathrm{C}$, os módulos de filme fino apresentam uma menor redução de potência frente às tecnologias de silício cristalino. Do ponto de vista técnico, sem considerar aspectos econômicos ou relacionados à área, os módulos de filme fino, apesar de possuírem uma menor eficiência, podem se mostrar interessantes, sobretudo em regiões mais quentes.

\footnotetext{
${ }^{4}$ Apesar de o vocábulo policristalino ser mais usual no mercado, aqui é adotado o termo técnico multicristalino.
} 
Figura 4.4 - Influência da temperatura na potência de cada tipo de módulo fotovoltaico.

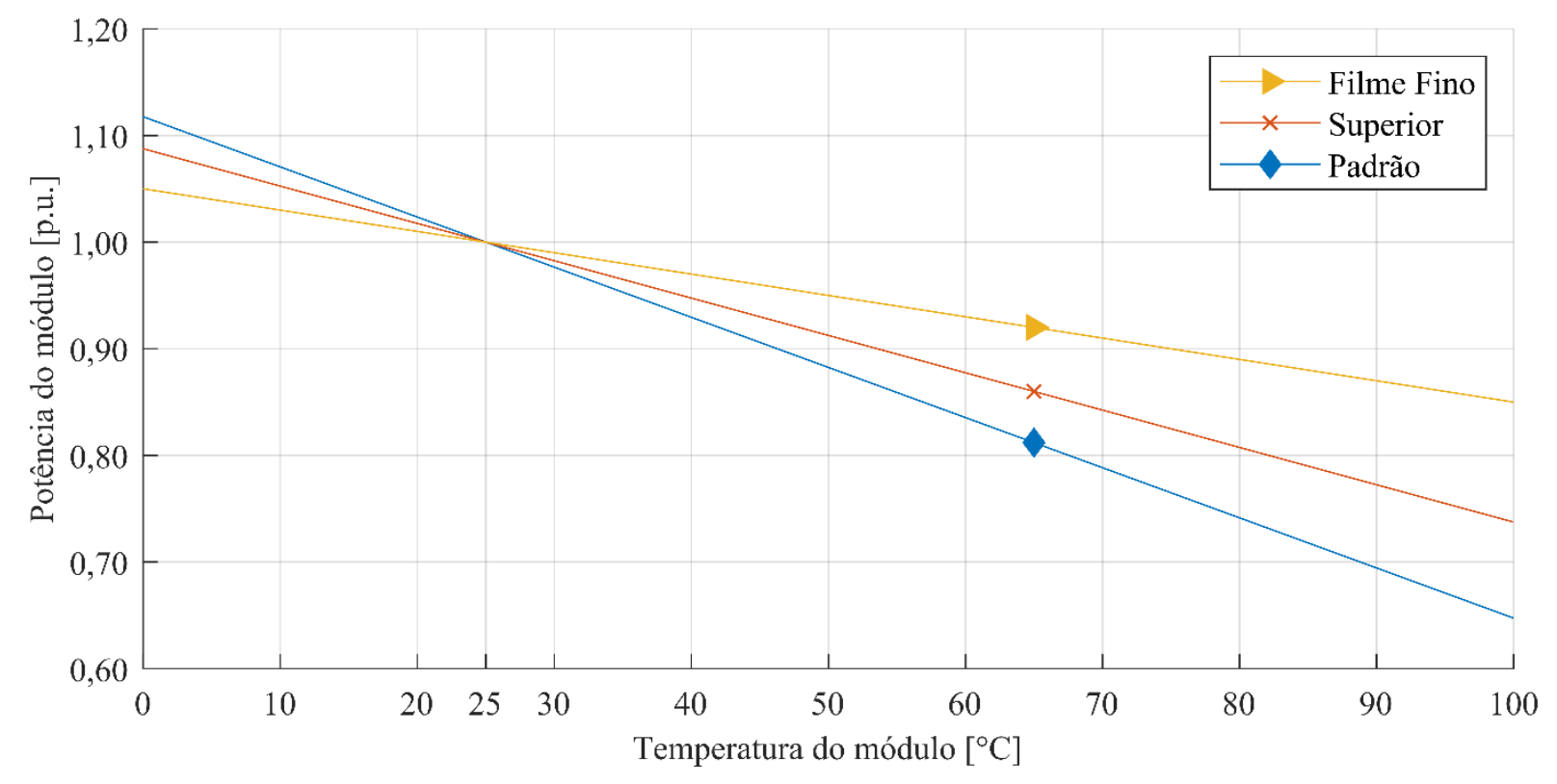

Fonte: elaborado a partir de (NATIONAL RENEWABLE ENERGY LABORATORY (NREL), 2014a).

\subsubsection{Etapas de cálculo}

$\mathrm{Na}$ figura 4.5, é mostrada a representação de um módulo fotovoltaico posicionado em uma orientação arbitrária no solo, com indicação dos ângulos notáveis utilizados em energia solar.

Figura 4.5 - Ângulos notáveis em energia solar.

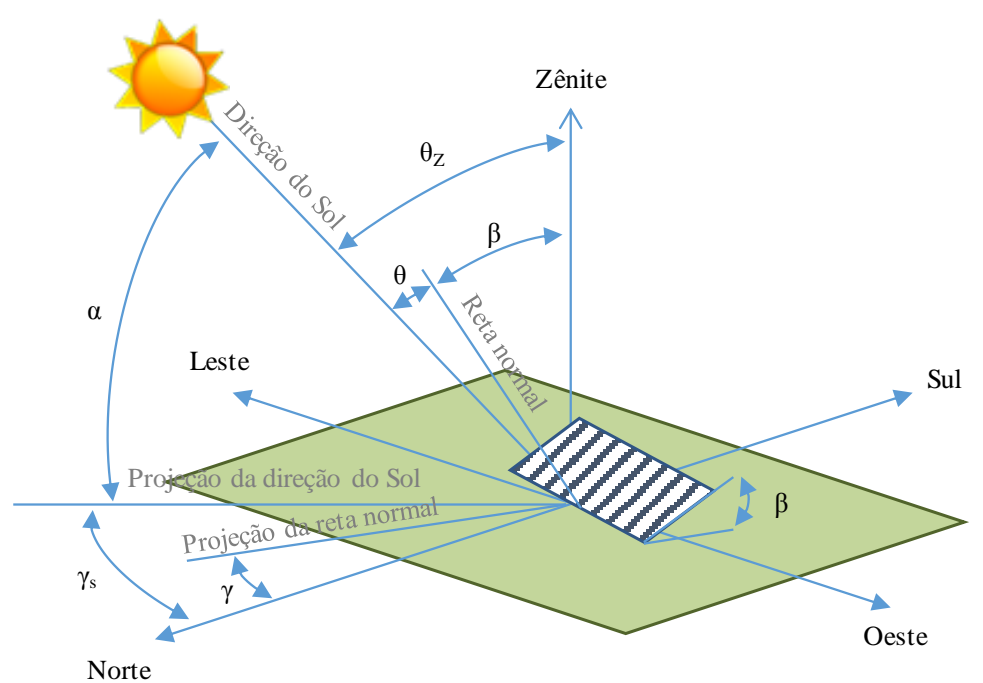

Fonte: elaborado a partir de (ASSOCIAÇÃO BRASILEIRA DE NORMAS TÉCNICAS (ABNT), 2013). 
Para cada uma das estruturas de suporte, é calculado o ângulo de incidência entre o raio solar e a normal ao plano dos módulos fotovoltaicos, utilizando a expressão (4.3) e os dados presentes no arquivo meteorológico.

$$
\cos (\theta)=\cos \left(\theta_{z}\right) \cos (\beta)+\operatorname{sen}\left(\theta_{z}\right) \operatorname{sen}(\beta) \cos \left(\gamma_{s}-\gamma\right)
$$

Para rastreadores solares de um eixo, com ou sem backtracking, são utilizados os algoritmos descritos em (NATIONAL RENEWABLE ENERGY LABORATORY (NREL), 2013) e (NATIONAL RENEWABLE ENERGY LABORATORY (NREL), 2015). No caso de rastreadores solares de dois eixos, o ângulo de incidência é mantido nulo, bastando para isso igualar os ângulos azimutal e de inclinação da superfície aos do Sol.

Em seguida, são calculadas as componentes da irradiância solar incidentes na superfície dos módulos fotovoltaicos para determinar a irradiância total recebida $\left(G_{T O T}\right)$, como indicado na expressão (4.4), utilizando o modelo de transposição de Perez et al. (PEREZ et al., 1990) para o plano com inclinação $\beta$ e azimute $\gamma$. Além das componentes direta $\left(G_{D I R}\right)$, e do albedo $\left(G_{A L B}\right)$, esse modelo é mais detalhado e divide a componente difusa em três partes: isotrópica, circunsolar e do horizonte, que são contabilizadas em $G_{D I F}$. Por padrão, o SAM adota o valor de 0,2 para o albedo, a menos que esteja determinado um valor horário diferente no arquivo meteorológico (NATIONAL RENEWABLE ENERGY LABORATORY (NREL), 2014a).

$$
G_{T O T}=G_{D I R}+G_{D I F}+G_{A L B}
$$

Na sequência, são consideradas as perdas por reflexão, utilizando uma modificação do modelo de transmitância através da cobertura do módulo proposto por (DE SOTO, KLEIN e BECKMAN, 2008). Nesse modelo, são utilizadas a lei de Snell $^{5}$-Descartes ${ }^{6}$ e as equações de Fresnel $^{7}$.

O modelo térmico adotado foi desenvolvido por (SANDIA NATIONAL LABORATORIES, 1987) e leva em consideração a irradiância incidente no plano dos módulos

\footnotetext{
${ }^{5}$ Willebrord Snel van Royen, ou Willebrord Snellius (1580 - 1626), astrônomo e matemático holandês, ficou conhecido pela lei da refração.

${ }^{6}$ René Descartes (1596 - 1650), filósofo, físico e matemático francês, é considerado o fundador da filosofia moderna e pai da matemática moderna. Conhecido também pelo sistema de coordenadas cartesianas e pela frase "penso, logo existo".

${ }^{7}$ Augustin-Jean Fresnel (1788 - 1827), físico e engenheiro francês, propôs relevantes contribuições na teoria da óptica ondulatória. Inventou lentes compactas, conhecidas como lentes de Fresnel e é considerado o fundador da óptica moderna.
} 
fotovoltaicos $\left(G_{T O T}\right)$, a velocidade do vento e a temperatura ambiente de bulbo seco para determinar a temperatura de operação da célula fotovoltaica.

Uma vez determinada a irradiância transmitida efetivamente para as células fotovoltaicas $\left(G_{T O T, T R}\right)$, é então utilizado o modelo de módulo fotovoltaico, o qual considera que a eficiência decresce linearmente com o aumento da temperatura, sendo a potência de saída dada pela expressão (4.5).

$$
P_{c c}=P_{c c 0} \frac{G_{T O T, T R}}{G_{r e f}}\left[1+\gamma_{P}\left(T_{c}-T_{r e f}\right)\right]
$$

As demais perdas não explicitadas nos modelos apresentados são mostradas na tabela 4.7, com os valores adotados como padrão para perdas por sujidade, sombreamento, neve, dispersão de parâmetros, cabeamento, conexões, degradação induzida por luz, potência nominal, envelhecimento e disponibilidade, obtidos a partir de alguns estudos como os de (MARION et al., 2005), (PINGEL et al., 2010) e (NATIONAL RENEWABLE ENERGY LABORATORY (NREL), 2012).

Tabela 4.7 - Perdas no sistema fotovoltaico.

\begin{tabular}{cc}
\hline Perdas & Valor padrão [\%] \\
\hline Sujidade & 2 \\
Sombreamento & 3 \\
Neve & 0 \\
Dispersão de parâmetros & 2 \\
Cabeamento & 2 \\
Conexões & 0,5 \\
Degradação induzida por luz & 1,5 \\
Potência nominal & 1 \\
Envelhecimento & 0 \\
Disponibilidade & 3 \\
\hline
\end{tabular}

Fonte: elaborado a partir de (NATIONAL RENEWABLE ENERGY LABORATORY (NREL), 2014a).

Vale salientar que a perda total não é obtida pela soma das perdas individuais, mas pela redução proporcionada por cada uma das perdas, segundo a expressão (4.6). 


$$
L_{\text {total }}=1-\prod_{i}\left(1-L_{i}\right)
$$

O usuário tem liberdade para atribuir valores individualizados para cada uma das perdas, mas, caso deseje, pode definir o valor da perda total. Com essas perdas, a potência c.c. líquida gerada pelos módulos fotovoltaicos é dada pela expressão (4.7), sendo a mesma potência observada na entrada do inversor.

$$
P_{c c, i n v}=P_{c c}\left(1-L_{t o t a l}\right)
$$

A potência nominal de saída do inversor, $P_{c a 0}$, é determinada levando-se em consideração a potência instalada de módulos fotovoltaicos, $P_{c c 0}$, e o fator de dimensionamento do inversor, FDI, segundo a expressão (4.8).

$$
P_{c a 0}=P_{c c 0} F D I
$$

O usuário define também uma eficiência nominal, $\eta_{\text {nom }}$, para o inversor utilizado, de acordo com a expressão (4.9), que é obtida pela relação entre as potências nominais de saída e de entrada. Caso não tenha o valor exato, pode-se utilizar o valor padrão de 0,96.

$$
\eta_{\text {nom }}=\frac{P_{c a 0}}{P_{c c 0, \text { inv }}}
$$

O modelo de inversor utilizado é baseado em dados de desempenho de inversores fabricados a partir de 2010, obtidos pela CEC. A partir desses dados reais, calcula-se uma curva média de eficiência em função do carregamento, para então selecionar o inversor que possui a curva que mais se aproxima da calculada. Os dados de eficiência são ajustados segundo o modelo quadrático de perdas de (DRIESSE; JAIN, 2008), cuja curva de eficiência resultante é escalonada em relação à eficiência nominal do inversor, $\eta_{\text {nom }}$. Assim, conforme a expressão (4.10), calcula-se uma eficiência horária do inversor, $\eta$, para cada um dos valores da potência c.c. gerada pelos módulos fotovoltaicos já considerando as perdas envolvidas, $P_{c c, i n v}$, com base em uma eficiência de referência, $\eta_{r e f}$, de 0,9637 e na potência nominal do inversor, $P_{c a 0}$, calculada previamente pela expressão (4.8) (NATIONAL RENEWABLE ENERGY LABORATORY (NREL), 2014a). 


$$
\eta=\frac{\eta_{\text {nom }}}{\eta_{\text {ref }}}\left(-0,0162 \frac{\eta_{\text {nom }} P_{c c, i n v}}{P_{c a 0}}-0,0059 \frac{P_{c a 0}}{\eta_{\text {nom }} P_{c c, i n v}}+0,9858\right)
$$

Dessa maneira, a potência injetada na rede pelo sistema fotovoltaico, $P_{c a}$, é dada pela expressão (4.11). Juntamente com a figura 4.6, é possível verificar a limitação de potência imposta pelo inversor quando a potência disponível na entrada for maior que a sua nominal de entrada. O gráfico foi normalizado, e, portanto, a potência c.a. representa a relação da potência de saída do inversor e a sua nominal, enquanto o carregamento c.c. indica a relação entre a potência de entrada do inversor e a sua máxima admitida na entrada.

$$
P_{c a}=\left\{\begin{array}{cl}
0 & \text {, se } P_{c c, i n v}=0 \\
\eta P_{c c, i n v} & \text {, se } 0<P_{c c, i n v}<P_{c c 0, i n v} \\
P_{c a 0} & \text {, se } P_{c c, i n v} \geq P_{c c 0, i n v}
\end{array}\right.
$$

Figura 4.6 - Curva de potência em relação ao carregamento.

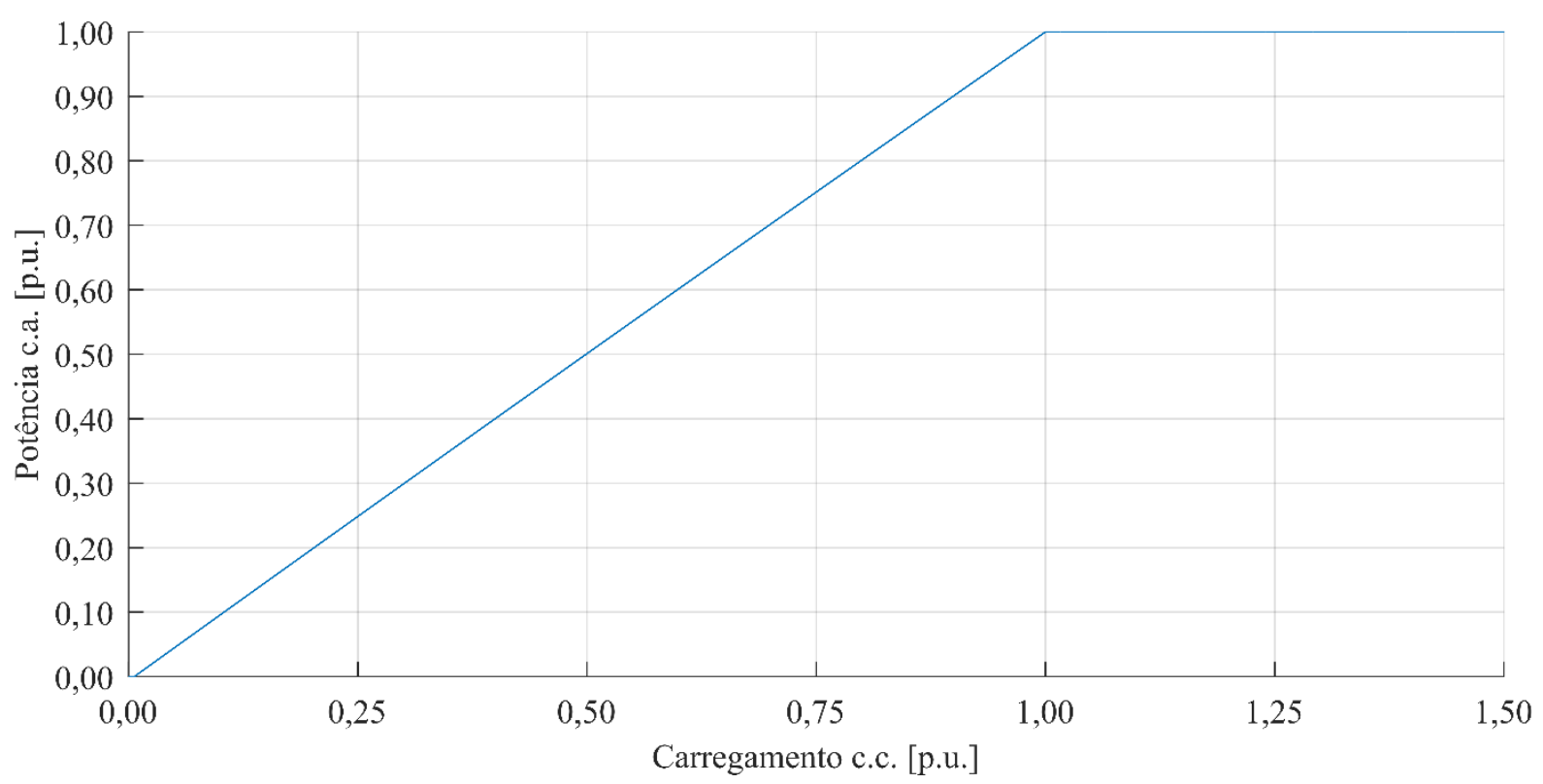

Fonte: elaborado a partir de (NATIONAL RENEWABLE ENERGY LABORATORY (NREL), 2014a).

$\mathrm{Na}$ figura 4.7, são apresentadas curvas de eficiência em função do respectivo carregamento c.c.. Cabe ressaltar que o carregamento c.c. unitário denota que a potência líquida gerada pelos módulos fotovoltaicos é numericamente igual à potência máxima de entrada admitida por aquele inversor. A partir desse ponto de carregamento, verifica-se a redução da eficiência imposta pela limitação de potência. As curvas foram elaboradas tomando como base 
uma mesma potência nominal para os inversores, diferindo-os em relação à eficiência nominal, o que implica potências máximas de entrada também diferentes.

Figura 4.7 - Curvas de eficiência em relação ao carregamento para diferentes eficiências nominais.

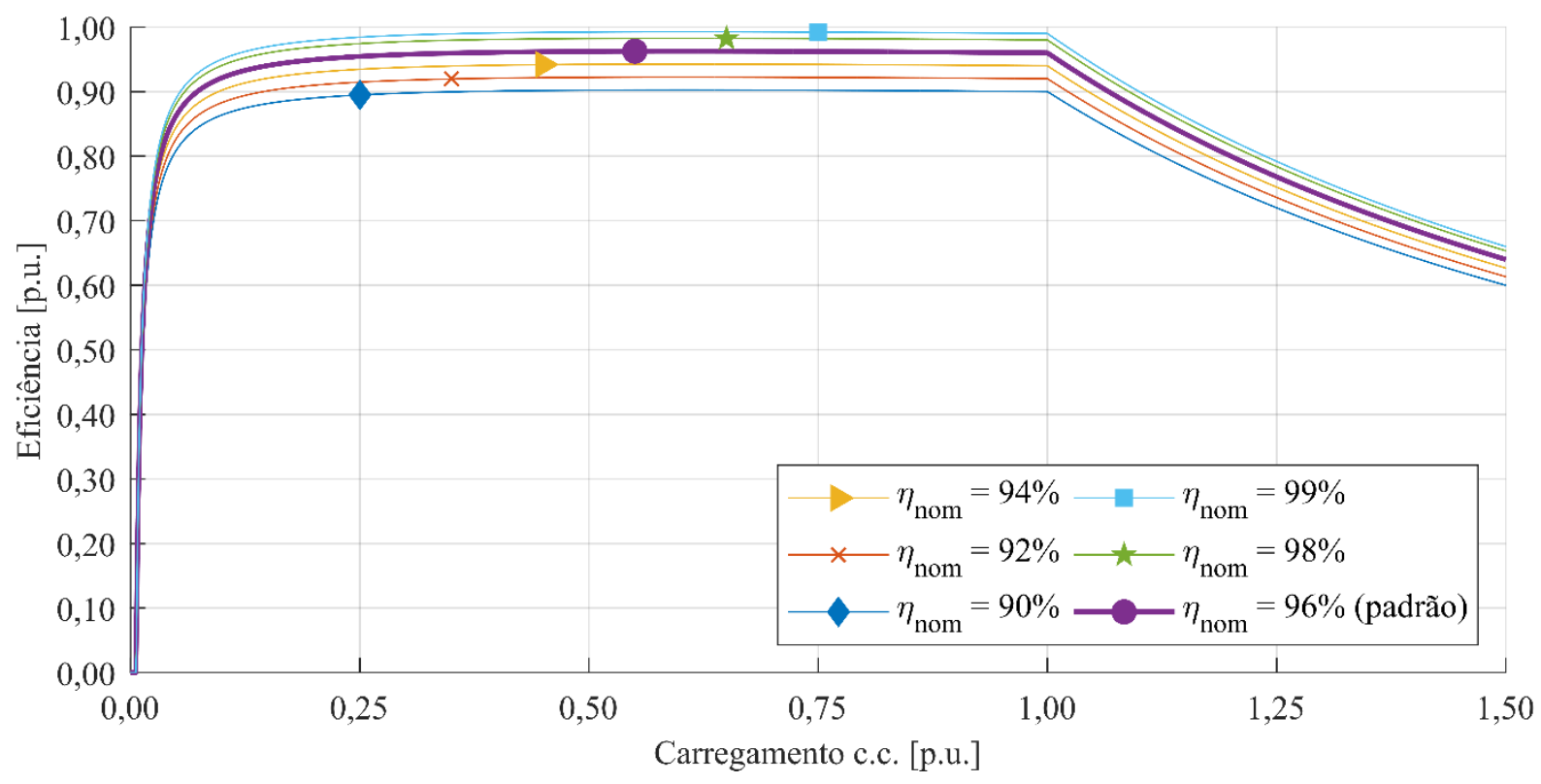

Fonte: elaborado a partir de (NATIONAL RENEWABLE ENERGY LABORATORY (NREL), 2014a).

Com o intuito de facilitar a compreensão do processo de conversão fotovoltaica descrito, na figura 4.8, é apresentado o diagrama de blocos, contendo o arranjo fotovoltaico e o inversor, além das perdas envolvidas e a indicação das principais variáveis relacionadas no processo.

Figura 4.8 - Diagrama de blocos da conversão fotovoltaica.

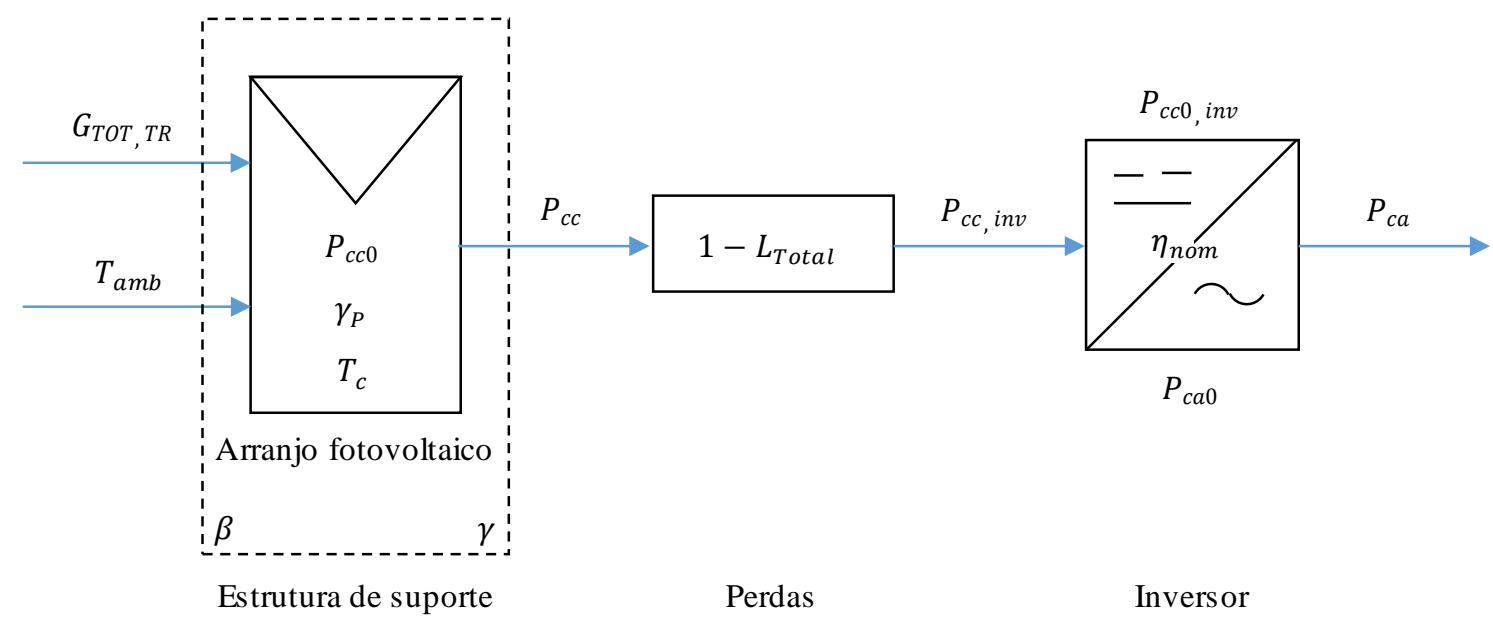

Fonte: elaborado a partir de (NATIONAL RENEWABLE ENERGY LABORATORY (NREL), 2014a). 
Com o objetivo de verificar a acurácia do modelo computacional, na figura 4.9, é mostrada uma comparação entre os resultados horários de simulação obtidos pelas versões 1 e 5 do módulo PVWatts e dados medidos de um sistema fotovoltaico com módulos de silício cristalino montados em estrutura fixa em solo, localizado no estado do Colorado, nos Estados Unidos. Visualmente, é possível constatar a boa aderência dos dados simulados aos medidos, com destaque para a versão 5 do módulo PVWatts, que incorporou melhorias à versão 1 , de modo a melhorar o desempenho do modelo computacional de simulação.

Figura 4.9 - Comparação horária entre dados de simulação e medidos.

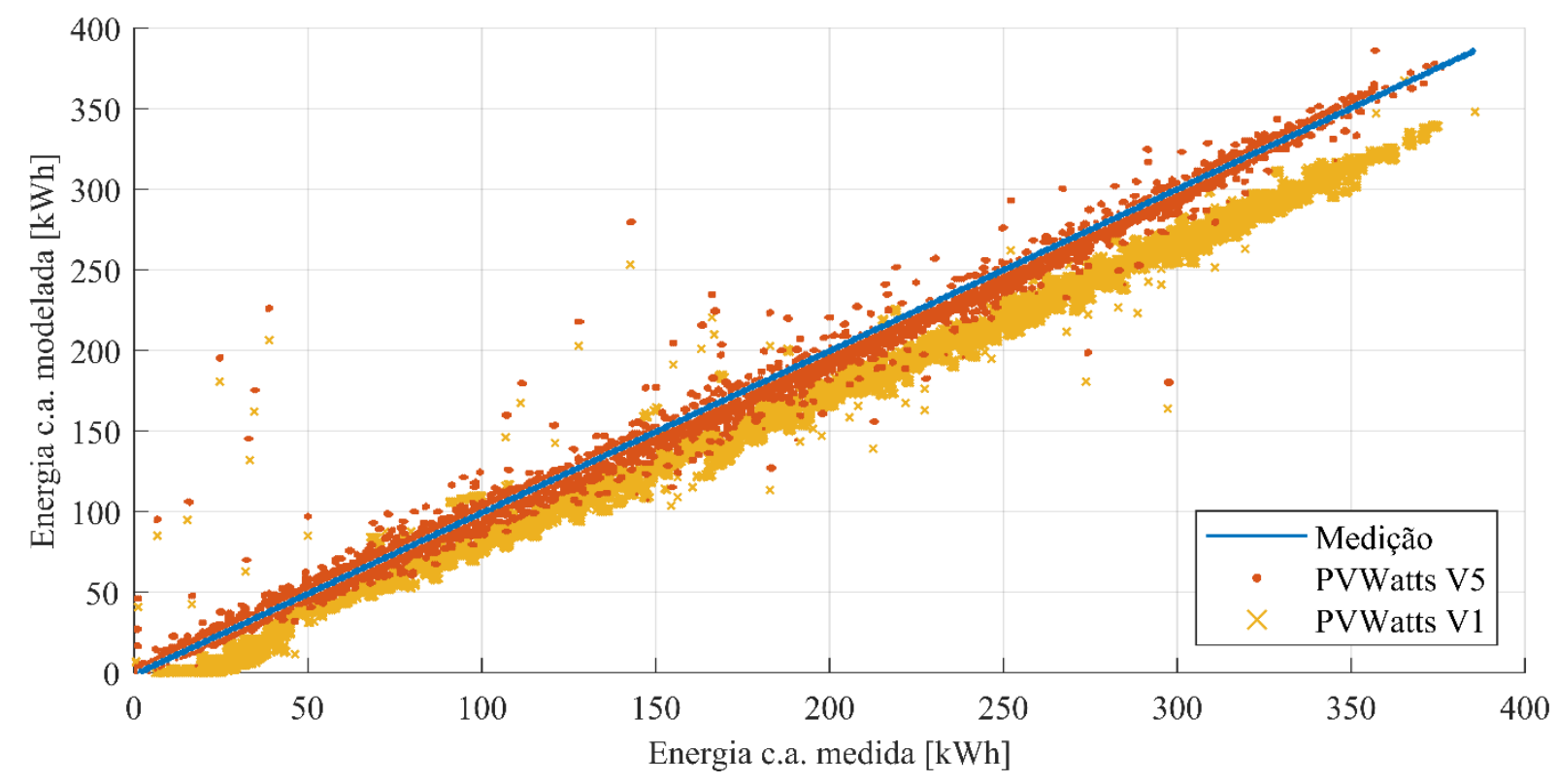

Fonte: elaborado a partir de (NATIONAL RENEWABLE ENERGY LABORATORY (NREL), 2014a).

As métricas estatísticas, erro médio, erro absoluto médio, erro quadrático médio e erro quadrático médio normalizado, calculadas respectivamente pelas expressões (4.12), (4.13), (4.14) e (4.15), podem ser observadas na tabela 4.8, juntamente com a equação da regressão linear. O erro quadrático médio normalizado apresentado pela versão 1 é de 7,63 \%, ao passo que o da versão 5 é de 4,64 \%, demonstrando a melhoria realizada entre os modelos.

$$
\begin{gathered}
E M=\frac{1}{N} \sum_{i=1}^{N} B_{i}-A_{i} \\
E A M=\frac{1}{N} \sum_{i=1}^{N}\left|B_{i}-A_{i}\right|
\end{gathered}
$$




$$
\begin{gathered}
E Q M=\sqrt{\frac{1}{N} \sum_{i=1}^{N}\left(B_{i}-A_{i}\right)^{2}} \\
E Q M N=\sqrt{\frac{1}{N} \sum_{i=1}^{N}\left(\frac{B_{i}-A_{i}}{\max (A)-\min (A)}\right)^{2}}
\end{gathered}
$$

Tabela 4.8 - Comparação das métricas estatísticas das versões do módulo PVWatts.

\begin{tabular}{cccccc}
\hline Módulo & Regressão linear & EM [kWh] & EAM [kWh] & EQM [kWh] & EQMN [\%] \\
\hline PVWatts V1 & $y=0,93 x-12,88$ & $-27,24$ & 27,91 & 29,44 & 7,63 \\
PVWatts V5 & $y=0,96 x+3,93$ & $-2,69$ & 11,25 & 17,93 & 4,64 \\
\hline
\end{tabular}

Fonte: elaborado a partir de (NATIONAL RENEWABLE ENERGY LABORATORY (NREL), 2014a).

Algumas comparações foram realizadas pelo NREL com nove sistemas fotovoltaicos, sendo sete com módulos de silício cristalino e dois com módulos de telureto de cádmio. Os resultados medidos foram comparados com os obtidos por simulações utilizando as versões $1 \mathrm{e}$ 5 do PVWatts, como indicado na figura 4.10. É possível verificar uma melhoria significativa no desempenho das simulações com o aprimoramento da versão um 1 para a 5. Nesse caso, o desvio médio passou de $-11,9 \%$ para $-1,8 \%$ entre a energia anual simulada e medida para os sistemas fotovoltaicos estudados (NATIONAL RENEWABLE ENERGY LABORATORY (NREL), 2014a). 
Figura 4.10 - Comparação anual entre dados de simulação e medidos.

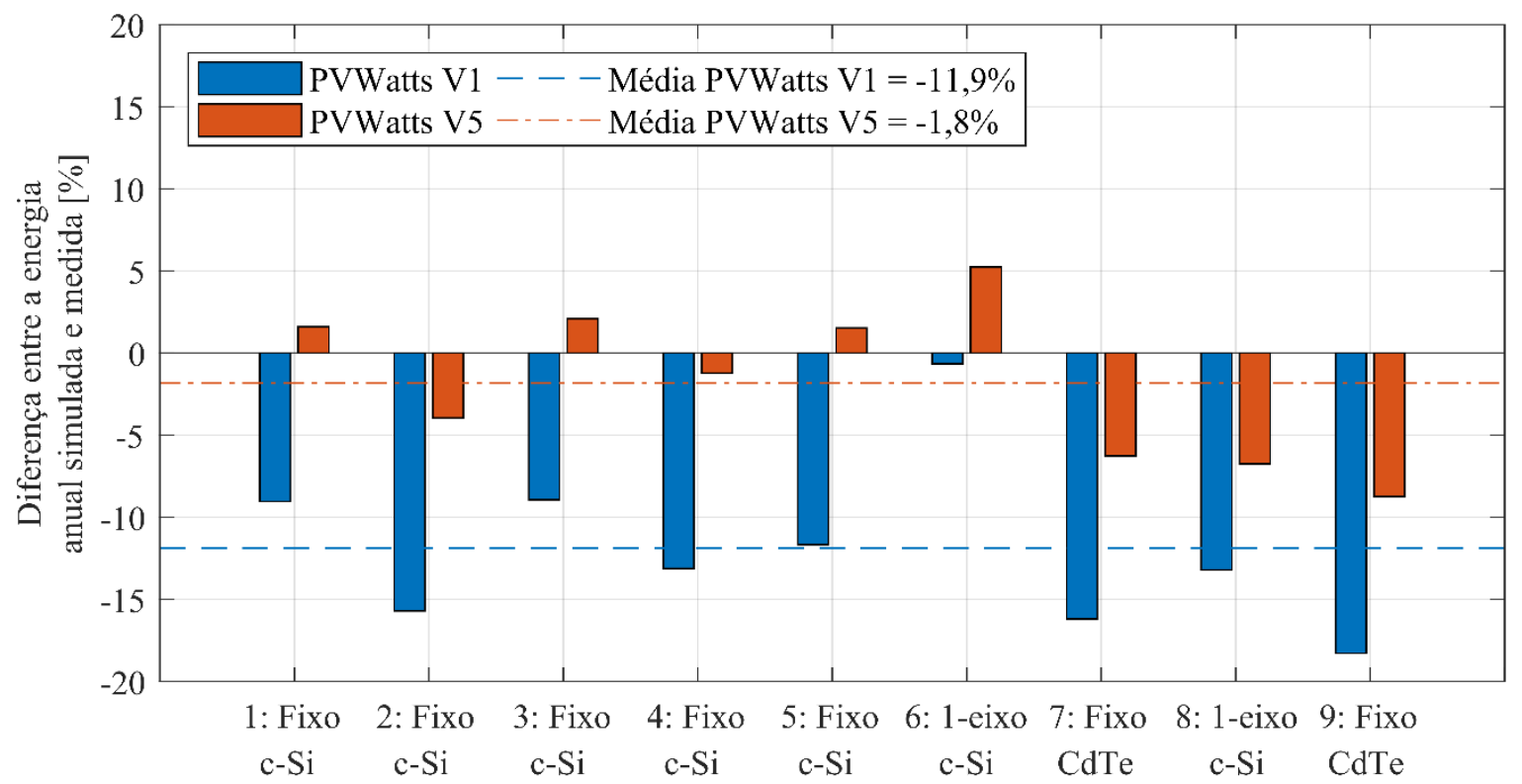

Fonte: elaborado a partir de (NATIONAL RENEWABLE ENERGY LABORATORY (NREL), 2014a).

\subsubsection{Influência das variáveis}

Para verificar a influência que cada uma das variáveis meteorológicas apresentadas na tabela 4.4 exerce na energia elétrica gerada por um sistema fotovoltaico, foram realizadas algumas simulações em que as grandezas foram modificadas isoladamente, coeteris paribus, sem levar em consideração, portanto, o efeito que alterações em uma variável podem exercer nas demais.

Primeiramente, realizou-se a aquisição dos arquivos dos anos meteorológicos típicos das nove capitais do Nordeste. Em seguida, isoladamente para cada uma das cinco variáveis, aplicou-se um mesmo fator multiplicativo para os 8.760 valores horários da grandeza em questão, sendo os fatores variados de zero a 1,5 com incremento de 0,1. Dessa maneira, por exemplo, para a cidade de Fortaleza/CE, foram produzidos 16 arquivos meteorológicos com modificações na irradiância direta, mantendo as demais variáveis inalteradas, idênticas aos valores contidos no respectivo arquivo original. $\mathrm{O}$ mesmo procedimento foi executado para as demais variáveis e para as outras cidades, totalizando 720 arquivos meteorológicos gerados.

Na sequência, simulou-se uma usina fotovoltaica genérica, com módulos montados em estruturas fixas em solo ${ }^{8}$, com azimute nulo e inclinação de $10^{\circ}$, para cada um dos três tipos de

\footnotetext{
${ }^{8}$ As estruturas fixas em solo são doravante denominadas simplesmente por estruturas fixas.
} 
módulos fotovoltaicos apresentados na tabela 4.6, o que resultou em 2.160 simulações. Para cada combinação de cidade e tipo de módulo, os resultados dos fatores de capacidade obtidos foram dispostos em tabelas, como a tabela 4.9.

Tabela 4.9 - Resultado genérico da simulações para cada combinação de cidade e tipo de módulo.

\begin{tabular}{clllll}
\hline $\begin{array}{c}\text { Fator } \\
\text { multiplicativo }\end{array}$ & $G_{D I R}$ & $G_{D I F}$ & Temperatura & $\begin{array}{c}\text { Velocidade do } \\
\text { vento }\end{array}$ & Albedo \\
\hline 0,0 & $F C_{1,1}$ & $F C_{1,2}$ & $F C_{1,3}$ & $F C_{1,4}$ & $F C_{1,5}$ \\
0,1 & $F C_{2,1}$ & $F C_{2,2}$ & $F C_{2,3}$ & $F C_{2,4}$ & $F C_{2,5}$ \\
0,2 & $F C_{3,1}$ & $F C_{3,2}$ & $F C_{3,3}$ & $F C_{3,4}$ & $F C_{3,5}$ \\
0,3 & $F C_{4,1}$ & $F C_{4,2}$ & $F C_{4,3}$ & $F C_{4,4}$ & $F C_{4,5}$ \\
0,4 & $F C_{5,1}$ & $F C_{5,2}$ & $F C_{5,3}$ & $F C_{5,4}$ & $F C_{5,5}$ \\
0,5 & $F C_{6,1}$ & $F C_{6,2}$ & $F C_{6,3}$ & $F C_{6,4}$ & $F C_{6,5}$ \\
0,6 & $F C_{7,1}$ & $F C_{7,2}$ & $F C_{7,3}$ & $F C_{7,4}$ & $F C_{7,5}$ \\
0,7 & $F C_{8,1}$ & $F C_{8,2}$ & $F C_{8,3}$ & $F C_{8,4}$ & $F C_{8,5}$ \\
0,8 & $F C_{9,1}$ & $F C_{9,2}$ & $F C_{9,3}$ & $F C_{9,4}$ & $F C_{9,5}$ \\
0,9 & $F C_{10,1}$ & $F C_{10,2}$ & $F C_{10,3}$ & $F C_{10,4}$ & $F C_{10,5}$ \\
1,0 & $F C_{11,1}$ & $F C_{11,2}$ & $F C_{11,3}$ & $F C_{11,4}$ & $F C_{11,5}$ \\
1,1 & $F C_{12,1}$ & $F C_{12,2}$ & $F C_{12,3}$ & $F C_{12,4}$ & $F C_{12,5}$ \\
1,2 & $F C_{13,1}$ & $F C_{13,2}$ & $F C_{13,3}$ & $F C_{13,4}$ & $F C_{13,5}$ \\
1,3 & $F C_{14,1}$ & $F C_{14,2}$ & $F C_{14,3}$ & $F C_{14,4}$ & $F C_{14,5}$ \\
1,4 & $F C_{15,1}$ & $F C_{15,2}$ & $F C_{15,3}$ & $F C_{15,4}$ & $F C_{15,5}$ \\
1,5 & $F C_{16,1}$ & $F C_{16,2}$ & $F C_{16,3}$ & $F C_{16,4}$ & $F C_{16,5}$ \\
\hline
\end{tabular}

Para cada umas das variáveis, os valores dos fatores de capacidade foram normalizados em relação à condição original, com fator multiplicativo unitário, segundo a expressão (4.16), para então serem traçados os gráficos de sensibilidade.

$$
\overline{F C_{l, j}}=\frac{F C_{i, j}}{F C_{11, j}}
$$

Adicionalmente, apesar de o sistema fotovoltaico não ser puramente linear, determinaram-se os polinômios interpoladores de primeiro grau apenas como forma qualitativa de estimar o efeito dessas variáveis na saída do sistema. A derivada de primeira ordem de cada equação representa a taxa de variação do fator de capacidade em relação à variável analisada e é descrita como sendo o coeficiente angular da reta, cujo módulo pode ser considerado um 
indicativo da sensibilidade da saída em relação à entrada. A norma dos resíduos da regressão linear, $\|r\|$, é proporcional ao erro quadrático médio e simboliza o desvio ao se utilizar essa equação para representar aquele conjunto de pontos.

Na figura 4.11, é apresentada a influência da variação da irradiância direta no fator de capacidade, de forma normalizada em relação à condição original. Cabe destacar que, como não foram observadas mudanças significativas ao modificar a cidade e ao variar a tecnologia do módulo fotovoltaico, o gráfico foi gerado com apenas uma das combinações, de modo a deixá-lo mais limpo, sem necessitar de identificação para a linha. Pela interpretação do gráfico, é possível verificar que uma redução de 50 \% na irradiância direta tende a gerar uma redução de aproximadamente $25 \%$ no fator de capacidade.

Figura 4.11 - Influência da variação da irradiância direta no fator de capacidade.

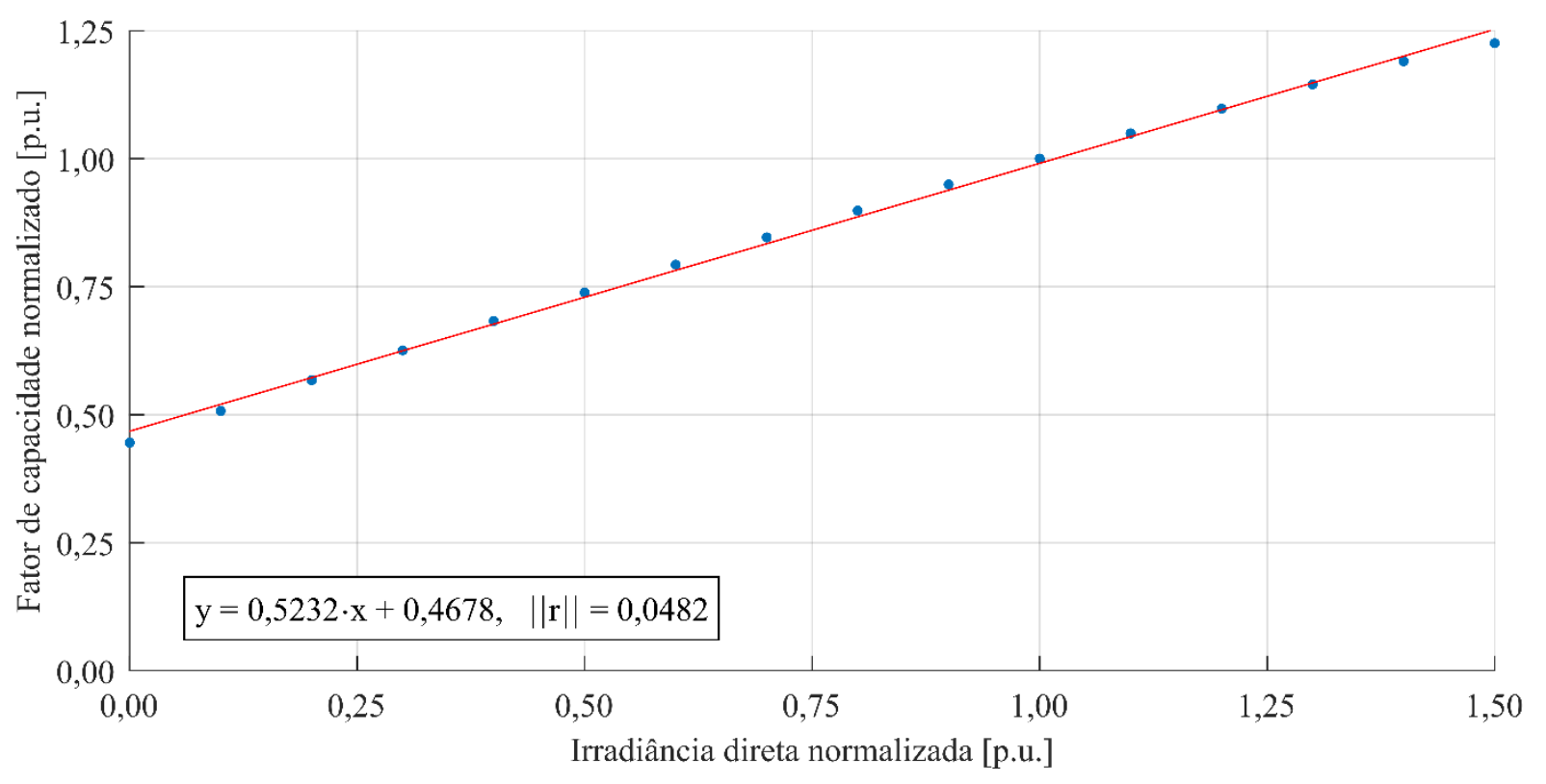

Fonte: elaborado a partir de (NATIONAL RENEWABLE ENERGY LABORATORY (NREL), 2018b).

Analogamente, o efeito no fator de capacidade causado pela variação da irradiância difusa é retratado no gráfico da figura 4.12, de onde se observa que o módulo do coeficiente angular é menor que o da figura 4.11, denotando uma menor influência da irradiância difusa em relação à direta na saída do sistema. 
Figura 4.12 - Influência da variação da irradiância difusa no fator de capacidade.

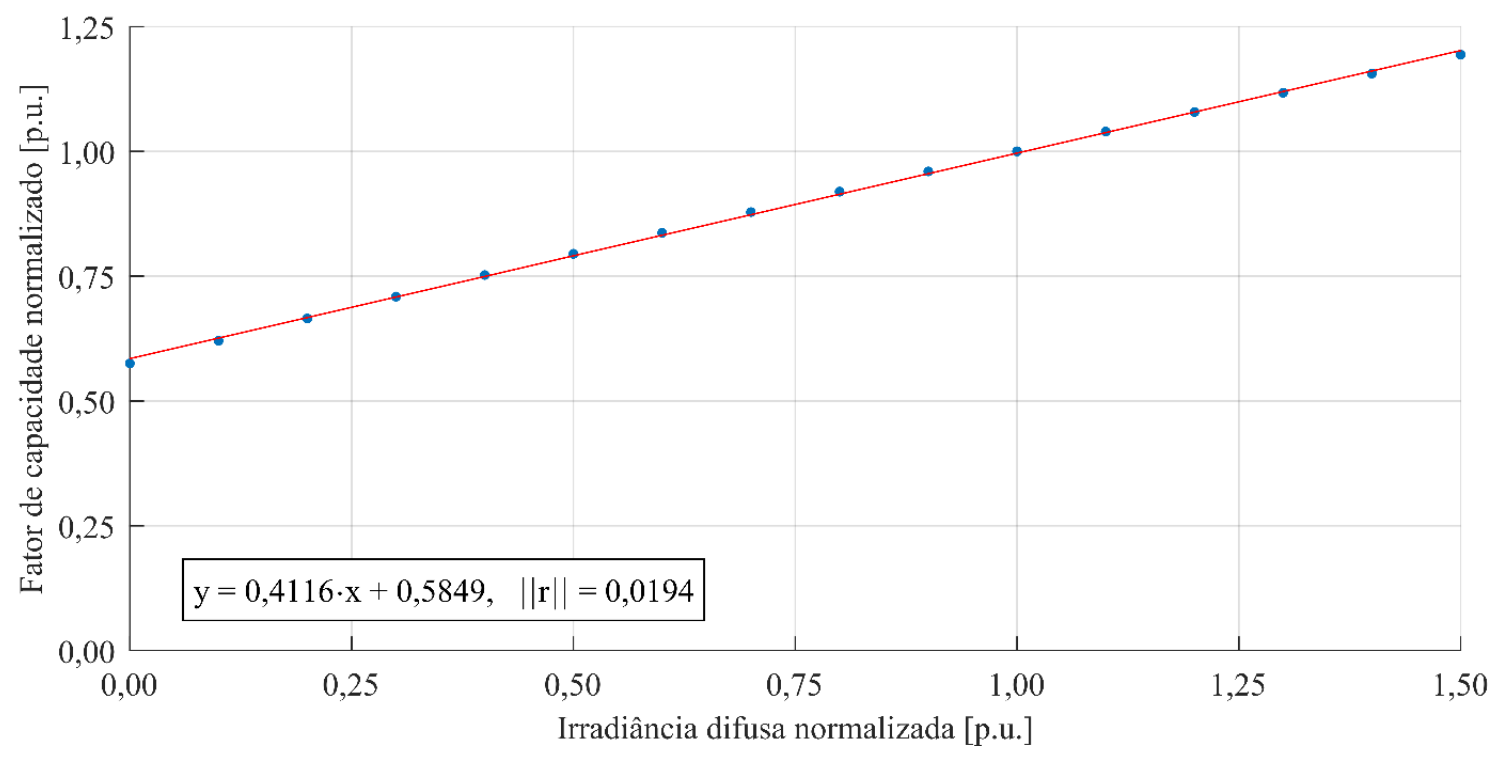

Fonte: elaborado a partir de (NATIONAL RENEWABLE ENERGY LABORATORY (NREL), 2018b).

O efeito da variação da velocidade do vento no fator de capacidade pode ser visto na figura 4.13. Verifica-se, pelo módulo do coeficiente angular da reta, que a saída do sistema é pouco sensível a modificações dessa entrada. Por exemplo, uma redução de $100 \%$ na velocidade do vento proporciona um decréscimo de aproximadamente $3 \%$ no fator de capacidade.

Figura 4.13 - Influência da variação da velocidade do vento no fator de capacidade.

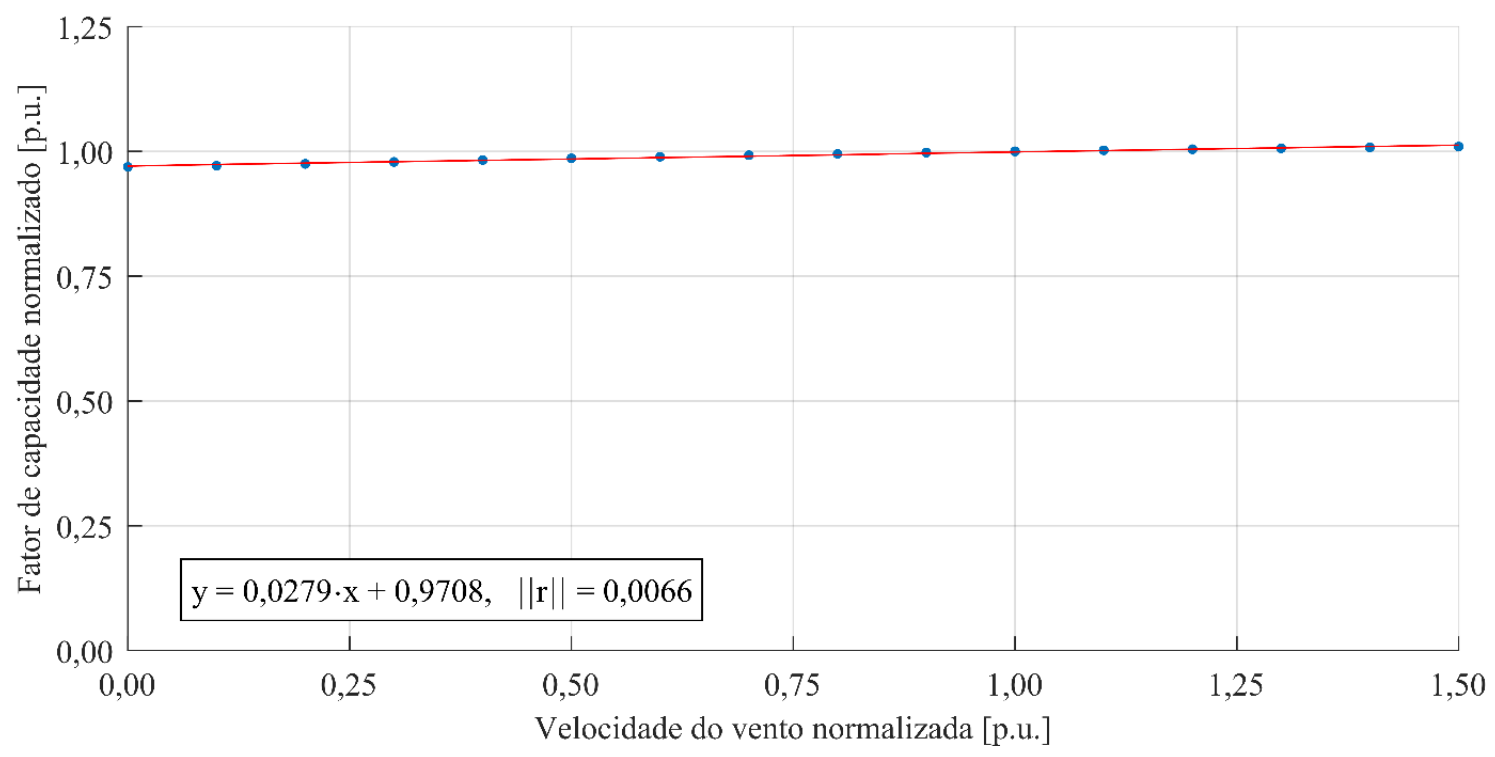

Fonte: elaborado a partir de (NATIONAL RENEWABLE ENERGY LABORATORY (NREL), 2018b). 
No que diz respeito à sensibilidade do fator de capacidade em relação à temperatura, foram observadas diferenças entre as tecnologias dos módulos fotovoltaicos e comportamentos opostos aos verificados com as irradiâncias e com a velocidade do vento, conforme ilustrado na figura 4.14. Um aumento nessa variável provoca reduções no fator de capacidade, sendo esse fato mais pronunciado para módulos do tipo padrão. Para um aumento de $50 \%$ na temperatura, os decréscimos observados foram de aproximadamente $7 \%, 5 \%$ e $3 \%$, para os módulos do tipo padrão, superior e filme fino, respectivamente.

Figura 4.14 - Influência da variação da temperatura ambiente no fator de capacidade.

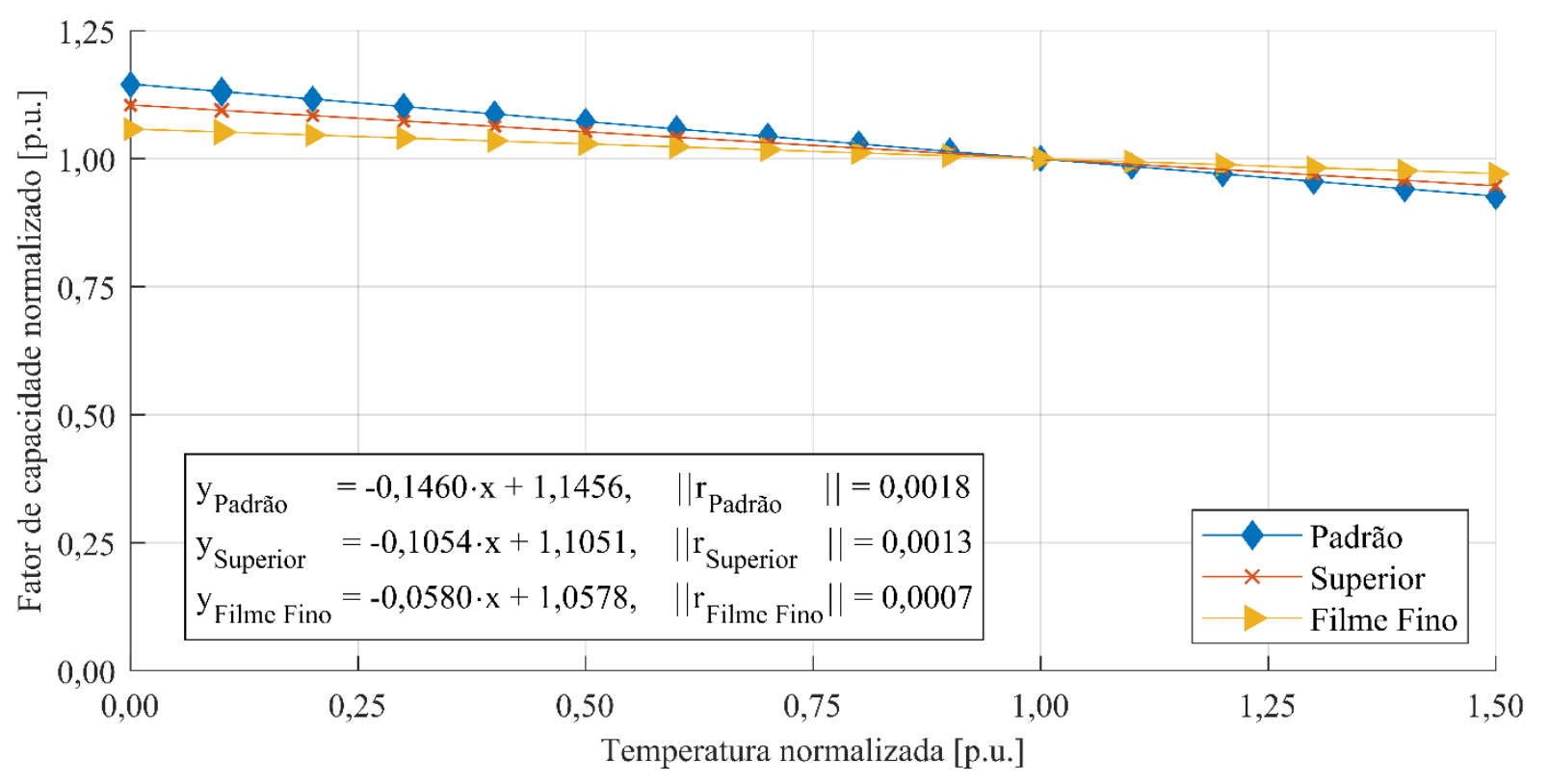

Fonte: elaborado a partir de (NATIONAL RENEWABLE ENERGY LABORATORY (NREL), 2018b).

Já para o albedo, o comportamento observado é diferente dos verificados com as demais variáveis, como apresentado na figura 4.15. Constata-se que, qualquer que seja a variação no albedo, o fator de capacidade permanece praticamente inalterado. Poder-se-ia argumentar que, como os módulos encontram-se pouco inclinados, com $10^{\circ}$, esse efeito não seria muito pronunciado. Nesse sentido, foram realizadas também simulações variando a inclinação dos módulos fotovoltaicos até $30^{\circ}$, mantidas constantes as perdas por sombreamento, não sendo observadas, entretanto, mudanças significativas na influência da variação do albedo no fator de capacidade. 
Figura 4.15 - Influência da variação do albedo no fator de capacidade.

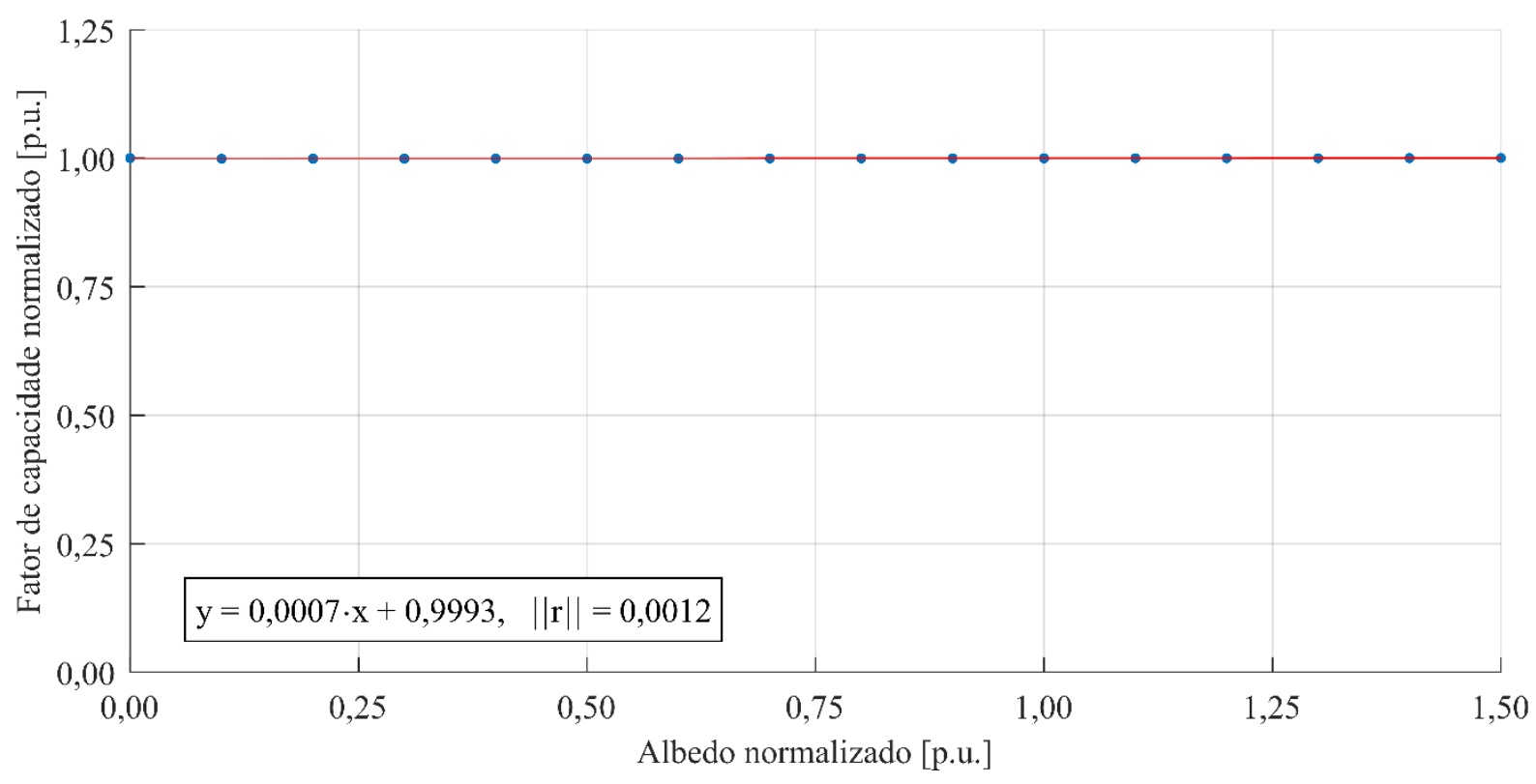

Fonte: elaborado a partir de (NATIONAL RENEWABLE ENERGY LABORATORY (NREL), 2018b).

\subsection{Simulações computacionais}

Nesta etapa, realizou-se a aquisição dos arquivos climáticos de anos meteorológicos típicos para a região continental do Nordeste brasileiro, utilizando uma resolução espacial de $10 \mathrm{~km}$ por $10 \mathrm{~km}$, a partir do NSRDB PSM (versão 3). Cada arquivo possui dados horários de irradiâncias global horizontal, direta normal e difusa horizontal, além de temperatura de bulbo seco, velocidade do vento e albedo de superfície.

Em seguida, realizou-se a conformação de uma usina fotovoltaica típica, para cada uma das diferentes configurações, levando em consideração os modelos típicos das principais tecnologias de módulos comercialmente disponíveis, diferentes níveis de carregamento de inversores e tipos de estruturas de suporte com ou sem rastreamento solar. Para isso, foram utilizadas as bases de dados disponíveis no SAM, oriundas de valores médios obtidos nas folhas de dados dos fabricantes de módulos e inversores ou modeladas pelo Sandia National Laboratory.

A partir dos dados de entrada e das diversas configurações estudadas, esses foram tratados por meio do ambiente MATLAB (versão R2018a) e utilizados como insumos para a simulação no SAM (versão 2017.9.5), executada em segundo plano, através do SSC SDK (versão 2017.1.17). Os resultados foram retornados ao MATLAB para posterior consolidação e análise. O diagrama da metodologia utilizada pode ser visto na figura 4.16. 
Figura 4.16 - Diagrama de blocos da metodologia.

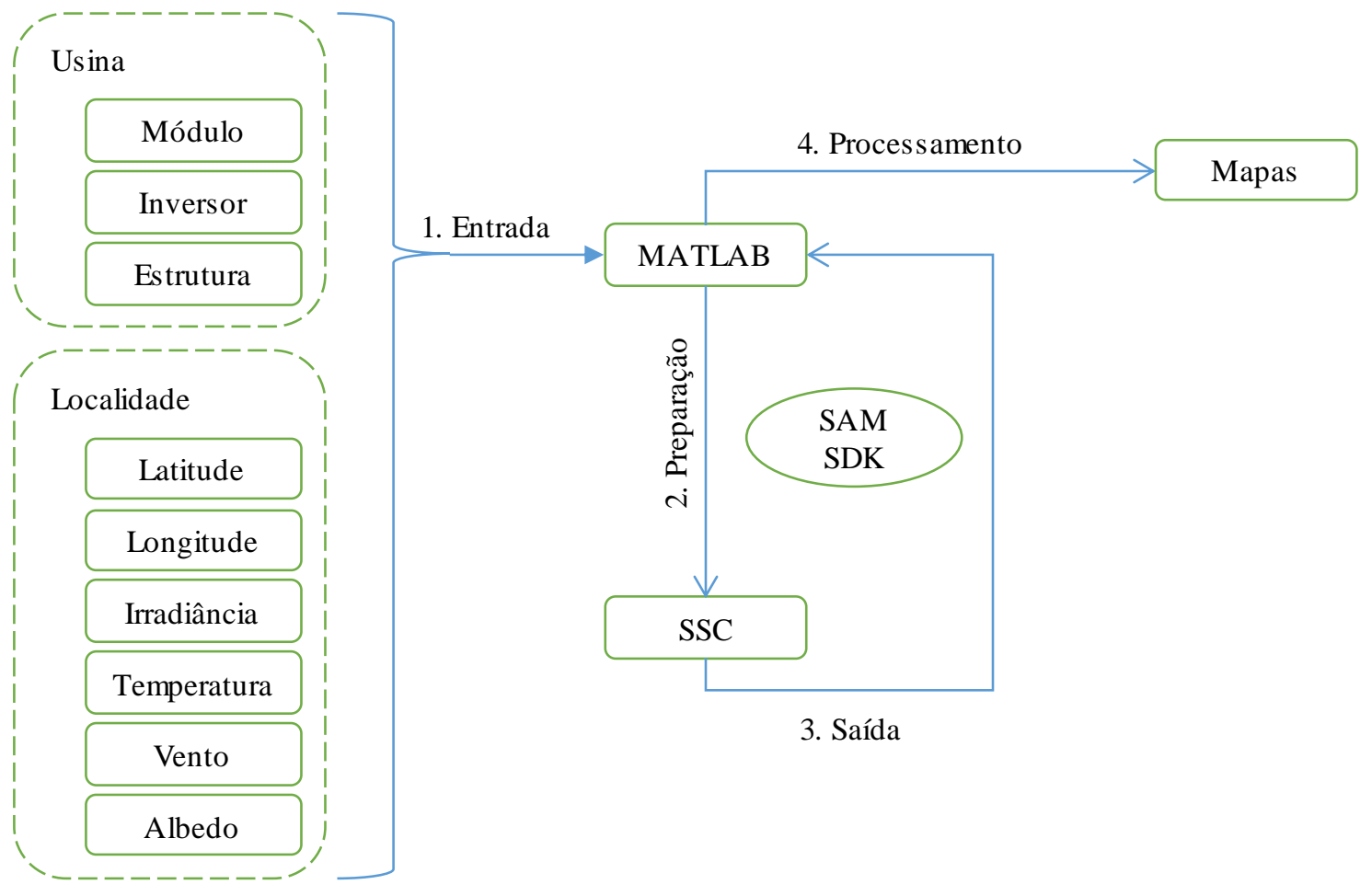

\subsection{Forma de análise dos resultados}

Os resultados, após o processamento dos dados e realização das simulações computacionais, são apresentados em formas de mapas, elaborados no QGIS (versão 2.18.20). São mostrados os fatores de capacidade c.a., agrupados por faixas de categorias, para cada um dos pontos do Nordeste brasileiro. Caso se deseje saber os valores de $Y_{f}$, basta utilizar as expressões (3.4), (3.5) e (3.6). Na figura 4.17, pode ser observado um mapa de parte do Brasil, com destaque para os estados do Nordeste, onde são efetuadas as simulações. 
Figura 4.17 - Mapa da região Nordeste do Brasil.

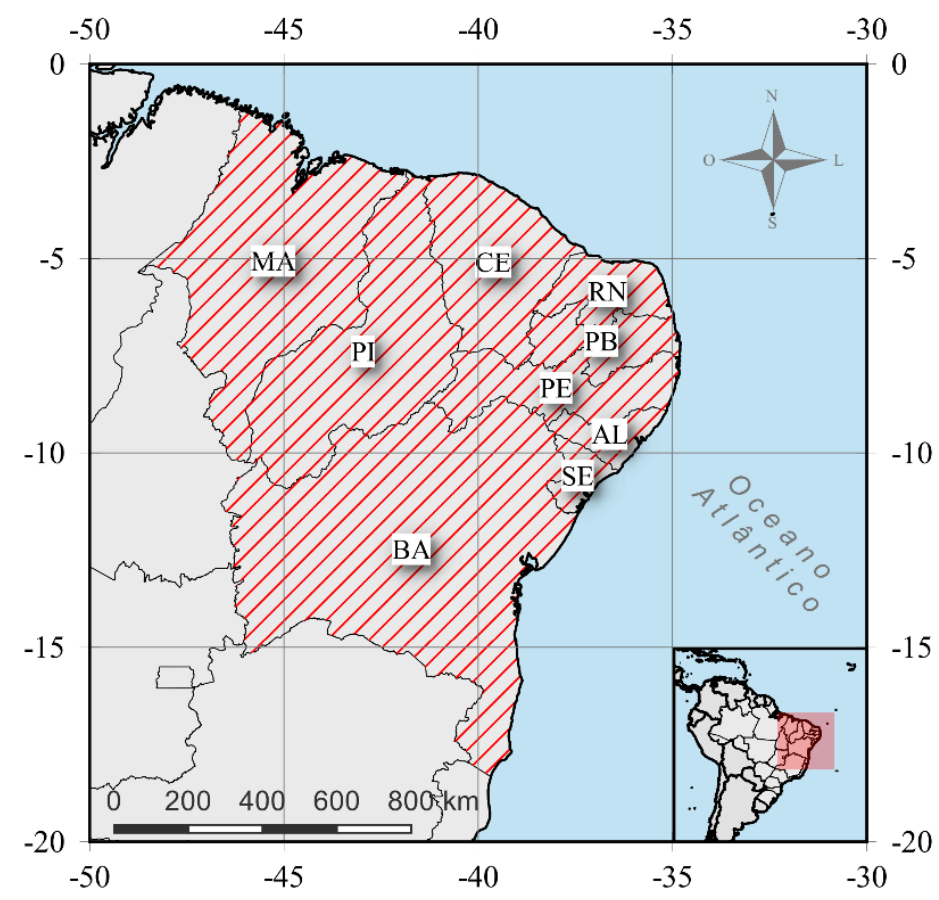

Fonte: elaborado a partir de (INSTITUTO BRASILEIRO DE GEOGRAFIA E ESTATÍSTICA (IBGE), 2018).

Os resultados permitem fazer comparações entre as principais tecnologias de módulos fotovoltaicos disponíveis no mercado e algumas estruturas de suporte com ou sem rastreamento solar. Com isso, é possível verificar geograficamente as faixas dos fatores de capacidade de cada uma das configurações e quais apresentam melhores resultados. Quanto aos diferentes níveis de carregamento de inversores, a comparação é feita previamente e determinado um FDI para as usinas simuladas. 


\section{RESULTADOS}

Nesta seção, são apresentados e discutidos os resultados das simulações computacionais realizadas. É importante salientar que, para efeitos comparativos, utilizou-se a mesma escala de cor para as diferentes simulações, e, portanto, alguns mapas podem não possuir todas as faixas de fatores de capacidade apresentadas na legenda.

\subsection{Estrutura fixa}

No SAM, através do editor gráfico de cenas tridimensionais, foi construída uma usina fotovoltaica genérica, com módulos fotovoltaicos montados em estruturas fixas e inclinados no valor absoluto da latitude do local, com mínimo de $10^{\circ}$ graus $^{9}$, representando um bloco de potência de $1 \mathrm{MW}$ de uma usina de maior porte. As coordenadas geográficas e os espaçamentos entre os arranjos fotovoltaicos foram variados, tendo sido elaborados mais de 130 mil arquivos de sombras para o Nordeste, utilizando a metodologia de sombreamento linear (DELINE et al., 2013). Esses arquivos foram levados em consideração para redução da irradiância incidente no plano dos módulos fotovoltaicos, de forma a ser contabilizada no cálculo do fator de capacidade das usinas fixas simuladas (NATIONAL RENEWABLE ENERGY LABORATORY (NREL), 2018b).

$\mathrm{Na}$ figura 5.1, é apresentada a variação do fator de capacidade relativo em função do índice de cobertura do terreno, para sistemas fotovoltaicos fixos, com indicação dos valores mínimos e máximos, além da faixa de variação. Para cada ICT, foi calculado o FC relativo dos pontos do Nordeste, tendo como base os respectivos valores de FC quando o ICT tende a zero. Nesse caso, para um ICT de 0,40 , as reduções nos FC foram de até $0,5 \%$, quando comparados à condição hipotética de espaçamento infinito entre os arranjos fotovoltaicos.

\footnotetext{
${ }^{9}$ A partir desse ponto, os sistemas fotovoltaicos com módulos montados em estruturas fixas e inclinados no valor absoluto da latitude do local, com mínimo de $10^{\circ}$ graus, são denominados simplesmente por sistemas fotovoltaicos fixos e têm azimute nulo.
} 
Figura 5.1 - Fatores de capacidade normalizados de sistemas fotovoltaicos fixos em função do ICT.

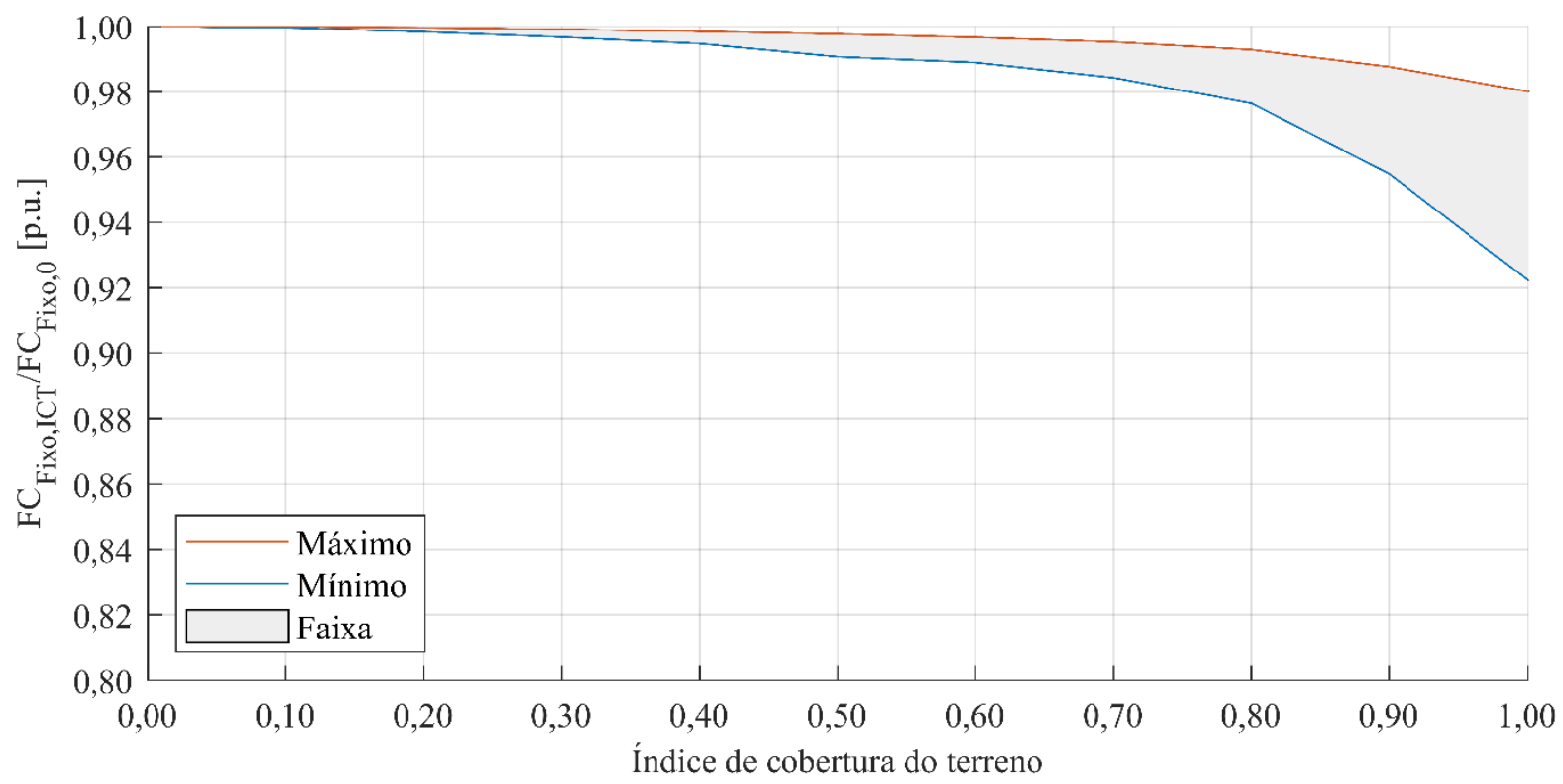

Fonte: elaborado a partir de (NATIONAL RENEWABLE ENERGY LABORATORY (NREL), 2018b).

É importante lembrar que esses pontos se situam em zonas tropicais de baixas latitudes absolutas, nas quais o Sol possui maiores elevações já nas primeiras horas da manhã e nas últimas da tarde ao longo do ano inteiro, quando comparado com locais de maiores latitudes absolutas. Isso possibilita uma maior compactação de sistemas fotovoltaicos fixos, sem que o efeito do sombreamento mútuo cause redução significativa no fator de capacidade.

\subsection{Rastreador solar de um eixo horizontal}

Análise semelhante foi realizada com usinas que utilizam rastreadores solares de um eixo horizontal com e sem backtracking, tendo sido verificada a relação entre os fatores de capacidade, como mostrada na figura 5.2. O gráfico foi obtido a partir de simulações para os pontos do Nordeste e nele estão indicados os valores máximos e mínimos da relação para cada ICT. Por exemplo, para um ICT de 0,80, o uso do backtracking proporcionou ganhos de 1,0\% a 5,0 \% no fator de capacidade, a depender da localidade do ponto simulado. Já para um ICT de 0,40, os ganhos são praticamente desprezíveis, chegando ao valor máximo de 0,6\%.

É possível constatar que o backtracking possui um efeito mais pronunciado para maiores compactações da usina, pois tende a reduzir o sombreamento mútuo entre os arranjos fotovoltaicos adjacentes, sobretudo em baixas elevações do Sol, através da mudança no ângulo de rastreamento. 
Figura 5.2 - Relação entre os fatores de capacidade de sistemas fotovoltaicos montados em rastreadores solares de um eixo horizontal com e sem backtracking em função do ICT.

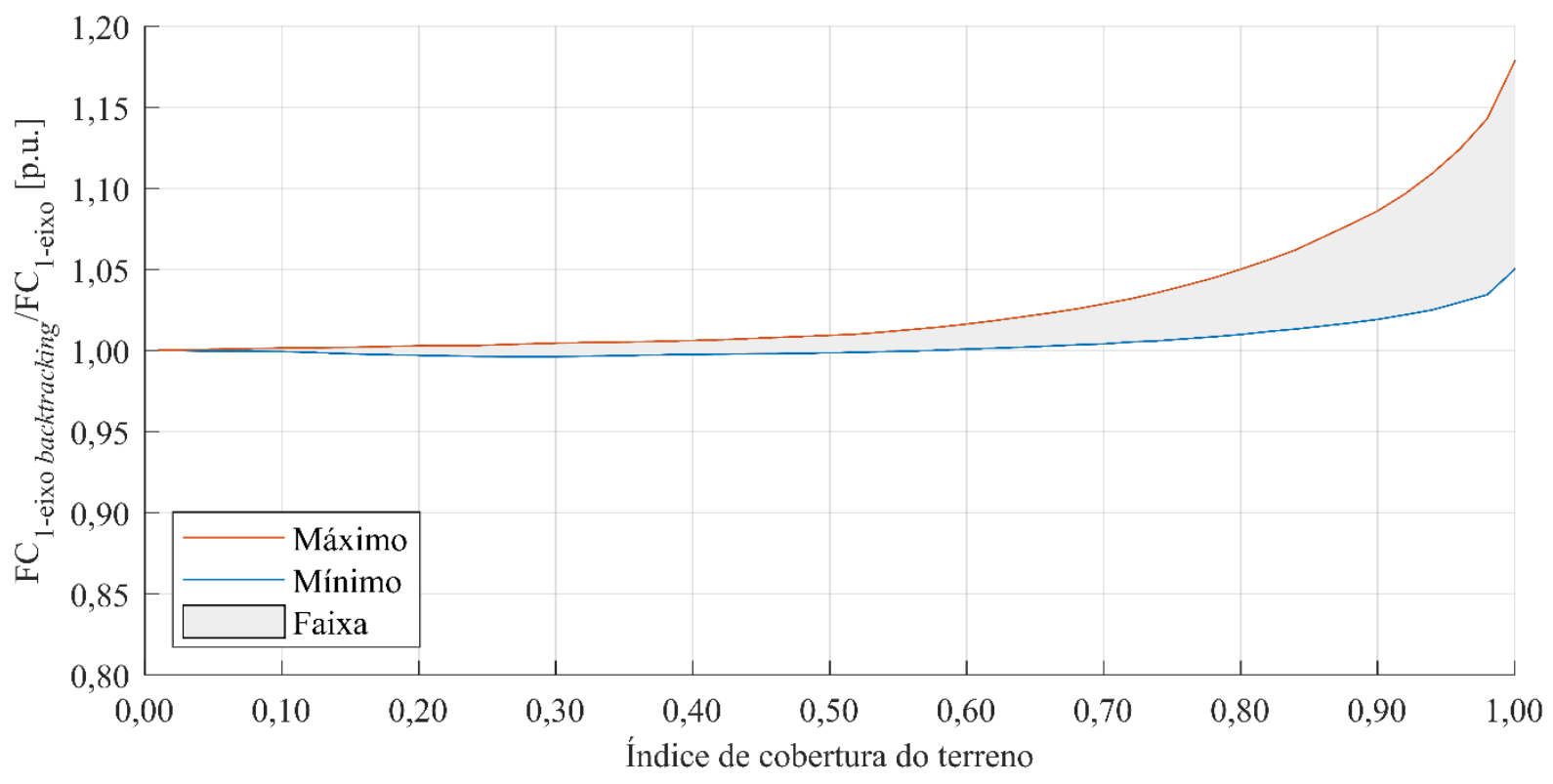

Fonte: elaborado a partir de (NATIONAL RENEWABLE ENERGY LABORATORY (NREL), 2018b).

Cabe ressaltar, no entanto, que isso não significa que sistemas com maiores ICT possuem maiores fatores capacidade. Pelo contrário, na figura 5.3, é mostrada a faixa de variação do fator de capacidade normalizado de um sistema fotovoltaico montado em rastreadores solares de um eixo horizontal com backtracking em função do ICT. Os valores para cada localidade foram normalizados em relação aos respectivos fatores de capacidade quando o ICT tende a zero.

Nessa situação, por exemplo, os sistemas fotovoltaicos com ICT de 0,40 teriam um fator de capacidade de 2,3 \% a 4,4 \% menor em relação à condição teórica de espaçamento infinito entre os rastreadores solares. Quando o ICT se aproxima de 1,00, o sistema fotovoltaico tende a se comportar como um sistema fixo horizontal, sem rastreamento solar, pois uma pequena mudança no ângulo de rastreamento é capaz provocar sombreamento mútuo entre os arranjos. 
Figura 5.3 - Fatores de capacidade normalizados de sistemas fotovoltaicos montados em rastreadores solares de um eixo horizontal com backtracking em função do ICT.

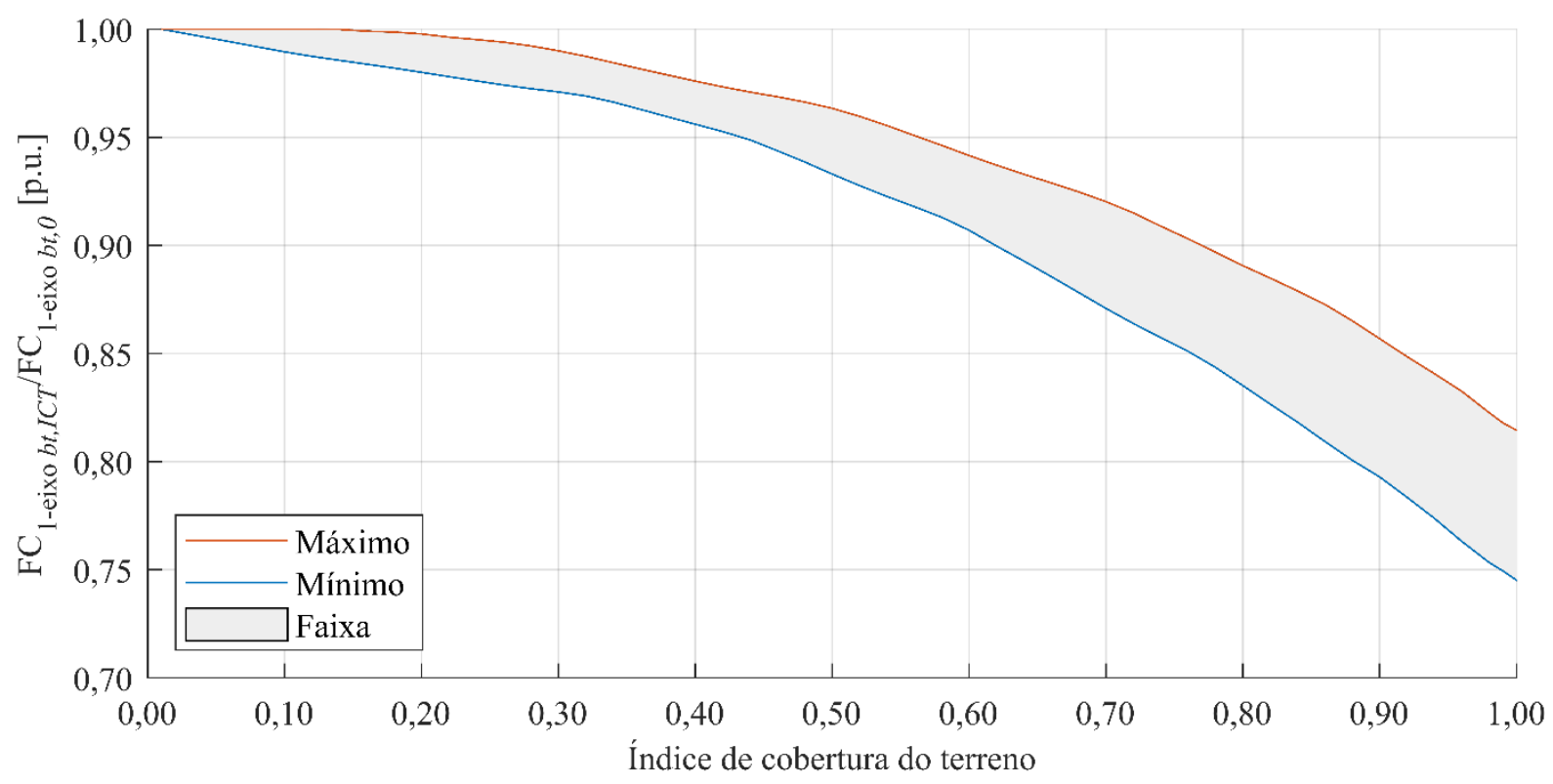

Fonte: elaborado a partir de (NATIONAL RENEWABLE ENERGY LABORATORY (NREL), 2018b).

Como praticamente não há diferenças construtivas e de custos entre rastreadores solares com e sem backtracking, serão adotados por padrão nas simulações os com backtracking ${ }^{10}$, pois esse algoritmo já está consagrado e bem difundido no meio fotovoltaico, sendo de implementação relativamente simples e fácil nos controladores dos rastreadores solares, praticamente sem custos adicionais.

\subsection{Comparação entre estruturas fixas e rastreadores solares de um eixo}

$\mathrm{Na}$ figura 5.4 é apresentada uma relação entre os fatores de capacidade de sistemas fotovoltaicos montados em rastreadores solares de um eixo e em estruturas fixas, em função do ICT, sendo possível observar os limites mínimo e máximo, além da faixa de variação. Para um ICT de 0,4, os ganhos nos fatores de capacidade proporcionados pelo emprego de rastreadores solares variaram de $18 \%$ a $28 \%$.

\footnotetext{
${ }^{10}$ Por questões de simplificação, os rastreadores solares de um eixo horizontal com backtracking serão doravante denominados aqui simplesmente por rastreador solar de um eixo.
} 
Figura 5.4 - Relação entre os fatores de capacidade de sistemas fotovoltaicos montados em rastreadores solares de um eixo e em estruturas fixas, em função do ICT.

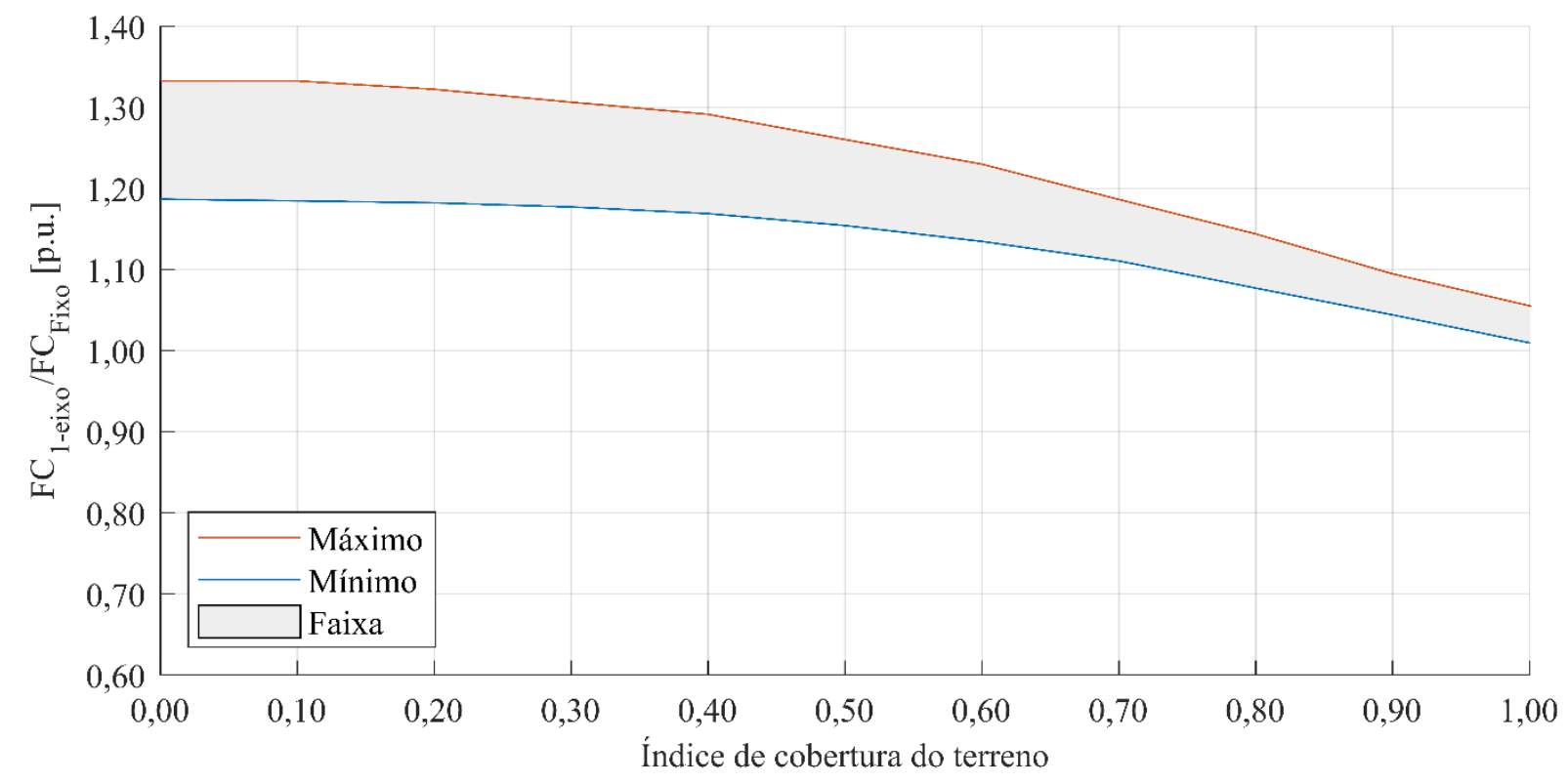

Fonte: elaborado a partir de (NATIONAL RENEWABLE ENERGY LABORATORY (NREL), 2018b).

Para ICT próximos de 1,00, são observados que os valores das relações entre os fatores de capacidade são superiores a 1,00, o que denota que os sistemas fixos inclinados são mais afetados pelo sombreamento mútuo. Conforme visto na seção 5.2, isso ocorre, para esses casos, pois os rastreadores solares tendem a se comportar como um sistema fixo horizontal quando o espaçamento entre os arranjos fotovoltaicos tende à zero.

\subsection{Fator de dimensionamento do inversor}

$\mathrm{Na}$ figura 5.5, é apresentado o efeito relativo do FDI na energia elétrica anual gerada por sistemas fotovoltaicos montados em rastreadores solares de um eixo, com indicação dos valores mínimos e máximos, além da faixa de variação. Para cada FDI, foi calculada a energia elétrica injetada na rede para os pontos do Nordeste. Em seguida, os resultados para cada localidade foram normalizados em relação aos respectivos valores de $E_{c a}$ para um FDI unitário. Nesse caso, a depender da localização, um sistema fotovoltaico com FDI de 0,60 gera de $87 \%$ a $98 \%$ da energia elétrica que seria possível gerar se não houvesse limitação de potência por parte do inversor. Vale ressaltar que essa é uma curva teórica, onde se admite que o inversor pode suportar quaisquer valores de corrente e de tensão de entrada, mesmo para baixos FDI. 
Figura 5.5 - Geração anual de energia elétrica normalizada de sistemas fotovoltaicos em função do FDI.

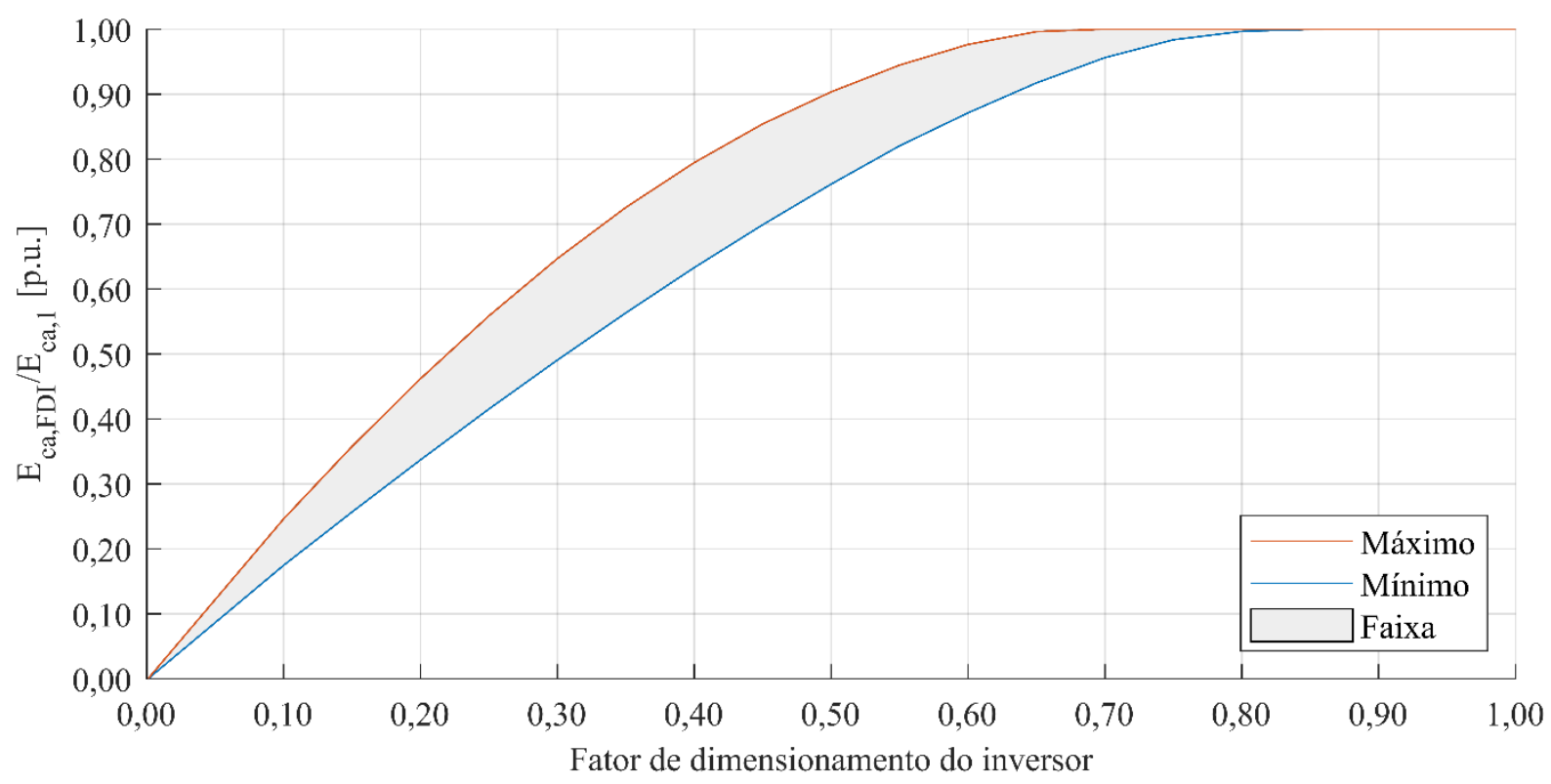

Fonte: elaborado a partir de (NATIONAL RENEWABLE ENERGY LABORATORY (NREL), 2018b).

É possível verificar que, a partir de um FDI de 0,75, não são observadas reduções significativas na energia elétrica anual gerada por esses sistemas. Cabe destacar ainda que tal fato foi constatado também para sistemas fixos. Dessa maneira, foi adotado um valor de 0,75 para o FDI nas simulações apresentadas nas seções 5.5, 5.6 e 5.7.

\subsection{Módulos do tipo padrão}

\subsubsection{Estrutura fixa}

$\mathrm{Na}$ figura 5.6, é mostrado o mapa com o fator de capacidade para um sistema fotovoltaico fixo, com módulos do tipo padrão, ICT de 0,4 e FDI de 0,75. Nessa simulação, os valores dos fatores de capacidade estão compreendidos entre $20,1 \%$ e $27,4 \%$, sendo os menores situados no noroeste do Maranhão e em parte do sudeste da Bahia, e os maiores, basicamente, encontram-se em alguns pontos dos estados Ceará, Rio Grande do Norte, Paraíba, Pernambuco e Bahia. A maior parte do Nordeste, 67,6\% do território, possui fatores de capacidade maiores que $24 \%$, sendo esses valores observados em pelo menos uma região de cada um dos nove estados. 
Figura 5.6 - Fator de capacidade para um sistema fotovoltaico fixo, com módulos do tipo padrão, ICT de 0,4 e FDI de 0,75 .

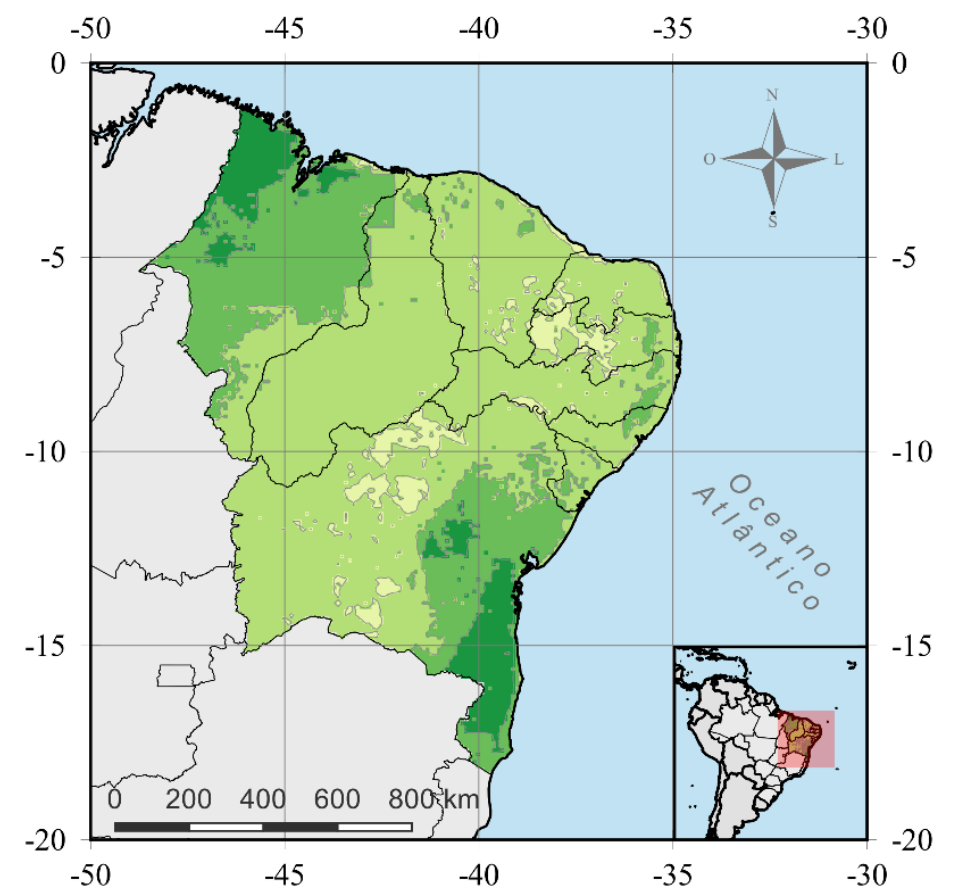

Montagem: estrutura fixa Módulo: padrão

ICT: 0,4

FDI: 0,75

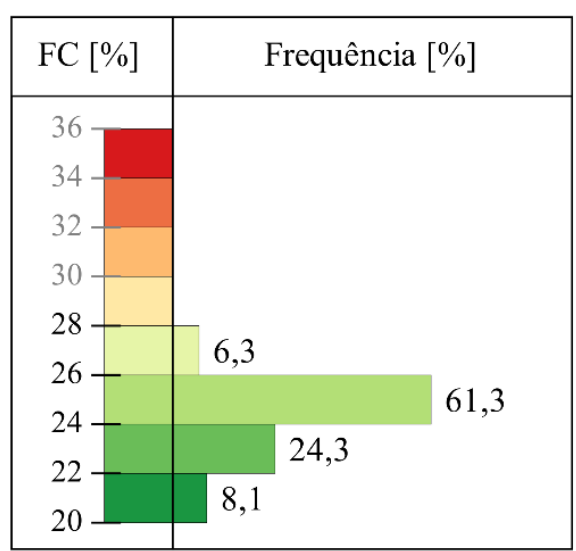

Fonte: elaborado a partir de (NATIONAL RENEWABLE ENERGY LABORATORY (NREL), $2018 \mathrm{~b})$.

\subsubsection{Rastreador solar de um eixo}

Os resultados do fator de capacidade de um sistema fotovoltaico com módulos do tipo padrão, montados em rastreadores solares de um eixo, ICT de 0,4 e FDI de 0,75 são observados na figura 5.7. Os fatores de capacidade observados variam de $24,2 \%$ a $34,5 \%$, sendo que $61,2 \%$ dos valores são maiores que $30 \%$. Cabe destacar que, por utilizar o mesmo tipo de módulo e possuir o mesmo ICT do sistema fixo, esses ocupam a mesma área de terreno, o que demonstra, de forma geral, o ganho obtido na energia elétrica gerada por se empregar rastreadores solares. 
Figura 5.7 - Fator de capacidade para um sistema fotovoltaico com módulos do tipo padrão, montados em rastreadores solares de um eixo, ICT de 0,4 e FDI de 0,75.

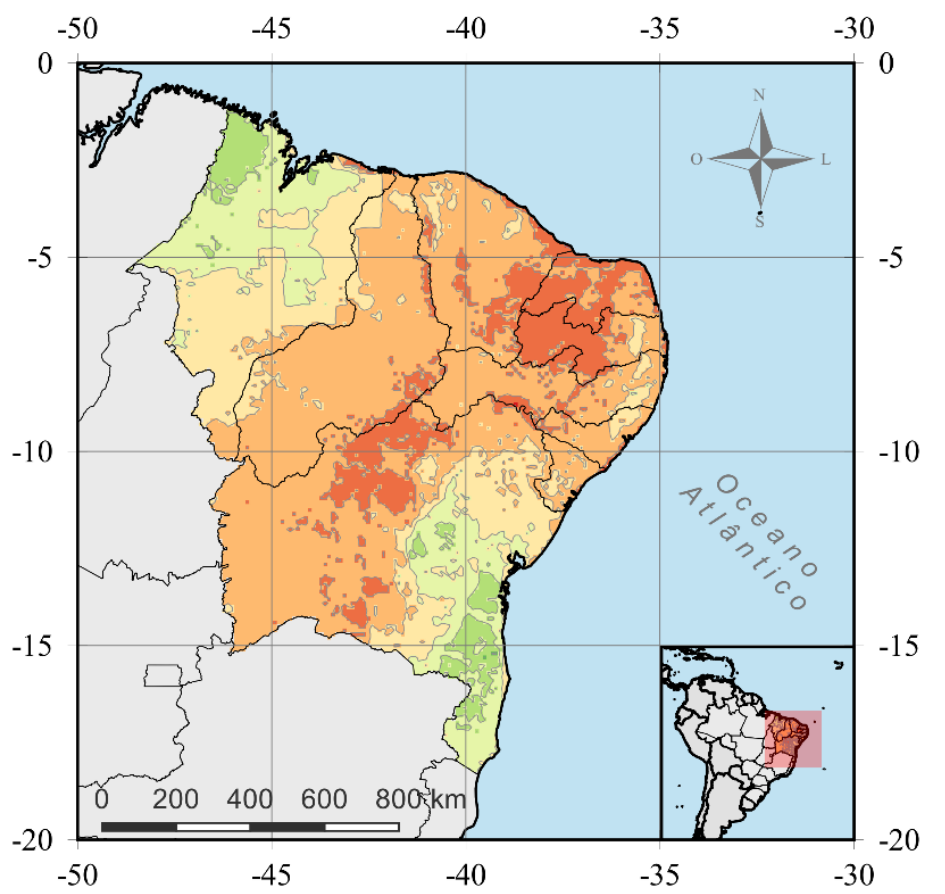

Montagem: rastreador de 1-eixo

Módulo: padrão

ICT: 0,4

FDI: 0,75

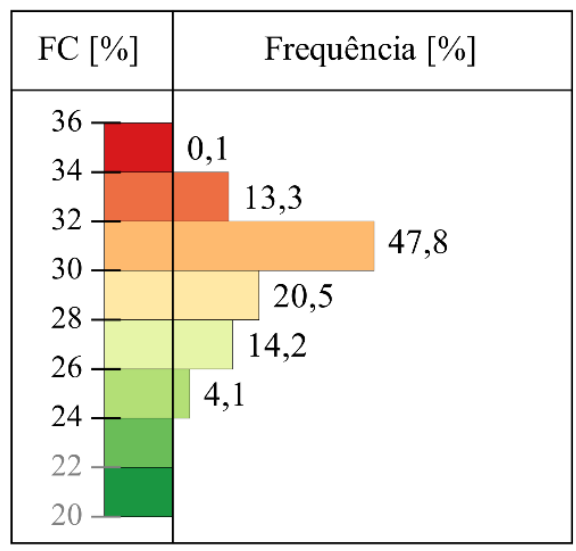

Fonte: elaborado a partir de (NATIONAL RENEWABLE ENERGY LABORATORY (NREL), $2018 \mathrm{~b})$.

Na figura 5.8, são apresentados os resultados dos ganhos obtidos no fator de capacidade ao se utilizarem rastreadores solares de um eixo, em vez de estruturas fixas. Os ganhos observados variam de $18,0 \%$ a $28,0 \%$, sendo que $71,5 \%$ dos pontos apresentam ganhos maiores ou iguais a 22 \%, com destaque para Ceará, Rio Grande do Norte e Paraíba. 
Figura 5.8 - Ganho no fator de capacidade para um sistema fotovoltaico com módulos do tipo padrão, montados em rastreadores solares de um eixo, ICT de 0,4 e FDI de 0,75, em relação ao montado em estrutura fixa.

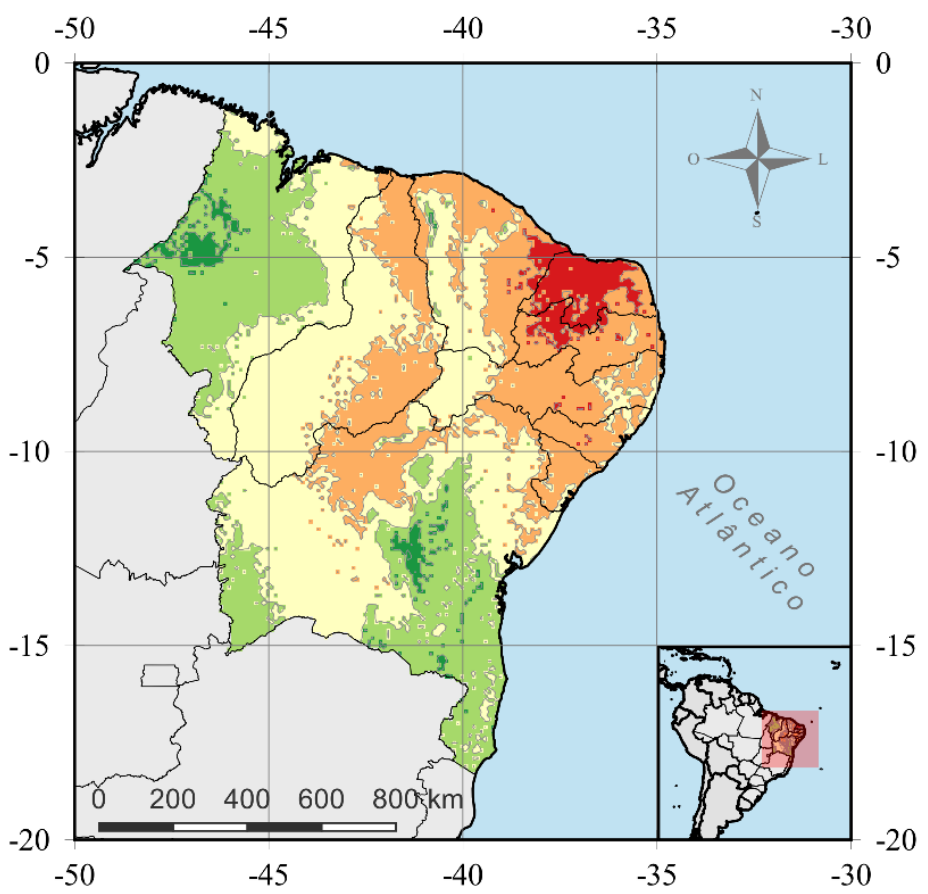

Ganho no fator de capacidade proporcionado pelo uso de rastreamento

Módulo: padrão

ICT: 0,4

FDI: 0,75

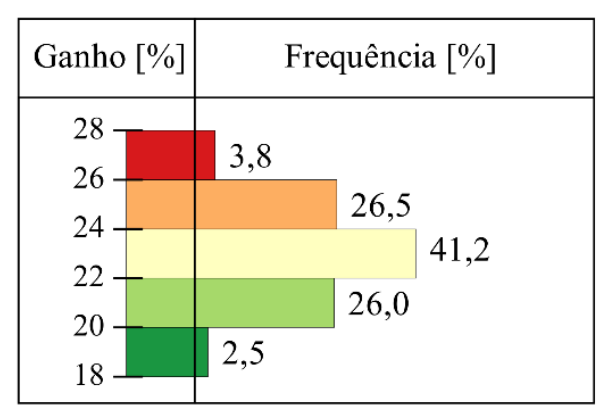

Fonte: elaborado a partir de (NATIONAL RENEWABLE ENERGY LABORATORY (NREL), 2018b).

\subsection{Módulos do tipo superior}

\subsubsection{Estrutura fixa}

O mapa com o fator de capacidade para um sistema fotovoltaico fixo, com módulos do tipo superior, ICT de 0,4 e FDI de 0,75, é apresentado na figura 5.9. Nesse caso, 80,1\% dos pontos apresentam fatores de capacidade maiores ou iguais a $24 \%$, sendo os limites observados de $20,3 \%$ a $28,3 \%$. 
Figura 5.9 - Fator de capacidade para um sistema fotovoltaico fixo, com módulos do tipo superior, ICT de 0,4 e FDI de 0,75 .

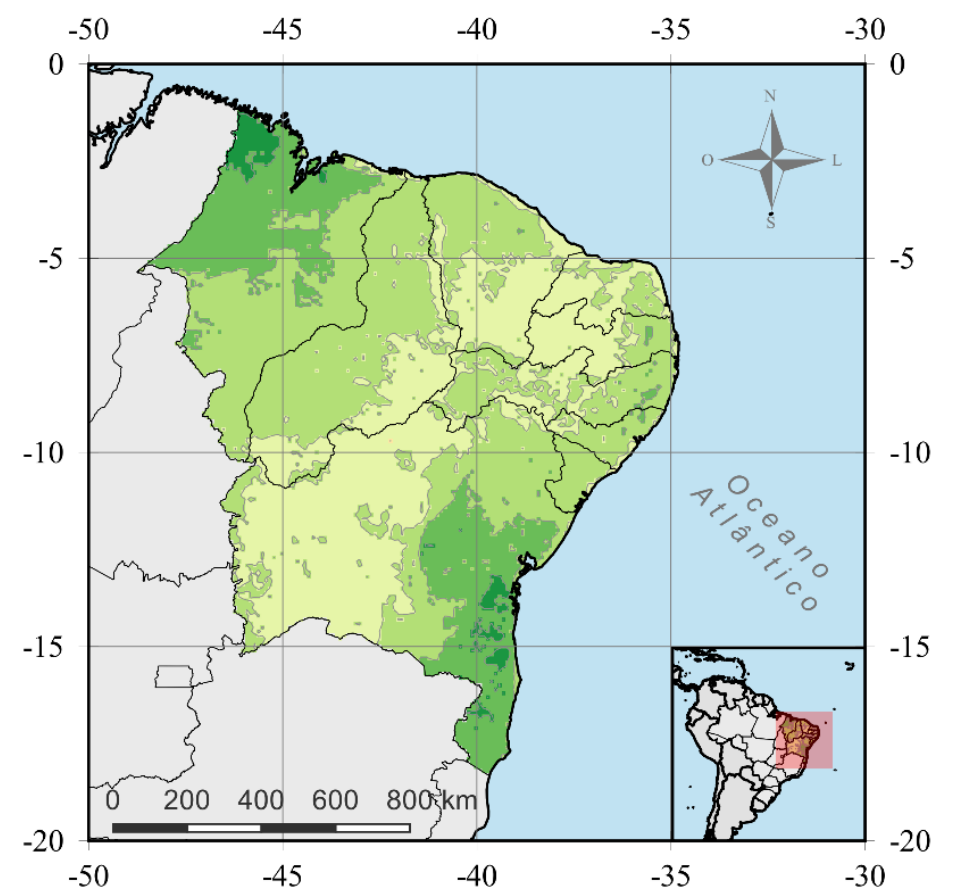

Montagem: estrutura fixa Módulo: superior

ICT: 0,4 FDI: 0,75

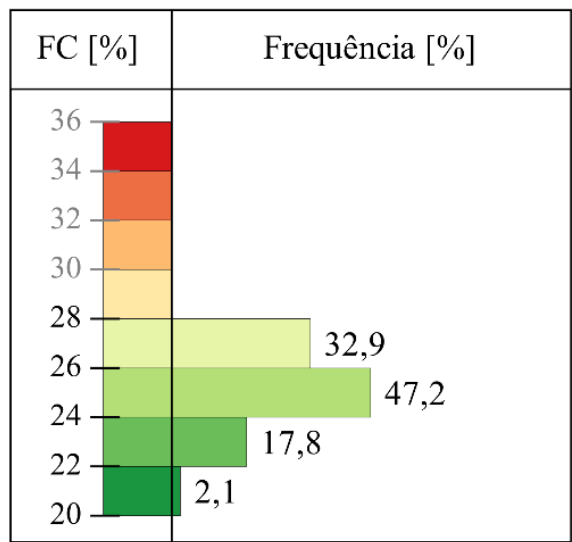

Fonte: elaborado a partir de (NATIONAL RENEWABLE ENERGY LABORATORY (NREL), 2018b).

Quando comparado com os sistemas fixos que utilizam módulos do tipo padrão, é possível verificar o aumento na abrangência dos pontos que possuem fatores de capacidade entre $26 \%$ e $28 \%$, e uma redução nos demais intervalos inferiores presentes. Isso denota o ganho na energia elétrica gerada proporcionado pela aplicação da cobertura antirreflexiva na superfície do módulo e pela redução do coeficiente de temperatura da potência.

\subsubsection{Rastreador solar de um eixo}

Para o mesmo sistema anterior, mas substituindo as estruturas fixas por rastreadores solares de um eixo, os fatores de capacidade situam-se no intervalo de $24,5 \%$ a $35,3 \%$, cuja disposição geográfica pode ser observada na figura 5.10. Cerca de $70 \%$ dos pontos possuem fatores de capacidade maiores ou iguais a $30 \%$. 
Figura 5.10 - Fator de capacidade para um sistema fotovoltaico com módulos do tipo superior, montados em rastreadores solares de um eixo, ICT de 0,4 e FDI de 0,75.

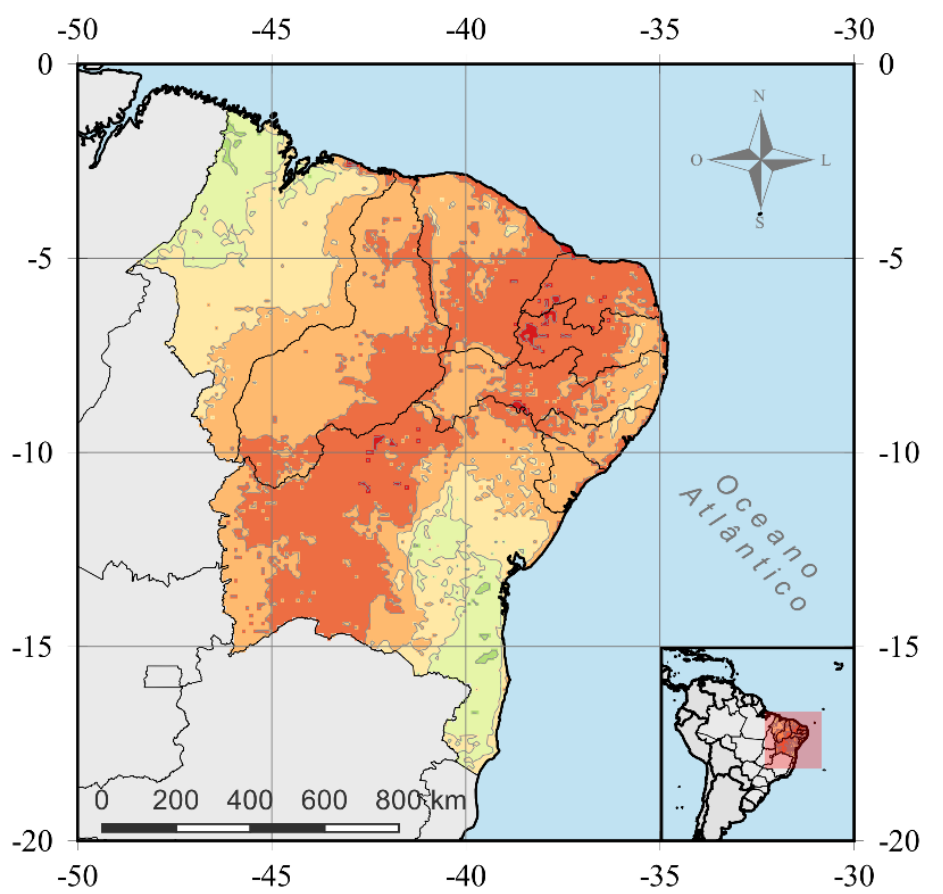

Montagem: rastreador de 1-eixo Módulo: superior

ICT: 0,4 FDI: 0,75

\begin{tabular}{|c|c|c|}
\hline FC [\%] & \multicolumn{2}{|c|}{ Frequência [\%] } \\
\hline $36-$ & 0,9 & 33,1 \\
$34-$ & \multicolumn{2}{|c|}{36,6} \\
$32-$ & \multicolumn{2}{|c|}{18,5} \\
$30-$ & \multicolumn{2}{|c|}{10,4} \\
$28-$ & 0,5 \\
$26-$ & \multicolumn{2}{|c|}{} \\
$24-$ & \\
$22-$ & \multicolumn{2}{|c|}{} \\
$20-$ & \\
\hline
\end{tabular}

Fonte: elaborado a partir de (NATIONAL RENEWABLE ENERGY LABORATORY (NREL), $2018 \mathrm{~b})$.

$\mathrm{Na}$ figura 5.11, são apresentados os ganhos obtidos no fator de capacidade proporcionados pelo emprego de rastreadores solares de um eixo. Os valores estão compreendidos entre $18,0 \%$ e $27,9 \%$, com $68,1 \%$ dos pontos apresentando ganhos superiores a $22 \%$. 
Figura 5.11 - Ganho no fator de capacidade para um sistema fotovoltaico com módulos do tipo superior, montados em rastreadores solares de um eixo, ICT de 0,4 e FDI de 0,75, em relação ao montado em estrutura fixa.

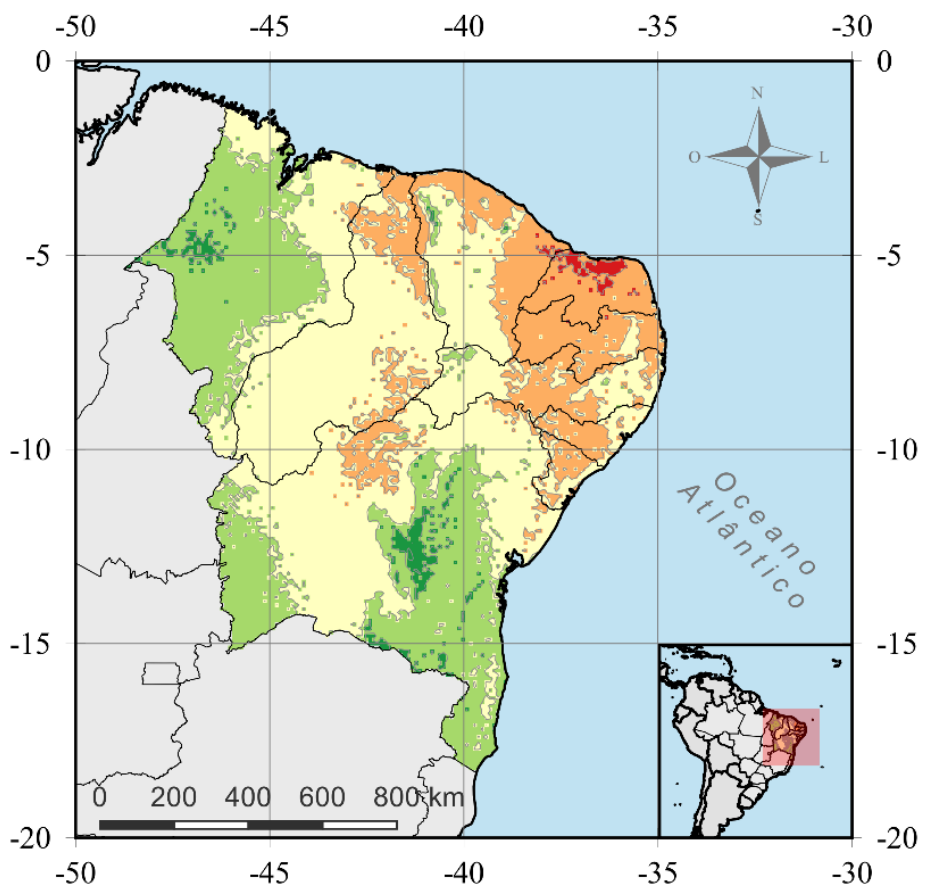

Ganho no fator de capacidade proporcionado pelo uso de rastreamento

Módulo: superior

ICT: 0,4

FDI: 0,75

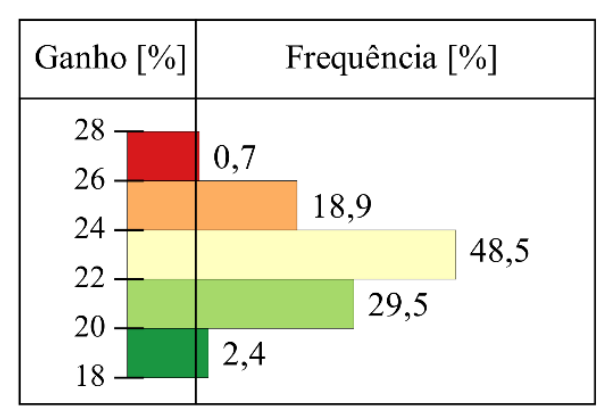

Fonte: elaborado a partir de (NATIONAL RENEWABLE ENERGY LABORATORY (NREL), 2018b).

\subsection{Módulos de filme fino}

\subsubsection{Estrutura fixa}

Na figura 5.12, é mostrada a distribuição geográfica dos fatores de capacidade obtidos por um sistema fotovoltaico fixo, com módulos de filme fino, ICT de 0,4 e FDI de 0,75. Nessa configuração, os valores variam entre $21,0 \%$ e $28,9 \%$, com $89,1 \%$ dos pontos com valores superiores a $24 \%$. 
Figura 5.12 - Fator de capacidade para um sistema fotovoltaico fixo, com módulos de filme fino, ICT de 0,4 e FDI de 0,75 .

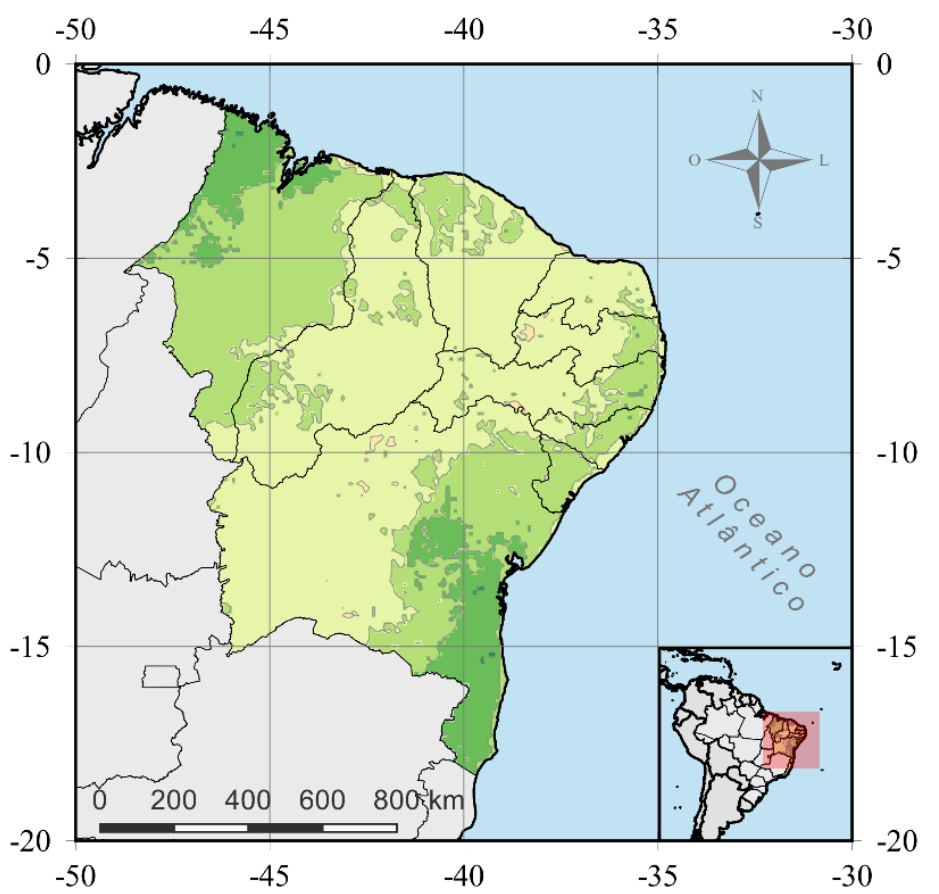

Montagem: estrutura fixa Módulo: filme fino

ICT: 0,4 FDI: 0,75

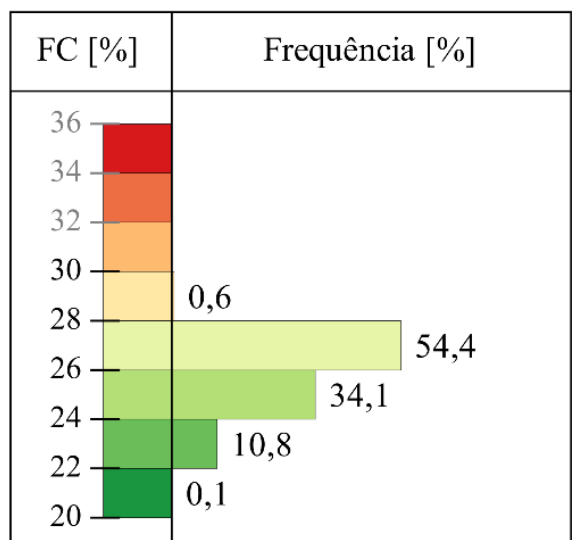

Fonte: elaborado a partir de (NATIONAL RENEWABLE ENERGY LABORATORY (NREL), 2018b).

\subsubsection{Rastreador solar de um eixo}

Quando a mesma análise da configuração anterior é realizada com a substituição das estruturas fixas por rastreadores solares de um eixo, os fatores de capacidade situam-se na faixa de $26,1 \%$ a 36,0 \%, sendo que $81,8 \%$ dos pontos têm valores superiores a $30 \%$. Cabe destaque para os estados do Ceará, Rio Grande do Norte, Paraíba, Pernambuco e Bahia, que concentram a maior parte da categoria dos maiores fatores de capacidade, como pode ser visto na figura 5.13 . 
Figura 5.13 - Fator de capacidade para um sistema fotovoltaico com módulos de filme fino, montados em rastreadores solares de um eixo, ICT de 0,4 e FDI de 0,75.

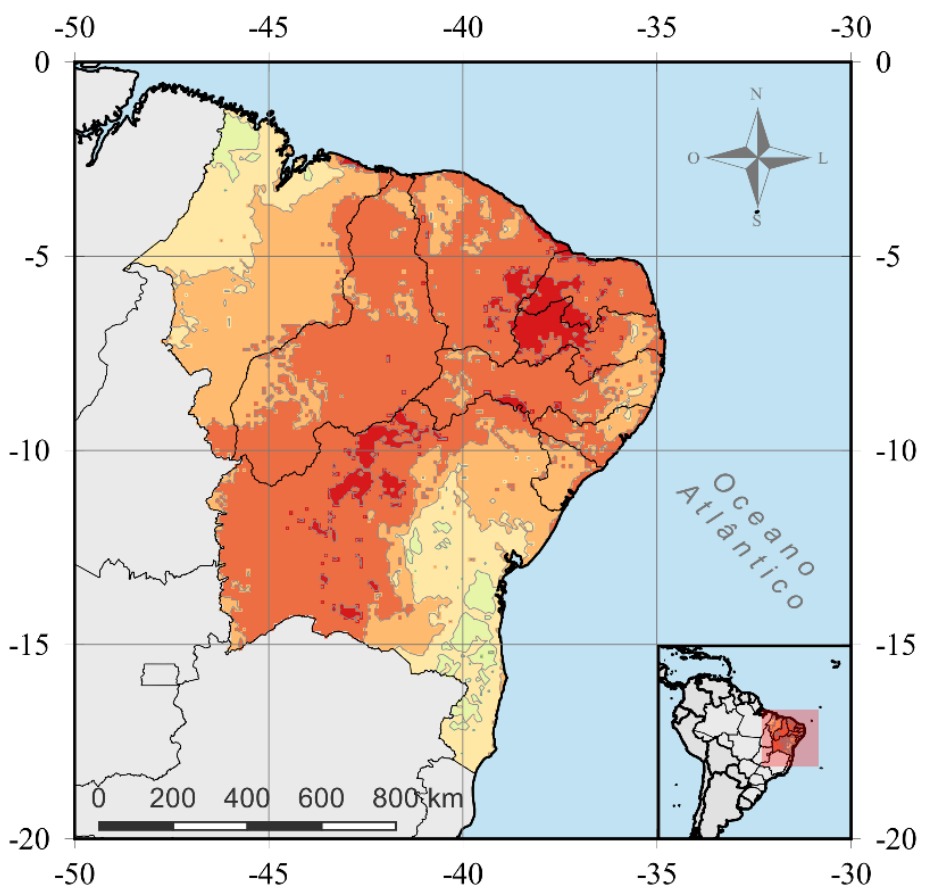

Montagem: rastreador de 1-eixo Módulo: filme fino

ICT: 0,4

FDI: 0,75

\begin{tabular}{|c|c|}
\hline FC [\%] & Frequência [\%] \\
\hline $36-12$ & 47,9 \\
$34-$ & 5,9 \\
$32-$ & \multicolumn{2}{|c|}{28,0} \\
$30-$ & \multicolumn{2}{|c|}{15,1} \\
$28-$ & \multicolumn{2}{|c|}{} \\
$26-$ & 3,1 \\
$24-$ & \multicolumn{2}{|}{} \\
$22-$ & \multicolumn{2}{|}{} \\
20 & \multicolumn{2}{|c|}{} \\
\hline
\end{tabular}

Fonte: elaborado a partir de (NATIONAL RENEWABLE ENERGY LABORATORY (NREL), 2018b).

Tomando como base os sistemas montados em estruturas fixas, os ganhos nos fatores de capacidade proporcionados pelos rastreadores solares estão compreendidos no intervalo $18,0 \%$ a $27,7 \%$, com $69,8 \%$ dos pontos apresentando ganhos maiores ou iguais a $22 \%$. Na figura 5.14, é mostrada a distribuição espacial dos referidos ganhos. 
Figura 5.14 - Ganho no fator de capacidade para um sistema fotovoltaico com módulos de filme fino, montados em rastreadores solares de um eixo, ICT de 0,4 e FDI de 0,75, em relação ao montado em estrutura fixa.

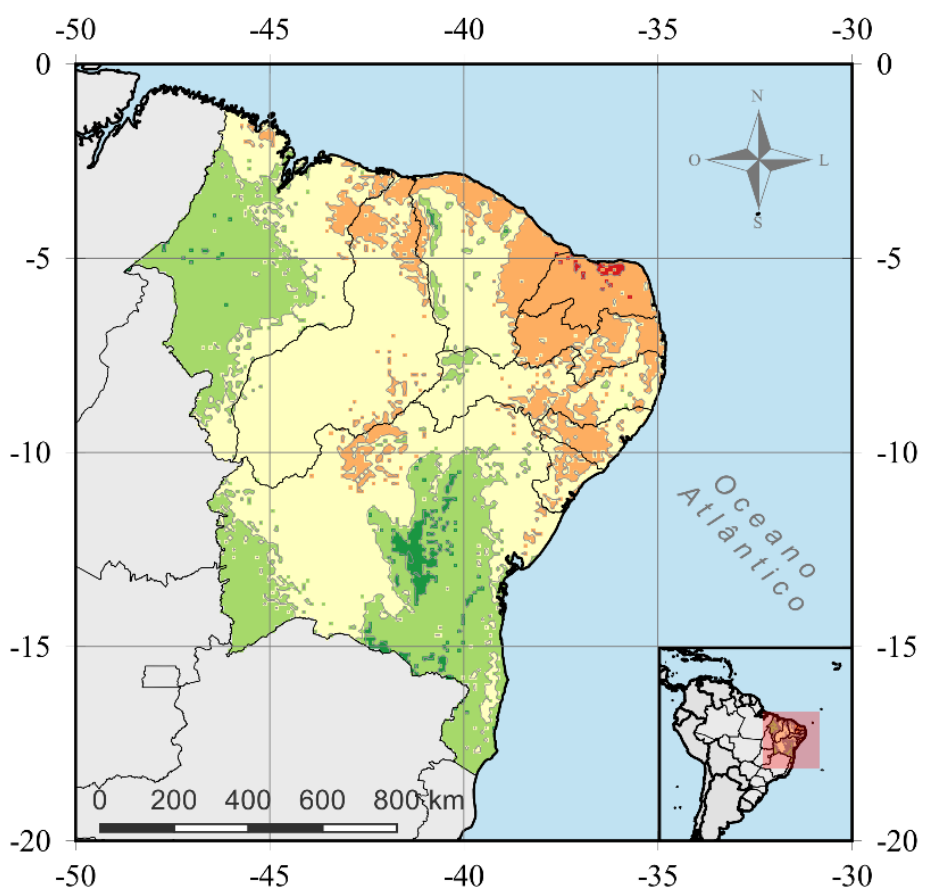

Ganho no fator de capacidade proporcionado pelo uso de rastreamento

Módulo: filme fino

ICT: 0,4

FDI: 0,75

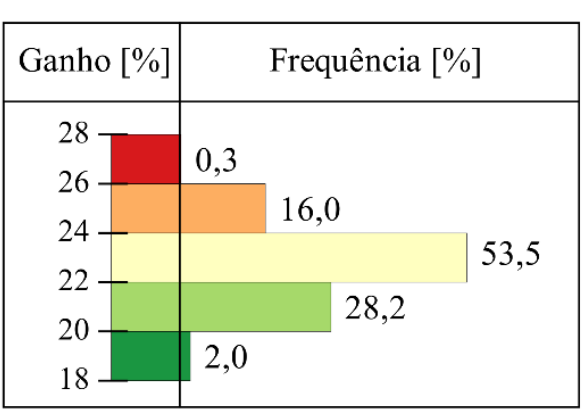

Fonte: elaborado a partir de (NATIONAL RENEWABLE ENERGY LABORATORY (NREL), 2018b).

Com o intuito de facilitar a comparação visual entre as configurações apresentadas anteriormente, na figura 5.15, são apresentados os resultados dos fatores de capacidade e dos respectivos ganhos. 
Figura 5.15 - Fatores de capacidade para sistemas fixos e com rastreadores solares de um eixo, com módulos dos tipos padrão, superior e filme fino e comparações entre as configurações de sistemas fotovoltaicos.
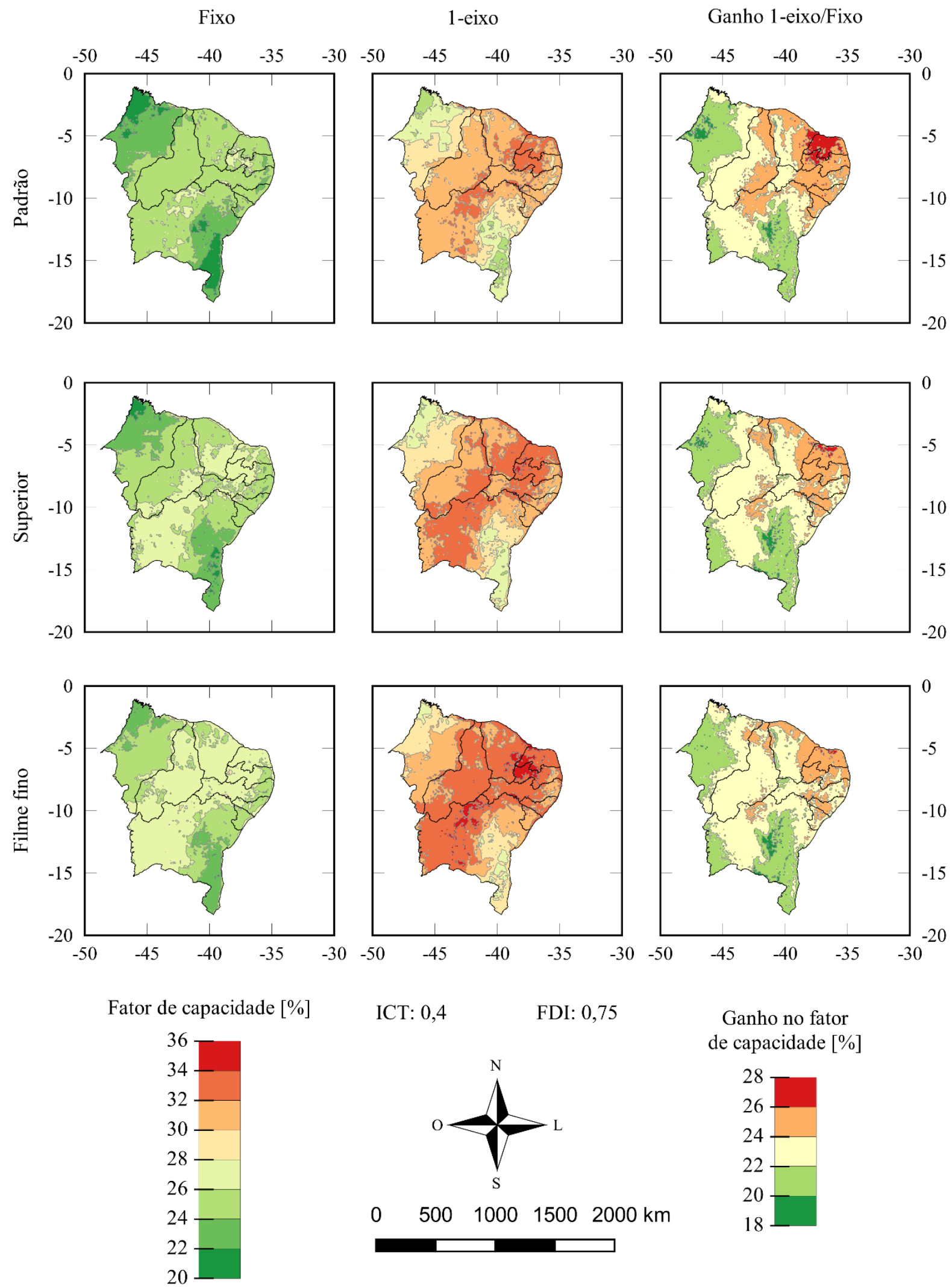

Ganho no fator de capacidade [\%]
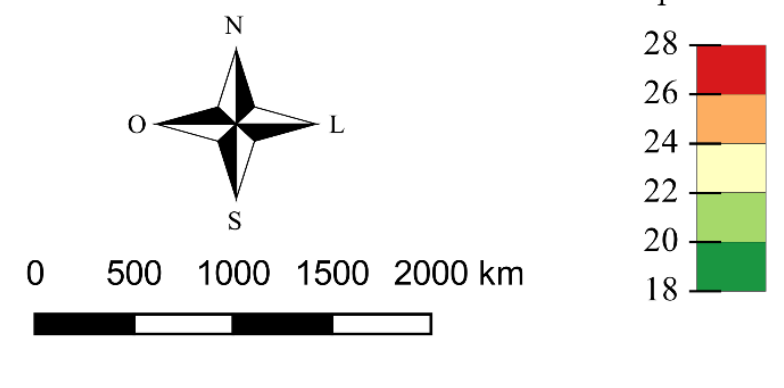

Fonte: elaborado a partir de (NATIONAL RENEWABLE ENERGY LABORATORY (NREL), 2018b). 


\section{ESTUDO DE CASO}

Neste capítulo, é apresentado o estudo de caso realizado, que utiliza os resultados operacionais da Usina Fotovoltaica Alto do Rodrigues (UFV-AR), sendo esses comparados com os dados obtidos pelas simulações realizadas.

\subsection{Usina Fotovoltaica Alto do Rodrigues (UFV-AR)}

Por meio da publicação do edital de chamada de projeto de P\&D estratégico n'013/2011, intitulado de "Arranjos técnicos e comerciais para inserção da geração solar fotovoltaica na matriz energética brasileira" (AGÊNCIA NACIONAL DE ENERGIA ELÉTRICA (ANEEL), 2011), a ANEEL buscou criar condições para o desenvolvimento de base tecnológica e infraestrutura técnica para a inserção da geração solar fotovoltaica na matriz energética nacional. De forma geral, isso objetivou colocar em evidência os avanços tecnológicos relacionados à geração solar fotovoltaica de modo a alavancar a cadeia produtiva dessa fonte no Brasil, no que diz respeito a aspectos tecnológicos, acadêmicos, mercadológicos e regulatórios (AGÊNCIA NACIONAL DE ENERGIA ELÉTRICA (ANEEL), 2018b).

Nesse âmbito, entre os requisitos definidos no referido edital, estava prevista a instalação de uma usina solar fotovoltaica conectada à rede de distribuição ou transmissão de energia elétrica. Dessa forma, alinhado à estratégia corporativa então vigente de ampliar seus negócios envolvendo a geração de energia elétrica, a Petrobras formalizou em 2012 junto à ANEEL o início do projeto "Estudo da geração fotovoltaica centralizada e seu impacto no sistema elétrico". O projeto consistiu, entre outras atividades, na construção da UFV-AR, que possui potência nominal de 1,1 MW e está conectada ao SIN (FONTENELE et al., 2015).

A UFV-AR entrou em operação comercial em 2014, tornando-se a primeira planta de geração solar fotovoltaica centralizada da Petrobras. Está localizada no terreno da Usina Termelétrica Jesus Soares Pereira (UTE-JSP), no município de Alto do Rodrigues/RN, tendo as coordenadas geográficas $5,38^{\circ} \mathrm{S}$ e $36,82^{\circ} \mathrm{O}$, conforme visto na figura 6.1. A área total ocupada pela UFV-AR encontra-se delimitada pelo polígono vermelho, correspondendo a aproximadamente $30.000 \mathrm{~m}^{2}$ (FONTENELE et al., 2017). 
Figura 6.1 - Vista de satélite da UFV-AR e da UTE-JSP.

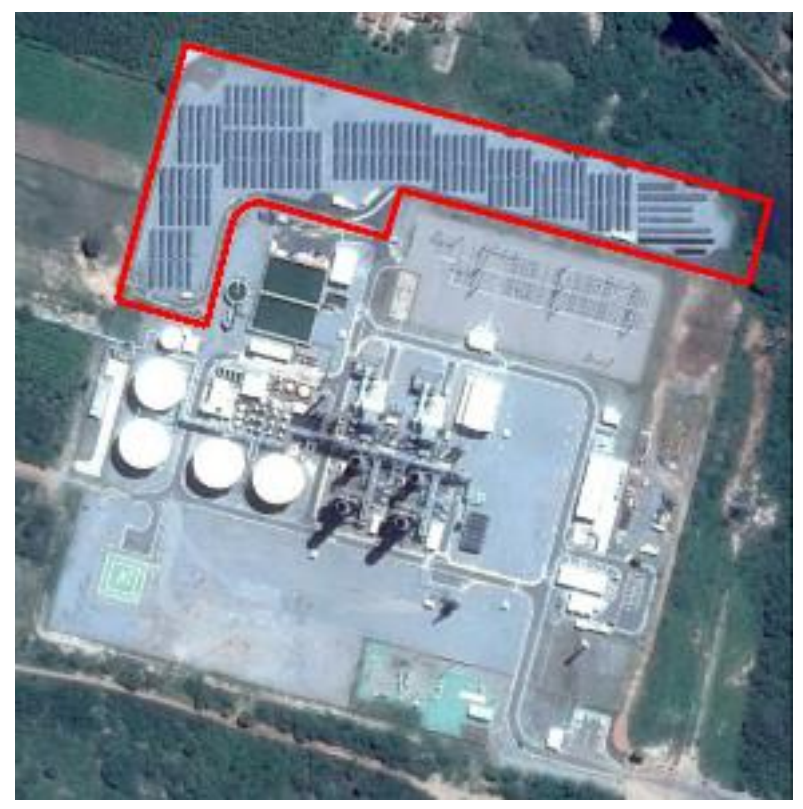

Fonte: elaborado a partir de (GOOGLE, 2018).

Conceitualmente, a usina é dividida em quatro subsistemas, que podem ser identificados por meio da figura 6.2, e cujas características estão sumarizadas na tabela 6.1. O primeiro e maior deles, com potência de 1,0 MW, é constituído por módulos fotovoltaicos de silício multicristalino (multi-Si), montados em rastreadores solares de um eixo horizontal norte-sul. Já o segundo compartilha da mesma tecnologia anterior, tem potência de $50 \mathrm{~kW}$ e é instalado em estruturas fixas. Os outros dois também são montados em estruturas fixas, cada um possuindo potência de $25 \mathrm{~kW}$, sendo um da tecnologia de silício amorfo (a-Si) e o outro de disseleneto de cobre, índio e gálio (CIGS) (INÁCIO et al., 2016). 
Figura 6.2 - Identificação dos subsistemas da UFV-AR.

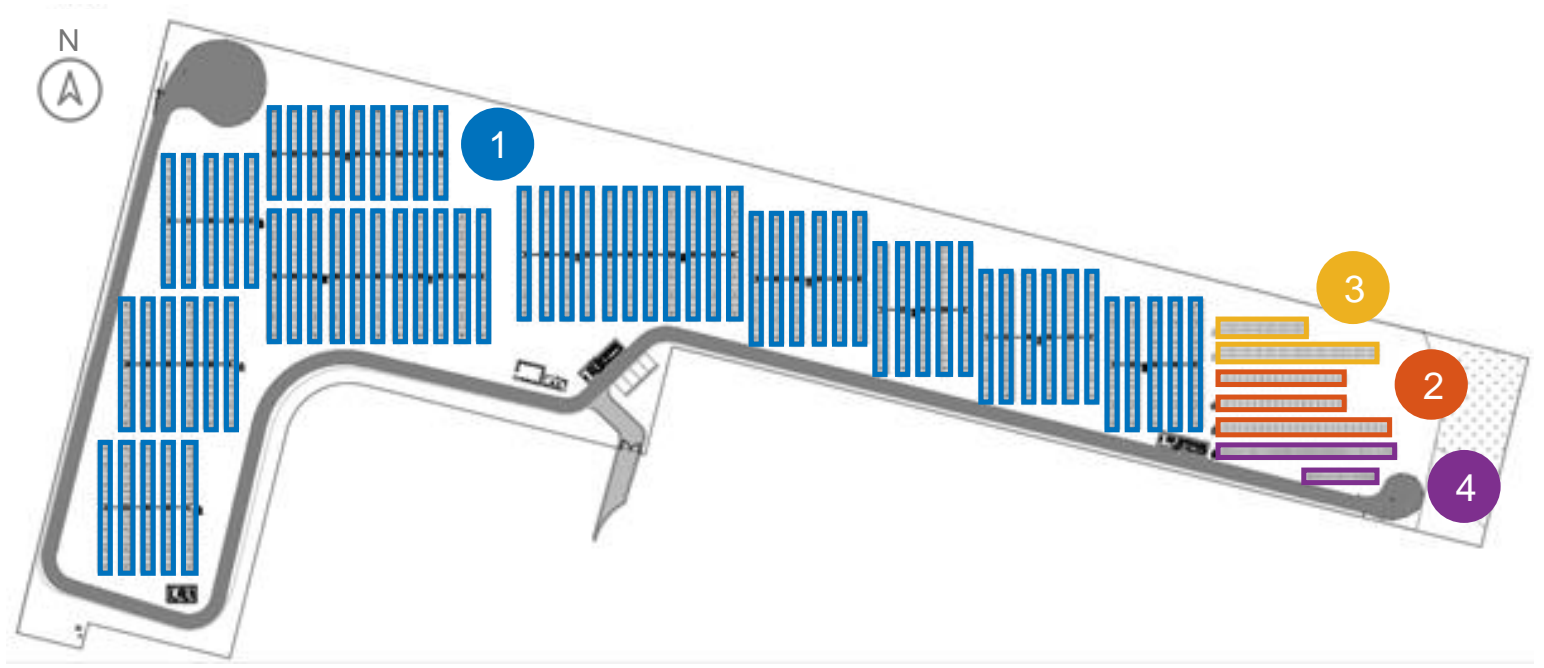

Fonte: elaborado a partir de (PETRÓLEO BRASILEIRO S.A. (PETROBRAS), 2014).

Tabela 6.1 - Características dos subsistemas da UFV-AR.

\begin{tabular}{|c|c|c|c|c|}
\hline \multirow{2}{*}{ Parâmetro } & \multicolumn{4}{|c|}{ Subsistema } \\
\hline & 1 & 2 & 3 & 4 \\
\hline $\begin{array}{l}\text { Tipo de módulo } \\
\text { fotovoltaico }\end{array}$ & multi-Si & multi-Si & $\mathrm{a}-\mathrm{Si}$ & CIGS \\
\hline$\eta[\%]$ & 14,8 & 14,8 & 9,1 & 11,9 \\
\hline$\gamma_{P}\left[\% /{ }^{\circ} \mathrm{C}\right]$ & $-0,45$ & $-0,45$ & $-0,32$ & $-0,39$ \\
\hline Capacidade [kWp] & $1.033,56$ & 52,20 & 26,27 & 25,48 \\
\hline Potência instalada [kW] & 1.038 & 50 & 25 & 25 \\
\hline FDI & 1,00 & 0,96 & 0,95 & 0,98 \\
\hline$\eta_{\text {nom }}[\%]$ & 98,5 & 96,1 & 96,1 & 96,1 \\
\hline Suporte & $\begin{array}{l}\text { Rastreador solar de um } \\
\text { eixo }\end{array}$ & $\begin{array}{l}\text { Fixa em } \\
\text { solo }\end{array}$ & $\begin{array}{l}\text { Fixa em } \\
\text { solo }\end{array}$ & $\begin{array}{l}\text { Fixa em } \\
\text { solo }\end{array}$ \\
\hline$\beta\left[^{\circ}\right]$ & 0 & 10 & 10 & 10 \\
\hline$\gamma\left[^{\circ}\right]$ & 0 & 0 & 0 & 0 \\
\hline ICT & 0,50 & 0,43 & 0,61 & 0,46 \\
\hline
\end{tabular}

Fonte: elaborado a partir de (SUNEDISON, 2012), (DUPONT, 2011), (AVANCIS, 2011), (INGETEAM, 2012) e (FONTENELE et al., 2017). 
Na figura 6.3 são apresentadas imagens de cada um dos quatro subsistemas, além de uma vista aérea da UFV-AR. A escolha das diferentes configurações apresentadas foi motivada pelo interesse em gerar informações para estudos, avaliações e comparações das características, desempenho, operação e manutenção (FONTENELE et al., 2015).

Figura 6.3 - Imagens das instalações da UFV-AR: (a) subsistema 1, (b) subsistema 2, (c) subsistema 3, (d) subsistema 4 e (e) vista aérea da UFV-AR.

(a)

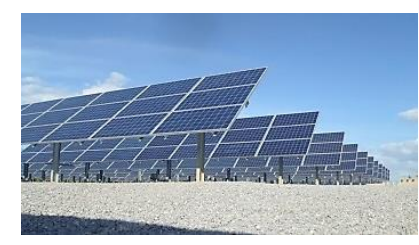

(c)

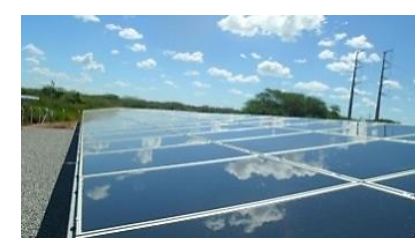

(b)

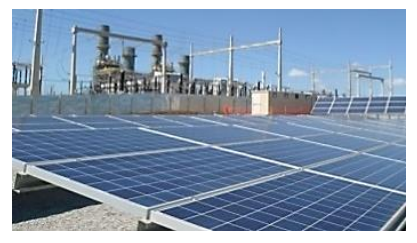

(d)

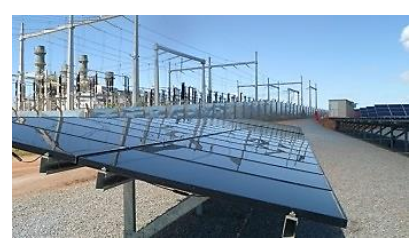

(e)

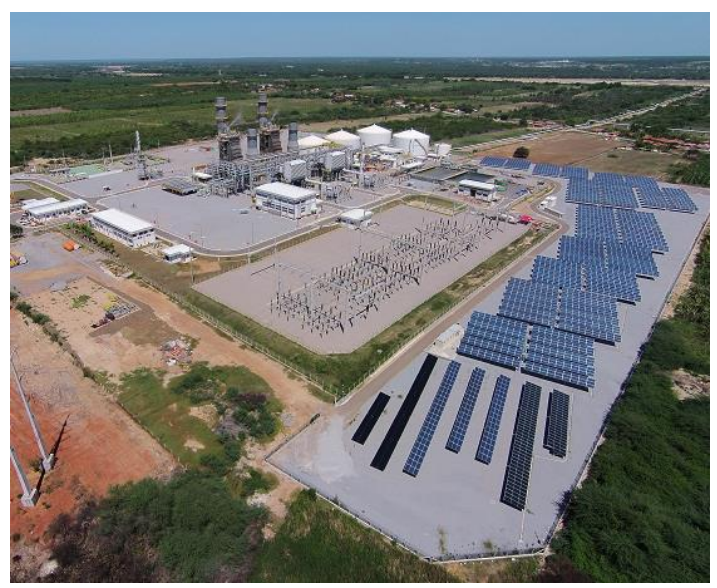

Fonte: elaborado a partir de (FONTENELE et al., 2017).

É importante salientar que, por se tratar de um projeto voltado à pesquisa científica, um esforço adicional foi dispendido na concepção e na implementação do sistema supervisório e de aquisição de dados. Esses apresentam especificações mais restritivas e maior variedade de registros da informação gerada, quando comparado com o que é usualmente encontrado em outros empreendimentos com finalidade estritamente comercial (INÁCIO et al., 2016).

Previu-se a instalação de diversos instrumentos de medição de grandezas meteorológicas, como irradiâncias, temperatura ambiente e velocidade do vento, e de grandezas elétricas, como tensão e corrente, tanto em corrente contínua quanto em alternada. Ainda no que diz respeito à parte de instrumentação, são monitoradas as temperaturas de alguns módulos, bem como as inclinações dos rastreadores solares. Na parte do recurso solar, são medidas as irradiâncias global e difusa horizontais e direta normal, pela estação meteorológica, e incidentes nos planos inclinados e dos rastreadores solares, por piranômetros, como pode ser observado na figura 6.4 . 
Figura 6.4 - Medição do recurso solar: (a) estação meteorológica, (b) piranômetro no plano do módulo com rastreador solar e (c) piranômetro no plano inclinado dos módulos fixos.

(a)

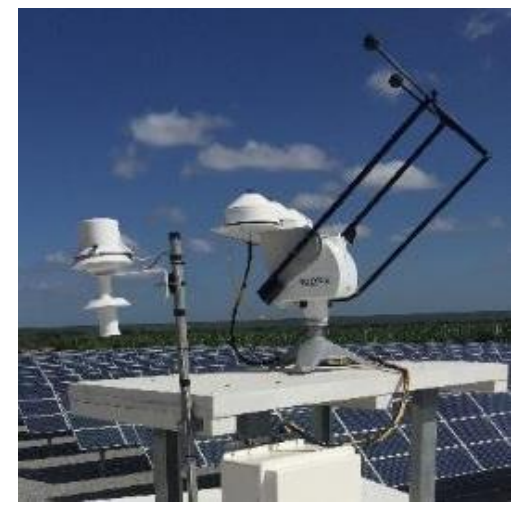

(b)

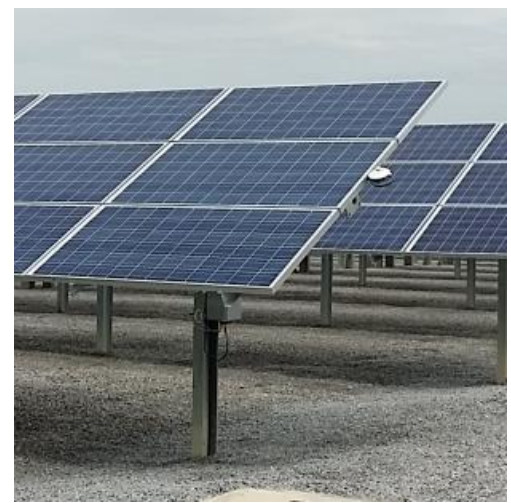

(c)

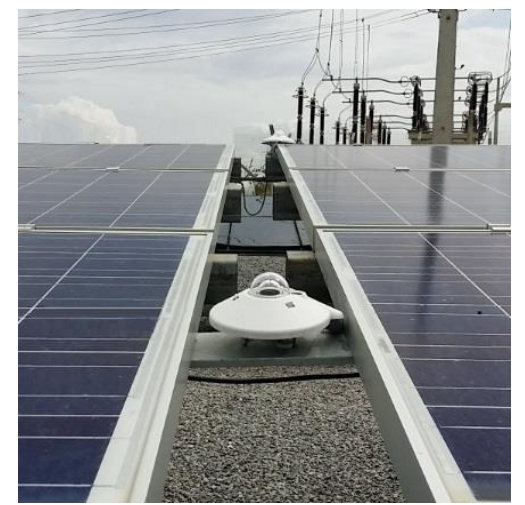

Fonte: elaborado a partir de (FONTENELE et al., 2017).

O diagrama unifilar simplificado da UFV-AR é apresentado na figura 6.5, com identificação dos subsistemas e dos principais componentes. Os dois inversores do subsistema 1 são ligados a um transformador elevador de três enrolamentos, cuja saída está conectada ao barramento da subestação 1 . Os quatro inversores dos subsistemas 2, 3 e 4 são associados em paralelo e então ligados a um transformador elevador, que, por sua vez, está indiretamente conectado ao mesmo barramento do transformador 1, após passar pela subestação 2. A partir daí, a ligação segue para o centro de seccionamento, onde é realizada a contabilização oficial da energia elétrica gerada pela Câmara de Comercialização de Energia Elétrica (CCEE), para então ser conectada à rede de distribuição da concessionária local. 
Figura 6.5 - Diagrama unifilar simplificado da UFV-AR.

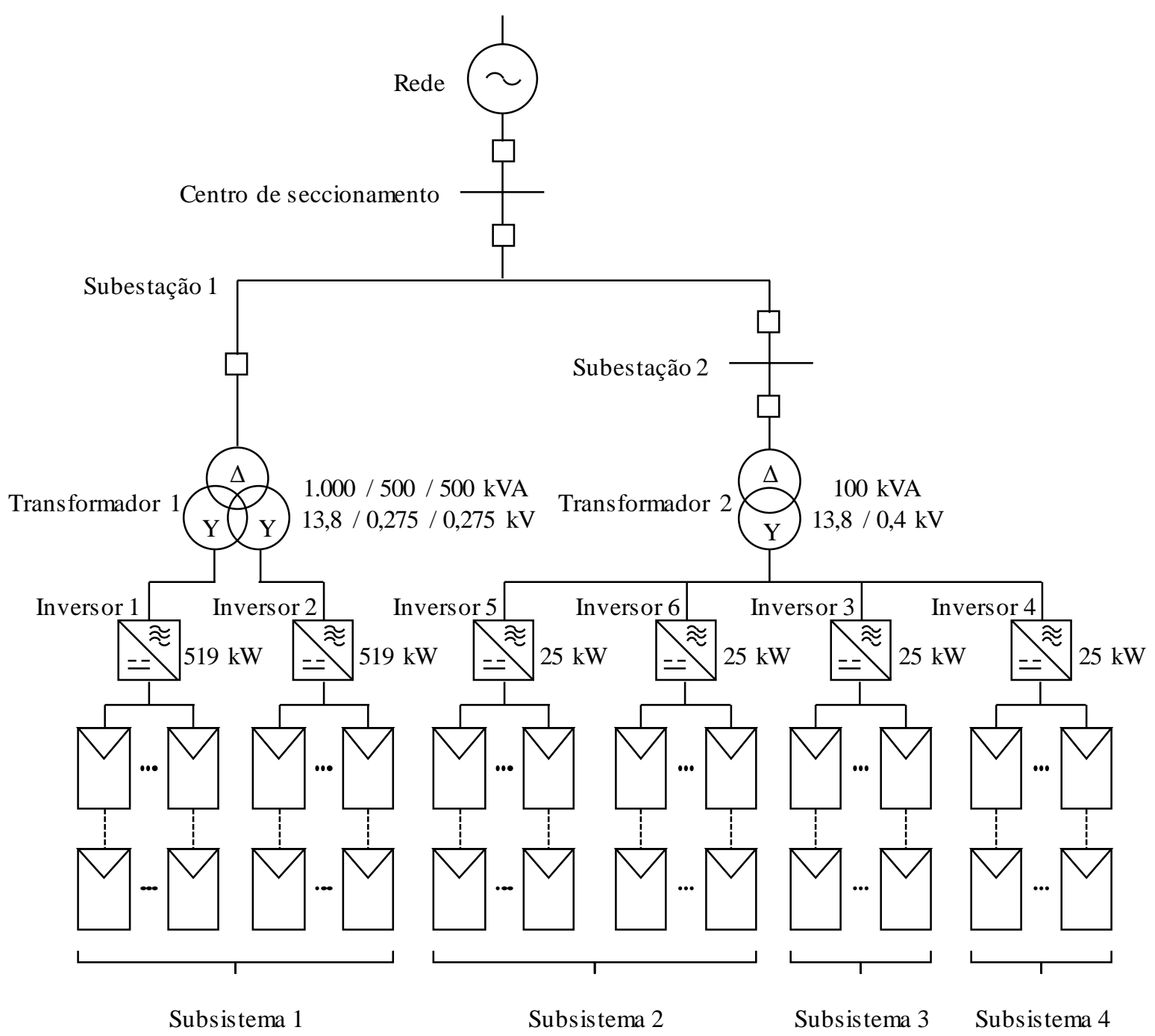

Fonte: elaborado a partir de (FONTENELE et al., 2017).

\subsection{Resultados medidos e simulados}

$\mathrm{Na}$ figura 6.6, é mostrado um diagrama de blocos, que retrata a metodologia utilizada para a comparação dos resultados medidos e simulados. A análise foi feita para um ano específico, 2016, utilizando os dados de medição correspondentes, coletados pelo sistema de aquisição de dados da UFV-AR. As comparações realizadas confrontam os dados reais de operação da usina com os teóricos, obtidos a partir de modelos físicos. 
Figura 6.6 - Metodologia da comparação entre os resultados medidos e simulados.

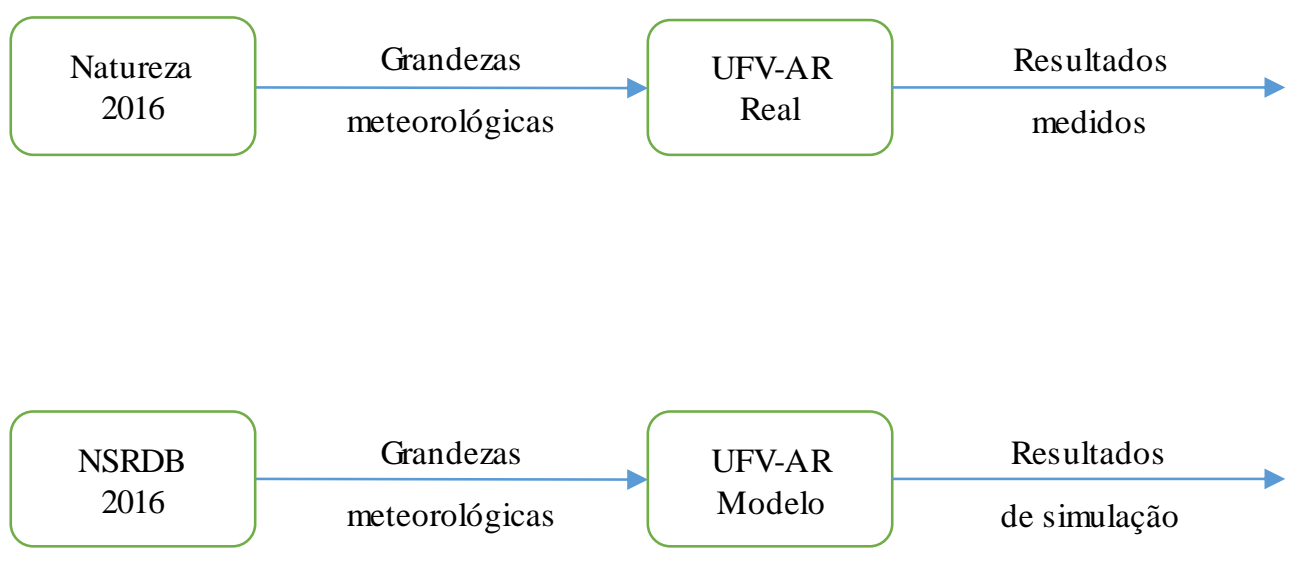

Cabe salientar que, na simulação, optou-se por utilizar os dados meteorológicos provenientes do NSRDB para o ano de 2016, em vez dos registros feitos pela estação meteorológica da UFV-AR, com o objetivo de verificar o desempenho do conjunto de modelos utilizado. Isso se mostra particularmente interessante quando se deseja estimar o comportamento de um sistema fotovoltaico em uma localidade onde não se dispõe de medições realizadas in situ.

Os quatro subsistemas foram modelados individualmente através do módulo PVWatts do SAM, utilizando as respectivas características apresentadas na tabela 6.1. É importante destacar que, apesar de os subsistemas 3 e 4 utilizarem módulos de filmes finos, esses foram simulados com módulos do tipo superior, pois apresentam os coeficientes térmicos das potências mais próximos aos informados pelos fabricantes nas folhas de dados. Além disso, os dados construtivos de projeto foram utilizados para confeccionar a cena tridimensional e gerar os arquivos de sombras, desprezando, portanto, o efeito da mudança das eficiências apresentadas na tabela 6.1, decorrentes da alteração da tecnologia dos módulos selecionados.

Em relação aos valores das perdas envolvidas no sistema, apresentados na tabela 4.7, a sujidade do subsistema 1 foi alterada de $2 \%$ para $3 \%$ por conta das condições da vizinhança. A dos subsistemas 2, 3 e 4 passou para $4 \%$, por, além do motivo citado, os módulos estarem montados em estruturas fixas pouco inclinadas, $10^{\circ}$, o que favorece o acúmulo de sujeira em regiões de baixa pluviosidade. As perdas no cabeamento foram adotadas em $3 \%$, considerando os transformadores do tipo seco, enquanto os desvios da potência nominal foram adotados em $2 \%$. A perda por envelhecimento passou de $0 \%$ para $3 \%$, considerando a degradação dos módulos desde o comissionamento da usina. Já as perdas por indisponibilidade foram 
consideradas nulas, uma vez que se almeja comparar os resultados de simulação com os dados medidos, com os quais é feito o desconto da indisponibilidade.

$\mathrm{Na}$ parte da medição, para cada dia, foram verificadas as correntes das séries fotovoltaicas, e, sendo que os dias em que houve falha foram desconsiderados da análise do respectivo subsistema. Isso contempla os dias em que houve desligamentos totais na planta, devido a faltas ocorridas na rede da concessionária, ou parciais, decorrentes de eventos de manutenção na usina, como substituição de fusíveis queimados e módulos danificados.

Dessa forma, como o intuito não é avaliar a indisponibilidade, são considerados somente dias em que não houve modificação na quantidade de séries operacionais. Portanto, se ao longo de um dia inteiro, um subsistema qualquer operou com alguma série indisponível, essa é desconsiderada da análise, e é feita a redução proporcional da potência do subsistema correspondente, mediante multiplicação pelo percentual de séries operacionais. Por exemplo, ao longo do dia 14/08/2016, o subsistema 2 operou com uma das dez séries indisponíveis, logo a potência dos seus dois inversores é multiplicada por 0,90 no cálculo do fator de capacidade desse dia.

A comparação entre os resultados medidos e simulados dos fatores de capacidade para cada um dos subsistemas da UFV-AR, para o ano de 2016, é apresentada na figura 6.7. É possível verificar que o subsistema 1, por utilizar rastreador solar de um eixo, apresentou os maiores fatores de capacidade, tanto para os dados medidos quanto para os simulados.

Figura 6.7 - Comparação entre os resultados medidos e simulados dos fatores de capacidade dos subsistemas da UFV-AR para o ano de 2016.

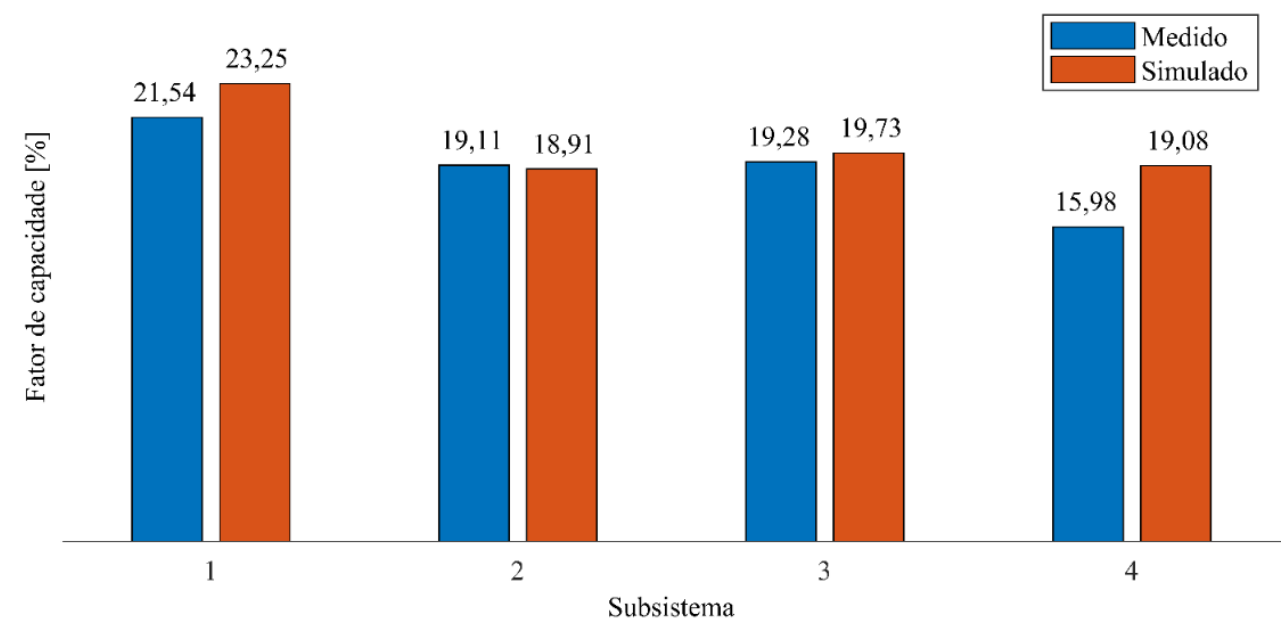

Fonte: elaborado a partir de (PETRÓLEO BRASILEIRO S.A. (PETROBRAS), 2018) e (NATIONAL RENEWABLE ENERGY LABORATORY (NREL), 2018b). 
Na figura 6.8, são mostrados os desvios dos resultados da simulação em relação aos dados medidos dos fatores de capacidade dos subsistemas da UFV-AR, durante a operação em 2016. Para o subsistema 1, a simulação apresentou um resultado $8,0 \%$ maior que os dados reais. Para o subsistema 2, 3 e 4, esse valor foi de $-1,0 \%, 2,3 \%$ e 19,4 \%, respectivamente.

Figura 6.8 - Desvios entre os resultados medidos e simulados dos fatores de capacidade dos subsistemas da UFV-AR para o ano de 2016.

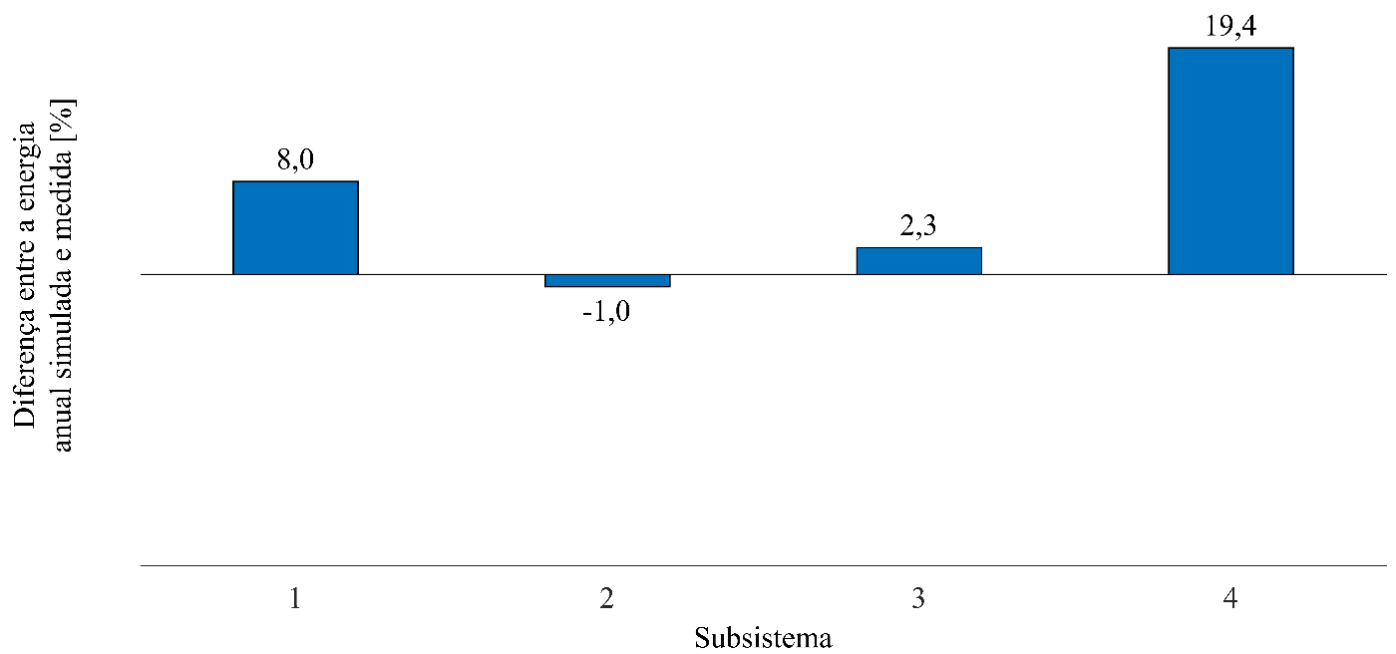

Fonte: elaborado a partir de (PETRÓLEO BRASILEIRO S.A. (PETROBRAS), 2018) e (NATIONAL RENEWABLE ENERGY LABORATORY (NREL), 2018b).

Quando esses resultados são comparados com os de (NATIONAL RENEWABLE ENERGY LABORATORY (NREL), 2014a), pela figura 4.10, constata-se que o desvio do subsistema 1 ficou acima do sistema equivalente, menos de três pontos percentuais. O desvio absoluto do subsistema 2 foi o menor entre os quatro subsistemas e compatível com os apresentados na figura 4.10. Os subsistemas 3 e 4 não apresentam correspondências diretas aos da figura 4.10, mas, por utilizarem módulos de filmes finos, foram comparados com os sistemas que utilizam módulos de telureto de cádmio (CdTe), sendo o desvio absoluto do subsistema 3 menor que os da figura 4.10. O subsistema 4 apresentou um desvio não esperado, bem superior a qualquer um da figura 4.10. No entanto, essa diferença é devida principalmente ao baixo desempenho observado na UFV-AR da tecnologia de CIGS frente às demais, como pode ser observado na figura 6.7. Aqui, pode-se supor que houve uma degradação mais acelerada em campo do que o previsto, ou ainda que há uma divergência entre a potência nominal do módulo indicada na folha de dados e a potência efetivamente medida. No entanto, não há como afirmar, pois não foram realizados ensaios dos módulos quando do recebimento deles na usina. 
Com o intuito de realizar uma comparação entre os dados de entrada apresentados na figura 6.6, as irradiâncias globais horizontais medidas pela estação meteorológica da UFV-AR e proveniente do NSRDB para o mês de setembro de 2016 são mostradas na figura 6.9. O ponto mais próximo disponível no NSRDB está situado nas coordenadas geográficas $5,39^{\circ} \mathrm{S}$ e $36,82^{\circ} \mathrm{O}$, distando aproximadamente $1 \mathrm{~km}$ do ponto de medição da usina. Apesar de os dados da UFV-AR estarem disponíveis na resolução temporal de um segundo, realizou-se a integração horária para deixar os dois conjuntos de dados com a mesma resolução.

Figura 6.9 - Comparação entre as irradiâncias globais horizontais medidas pela estação solarimétrica da UFVAR e proveniente do NSRDB para 09/2016.

Dom

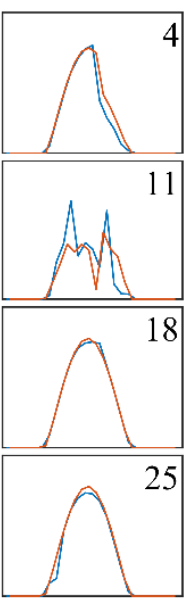

Seg

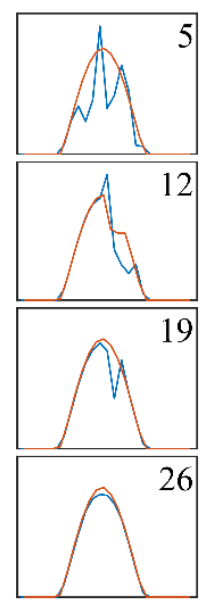

Ter

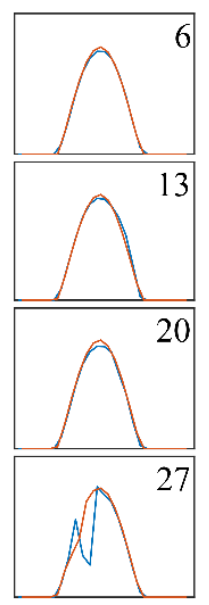

Qua

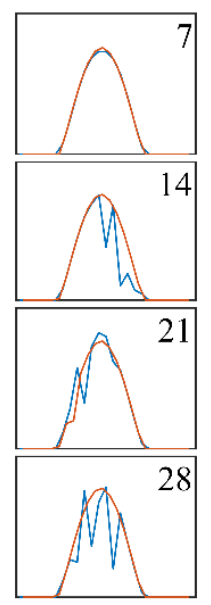

Qui

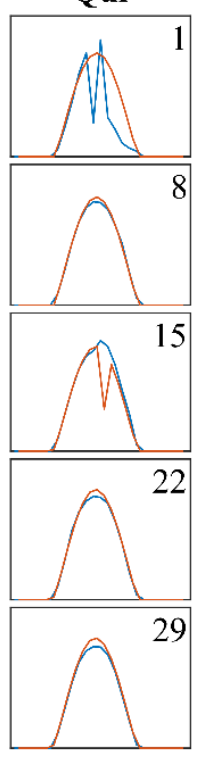

Sex

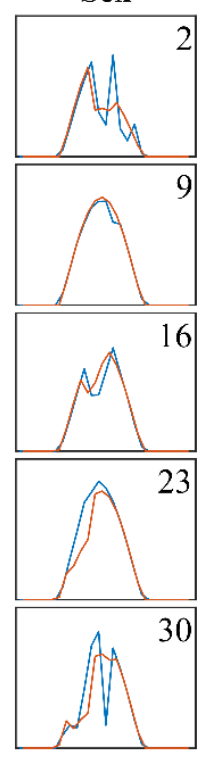

Sáb
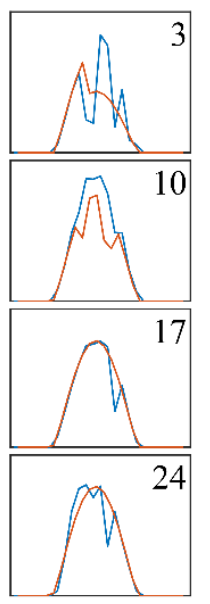

- UFV-AR
- NSRDB

Fonte: elaborado a partir de (PETRÓLEO BRASILEIRO S.A. (PETROBRAS), 2018) e (NATIONAL RENEWABLE ENERGY LABORATORY (NREL), 2018a).

Visualmente, é possível inferir que, em alguns dias, a irradiação fornecida pelo NSRDB é maior que a medida na UFV-AR, como em 14/09/2016. Já em outros, como 10/09/2016, ocorre o contrário. Observa-se ainda a concordância quase que exata entre os valores em alguns dias, como em 07/09/2016, em que o NSRDB apresentou um desvio de 0,62 \% acima do medido pela UFV-AR. No mês selecionado, a média diária da irradiação global horizontal registrada pela estação da UFV-AR foi de $6,80 \mathrm{kWh} / \mathrm{m}^{2}$, enquanto os dados provenientes do NSRDB apresentaram uma média diária $7,02 \mathrm{kWh} / \mathrm{m}^{2}$, com 3,20\% a mais que a da UFV-AR. É importante ter em mente a distância entre os pontos em questão e que o do NSRDB representa uma área de $4 \mathrm{~km}$ por $4 \mathrm{~km}$. 
Por ser considerado um dia de céu limpo, foi selecionado o dia 07/09/2016 para realizar uma comparação entre os resultados medidos e simulados das potências injetadas na rede pelos subsistemas, como pode ser observado na figura 6.10 .

Figura 6.10 - Comparação entre os resultados medidos e simulados das potências dos subsistemas da UFV-AR para o dia 07/09/2016.

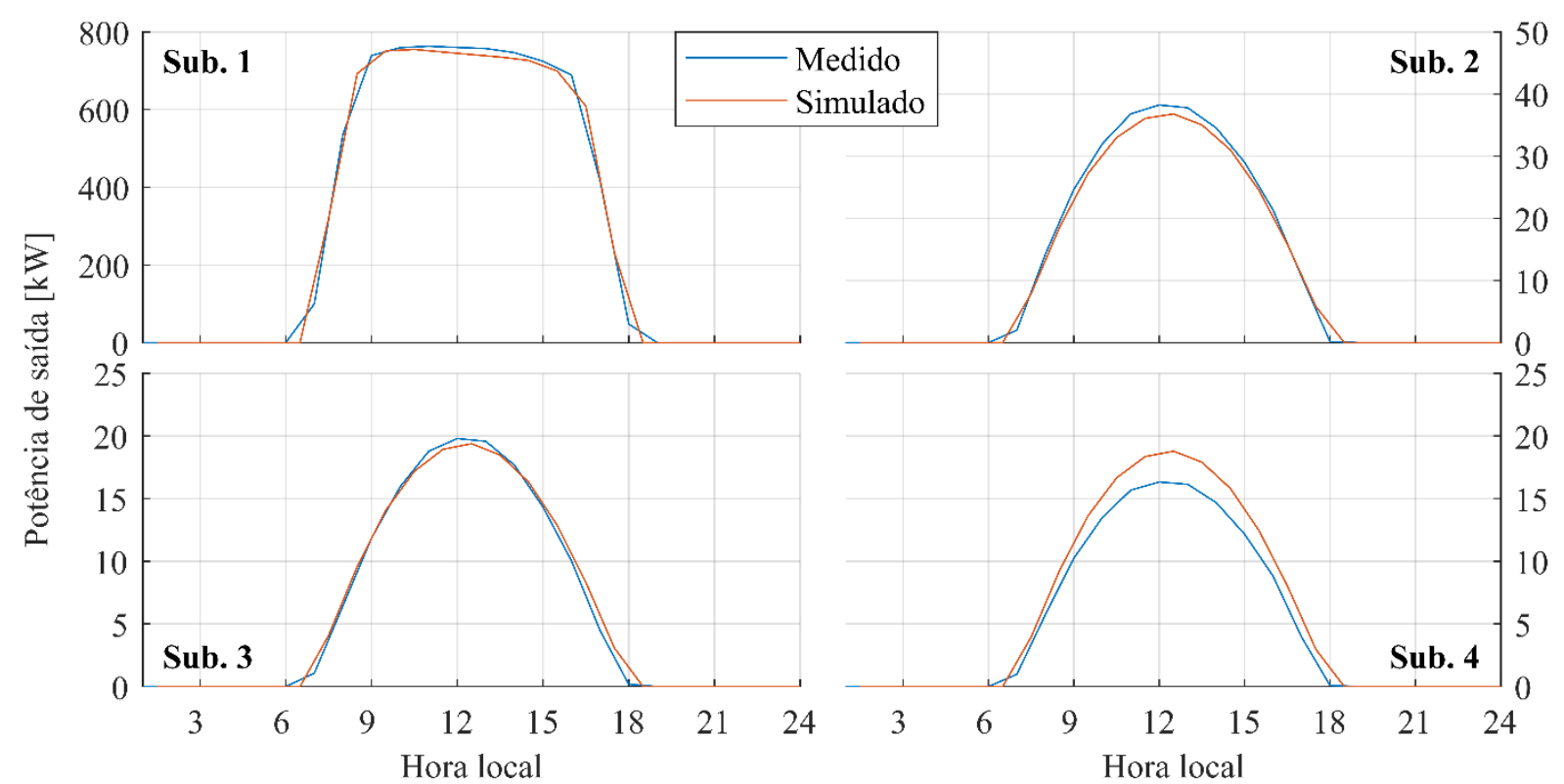

Fonte: elaborado a partir de (PETRÓLEO BRASILEIRO S.A. (PETROBRAS), 2018) e (NATIONAL RENEWABLE ENERGY LABORATORY (NREL), 2018b).

Os fatores de capacidade medidos e simulados dos quatro subsistemas para o dia selecionado são apresentados na figura 6.11, de onde é possível calcular que os ganhos proporcionados pelo uso de rastreamento solar foram de 20,4\% para os dados medidos e de $24,3 \%$ para a simulação. Tomando o subsistema 2 como base, o subsistema 3 apresentou um fator de capacidade $0,9 \%$ menor nos dados medidos, e 4,9\% maior na simulação. Para o subsistema 4 , esses valores foram de $-16,2 \%$ e de $1,8 \%$. Os desvios entre os fatores de capacidade medidos e simulados podem ser observados na figura 6.12, que corrobora a eficiência das simulações e a suspeita da degradação acelerada ou divergência da potência nominal dos módulos do subsistema 4. 
Figura 6.11 - Comparação entre os resultados medidos e simulados dos fatores de capacidade dos subsistemas da UFV-AR para o dia 07/09/2016.

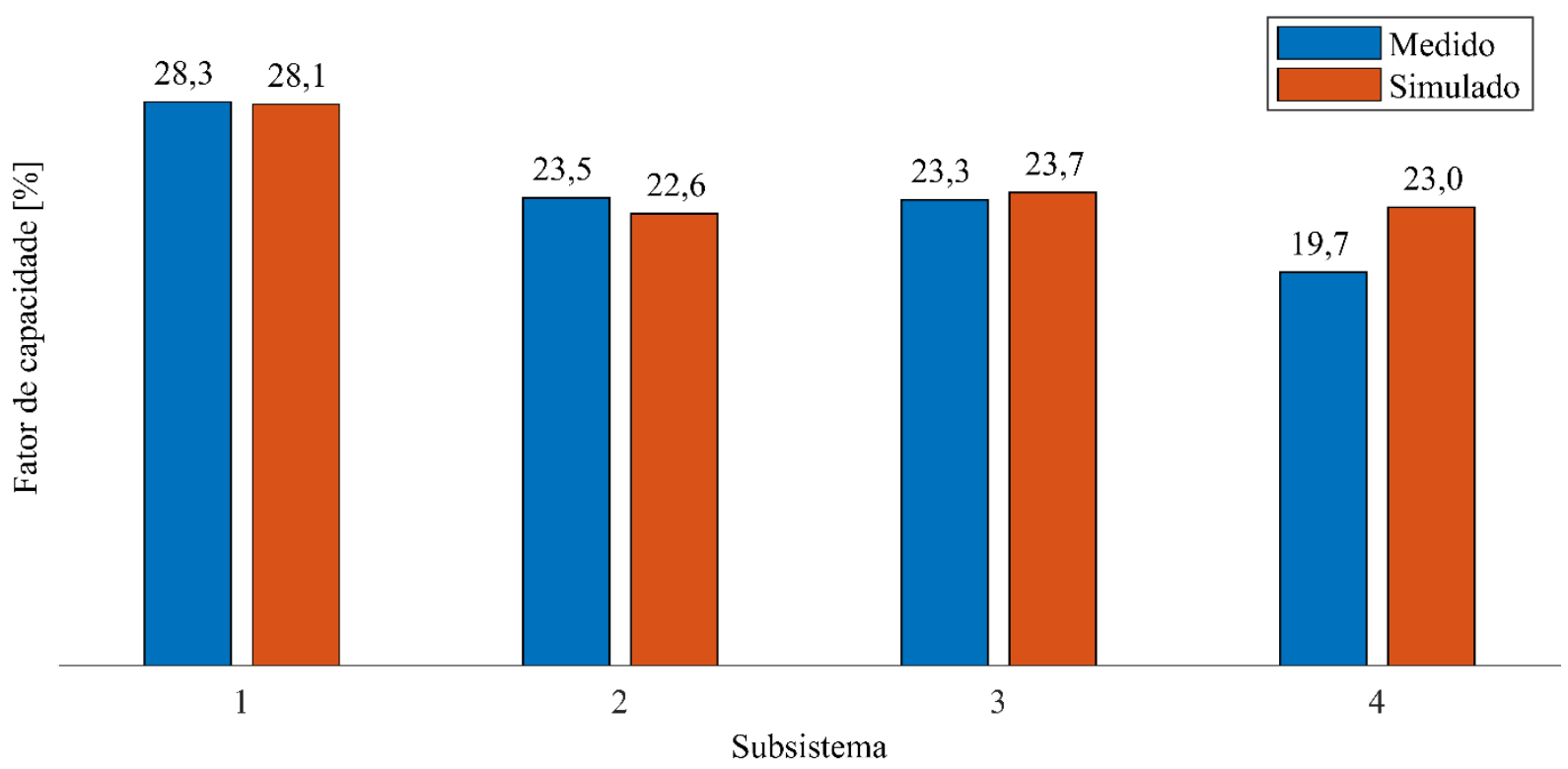

Fonte: elaborado a partir de (PETRÓLEO BRASILEIRO S.A. (PETROBRAS), 2018) e (NATIONAL RENEWABLE ENERGY LABORATORY (NREL), 2018b).

Figura 6.12 - Desvios entre os resultados medidos e simulados dos fatores de capacidade dos subsistemas da UFV-AR para o dia 07/09/2016.

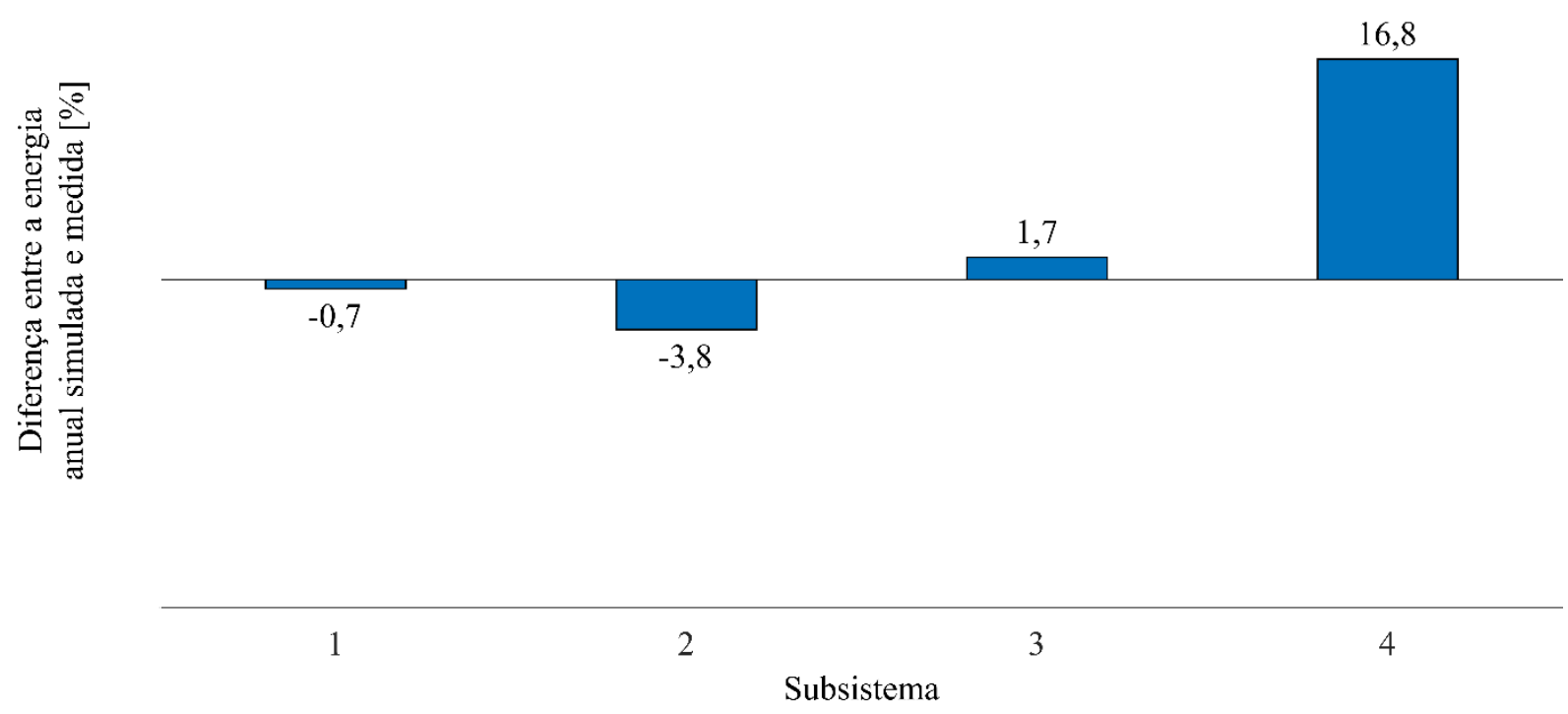

Fonte: elaborado a de (PETRÓLEO BRASILEIRO S.A. (PETROBRAS), 2018) e (NATIONAL RENEWABLE ENERGY LABORATORY (NREL), 2018b). 


\section{CONCLUSÕES}

Este tópico tem por finalidade apresentar as conclusões e considerações finais do trabalho, fazendo uma consolidação dos resultados obtidos e um paralelo com os dados dos leilões de energia elétrica aqui relatados. Além disso, são fornecidas sugestões para trabalhos futuros, visando à continuidade e ao aprimoramento da pesquisa.

A partir da análise dos resultados apresentados no capítulo 5, ficam evidentes os ganhos proporcionados pelo uso de rastreadores solares em vez de estruturas fixas para suporte dos módulos fotovoltaicos, sobretudo para usinas com ICT de até 0,70. Nessa faixa, os ganhos observados no Nordeste foram de no mínimo $11 \%$, podendo chegar a mais de $33 \%$ em alguns casos, conforme explicitado pela figura 5.4.

Os fatores de capacidade podem ser ainda maiores ao se conjugarem os rastreadores solares com módulos da tecnologia de filme fino. Os rastreadores solares possibilitam aos módulos interceptarem uma maior parcela da irradiância direta, de modo a haver um aumento na irradiância total incidente nas suas superfícies. Isoladamente, isso é acompanhado de uma maior elevação da temperatura das células, o que tende a diminuir a potência de saída. Entretanto, conforme a expressão (4.5) e as figuras 4.11 e 4.14, o ganho proporcionado pelo aumento da irradiância total é superior à redução causada pelo aumento da temperatura. Como os módulos de filmes finos possuem um coeficiente de temperatura menor que o das tecnologias tradicionais, essa diferença torna-se ainda mais perceptível.

Esses resultados corroboram os observados nos últimos leilões de energia elétrica em que houve participação da fonte solar fotovoltaica. Como abordado na seção 2.3.8, foi verificada a tendência do uso de rastreamento solar em usinas, com destaque para os leilões de 2017 e 2018, nos quais todos os empreendimentos vendedores se utilizaram dessa estrutura de suporte. Como explicado anteriormente, o uso de módulos de filmes finos potencializa o ganho obtido no fator de capacidade pelo emprego de rastreadores solares, mas a principal contribuição é devida ao seguimento, ainda que em um eixo, do movimento aparente do Sol.

O fato de não terem sido observadas usinas com módulos de filmes finos nos leilões se deve, basicamente, aos custos globais de implantação dos empreendimentos. Apesar de haver uma proximidade nos preços por potência dos módulos de filmes finos e de silício cristalino (FRAUNHOFER INSTITUTE FOR SOLAR ENERGY SYSTEMS, 2018), os de silício, por possuírem maiores eficiências, necessitam de menores áreas para instalação. Consequentemente, os custos decorrentes desse fato são menores, pois a montagem requer menos materiais, como estruturas e cabeamentos. Além disso, há uma maior disponibilidade 
dessa tecnologia e uma ampla concorrência entre os fabricantes desse tipo de módulo. Os fatores elencados auxiliam na compreensão da pequena amplitude observada no preço de venda da energia comercializada no leilão de 2018.

Ademais, uma usina fotovoltaica real, com quatro configurações distintas, teve seus resultados medidos comparados com os de simulação. De forma geral, excetuando-se o subsistema com suspeita de degradação acelerada ou divergência da potência nominal, os resultados de simulação apresentaram desvios no fator de capacidade anual de $-1,0 \%$ a 8,0 \%, mostrando-se compatíveis com os obtidos por outros autores em sistemas semelhantes. Isso fornece um indicativo da eficácia da simulação, mesmo com a associação em série entre os modelos utilizados, apresentados na figura 6.6. É importante deixar claro que o desempenho da tecnologia de módulos de CIGS não deve ser verificado pelos resultados obtidos no estudo de caso, seção 6.2, por conta de necessidade de mais informações relacionadas à potência nominal. Caso contrário, a tecnologia de CIGS poderia ser penalizada injustamente.

\subsection{Sugestões para trabalhos futuros}

Para o aprimoramento e continuidade da pesquisa, algumas sugestões de trabalhos a serem desenvolvidos podem ser elencadas, sendo algumas de viés técnico e outras de cunhos econômico, social e ambiental.

Uma vez que se dispõe das eficiências típicas dos módulos fotovoltaicos e dos ICT das diferentes configurações de sistemas fotovoltaicos simulados, é possível estimar as áreas de módulos e de terreno necessárias para a instalação das usinas. Com isso, podem ser inferidos os custos decorrentes, como os de estruturas de suporte, cabeamento, obras civis, além do próprio custo referente ao uso da terra, seja via aquisição, aluguel ou arrendamento.

Sugere-se também realizar uma análise econômica, levando em consideração os investimentos para implantação das usinas, bem como suas características apresentadas no capítulo 2 e os resultados obtidos no capítulo 5. Essas informações reunidas e tratadas adequadamente podem ser utilizadas como insumos para a estimativa do custo nivelado da energia elétrica e de indicadores econômicos, como a taxa interna de retorno (TIR), valor presente líquido (VPL) e tempo de retorno do investimento.

Além disso, baseando-se nos custos de conexão de uma usina ao SIN, podem-se priorizar regiões próximas a subestações e linhas de transmissão, atribuindo-se pesos ou criando uma função custo em relação à distância. Os resultados obtidos nessa etapa podem ser utilizados para refinar a análise econômica. 
Com o intuito de aumentar a precisão geográfica do estudo, podem-se remover da análise as áreas de restrições. Essas são consideradas regiões onde não é possível ou há impedimentos para instalar uma usina fotovoltaica, como áreas de proteção, preservação ou conservação ambiental; terras indígenas, quilombolas ou de assentamentos; centros urbanos, corpos de água e terrenos com relevo acidentado.

Uma das contribuições do presente trabalho foi a elaboração de um atlas fotovoltaico da região Nordeste do Brasil. Nesse sentido, surge naturalmente a proposta de elaboração de um atlas semelhante que englobe todo o território nacional. Adicionalmente, o leitor é encorajado a realizar estudo análogo, utilizando o modelo detalhado do SAM em vez do PVWatts, de forma a verificar com mais minúcia os resultados obtidos por usinas que utilizam módulos e inversores específicos.

Propõe-se ainda a inclusão dos termos fator de dimensionamento do inversor, fator de carregamento do inversor ${ }^{11}$, índice de cobertura do terreno ${ }^{12}$ e backtracking ${ }^{13}$ na norma de terminologia de energia solar fotovoltaica, NBR 10899 (ASSOCIAÇÃO BRASILEIRA DE NORMAS TÉCNICAS (ABNT), 2013).

\footnotetext{
${ }^{11} \mathrm{O}$ fator de carregamento do inversor é definido pela relação entre a potência nominal do arranjo fotovoltaico e a do inversor. É o inverso do fator de dimensionamento do inversor.

${ }^{12}$ Podem ser sugeridas também outras expressões para índice de cobertura do terreno, como combinações entre índice/fator de cobertura/utilização/ocupação/preenchimento do terreno.

${ }^{13}$ Como tradução, pode-se sugerir o termo retrorrastreamento.
} 


\section{REFERÊNCIAS BIBLIOGRÁFICAS}

AGÊNCIA NACIONAL DE ENERGIA ELÉTRICA (ANEEL). Chamada n 013/2011. Projeto estratégico: "arranjos técnicos e comerciais para inserção da geração solar fotovoltaica na matriz energética brasileira", 2011. Disponivel em: <http://www2.aneel.gov.br/arquivos/pdf/ped_2011-chamadape13-2011.pdf >. Acesso em: 14 de junho de 2018.

AGÊNCIA NACIONAL DE ENERGIA ELÉTRICA (ANEEL). Resolução normativa n ${ }^{\circ} 482$, de 17 de abril de 2012, 2012. Disponivel em: <http://www2.aneel.gov.br/cedoc/ren2012482.pdf>. Acesso em: 17 de janeiro de 2017.

AGÊNCIA NACIONAL DE ENERGIA ELÉTRICA (ANEEL). Leilão nº 08/2014, 2014. Disponivel em: <http://www2.aneel.gov.br/aplicacoes/editais_geracao/documentos/Edital_Ler_08_14RF_p\% C3\%B3s\%20RAC_SCG_v2_final_para\%20publicar.pdf $>$. Acesso em: 7 de fevereiro de 2017.

AGÊNCIA NACIONAL DE ENERGIA ELÉTRICA (ANEEL). Leilão nº 08/2015, 2015. Disponivel em: <http://www2.aneel.gov.br/aplicacoes/editais_geracao/documentos/Edital_1\%C2\%BA\%20L ER\%20de\%202015_082015.pdf>. Acesso em: 6 de fevereiro de 2017.

AGÊNCIA NACIONAL DE ENERGIA ELÉTRICA (ANEEL). Consulta ao cadastro de empreendimentos da ANEEL com os respectivos CEG, 2018a. Disponivel em: <http://www2.aneel.gov.br/scg/Consulta_Empreendimento.asp >. Acesso em: 22 de junho de 2018 .

AGÊNCIA NACIONAL DE ENERGIA ELÉTRICA (ANEEL). Projetos de chamada estratégica, 2018b. Disponivel em: <http://www.aneel.gov.br/programa-de-p-d//asset_publisher/ahiml6B12kVf/content/temas-para-investimentos-em-p-d/656831>. Acesso em: 18 de maio de 2018.

ASSOCIAÇÃO BRASILEIRA DE ENERGIA SOLAR FOTOVOLTAICA (ABSOLAR). Marco histórico para o setor fotovoltaico brasileiro, 2014. Disponivel em: $<$ http://www.absolar.org.br/noticia/artigos-da-absolar/marco-historico-para-o-setorfotovoltaico-brasileiro.html> . Acesso em: 17 de janeiro de 2017.

ASSOCIAÇÃO BRASILEIRA DE ENERGIA SOLAR FOTOVOLTAICA (ABSOLAR). Fonte solar fotovoltaica surpreende em leilão de energia nova com forte redução de preço e liderando em volume contratado, 2018. Disponivel em: <http://www.absolar.org.br/noticia/noticias-externas/fonte-solar-fotovoltaica-surpreende-emleilao-de-energia-nova-com-forte-reducao-de-preco-e-liderando.html>. Acesso em: 28 de junho de 2018.

ASSOCIAÇÃO BRASILEIRA DE NORMAS TÉCNICAS (ABNT). NBR 11704: sistemas fotovoltaicos - classificação. Rio de Janeiro: ABNT, 2008. 
ASSOCIAÇÃO BRASILEIRA DE NORMAS TÉCNICAS (ABNT). NBR 10899: energia solar fotovoltaica - terminologia. Rio de Janeiro: ABNT, 2013.

ASTM INTERNATIONAL. ASTM G173 - 03. Standard tables for reference solar spectral irradiances: direct normal and hemispherical on $37^{\circ}$ tilted surface, 2012. Disponivel em: <https://www.astm.org/Standards/G173.htm>. Acesso em: 17 de abril de 2018.

ATMOSPHERIC RADIATION MEASUREMENT (ARM). ARM data products for carbon cycle $\quad 2004.2$ Disponivel em: <https://adc.arm.gov/Carbon/dataneeds/radiation_pres.jpg>. Acesso em: 18 de janeiro de 2017.

AVANCIS. Avancis, 2011. Disponivel em: <http://www.avancis.de/>. Acesso em: 3 de setembro de 2013.

BESSEMOULIN, P.; OLIVIÉRI, J. Le rayonnement solaire et sa composante ultraviolette. La météorologie, v. 31, n. 8, p. 18, 2000.

BLOOMBERG NEW ENERGY FINANCE (BNEF). Clean energy investment trends, 2017, 2018. Disponivel em: <https://data.bloomberglp.com/bnef/sites/14/2018/01/BNEF-CleanEnergy-Investment-Investment-Trends-2017.pdf>. Acesso em: 27 de maio de 2018.

BUREAU OF LABOR STATISTICS. Historical Consumer Price Index for All Urban Consumers (CPI-U): U.S. city average, all items, by month, 2018. Disponivel em: $<$ https://www.bls.gov/cpi/tables/supplemental-files/historical-cpi-u-201805.pdf >. Acesso em: 27 de junho de 2018.

CÂMARA DE COMERCIALIZAÇÃO DE ENERGIA ELÉTRICA (CCEE). $8^{\circ}$ Leilão de energia de reserva - Resultado completo, 2015. Disponivel em: <https://www.ccee.org.br/ccee/documentos/CCEE_359498>. Acesso em: 17 de janeiro de 2017.

CÂMARA DE COMERCIALIZAÇÃO DE ENERGIA ELÉTRICA (CCEE). 25 Leilão de Energia Nova A-4, 2017a. Disponivel em: <https://www.ccee.org.br/ccee/documentos/CCEE_548033>. Acesso em: 12 de abril de 2018.

CÂMARA DE COMERCIALIZAÇÃO DE ENERGIA ELÉTRICA (CCEE). Mecanismo de Descontratação de Energia de Reserva, 2017b. Disponivel em: <https://www.ccee.org.br/ccee/documentos/CCEE_458632>. Acesso em: 26 de junho de 2018.

CÂMARA DE COMERCIALIZAÇÃO DE ENERGIA ELÉTRICA (CCEE). $27^{\circ}$ Leilão de Energia Nova A-4, 2018. Disponivel <https://www.ccee.org.br/ccee/documentos/CCEE_640137>. Acesso em: 12 de abril de 2018.

CEBECAUER, T.; SURI, M. Typical Meteorological Year data: SolarGIS approach. Energy Procedia, 69, 2015. 1958-1969.

CURY, A. J. O futuro da humanidade: a saga de um pensador. Rio de Janeiro: Sextante, 2005. 
DE SOTO, W.; KLEIN, S. A.; BECKMAN, W. A. Improvement and validation of a model for photovoltaic array performance. Solar Energy, 80, 2008. 78-88.

DELINE, C.; DOBOS, A.; JANZOU, S.; MEYDBRAY, J.; DONOVAN, M. A simplified model of uniform shading in large photovoltaic arrays. Solar Energy, 96, 2013. 274-282.

DHERE, N. G.; CRUZ, L. R.; LOBO, P. C.; BRANCO, J. R. T.; RÜTHER, R.; ZANESCO, I.; LIMA, J. H. G. History of solar energy research in Brazil. Proceedings of the ISES 2005 Solar World Congress, Orlando, 2005.

DRIESSE, A.; JAIN, P. Beyond the curves: modeling the electrical efficiency of photovoltaic inverters. 33rd IEEE Photovoltaic Specialists Conference, 2008.

DUPONT. DuPont, 2011. Disponivel em: <http://www.dupont.com>. Acesso em: 3 de setembro de 2013.

EBRAHIMPOUR, A.; MAEREFAT, M. A method for generation of typical meteorological year. Energy Conversion and Management, 51, 2010. 410-417.

EMPRESA DE PESQUISA ENERGÉTICA (EPE). $6^{\circ}$ Leilão de Energia de Reserva tem deságio de $9,94 \quad \%$ 2014a $\quad$ Disponivel em: <http://www.epe.gov.br/leiloes/Documents/Leil\%C3\%B5es\%202014/Leilao\%20de\%20Reser va\%202014.pdf>. Acesso em: 17 de janeiro de 2017.

EMPRESA DE PESQUISA ENERGÉTICA (EPE). Leilão de energia de reserva de 2014. Participação dos empreendimentos solares fotovoltaicos: visão geral. EPE-DEE-NT-150/2014r0, 2014b. Disponivel em: <http://www.epe.gov.br/leiloes/Documents/Leil\%C3\%B5es\%202014/NT_EPE-DEE-NT150_2014.pdf>. Acesso em: 17 de janeiro de 2017.

EMPRESA DE PESQUISA ENERGÉTICA (EPE). Expansão da geração. $1^{\circ}$ Leilão de Energia de Reserva de 2015. Participação dos empreendimentos fotovoltaicos: visão geral. EPE-DEE127/2015-r0, $2015 . \quad$ Disponivel em: <http://www.epe.gov.br/leiloes/Documents/Leil\%C3\%A3o\%20de\%20Reserva\%20\%282015 \%29/NT_EPE-DEE-NT-127_2015-r0_completo.pdf>. Acesso em: 17 de janeiro de 2017.

EMPRESA DE PESQUISA ENERGÉTICA (EPE). Contratação de energia de reserva para o SIN. $2^{\circ}$ Leilão de Energia de Reserva de 2016. EPE-DEE-RE-105/2016-r0, 2016a. Disponivel em:

<http://www.epe.gov.br/leiloes/Documents/Leil\%C3\%B5es\%20de\%20Energia\%20de\%20Re serva\%202016/Nota\%20T\%C3\%A9cnica\%20Contrata\%C3\%A7\%C3\%A3o\%20de\%20Energ ia\%20de\%20Reserva.pdf>. Acesso em: 17 de janeiro de 2017.

EMPRESA DE PESQUISA ENERGÉTICA (EPE). EPE cadastra 35.147 MW em projetos de energias eólica e solar no $2^{\circ}$ LER, 2016b. Disponivel em: <http://www.epe.gov.br/leiloes/Documents/Leil\%C3\%B5es\%20de\%20Energia\%20de\%20Re 
serva\%202016/2\%C2\%BA\%20LER\%202016\%20-\%20Cadastrados.pdf>. Acesso em: 17 de janeiro de 2017.

EMPRESA DE PESQUISA ENERGÉTICA (EPE). EPE cadastra 428 projetos com oferta de 10.195 MW para $1^{\circ}$ LER 2016, 2016c. Disponivel em: <http://www.epe.gov.br/leiloes/Documents/Leil\%C3\%B5es\%20de\%20Energia\%20de\%20Re serva\%202016/1LER2016a.pdf>. Acesso em: 17 de janeiro de 2017.

EMPRESA DE PESQUISA ENERGÉTICA (EPE). Expansão da geração. $2^{\circ}$ leilão de energia de reserva de 2015. Participação dos empreendimentos solares fotovoltaicos: visão geral. EPEDEE-NT-023/2016-r0, 2016d. Disponivel em: <http://www.epe.gov.br/leiloes/Documents/Leil\%C3\%A3o\%20de\%20Reserva\%20\%282015 \%29/NT_EPE-DEE-NT-023_2016-r0_completo.pdf>. Acesso em: 17 de janeiro de 2016.

EMPRESA DE PESQUISA ENERGÉTICA (EPE). Informe técnico. Leilão de energia de reserva A-4/2017. EPE-DEE-IT-096/2017, 2017. Disponivel em: <http://epe.gov.br/sitespt/publicacoes-dados-abertos/publicacoes/PublicacoesArquivos/publicacao-110/EPE-DEEIT-096\%20-\%20A4\%202017\%20-\%20Vers\%C3\%A3o\%20Final.pdf>. Acesso em: 23 de maio de 2018.

EMPRESA DE PESQUISA ENERGÉTICA (EPE). EPE conclui cadastramento para leilão "A4" de 2018, 2018a. Disponivel em: <http://epe.gov.br/sites-pt/publicacoes-dadosabertos/publicacoes/PublicacoesArquivos/publicacao-265/Release \%20Cadastramento\%20A4_2018.pdf>. Acesso em: 30 de maio de 2018.

EMPRESA DE PESQUISA ENERGÉTICA (EPE). Informações técnicas sobre os Leilões de Energia Nova A-4 de 2017 e 2018, 2018 b.

EMPRESA DE PESQUISA ENERGÉTICA (EPE). Leilão de geração A-4/2018, 2018c. Disponivel em: <http://epe.gov.br/sites-pt/publicacoes-dadosabertos/publicacoes/PublicacoesArquivos/publicacao-265/topico383/Informe\%20Leil\%C3\%A3o\%20A-4\%202018_r4.pdf>. Acesso em: 23 de maio de 2018.

FARAH, S.; SAMAN, W.; BOLAND, J. Development of robust meteorological year weather data. Renewable Energy, 118, 2018. 343-350.

FESTA, R.; RATTO, C. F. Proposal of a numerical procedure to select reference years. Solar Energy, 50, 1993. 9-17.

FINKELSTEIN, J. M.; SCHAFER, R. E. Improved goodness-of-fit tests. Biometrika, 58, 1971.

FONTENELE, L. F. A.; GOUVEIA, H. T. V.; ARAÚJO, R. G.; INÁCIO, C. O.; FERREIRA, P. H. F. Comparação de tecnologias de módulos fotovoltaicos e estruturas de montagem na Usina Fotovoltaica Alto do Rodrigues. XXIII Seminário Nacional de Produção e Transmissão de Energia Elétrica (XXIII SNPTEE), For do Iguaçu/PR, 2015. 
FONTENELE, L. F. A.; INÁCIO, C. O.; GOUVEIA, H. T. V.; FERREIRA, P. H. F.; ARAÚJO, R. G. O efeito lente e a sua influência na operação de uma usina fotovoltaica no Nordeste brasileiro. XXIV Seminário Nacional de Produção e Transmissão de Energia Elétrica (XXIV SNPTEE), Curitiba/PR, 2017.

FRAUNHOFER INSTITUTE FOR SOLAR ENERGY SYSTEMS. Photovoltaics report, 2018. Disponivel em: $<$ https://www.ise.fraunhofer.de/content/dam/ise/de/documents/publications/studies/Photovolt aics-Report.pdf>. Acesso em: 4 de junho de 2018.

GARRISON, J. An evaluation of the effect of volcanic eruption on the solar radiation at six Canadian stations. Solar Energy, 55, n. 6, 1995. 513-525.

GOOGLE. Google Earth, 2018. Disponivel em: <https://www.google.com/earth/>. Acesso em: 17 de maio de 2018.

GREENPEACE INTERNATIONAL; GLOBAL WIND ENERGY COUNCIL; SOLARPOWER EUROPE. Energy revolution 2015., 2015. Disponivel em: $<$ http://www.greenpeace.org/international/Global/international/publications/climate/2015/Ene rgy-Revolution-2015-Full.pdf>. Acesso em: 21 de fevereiro de 2017.

GUEYMARD, C. A. REST2: High-performance solar radiation model for cloudless-sky irradiance, illuminance, and photosynthetically active radiation - Validation with a benchmark dataset. Solar Energy, 82, 2008.

HÄBERLIN, H. Photovoltaics: system design and practice. Chichester: John Wiley \& Sons, 2012.

HALL, I. J.; PRAIRIE, R. R.; ANDERSON, H. E.; BOES, E. C. Generation of Typical Meteorological Years for 26 SOLMET stations. Albuquerque: Sandia Laboratories, 1978.

HEIDINGER, A. K.; FOSTER, M. J.; WALTHER, A.; ZHAO, X. (. The Pathfinder Atmospheres-Extended AVHRR climate dataset. Bulletin of the American Meteorological Society, 95, 2014.

INÁCIO, C. O.; GOUVEIA, H. T. V.; FONTENELE, L. F. A.; FERREIRA, P. H. F.; ARAÚJO, R. G. Início da operação da Usina Fotovoltaica Alto do Rodrigues (UFV-AR) - Resultados preliminares. VI Congresso Brasileiro de Energia Solar (VI CBENS), Belo Horizonte/MG, 2016.

INGETEAM. Photovoltaic solar energy, 2012. Disponivel em: <https://www.ingeteam.com/>. Acesso em: 3 de setembro de 2013.

INSTITUTO BRASILEIRO DE GEOGRAFIA E ESTATÍSTICA (IBGE). Anuário estatístico do Brasil, 2016. Disponivel em: <https://biblioteca.ibge.gov.br/visualizacao/periodicos/20/aeb_2016.pdf>. Acesso em: 18 de janeiro de 2017. 
INSTITUTO BRASILEIRO DE GEOGRAFIA E ESTATÍSTICA (IBGE). Divisões regionais do Brasil, 2018. Disponivel em: <https://www.ibge.gov.br/geocienciasnovoportal/organizacao-do-territorio/divisao-regional/15778-divisoes-regionais-dobrasil.html>. Acesso em: 27 de maio de 2018.

INTERNATIONAL ELECTROTECHNICAL COMMISION (IEC). IEC 61724-3. Photovoltaic system performance. Part 3: energy evaluation method. [S.l.]: IEC, 2016.

INTERNATIONAL ELECTROTECHNICAL COMMISION (IEC). IEC 61724-1. Photovoltaic system performance. Part 1: monitoring. [S.1.]: IEC, 2017.

INTERNATIONAL ENERGY AGENCY (IEA). Snapshot of global photovoltaics markets, 2018a. Disponivel em: <http://www.iea-pvps.org/fileadmin/dam/public/report/statistics/IEAPVPS_-_A_Snapshot_of_Global_PV_-_1992-2017.pdf>. Acesso em: 4 de junho de 2018.

INTERNATIONAL ENERGY AGENCY (IEA). Uncertainties in PV system yield predictions and assessments, 2018b. Disponivel em: <http://www.ieapvps.org/index.php?id=477\&eID=dam_frontend_push\&docID=4311>. Acesso em: $17 \mathrm{de}$ junho de 2018.

INTERNATIONAL TECHNOLOGY ROADMAP FOR PHOTOVOLTAIC (ITRPV). 2017 results, 2018.2 Disponivel em: <http://itrpv.net/.cm4all/mediadb/ITRPV\%20Ninth\%20Edition\%202018_1.pdf>. Acesso em: 16 de junho de 2018.

KACO NEW ENERGY. DC/AC ratio optimization, 2013. Disponivel em: $<$ https://sam.nrel.gov/sites/default/files/content/virtual_conf_july_2013/07-sam-virtualconference-2013-woodcock.pdf>. Acesso em: 22 de maio de 2018.

KALOGIROU, S. A. Generation of typical meteorological year (TMY-2) for Nicosia, Cyprus. Renewable Energy, 28, 2003. 2317-2334.

KHALIL, S. A.; SHAFFIE, A. M. Attenuation of the solar energy by aerosol particles: a review and case study. Renewable and Sustainable Energy Reviews, 54, 2016. 363-375.

KLEIN, S. A.; BECKMAN, W. A.; DUFFIE, J. A. A design procedure for solar heating systems. Solar energy, 18, 1976.

LUQUE, A.; HEGEDUS, S. Handbook of photovoltaic science and engineering. Chichester: John Wiley \& Sons, 2003.

MALVONI, M.; DE GIORGI, M. G.; CONGEDO, P. M. Study of degradation of a grid connected photovoltaic system. Energy Procedia, 126, 2017. 644-650.

MARION, B.; ADELSTEIN, J.; BOYLE, K.; HAYDEN, H.; HAMMOND, B.; FLETCHER, T.; CANADA, B.; NARANG, D.; KIMBER, A.; MITCHELL, L. et al. Performance 
parameters for grid-connected PV systems. Conference Record of the 31st IEEE Photovoltaic Specialists Conference. Lake Buena Vista: IEEE. 2005.

MAXWELL, E. L. A quasi-physical model for converting hourly global horizontal to direct normal insolation. Golden: Energy Research Institute, 1987.

MICHALSKY, J. J. The astronomical almanac's algorithm for approximate solar position (1950-2050). Solar Energy, p. 227-235, 1988a.

MICHALSKY, J. J. Errata. Solar Energy, p. 113, 1988b.

MICHALSKY, J. J.; PEREZ, R.; SEALS, R.; INEICHEN, P. Degradation of solar concentrator performance in the aftermath of Mount Pinatubo. Solar Energy, 52, n. 2, 1994. 205-213.

MINISTÉRIO DE MINAS E ENERGIA (MME). Portaria no 236, de 30 de maio de 2014, 2014a. Disponivel em: <http://www.mme.gov.br/documents/10584/1169554/Portaria+236+de+30-052014+Publicado+no+DOU+de+02-06-2014>. Acesso em: 17 de janeiro de 2017.

MINISTÉRIO DE MINAS E ENERGIA (MME). Portaria no 320, de 9 de julho de 2014, 2014b. Disponivel em: <http://www.mme.gov.br/documents/10584/1169554/Portaria+320+de+0907-2014+Publicado+no+DOU+de+10-07-2014>. Acesso em: 17 de janeiro de 2017.

MINISTÉRIO DE MINAS E ENERGIA (MME). Portaria $n^{\circ}$ 69, de 13 de março de 2015, 2015a. Disponivel em: <http://www.mme.gov.br/documents/10584/1942329/Portaria_n_692015>. Acesso em: 17 de janeiro de 2017.

MINISTÉRIO DE MINAS E ENERGIA (MME). Portaria $n^{\circ}$ 70, de 16 de março de 2015, 2015b. Disponivel em: <http://www.mme.gov.br/documents/10584/1942329/Portaria_n_702015>. Acesso em: 17 de janeiro de 2017.

MINISTÉRIO DE MINAS E ENERGIA (MME). Portaria n $^{\circ}$ 104, de 23 de março de 2016, 2016a. Disponivel em: <http://www.mme.gov.br/documents/10584/3189515/Portaria_n_1042016>. Acesso em: 17 de janeiro de 2017.

MINISTÉRIO DE MINAS E ENERGIA (MME). Portaria no 390, de 26 de julho de 2016, 2016b. Disponivel em: <http://www.mme.gov.br/documents/10584/3189515/Portaria_n_3902016>. Acesso em: 17 de janeiro de 2017.

MINISTÉRIO DE MINAS E ENERGIA (MME). Portaria nº 621, de 17 de novembro de 2016, 2016c. Disponivel em: <http://www.mme.gov.br/documents/10584/3189515/Portaria_n_6212016>. Acesso em: 17 de janeiro de 2017.

MINISTÉRIO DE MINAS E ENERGIA (MME). Portaria n 705, de 14 de dezembro de 2016, 2016d. Disponivel em: <http://www.mme.gov.br/documents/10584/3189515/Portaria_n_7052016>. Acesso em: 17 de janeiro de 2017. 
MINISTÉRIO DE MINAS E ENERGIA (MME). Portaria n ${ }^{\circ}$ 151, de 18 de abril de 2017, 2017a. Disponivel em: <http://www.mme.gov.br/documents/10584/4401929/Portaria_n_151-2017>. Acesso em: 30 de maio de 2017.

MINISTÉRIO DE MINAS E ENERGIA (MME). Portaria no 293, de 4 de agosto de 2017, 2017b. Disponivel em: <http://www.mme.gov.br/documents/10584/4401929/Portaria_n_2932017>. Acesso em: 10 de novembro de 2017.

MINISTÉRIO DE MINAS E ENERGIA (MME). Portaria n ${ }^{\circ} 465$, de 30 de novembro de 2017, 2017c. Disponivel em: <http://www.mme.gov.br/documents/10584/4401929/Portaria_n_4652017>. Acesso em: 29 de março de 2018.

MOLINEAUX, B.; INEICHEN, P. Impact of Pinatubo aerosols on the seasonal trends of global, direct and diffuse irradiance in two northern mid-latitudes sites. Solar Energy, 58, n. 1-3, 1996. 91-101.

MURPHY, S. The construction of a modified Typical Meteorological Year for photovoltaic modeling in India. Renewable Energy, 111, 2017. 447-454.

NATIONAL OCEANIC AND ATMOSPHERIC ADMINISTRATION (NOOA). Energy on a sphere, 2016. Disponivel em: <http://sos.noaa.gov/Datasets/dataset.php?id=579>. Acesso em: 5 de agosto de 2016.

NATIONAL RENEWABLE ENERGY LABORATORY (NREL). User manual for TMY3 data sets, 2008. Disponivel em: <https://www.nrel.gov/docs/fy08osti/43156.pdf>. Acesso em: 22 de janeiro de 2018.

NATIONAL RENEWABLE ENERGY LABORATORY (NREL). Photovoltaic shading testbed for module-level power electronics, 2012. Disponivel em: <https://www.nrel.gov/docs/fy12osti/54876.pdf>. Acesso em: 28 de janeiro de 2017.

NATIONAL RENEWABLE ENERGY LABORATORY (NREL). Rotation angle for the optimum tracking of one-axis trackers, 2013. Disponivel em: <https://www.nrel.gov/docs/fy13osti/58891.pdf>. Acesso em: 8 de março de 2017.

NATIONAL RENEWABLE ENERGY LABORATORY (NREL). PVWatts version 5 manual, 2014a. Disponivel em: <https://www.nrel.gov/docs/fy14osti/62641.pdf>. Acesso em: 8 de janeiro de 2017.

NATIONAL RENEWABLE ENERGY LABORATORY (NREL). System Advisor Model, SAM 2014.1.4: general description, 2014b. Disponivel em: <https://www.nrel.gov/docs/fy14osti/61019.pdf>. Acesso em: 8 de janeiro de 2017.

NATIONAL RENEWABLE ENERGY LABORATORY (NREL). SAM photovoltaic model technical reference, 2015. Disponivel em: <https://www.nrel.gov/docs/fy15osti/64102.pdf>. Acesso em: 9 de março de 2017. 
NATIONAL RENEWABLE ENERGY LABORATORY (NREL). National Solar Radiation Database (NSRDB), 2018a. Disponivel em: 〈https://nsrdb.nrel.gov>. Acesso em: 21 de junho de 2018.

NATIONAL RENEWABLE ENERGY LABORATORY (NREL). System Advisor Model (SAM), 2018b. Disponivel em: <https://sam.nrel.gov>. Acesso em: 17 de maio de 2018.

NATIONAL RENEWABLE ENERGY LABORATORY (NREL). Photovoltaic research, 2018c. Disponivel em: <https://www.nrel.gov/pv/assets/images/efficiency-chart20180716.jpg>. Acesso em: 20 de julho de 2018.

OLMO, F. J.; BATLlES, F. J.; ALADOS-ARBOLEDAS, L. Performance of global to driect/diffuse decomposition models before and after the eruption of Mt. Pinatubo, June 1991. Solar Energy, 57, n. 6, 1996. 433-443.

OLMO, F. J.; TOVAR, J.; ARLADOS-ARBOLEDAS, L.; OKULOV, O.; OHVRIL, H. O. A comparison of ground level solar radiative effects of recent volcanic eruptions. Atmospheric Environment, 33, n. 28, 1999. 4589-4596.

PEREZ, R.; INEICHEN, P.; SEALS, R.; MICHALSKY, J.; STEWART, R. Modeling daylight availability and irradiance components from direct and global irradiance. Solar Energy, p. 271289, 1990.

PETRAKIS, M.; KAMBEZIDIS, H. D.; LYKOUDIS, S.; ADAMOPOULOS, A. D.; KASSOMENO, P. Generation of a "typical meteorological year" for Nicosia, Cyprus. Renewable Energy, 13, 1998. 381-388.

PETRIE, W. R.; MCCLINTOCK, M. Determining typical weather for use in solar energy simulations. Solar Energy, 21, 1978. 55-59.

PETRÓLEO BRASILEIRO S.A. (PETROBRAS). Estudo da Geração Fotovoltaica Centralizada e seu Impacto no Sistema Elétrico. IV Workshop Inovação para o Estabelecimento do Setor de Energia Solar Fotovoltaica no Brasil (IV InovaFV). Recife/PE: [s.n.]. 2014.

PETRÓLEO BRASILEIRO S.A. (PETROBRAS). Dados do sistema supervisório da UFVAR. Rio de Janeiro: Petrobras, 2018.

PINGEL, S.; KOSHNICHAROV, D.; FRANK, O.; GEIPEL, T.; ZEMEN, Y.; STRINER, B.; BERGHOLD, J. Initial degradation of industrial silicon solar cells in solar panels. 25 th EU PVSEC. [S.1.]: [s.n.]. 2010.

PINHO, J. T.; GALDINO, M. A. Manual de engenharia para sistemas fotovoltaicos. Rio de Janeiro: CRESESB, 2014.

PISSIMANIS, D.; KARRAS, G.; NOTARIDOU, V.; GAVRA, K. The generation of a typical meteorological year for the city of Athens. Solar Energy, 40, 1988. 405-411. 
PVSYST. Home, 2018. Disponivel em: <http://www.pvsyst.com>. Acesso em: 21 de maio de 2018.

RENEWABLE ENERGY POLICY NETWORK FOR THE 21ST CENTURY (REN21). Renewables global futures report: great debates towards 100\% renewable energy, 2017. Disponivel em: <http://www.ren21.net/wp-content/uploads/2017/07/16-8325-GFR-FullReport-2017_X1.pdf>. Acesso em: 17 de agosto de 2017.

RENEWABLE ENERGY POLICY NETWORK FOR THE 21ST CENTURY (REN21). Renewables 2018. Global status report, 2018. Disponivel em: <http://www.ren21.net/wpcontent/uploads/2018/06/17-8652_GSR2018_FullReport_web_-1.pdf >. Acesso em: 4 de junho de 2018.

RICHARDSON, A. J. El Chichón volcanic ash effects on atmospheric haze measurements by NOAA7 AVHRR data. Remote Sensing of Environment, 16, n. 2, 1984. 157-164.

RUSTEMLI, S.; DINCER, F.; UNAL, E.; KARAASLAN, M.; SABAH, C. The analysis on sun tracking and cooling systems for photovoltaic panel. Renewable and sustainable energy reviews, 22, 2013. 598-603.

RÜTHER, R. Edifícios solares fotovoltaicos. Florianópolis: UFSC, 2004.

SAHAI, Y.; KIRCHHOFF, V. W. J. H.; AVALÁ, P. C. Pinatubo eruptions: effects on stratospheric $\mathrm{O} 3$ and SO 2 over Brazil. Journal of Atmospheric and Solar-Terrestrial Physics, 59, n. 3, 1997. 265-269.

SANDIA NATIONAL LABORATORIES. A simplified thermal model for flat-plate photovoltaic arrays, 1987. Disponivel em: <http://prod.sandia.gov/techlib/accesscontrol.cgi/1985/850330.pdf>. Acesso em: 22 de janeiro de 2018.

SAWAQED, N. M.; ZURIGAT, Y. H.; AL-HINAI, H. A step-by-step application of Sandia method in developing typical meteorological years for differente locations in Oman. International Journal of Energy Research, 29, 2005. 723-737.

SENGUPTA, M.; HABTE, A.; GOTSEFF, P.; WEEKLEY, A.; LOPEZ, A.; ANDERBERG, M.; MOLLING, C.; HEIDINGER, A. A physics based GOES satellite product for use in NREL's National Solar Radiation Database. Proceedings of the 29th European Photovoltaic Solar Energy Conference and Exhibition, 2014.

SOLARGIS, 2018. Disponivel em: <https://solargis.com/maps-and-gis-data/download/> . Acesso em: 26 de junho de 2018.

SUNEDISON. SunEdison, 2012. Disponivel em: <http://www.sunedison.com/>. Acesso em: 3 de setembro de 2013. 
VALENTIN SOFTWARE. Photovoltaic planning software PV*SOL, 2018. Disponivel em: <https://www.valentin-software.com/en/products/photovoltaics/55/pvsol>. Acesso em: $11 \mathrm{de}$ julho de 2018.

VERDECCHIA, M.; VISCONTI, G.; PITARI, G. Radiative perturbation due to the eruption of El Chichón: effects on ozone. Journal of Atmospheric and Terrestrial Physics, 54, n. 7-8, 1992. 1081-1084.

WITTMER, B.; MERMOUD, A.; SCHOTT, T. Analysis of PV grid installations performance, comparing measured data to simulation results to identify problems in operation and monitoring. European Photovoltaic Solar Energy Conference, Hamburg, 2015.

XIE, Y.; SENGUPTA, M.; DUDHIA, J. A Fast All-sky Radiation Model for Solar applications (FARMS): algorithm and performance evaluation. Solar Energy, 135, 2016.

X-RATES. Exchange rate average (US Dollar, Brazilian Real), 2018. Disponivel em: $<$ https://www.X-rates.com/average/?from=USD\&to=BRL\&amount=1>. Acesso em: $27 \mathrm{de}$ junho de 2018.

ZILLES, R.; MACÊDO, W. N.; GALHARDO, M. A. B.; DE OLIVEIRA, S. H. F. Sistemas fotovoltaicos conectados à rede elétrica. São Paulo: Oficina de Textos, 2012. 